Programme for International Student Assessment

\title{
Problem Solving for Tomorrow's World
}

First Measures of Cross-Curricular

Competencies from PISA 2003 


\section{ORGANISATION FOR ECONOMIC CO-OPERATION AND DEVELOPMENT}

Pursuant to Article 1 of the Convention signed in Paris on 14th December 1960, and which came into force on 30th September 1961, the Organisation for Economic Co-operation and Development (OECD) shall promote policies designed:

- to achieve the highest sustainable economic growth and employment and a rising standard of living in member countries, while maintaining financial stability, and thus to contribute to the development of the world economy;

- to contribute to sound economic expansion in member as well as non-member countries in the process of economic development; and

- to contribute to the expansion of world trade on a multilateral, non-discriminatory basis in accordance with international obligations.

The original member countries of the OECD are Austria, Belgium, Canada, Denmark, France, Germany, Greece, Iceland, Ireland, Italy, Luxembourg, the Netherlands, Norway, Portugal, Spain, Sweden, Switzerland, Turkey, the United Kingdom and the United States. The following countries became members subsequently through accession at the dates indicated hereafter: Japan (28th April 1964), Finland (28th January 1969), Australia (7th June 1971), New Zealand (29th May 1973), Mexico (18th May 1994), the Czech Republic (21st December 1995), Hungary (7th May 1996), Poland (22nd November 1996), Korea (12th December 1996) and the Slovak Republic (14th December 2000). The Commission of the European Communities takes part in the work of the OECD (Article 13 of the OECD Convention).

Publié en français sous le titre :

Résoudre des problèmes, un atout pour réussir Premières évaluations des compétences transdisciplinaires issues de PISA 2003

$\mathrm{PISA}^{\mathrm{TM}}$, OECD/PISA ${ }^{\mathrm{TM}}$ and the PISA logo are trademarks of the Organisation for Economic Co-operation and Development (OECD). All use of OECD trademarks is prohibited without written permission from the OECD.

(C) OECD 2004

Permission to reproduce a portion of this work for non-commercial purposes or classroom use should be obtained through the Centre français d'exploitation du droit de copie (CFC), 20, rue des Grands-Augustins, 75006 Paris, France, tel. (33-1) 440747 70, fax (33-1) 463467 19, for every country except the United States. In the United States permission should be obtained through the Copyright Clearance Center, Customer Service, (508)750-8400, 222 Rosewood Drive, Danvers, MA 01923 USA, or CCC Online: www.copyright.com. All other applications for permission to reproduce or translate all or part of this book should be made to OECD Publications, 2, rue André-Pascal, 75775 Paris Cedex 16, France. 


\section{Foreword}

All stakeholders - parents, students, those who teach and run education systems as well as the general public - need to be informed on how well their education systems prepare students for life. Knowledge and skills in school subjects such as languages, mathematics and science are an essential foundation for this but a much wider range of competencies is needed for students to be well prepared for the future. Problem-solving skills, i.e. the capacity of students to understand problems situated in novel and cross-curricular settings, to identify relevant information or constraints, to represent possible alternatives or solution paths, to develop solution strategies, and to solve problems and communicate the solutions, are an example of this wider range of competencies.

The 2003 assessment of the Organisation for Economic Co-operation and Development's (OECD) Programme for International Student Assessment (PISA) included an assessment of students' problem-solving skills, providing for the first time a direct assessment of life competencies that apply across different areas of the school curriculum.

About one in five 15-year-olds in OECD countries can be considered a reflective, communicative problem solver. These students are able not only to analyse a situation and make decisions, they are also capable of managing multiple conditions simultaneously. They can think about the underlying relationships in a problem, solve it systematically, check their work and communicate the results. In some countries, more than a third of students reach this high level of problem-solving competencies. In other countries, however, the majority of students cannot even be classified as basic problem solvers, a level at which they are required to deal with only a single data source containing discrete, well-defined information.

How can countries raise their performance in this increasingly important competency area and what can countries with lower performance levels learn from those where students do well? This report seeks to answer such questions. It complements Learning for Tomorrow's World - First Results from PISA 2003, which focuses on knowledge and skills in mathematics, science and reading, and it goes beyond an examination of the relative standing of countries in students' problemsolving performance by considering how problem-solving performance relates to learning outcomes in other areas and how it varies between the genders and between socio-economic groups. It also provides insights into some of the factors that are associated with the development of problem-solving skills and into how these factors interact and what the implications are for policy development. Most importantly, the report sheds light on countries that succeed 
in achieving high performance standards while at the same time providing an equitable distribution of learning opportunities. Results in these countries pose challenges for other countries by showing what it is possible to achieve.

The report is the product of a collaborative effort between the countries participating in PISA, the experts and institutions working within the framework of the PISA Consortium, and the OECD. The report was drafted by John Dossey, Johannes Hartig, Eckhard Klieme and Margaret Wu, under the direction of the OECD Directorate for Education, principally by Claire Shewbridge and Andreas Schleicher, with advice and analytic support from Raymond Adams, Barry McCrae and Ross Turner. The PISA problem-solving framework and assessment instruments were prepared by the PISA Consortium and PISA Problem Solving Expert Group under the direction of Raymond Adams at the Australian Council for Educational Research. Data analytic support was provided by Alla Berezener, Johannes Hartig and Margaret Wu.

The development of the report was steered by the PISA Governing Board, which is chaired by Ryo Watanabe (Japan). Annex $\mathrm{C}$ of the report lists the members of the various PISA bodies as well as the individual experts and consultants who have contributed to this report and to PISA in general.

The report is published on the responsibility of the Secretary-General of the OECD.

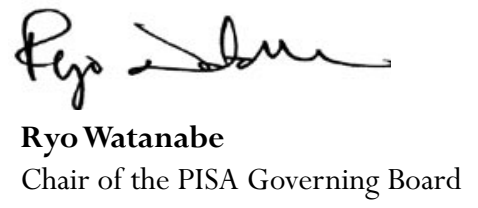

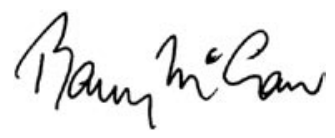

Barry McGaw

Director for Education, OECD 


\section{Table of Contents}

CHAPTER 1

PISA 2003 AND PROBLEM SOLVING ............................................................... 11

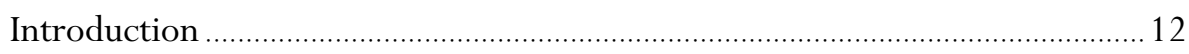

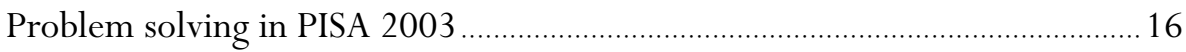

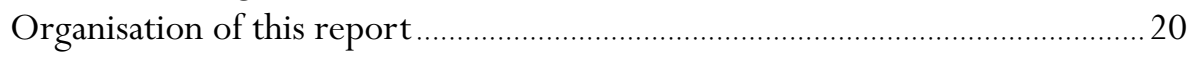

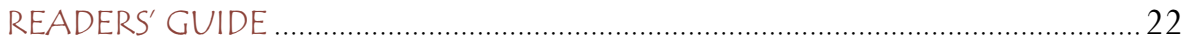

CHAPTER 2

PROBLEM SOLVING IN PISA 2003 - HOW IT WAS MEASURED

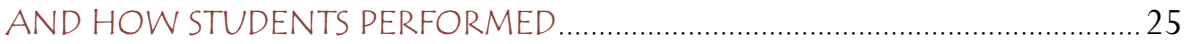

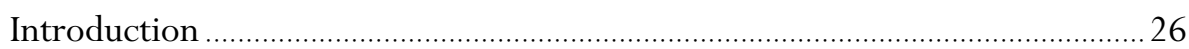

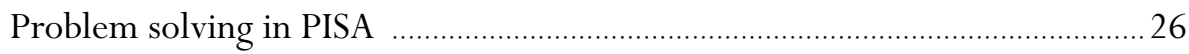

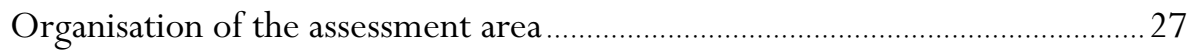

Problems chosen for the PISA problem-solving assessment.............................28

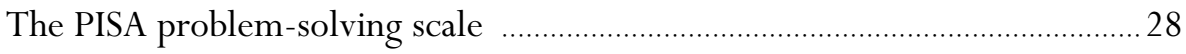

- Level 3: Reflective, communicative problem solvers................................. 29

- Level 2: Reasoning, decision-making problem solvers .............................. 30

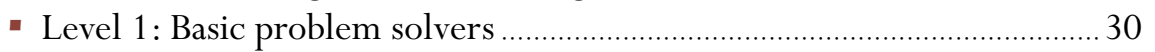

- Below Level 1: Weak or emergent problem solvers .................................... 30

- Decision making - the Cinema Outing problem ........................................ 32

- System analysis and design - the Children's Camp problem ..................... 34

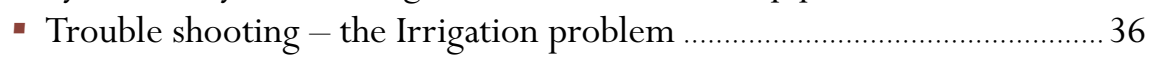

The percentage of students at each proficiency level of problem solving .......... 39

- Mean performance of countries................................................................ 41

The distribution of problem-solving capabilities within countries .................44

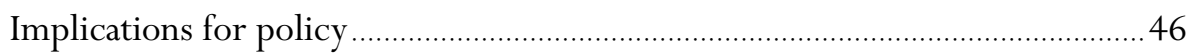

CHAPTER 3

STUDENT PERFORMANCE IN PROBLEM SOLVING COMPARED WITH

PERFORMANCE IN MATHEMATICS, READING AND SCIENCE ....................49

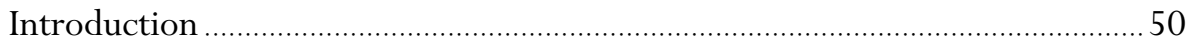

Problem-solving framework and test development .......................................50

- Emphasis on problem-solving processes ....................................................50

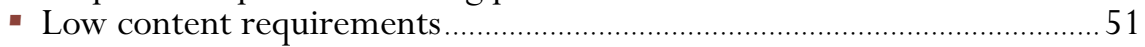

- The key skills tested in problem solving …………………………..............51

- Correlations between performance in reading, mathematics, science and problem solving 
Comparison between performances in mathematics and

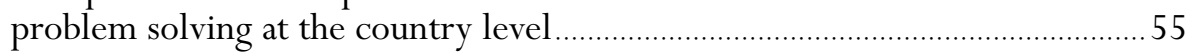

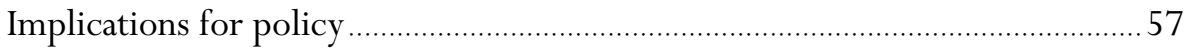

CHAPTER 4

STUDENT PERFORMANCE ON THE PROBLEM-SOLVING ITEMS …...............55

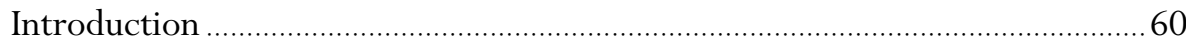

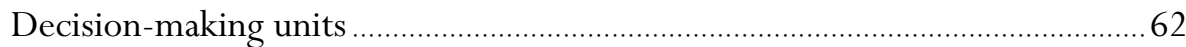

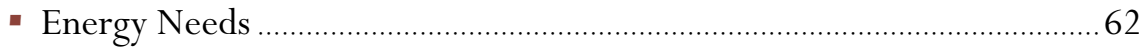

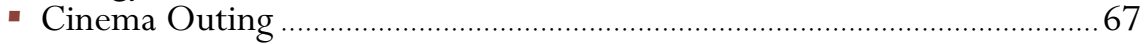

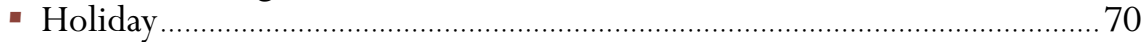

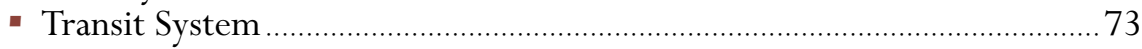

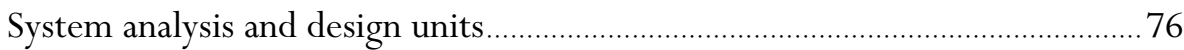

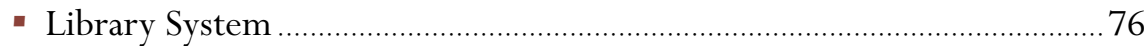

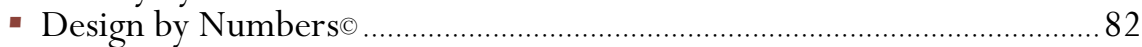

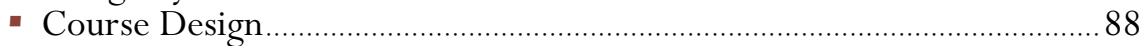

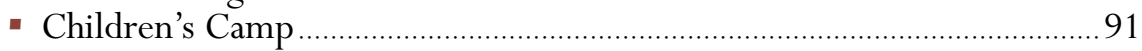

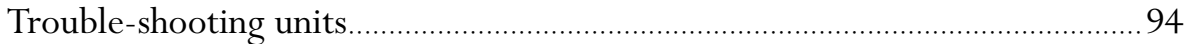

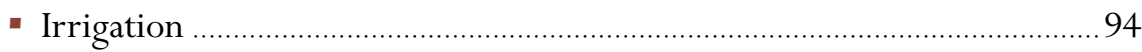

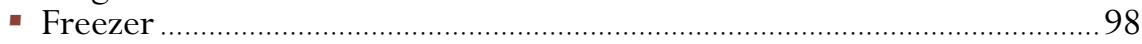

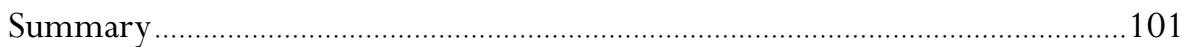

CHAPTER 5

THE ROLE THAT GENDER AND STUDENT BACKGROUND

CHARACTERISTICS PLAY IN STUDENT PERFORMANCE IN PROBLEM

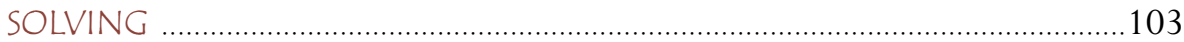

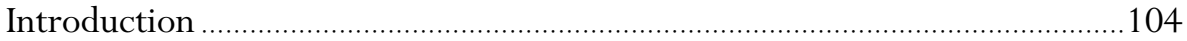

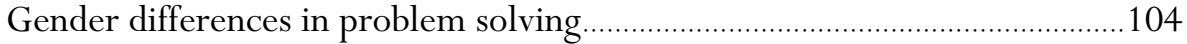

Comparison with gender differences in other assessment areas........................107

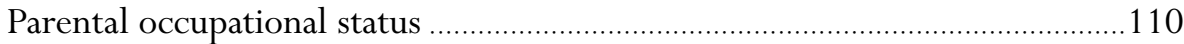

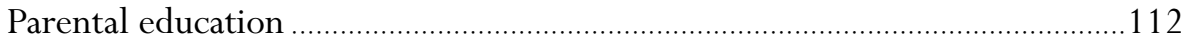

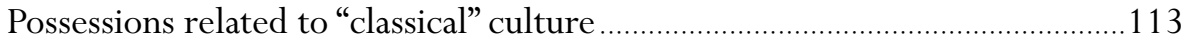

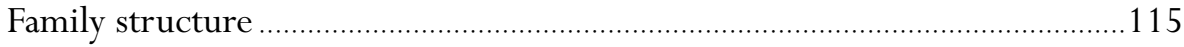

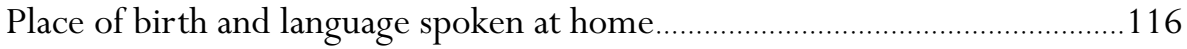

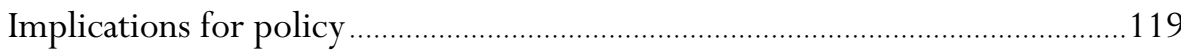

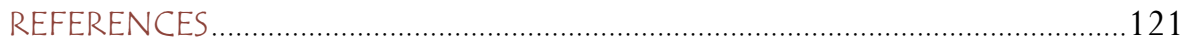

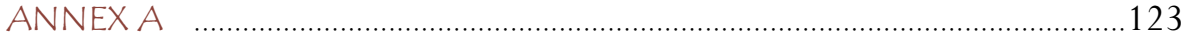

Annex A1 Construction of indices and other derived measures from the student context questionnaire ........................................... 124

Annex A2 Detailed results from the factor analysis in Chapter 3 .................126

Annex A3 The PISA target population and the PISA samples.........................128 
Annex A4 Standard errors, significance tests and subgroup comparisons ......137

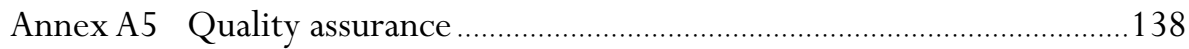

Annex A6 Development of the PISA assessment instruments .......................139

Annex A7 Reliability of the marking of open-ended items ..........................141

ANNEX B

Data tables for the chapters. 143

ANNEXC

The development and implementation of PISA - a collaborative effort 157 

Table 2.1 Percentage of students at each level of proficiency on the problem-solving scale

Table 2.2 Mean score and variation in student performance on the problem-solving scale

Table 3.1

Factor loadings of mathematics, reading and problem-solving items

Table 5.1 Gender differences in mean score in student performance on the problem-solving, mathematics and reading scales and percentage of males and females below Level 1 and at Level 3 of the problem-solving scale

Table 5.2 International socio-economic index of occupational status (HISEI) and performance on the problem-solving scale, by national quarters of the index

Table 5.3 Index of highest educational level of parents (HISCED) and performance on the problem-solving scale, by national quarters of the index

Table 5.4 Index of possessions related to "classical" culture in the family home and performance on the problem-solving scale, by national quarters of the index

Table 5.5 Percentage of students and performance on the problem-solving scale, by type of family structure

Table 5.6 Percentage of students and performance on the problem-solving scale, by students' nationality and the nationality of their parents

Table 5.7 Percentage of students and performance on the problem-solving scale, by language spoken at home 


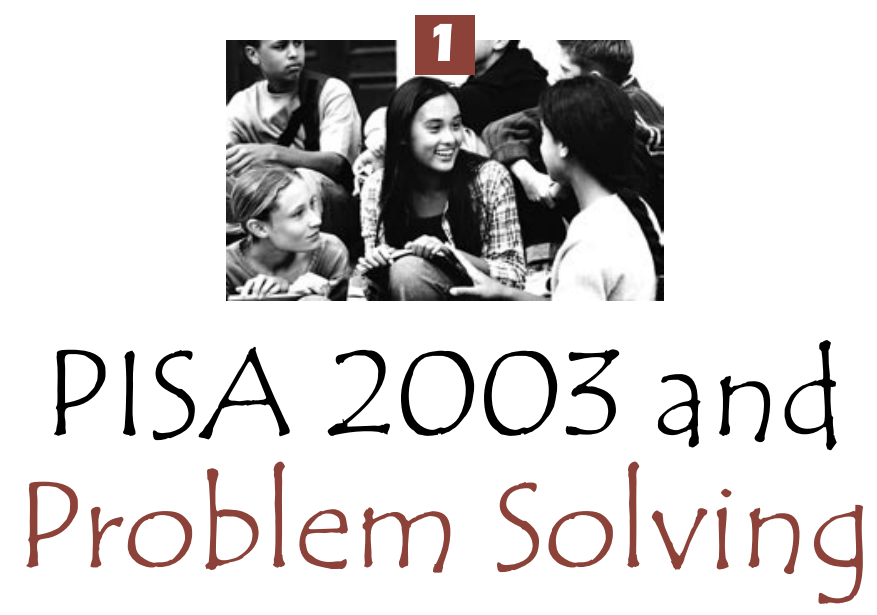

Introduction

Problem solving in PISA 2003 16

Organisation of this report 20 

- its relevance to lifelong learning, which does not limit PISA to assessing students' curricular and cross-curricular competencies but also asks them to report on their motivation to learn, their beliefs about themselves and their learning strategies;

- its regularity, which will enable countries to monitor their progress in meeting key learning objectives; and

- its breadth of geographical coverage, with the 48 countries that have participated in a PISA assessment so far and the 11 additional ones that will join the PISA 2006 assessment, representing a total of one-third of the world population and almost nine-tenths of the world's GDP. ${ }^{1}$

PISA is the most comprehensive and rigorous international programme to assess student performance and to collect data on the student, family and institutional factors that can help to explain differences in performance. Decisions about the scope and nature of the assessments and the background information to be collected are made by leading experts in participating countries, and steered jointly by their governments on the basis of shared, policy-driven interests. Substantial efforts and resources are devoted to achieving cultural and linguistic breadth and balance in the assessment materials. Stringent quality assurance mechanisms are applied in translation, sampling and data collection. As a consequence, the results of PISA have a high degree of validity and reliability, and can significantly improve understanding of the outcomes of education in the world's most developed countries, as well as in many others at earlier stages of economic development.

The first PISA survey was conducted in 2000 in 32 countries (including 28 OECD member countries) and repeated in 11 additional partner countries in 2002. In PISA 2000, where the focus was on reading, students performed written tasks under independently supervised test conditions in their schools. The first results were published in 2001 (OECD, 2001a) and 2003 (OECD, 2003a), and followed by a series of thematic reports looking in more depth at various aspects of the results. ${ }^{2}$ PISA 2003, reported on here, was conducted in 41 countries, including all 30 OECD member countries (Figure 1.1). It included an in-depth assessment of mathematics as well as less detailed assessments in science and reading. A special feature of the 2003 survey was the one-off assessment of problem-solving skills. In the next three-yearly survey, PISA 2006, the primary focus will be on science, and there will be a return to the focus on reading in 2009.3

Although PISA was originally created by the OECD governments in response to their own needs, it has now become a major policy tool for many other countries and economies as well. PISA is playing an increasing role in regions around the world, and the survey has now been conducted or is planned in the partner countries in Southeast Asia (Hong Kong-China, Indonesia, Macao-China, Chinese Taipei and Thailand), Eastern Europe (Albania, Bulgaria, Croatia, Estonia, Latvia,

PISA is being used not just in the OECD area but across the world. 
Figure 1.1 - A map of PISA countries

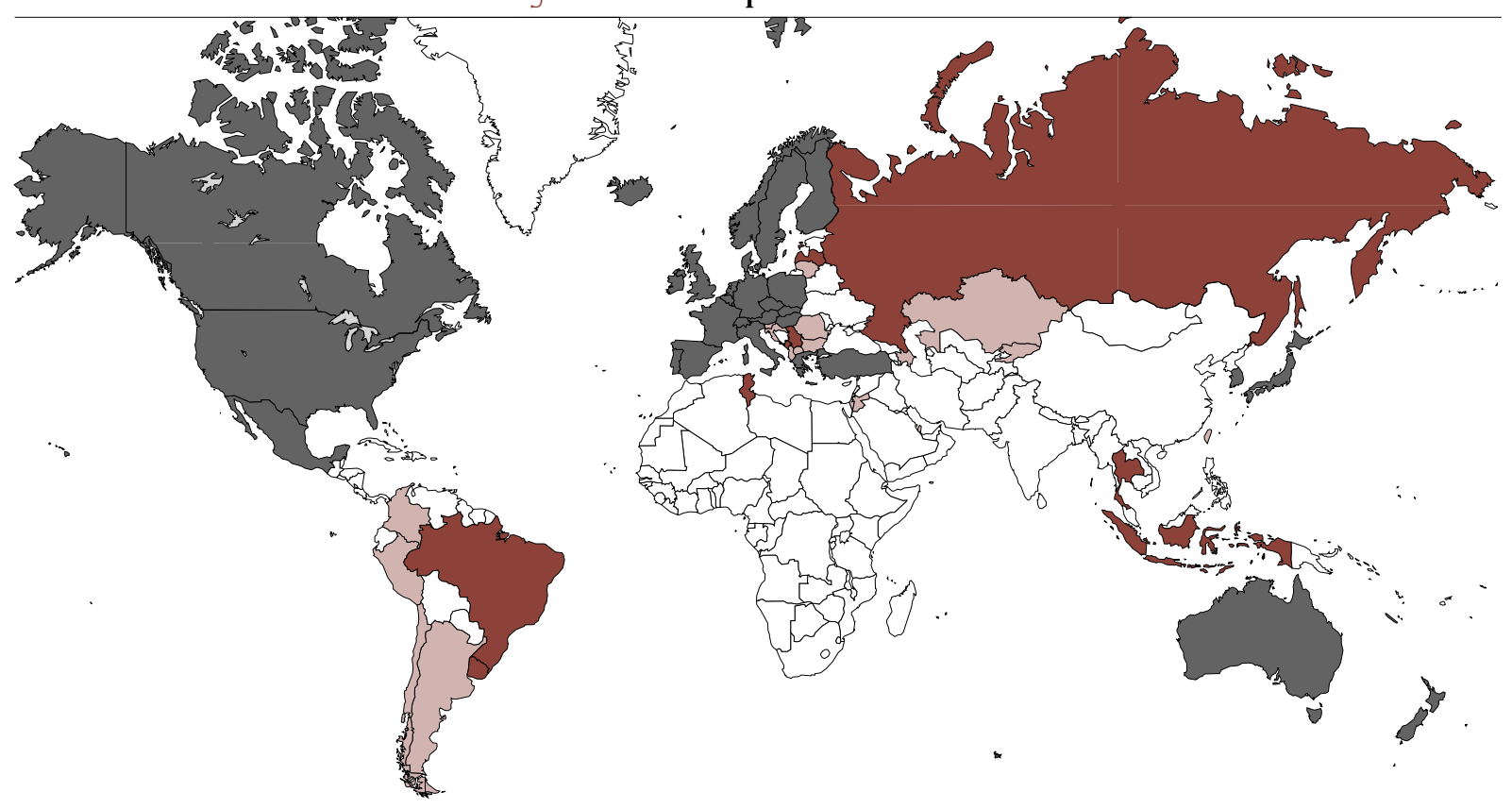

\section{OECD countries}

Australia

Austria

Belgium

Canada

Czech Republic

Denmark

Finland

France

Germany

Greece

Hungary

Iceland

Ireland

Italy

Japan

Korea

Luxembourg

Mexico

Netherlands

New Zealand

Norway

Poland

Portugal

Slovak Republic

Spain

Sweden

Switzerland

Turkey

United Kingdom

United States
Partner countries in PISA 2003

Brazil

Hong Kong-China

Indonesia

Latvia

Liechtenstein

Macao-China

Russian Federation

Serbia and Montenegro

Thailand

Tunisia

Uruguay
Partner countries in other PISA assesments

Albania

Argentina

Azerbaijan

Bulgaria

Chile

Colombia

Croatia

Estonia

Israel

Jordan

Kazakhstan

Kyrgyz Republic

Lithuania

Macedonia

Peru

Qatar

Romania

Slovenia

Chinese Taipei 
Lithuania, the Former Yugoslav Republic of Macedonia, Romania, the Russian Federation, Serbia ${ }^{4}$ and Slovenia), the Middle East (Jordan, Israel and Qatar), South America (Argentina, Brazil, Chile, Colombia, Peru and Uruguay) and North Africa (Tunisia). Across the world, policy makers use PISA findings to:

- gauge the literacy skills of students in their own country in comparison with those of the other participating countries;

- establish benchmarks for educational improvement, for example, in terms of the mean scores achieved by other countries or their capacity to provide high levels of equity in educational outcomes and opportunities; and

- understand relative strengths and weaknesses of their education system.

National interest in PISA is illustrated by the many reports produced in Globally, it has become participating countries and by the numerous references to the results of PISA in public debates and the media throughout the world (see www.pisa.oecd.org for part of the public debate. examples).

\section{Box 1.1 Key features of the PISA 2003 assessment}

\section{Content}

- The survey covers mathematics (the main focus in 2003), reading, science and problem solving. PISA considers student knowledge in these areas not in isolation but in relation to students' ability to reflect on their knowledge and experience and to apply them to real world issues. The emphasis is on the mastery of processes, the understanding of concepts, and the ability to function in various situations within each assessment area.

- PISA integrates the assessment of subject-specific knowledge with cross-curricular competencies. In PISA 2003, as in 2000, students assessed their own characteristics as learners. The 2003 survey also introduced the first assessment of wider student competencies - assessing problem-solving abilities.

\section{Methods}

- Each participating student spent two hours carrying out pencil-and-paper tasks.

- Questions requiring students to construct their own answers were combined with multiple-choice items. Items were typically organised in units based on a written passage or graphic, of the kind that students might encounter in real life.

- A total of six-and-a-half hours of assessment items was included, with different students taking different combinations of the assessment items. Three-and-a-half hours of testing time was in mathematics, with one hour each for reading, science and problem solving.

- Students answered a questionnaire that took about 30 minutes to complete and focused on their background, their learning habits and their perceptions of the learning environment, as well as on their engagement and motivation.

- School principals completed a questionnaire about their school that included demographic characteristics as well as an assessment of the quality of the learning environment at school. 

Working with these types of problems, a large set of tasks was developed and field tested in participating countries. The results were 19 tasks that required problem-solving skills, most of which are set in units consisting of two or three related items dealing with the same contextual situation. For example, the unit Holiday (shown below) consists of two items - the first asking students a direct question that assesses to what degree they understand the problem and are able to grasp the scheduling decisions that must be made, the second question asking for an itinerary that meets the criteria given. In responding, students have to deal with the constraints of the roads, distances, camp locations, towns that the individual (Zoe) wants to visit; the maximum amounts of travel per day; and the visiting times in the specific towns she wants to visit on her trip.

\section{HOLIDAY}

This problem is about planning the best route for a holiday.

Figures 1 and 2 show a map of the area and the distances between towns.

Figure 1. Map of roads between towns

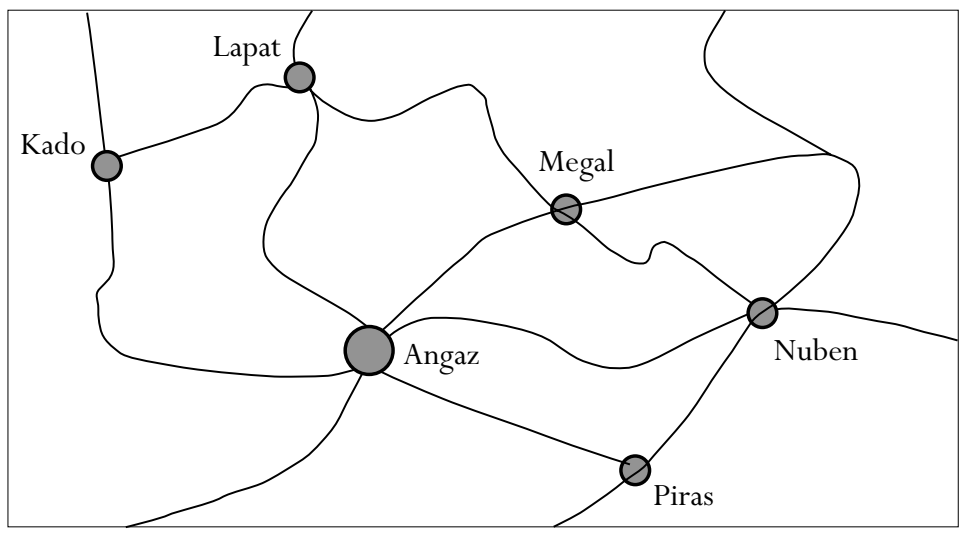

Figure 2. Shortest road distance of towns from each other in kilometres.

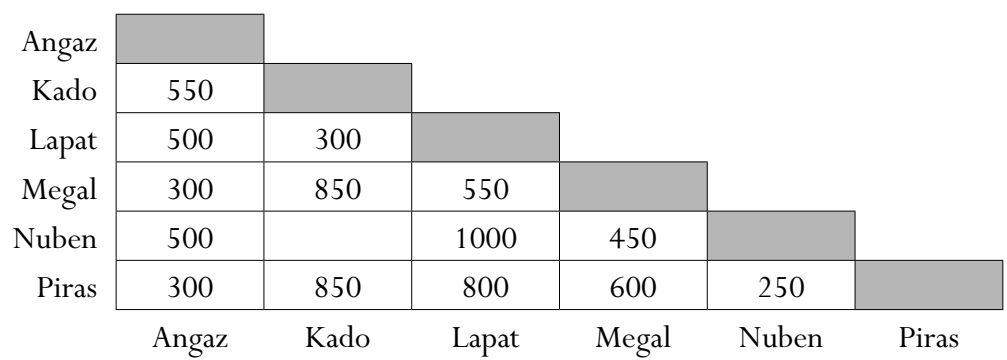

\section{HOLIDAY - Question 1}

Calculate the shortest distance by road between Nuben and Kado. 

school grades to be defined so that they are internationally comparable. Valid international comparisons of educational performance must, therefore, define their populations with reference to a target age. PISA covers students who are aged between 15 years 3 months and 16 years 2 months at the time of the assessment, regardless of the grade or type of institution in which they are enrolled and of whether they are in full-time or part-time education. The use of this age in PISA, across countries and over time, allows a consistent comparison of the performance of students shortly before they complete compulsory education.

As a result, this report is able to make statements about the knowledge and skills of individuals born in the same year and still at school at 15 years of age, but having differing educational experiences, both within and outside school. The number of school grades in which these students are to be found depends on a country's policies on school entry and promotion. Furthermore, in some countries, students in the PISA target population represent different education systems, tracks or streams.

Stringent technical standards were established for the definition of national target populations. PISA excludes 15-year-olds not enrolled in educational institutions. In the remainder of this report " 15 -year-olds" is used as shorthand to denote the PISA student population. Coverage of the target population of 15-year-olds within education is very high compared with other international surveys: relatively few schools were ineligible for participation, for example because of geographically remoteness or because their students had special needs. In 24 out of 41 participating countries, the percentage of school-level exclusions amounted to less than 1 per cent, and to less than 3 per cent in all countries except Mexico (3.6 per cent), Switzerland (3.4 per cent), the United Kingdom (3.4 per cent) and the partner countries Latvia (3.8 per cent) and Serbia (5.3 per cent). When accounting for the exclusion within schools of students who met certain internationally established criteria, ${ }^{5}$ the exclusion rates increase slightly. However, it remains below 2 per cent in 19 participating countries, below 4 per cent in 29 participating countries, below 6 per cent in all but two countries and below 8 per cent in all countries (Annex A3). This high level of coverage contributes to the comparability of the assessment results. For example, even assuming that the excluded students would have systematically scored worse than those who participated, and that this relationship is moderately strong, an exclusion rate in the order of 5 per cent would likely lead to an overestimation of national mean scores of less than 5 score points. ${ }^{6}$ Moreover, in most cases the exclusions were inevitable. For example, in New Zealand 2.3 per cent of the students were excluded because they had less than one year of instruction in English (often because they were foreign fee-paying students) and were therefore not able to follow the instructions of the assessment.

The specific sample design and size for each country was designed to maximise sampling efficiency for student-level estimates. In OECD countries, sample sizes ranged from 3350 students in Iceland to 30000 students in Mexico.

... with sufficiently large scientific samples to allow for valid comparisons. 

1. The combined population of all countries (Chinese Taipei not included) that participate in the PISA 2000, 2003 or 2006 assessments amounts to 32 per cent of the 2002 world population. The combined GDP of these countries amounts to 87.4 per cent of the 2002 world GDP. The data on GDP and population sizes were derived from the U.N. World Development Indicators database.

2. Themes of international thematic reports included: Reading for Change - Performance and Engagement Across Countries (OECD, 2002a), Learners for Life - Student Approaches to Learning (OECD, 2003c), Student Engagement at School -A Sense of Belonging and Participation (OECD, 2003d), What Makes School Systems Perform (OECD, 2004b) and School Factors Relating to Quality and Equity (OECD, forthcoming)

3. The framework for the PISA 2006 assessment has been finalised and preparations for the implementation of the assessment are currently underway. Governments will decide on subsequent PISA assessments in 2005.

4. For the country Serbia and Montenegro, data for Montenegro are not available. The latter accounts for 7.9 per cent of the national population. The name "Serbia" is used as a shorthand for the Serbian part of Serbia and Montenegro.

5. Countries were permitted to exclude up to 2.5 per cent of the national desired target population within schools if these students were: i) considered in the professional opinion of the school principal or of other qualified staff members, to be educable mentally retarded or who had been defined as such through psychological tests (including students who were emotionally or mentally unable to follow the general instructions given in PISA); ii) permanently and physically disabled in such a way that they could not perform in the PISA assessment situation (functionally disabled students who could respond were to be included in the assessment); or iii) non-native language speakers with less than one year of instruction in the language of the assessment (for details see Annex A3).

6. If the correlation between the propensity of exclusions and student performance is 0.3 , resulting mean scores would likely be overestimated by 1 score point if the exclusion rate is 1 per cent, by 3 score points if the exclusion rate is 5 per cent, and by 6 score points if the exclusion rate is 10 per cent. If the correlation between the propensity of exclusions and student performance is 0.5 , resulting mean scores would be overestimated by 1 score point if the exclusion rate is 1 per cent, by 5 score points if the exclusion rate is 5 per cent, and by 10 score points if the exclusion rate is 10 per cent. For this calculation, a model was employed that assumes a bivariate normal distribution for the propensity to participate and performance. For details see the PISA 2000 Technical Report (OECD 2002b). 



\section{Reporting of student data}

The report usually uses " 15 -year-olds" as shorthand for the PISA target population. In practice, this refers to students who were aged between 15 years and 3 (complete) months and 16 years and 2 (complete) months at the beginning of the assessment period and who were enrolled in an educational institution, regardless of the grade level or type of institution, and of whether they were attending full-time or part-time (for details see Annex A3).

\section{Abbreviations used in this report}

The following abbreviations are used in this report:

\section{GDP Gross Domestic Product}

ISCED International Standard Classification of Education

SD Standard deviation

SE Standard error

\section{Further documentation}

For further information on the PISA assessment instruments and the methods used in PISA, see the PISA 2000 Technical Report (OECD, 2002b) and the PISA Web site (www.pisa.oecd.org). 


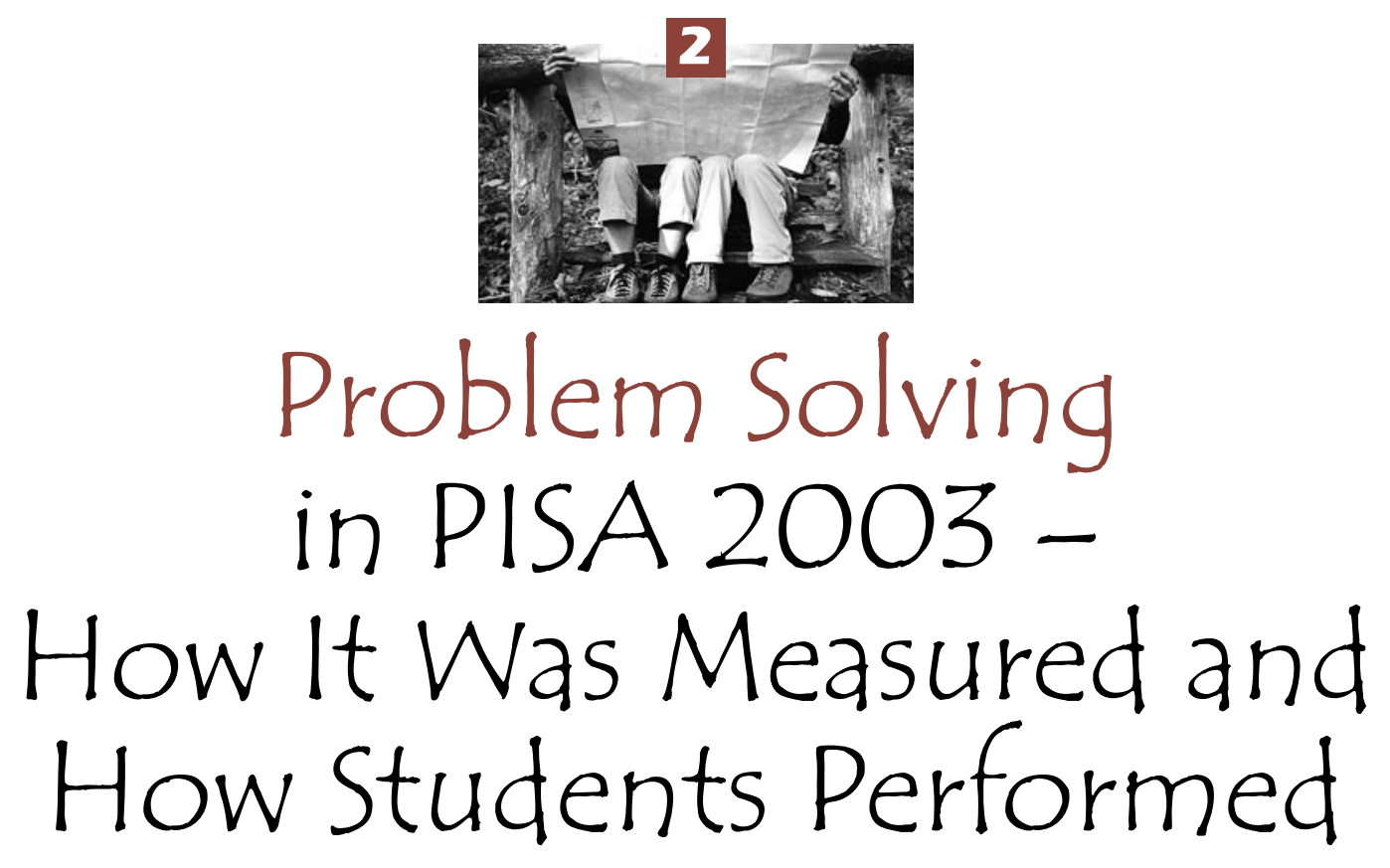

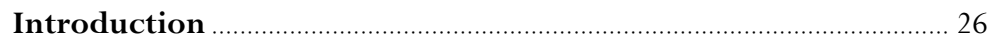

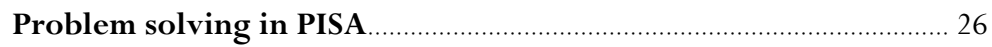

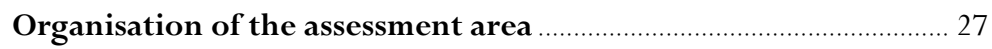

Problems chosen for the PISA problem-solving assessment .......... 28

The PISA problem-solving scale ......................................................... 28

- Level 3: Reflective, communicative problem solvers.................................. 29

- Level 2: Reasoning, decision-making problem solvers .............................. 30

- Level 1: Basic problem solvers ................................................................... 30

- Below Level 1: Weak or emergent problem solvers ................................... 30

- Decision making - the Cinema Outing problem........................................... 32

- System analysis and design - the Children's Camp problem ..................... 34

- Trouble shooting - the Irrigation problem............................................... 36

The percentage of students at each proficiency level

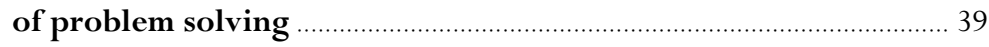

- Mean performance of countries .................................................................. 41

The distribution of problem-solving capabilities within countries 
This chapter describes how PISA measured problem solving and summarises student performance overall.
- First, the chapter defines problem solving, reviews the kind of problem- solving tasks that were used in PISA 2003 and describes the requirements made of students in solving these problems.

- Second, the chapter describes the way in which student performance in problem solving was measured. This is illustrated in relation to items used in this assessment, and the percentage of each country's students at each proficiency level of the problem-solving scale is reported.

- Third, the chapter summarises the performance of students in each of the countries participating in PISA 2003 by reporting their mean performance and describing the distribution of scores on the problem-solving assessment for the students within each country.

\section{Problem solving in PISA}

Problem solving is a central part of education across the curriculum.

To assess it requires tasks that are...

... situated in real-life contexts...
Curricula in various subject areas often call for students to confront problem situations by understanding information that is given, identifying critical features and any relationships in a situation, constructing or applying one or more external representations, resolving ensuing questions and, finally, evaluating, justifying and communicating results as a means to further understanding the situation. This is because problem solving is widely seen as providing an essential basis for future learning, for effectively participating in society, and for conducting personal activities.

The PISA 2003 Assessment Framework: Mathematics, Reading, Science and Problem Solving Knowledge and Skills (OECD, 2003b) through which OECD countries established the guiding principles for comparing problem-solving performance across countries in PISA, defines problem competencies as:

... an individual's capacity to use cognitive processes to confront and resolve real, cross-disciplinary situations where the solution path is not immediately obvious and where the content areas or curricular areas that might be applicable are not within a single subject area of mathematics, science or reading.

Several aspects of this definition are worth noting.

- The first is that the settings for the problems should be real. They should draw on situations that represent contexts that could conceivably occur in a student's life or, at least, be situations the student can identify as being important to society, if not directly applicable to his or her personal life. Thus, a real-life problem calls on individuals to merge knowledge and strategies to confront and resolve a problem, when the method by which this needs to be accomplished is not readily apparent to the problem solver. 
- The second feature is that they are not immediately resolvable through the application of some defined process that the student has studied, and probably practised, at school. The problems should present new types of questions requiring the student to work out what to do. This is what causes the item really to be a problem-solving item. Such problems call on individuals to move among different, but sometimes related, representations and to exhibit a certain degree of flexibility in the ways in which they access, manage, evaluate and reflect on information.

- Finally, the problems used should not be limited to a single content area that students would have studied and practised as part of their study of a single school subject in school.

\section{Organisation of the assessment area}

With this definition of problem solving, the nature of the tasks to be used in the assessment was established in The PISA 2003 Assessment Framework: Mathematics, Reading, Science and Problem Solving Knowledge and Skills (OECD, 2003b), based on the following components:

- Problem types. PISA 2003 focused on three problem types: decision making, system analysis and design, and trouble shooting. These were chosen because they are widely applicable and occur in a variety of settings. The problem types used for PISA are described in more detail in the next section.

- Problem context. The problems used in the assessment were not set in the classroom or based on materials studied in the curriculum, but rather set in contexts that a student would find in his/her personal life, work and leisure, and in the community and society.

- Problem-solving processes. The assessment was designed such that the results would describe the degree to which students are able to confront, structure, represent and solve problems effectively. Accordingly, the tasks included in the assessment were selected to collect evidence of students' knowledge and skills associated with the problem-solving process. In particular, students had to demonstrate that they could:

- Understand the problem: This included understanding text, diagrams, formulas or tabular information and drawing inferences from them; relating information from various sources; demonstrating understanding of relevant concepts; and using information from students' background knowledge to understand the information given.

- Characterise the problem: This included identifying the variables in the problem and noting their interrelationships; making decisions about which variables are relevant and irrelevant; constructing hypotheses; and retrieving, organising, considering and critically evaluating contextual information.

- Represent the problem: This included constructing tabular, graphical, symbolic or verbal representations; applying a given external representation to the solution of the problem; and shifting between representational formats. ...not resolvable through the application of routine solutions...

... and require

connections between

multiple content areas.

The problem-solving tasks were defined by the ...

...the type of problem ...

...the problem context...

... and the problemsolving processes involved.

Students had to show their ability to understand the problem...

...identify the variables involved and their interrelationships...

...represent the problem... 
... solve the problem...

...reflect on the solution...

.... and communicate it.

Beyond drawing on a student's knowledge, good problems also draw upon their reasoning skills.

Problem types included tasks related to decision making, system analysis and design and trouble shooting.

Student performance was rated on a scale based on aspects of the above framework, with three levels of proficiency distinguishing between...
- Solve the problem: This included making decisions (in the case of decision making); analysing a system or designing a system to meet certain goals (in the case of system analysis and design); and diagnosing and proposing a solution (in the case of trouble shooting).

- Reflect on the solution: This included examining solutions and looking for additional information or clarification; evaluating solutions from different perspectives in an attempt to restructure the solutions and making them more socially or technically acceptable; and justifying solutions.

- Communicate the problem solution: This included selecting appropriate media and representations to express and to communicate solutions to an outside audience.

Beyond drawing on a student's knowledge, good problems also draw upon their reasoning skills. In understanding a problem situation, the problem solver may need to distinguish between facts and opinion. In formulating a solution, the problem solver may need to identify relationships between variables. In selecting a strategy, the problem solver may need to consider cause and effect. In solving a problem and communicating the results, the problem solver may need to organise information in a logical manner. These activities often require analytical reasoning, quantitative reasoning, analogical reasoning and combinatorial reasoning skills.

Thus, a student needs to combine many different cognitive processes to solve a problem and the PISA problem-solving assessment strives to identify the processes students use and to describe and quantify the quality of the students' work in problem solving.

\section{Problems chosen for the PISA problem-solving assessment}

Three types of problem were chosen for the PISA problem-solving assessment: decision making, system analysis and design and trouble shooting. Figure 2.1 compares the features of each problem type. The three features outlined in the table (goals, processes and sources of complexity) serve as the basis for establishing a scale to describe increasing student proficiency in problem solving. The PISA problem-solving scale provides a representation of students' capacity to understand, characterise, represent, solve, reflect on and communicate their solutions to a problem.

\section{The PISA problem-solving scale}

The PISA problem-solving scale derives from an analysis of the theoretical constructs underlying the problem-solving components detailed in Figure 2.1 and was validated by an analysis of student work on related tasks. The scale runs from students with the weakest problem-solving skills to those with the strongest problem-solving skills and has three distinct, described performance levels. These are referred to as proficiency levels, and provide an analytical model for describing what individual students are capable of, as well as comparing and contrasting student proficiency across countries. 
Figure 2.1 - Features of the three types of problem solving

\begin{tabular}{|c|c|c|c|}
\hline & Decision making & System analysis and design & Trouble shooting \\
\hline Goals & $\begin{array}{l}\text { Choosing among } \\
\text { alternatives under } \\
\text { constraints }\end{array}$ & $\begin{array}{l}\text { Identifying the relationships } \\
\text { between parts of a system } \\
\text { and/or designing a system } \\
\text { to express the relationships } \\
\text { between parts }\end{array}$ & $\begin{array}{l}\text { Diagnosing and correcting a } \\
\text { faulty or underperforming system } \\
\text { or mechanism }\end{array}$ \\
\hline \multirow[t]{6}{*}{$\begin{array}{l}\text { Processes } \\
\text { involved }\end{array}$} & $\begin{array}{l}\text { Understanding a situation } \\
\text { where there are several } \\
\text { alternatives and constraints } \\
\text { and a specified task }\end{array}$ & $\begin{array}{l}\text { Understanding the information } \\
\text { that characterises a given } \\
\text { system and the requirements } \\
\text { associated with a specified task }\end{array}$ & $\begin{array}{l}\text { Understanding the main features } \\
\text { of a system or mechanism and its } \\
\text { malfunctioning, and the demands } \\
\text { of a specific task }\end{array}$ \\
\hline & $\begin{array}{l}\text { Identifying relevant } \\
\text { constraints }\end{array}$ & $\begin{array}{l}\text { Identifying relevant parts of } \\
\text { the system }\end{array}$ & $\begin{array}{l}\text { Identifying causally related } \\
\text { variables }\end{array}$ \\
\hline & $\begin{array}{l}\text { Representing the possible } \\
\text { alternatives }\end{array}$ & $\begin{array}{l}\text { Representing the relationships } \\
\text { among parts of the system }\end{array}$ & $\begin{array}{l}\text { Representing the functioning of } \\
\text { the system }\end{array}$ \\
\hline & $\begin{array}{l}\text { Making a decision among } \\
\text { alternatives }\end{array}$ & $\begin{array}{l}\text { Analysing or designing a system } \\
\text { that captures the relationships } \\
\text { between parts }\end{array}$ & $\begin{array}{l}\text { Diagnosing the malfunctioning of } \\
\text { the system and/or proposing a } \\
\text { solution }\end{array}$ \\
\hline & $\begin{array}{l}\text { Checking and evaluating } \\
\text { the decision }\end{array}$ & $\begin{array}{l}\text { Checking and evaluating the } \\
\text { analysis or the design of the } \\
\text { system }\end{array}$ & $\begin{array}{l}\text { Checking and evaluating the } \\
\text { diagnosis/solution }\end{array}$ \\
\hline & $\begin{array}{l}\text { Communicating or } \\
\text { justifying the decision }\end{array}$ & $\begin{array}{l}\text { Communicating the analysis or } \\
\text { justifying the proposed design }\end{array}$ & $\begin{array}{l}\text { Communicating or justifying the } \\
\text { diagnosis and the solution }\end{array}$ \\
\hline \multirow[t]{2}{*}{$\begin{array}{l}\text { Possible sources } \\
\text { of complexity }\end{array}$} & Number of constraints & $\begin{array}{l}\text { Number of interrelated } \\
\text { variables and nature of } \\
\text { relationships }\end{array}$ & $\begin{array}{l}\text { Number of interrelated parts of } \\
\text { the system or mechanism and the } \\
\text { ways in which these parts interact }\end{array}$ \\
\hline & $\begin{array}{l}\text { Number and type of } \\
\text { representations used (verbal, } \\
\text { pictorial, numerical) }\end{array}$ & $\begin{array}{l}\text { Number and type of } \\
\text { representations used (verbal, } \\
\text { pictorial, numerical) }\end{array}$ & $\begin{array}{l}\text { Number and type of } \\
\text { representations used (verbal, } \\
\text { pictorial, numerical) }\end{array}$ \\
\hline
\end{tabular}

\section{Level 3: Reflective, communicative problem solvers}

Students proficient at Level 3 score above 592 points on the PISA problemsolving scale and typically do not only analyse a situation and make decisions, but also think about the underlying relationships in a problem and relate these to the solution. Students at Level 3 approach problems systematically, construct their own representations to help them solve it and verify that their solution satisfies all requirements of the problem. These students communicate their solutions to others using accurate written statements and other representations.

Students at Level 3 tend to consider and deal with a large number of conditions, such as monitoring variables, accounting for temporal restrictions, and other constraints. Problems at this level are demanding and require students to regulate their work. Students at the top of Level 3 can cope with multiple interrelated conditions that require students to work back and forth between their solution and the conditions laid out in the problem. Students at this level ...reflective problem solvers that do not only analyse a situation and make correct decisions but also think about underlying relationships and relate these to solutions... 
organise and monitor their thinking while working out their solution. Level 3 problems are often multi-faceted and require students to manage all interactions simultaneously and develop a unique solution, and students at Level 3 are able to address such problems successfully and communicate their solutions clearly.

Students at Level 3 are also expected to be able to successfully complete tasks located at lower levels of the PISA problem-solving scale.

\section{Level 2: Reasoning, decision-making problem solvers}

...reasoning, decisionmaking problemsolvers...

... and basic problem solvers.
Students proficient at Level 2 score from 499 to 592 points on the problem-solving scale and use reasoning and analytic processes and solve problems requiring decisionmaking skills. These students can apply various types of reasoning (inductive and deductive reasoning, reasoning about causes and effects, or reasoning with many combinations, which involves systematically comparing all possible variations in well-described situations) to analyse situations and to solve problems that require them to make a decision among well-defined alternatives. To analyse a system or make decisions, students at Level 2 combine and synthesise information from a variety of sources. They are able to combine various forms of representations (e.g. a formalised language, numerical information, and graphical information), handle unfamiliar representations (e.g. statements in a programming language or flow diagrams related to a mechanical or structural arrangement of components) and draw inferences based on two or more sources of information.

Students at Level 2 are also expected to be able to successfully complete tasks located at Level 1 of the PISA problem-solving scale.

\section{Level 1: Basic problem solvers}

Students proficient at Level 1 score from 405 to 499 points on the problem-solving scale and typically solve problems where they have to deal with only a single data source containing discrete, well-defined information. They understand the nature of a problem and consistently locate and retrieve information related to the major features of the problem. Students at Level 1 are able to transform the information in the problem to present the problem differently, e.g. take information from a table to create a drawing or graph. Also, students can apply information to check a limited number of well-defined conditions within the problem. However, students at Level 1 do not typically deal successfully with multi-faceted problems involving more than one data source or requiring them to reason with the information provided.

\section{Below Level 1: Weak or emergent problem solvers}

The PISA problem-solving assessment was not designed to assess elementary problem-solving processes. As such, the assessment materials did not contain sufficient tasks to describe fully performances that fall below Level 1. Students with performances below Level 1 have scores of less than 405 points on the problem-solving scale and consistently fail to understand even the easiest items in the assessment or fail to apply the necessary processes to characterise important features or represent the problems. At most, they can deal with straightforward problems with carefully structured tasks that require the students to give 
responses based on facts or to make observations with few or no inferences. Students below Level 1 have significant difficulties in making decisions, analysing or evaluating systems, and trouble-shooting situations.

The three levels of problem solving are associated with a defined range of scores on the PISA problem-solving scale. In Figure 2.2 this scale is represented as a vertical line, with students' scores representing their level of problem-solving proficiency. A student can score full, partial or no credit for a given item. Scores for full or partial credit (including two levels of partial credit on one of the items) are expressed in terms of particular scores along the scale. Each assessment item is assigned a score, such that the majority of students with this score could expect to get the item correct. The mean student performance across OECD countries, weighted equally, was set at 500 score points, and the standard deviation was set at 100 score points. Thus, approximately two-thirds of student performances fall between 400 and 600 score points.

Figure 2.2 - The PISA problem-solving scale

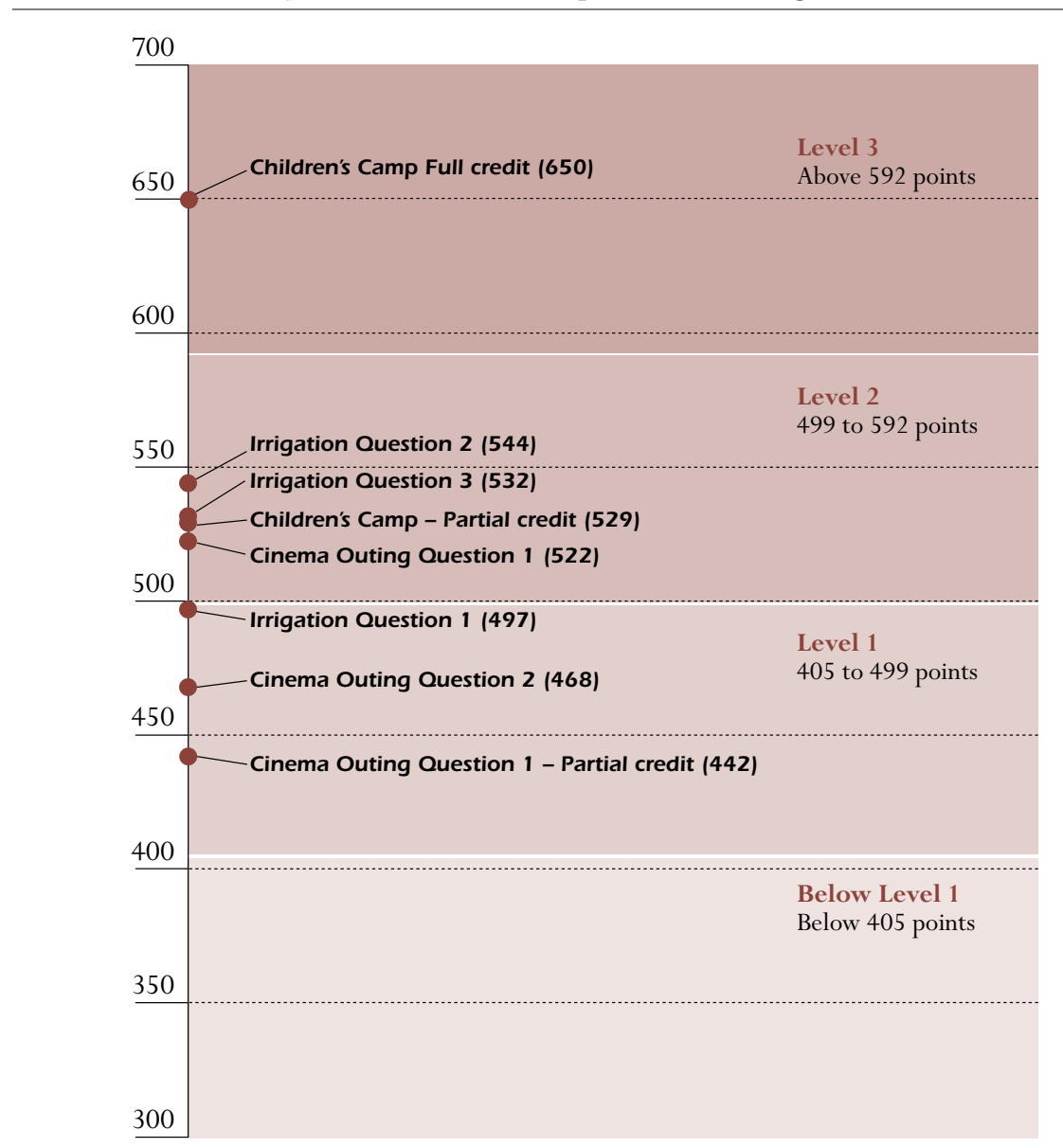

The three items shown below illustrate the nature of the various problem types and the processes required for students to succeed in problem-solving tasks at various levels of difficulty.
These proficiency levels are represented on a scale for which the mean score is 500 points and two-thirds score between 400 and 600 points. 
Decision making - the CINEMA OUTING problem

Context: Personal

Levels: Level 1 (Cinema Outing, Question 2) and

Level 2 (Cinema Outing, Question 1)

PISA scale score: 468 (Cinema Outing, Question 2) and 522 (Cinema Outing, Question 1)

Cinema Outing is a decision-making problem that presents students with a significant amount of information and a set of well-defined decisions to make based on the information given. Students proficient at Level 2 will typically be able to respond correctly to Cinema Outing, Question 1. Such students are capable of making decisions while considering a wide variety of boundary constraints and reasoning through what works and what does not work. Most of the decisions require the use of two or more pieces of the provided information. In addition, the student has to merge information from boundary conditions in the stated context, e.g. information about individuals' weekly schedules, commitments, and movies they had already seen, as well as noting which movies are showing, the showing times and film lengths, and the film ratings. Cinema Outing, Question 2 is a less demanding task. It requires students to make a decision when only temporal constraints have to be satisfied. Students can use the boundary conditions on times when Fred, Stanley, and Isaac can see movies, match these against the showing times for "Children in the Net" in the table and determine the correct answer. A correct performance on Cinema Outing, Question 2 corresponds to Level 1 on the PISA problem-solving proficiency scale, as students only need to understand and check some information that is easily retrievable from the problem statement.

This problem is about finding a suitable time and date to go to the cinema.

Isaac, a 15 -year-old, wants to organise a cinema outing with two of his friends, who are of the same age, during the one-week school vacation. The vacation begins on Saturday, $24^{\text {th }}$ March and ends on Sunday, $1^{\text {st }}$ April.

Isaac asks his friends for suitable dates and times for the outing. The following information is what he received.

Fred: "I have to stay home on Monday and Wednesday afternoons for music practice between 2:30 and 3:30.”

Stanley: "I have to visit my grandmother on Sundays, so it can't be Sundays. I have seen Pokamin and don't want to see it again."

Isaac's parents insist that he only goes to movies suitable for his age and does not walk home. They will fetch the boys home at any time up to 10 p.m.

Isaac checks the movie times for the vacation week. This is the information that he finds. 
Advance Booking Number: 01924423000

24 hour phone number: 01924420071

Bargain Day Tuesdays: All films $\$ 3$

Films showing from Fri $23^{\text {rd }}$ March for two weeks:

\section{Children in the Net}

113 mins

14:00 (Mon-Fri only)

21:35 (Sat/Sun only)

\section{Monsters from the Deep}

164 mins

19:55 (Fri/Sat only)

Carnivore

148 mins

18:30 (Daily)
Suitable only for persons of 18 years and over

Suitable only for persons of 12 years and over

105 mins

13:40 (Daily)

16:35 (Daily)

\section{Enigma}

144 mins

15:00 (Mon-Fri only) 18:00 (Sat/Sun only)

\section{King of the Wild}

Suitable only for persons of 18 years and over
117 mins

14:35 (Mon-Fri only)

18:50 (Sat/Sun only)
Parental Guidance. General viewing, but some scenes may be unsuitable for young children

Suitable only for persons of 12 years and over

Suitable for persons of all ages

\section{CINEMA OUTING - Question 1}

Taking into account the information Isaac found on the movies, and the information he got from his friends, which of the six movies should Isaac and the boys consider watching?

Circle "Yes" or "No" for each movie.

\begin{tabular}{l|c}
\hline Movie & Should the three boys consider watching the movie? \\
\hline Children in the Net & Yes / No \\
\hline Monsters from the Deep & Yes / No \\
\hline Carnivore & Yes / No \\
\hline Pokamin & Yes / No \\
\hline Enigma & Yes / No \\
\hline King of the Wild & Yes / No \\
\hline
\end{tabular}

\section{Response Coding guide for CINEMA OUTING Question 1}

Full Credit

Code 2: Yes, No, No, No, Yes, Yes, in that order.

Partial Credit

Code 1: One incorrect answer.

No Credit

Code 0: Other responses.

Code 9: Missing. 


\section{CINEMA OUTING - Question 2}

If the three boys decided on going to "Children in the Net", which of the

following dates is suitable for them?

A. Monday, $26^{\text {th }}$ March

B. Wednesday, $28^{\text {th }}$ March

C. Friday, $30^{\text {th }}$ March

D. Saturday, $31^{\text {st }}$ March

E. Sunday, $1^{\text {st }}$ April

\section{Response Coding guide for CINEMA OUTING Question 2}

Full Credit

Code 1: C. Friday, $30^{\text {th }}$ March.

No Credit

Code 0: Other responses.

Code 9: Missing.

\section{System analysis and design - the CHILDREN'S CAMP problem}

Context: Community/Leisure

Levels: Level 2 (partial credit) and Level 3 (full credit)

PISA scale score: 529 (partial credit) and 650 (full credit)

Children's Camp is an example of a system analysis and design problem. Students have to understand the various constraints and their interrelationships, and design a solution that complies with them. This problem presents students with a statement about the context of a summer camp, lists of adult and child participants, and a set of boundary constraints that must be satisfied in the assignment of participants to the different dormitories at the camp. Full credit on this problem corresponds to proficiency Level 3. A correct solution requires students to combine different pieces of information about both the age and gender of the individuals involved. The students must arrange a match between the characteristics of the adults and children involved, and assign individuals to dormitories taking into account the capacities of the dormitories with respect to the number and gender of the children participating.

While a certain amount of trial and error can be used in working through the first phases to understand the problem, the successful solution requires students to monitor and adjust partial solutions relative to a number of interrelated conditions. A correct solution requires careful communication that details an appropriate number of the correctly matched students with an adult counsellor for each of the cabin dormitories. Students must work with several interrelated conditions and continually cross check until they have a solution that satisfies the constraints given. To do this, they must constantly shift between the desired state, the constraints, and the current status of their emerging solution. This requirement to manage the interactions simultaneously with the development of a unique solution is what makes the problem a Level 3 task. 
The Zedish Community Service is organising a five-day Children's Camp. 46 children ( 26 girls and 20 boys) have signed up for the camp, and 8 adults ( 4 men and 4 women) have volunteered to attend and organise the camp.

Table 1. Adults

\begin{tabular}{l}
\hline Mrs Madison \\
\hline Mrs Carroll \\
\hline Ms Grace \\
\hline Ms Kelly \\
\hline Mr Stevens \\
\hline Mr Neill \\
\hline MrWilliams \\
\hline Mr Peters \\
\hline
\end{tabular}

Table 2. Dormitories

\begin{tabular}{l|c}
\hline Name & Number of beds \\
\hline Red & 12 \\
\hline Blue & 8 \\
\hline Green & 8 \\
\hline Purple & 8 \\
\hline Orange & 8 \\
\hline Yellow & 6 \\
\hline White & 6 \\
\hline
\end{tabular}

\section{Dormitory rules:}

1. Boys and girls must sleep in separate dormitories.

2. At least one adult must sleep in each dormitory.

3. The adult(s) in a dormitory must be of the same gender as the children.

\section{CHILDREN'S CAMP - Question 1}

\section{Dormitory Allocation}

Fill the table to allocate the 46 children and 8 adults to dormitories, keeping to all the rules.

\begin{tabular}{l|l|l|l} 
Name & Number of boys & Number of girls & Name(s) of adult(s) \\
\hline Red & & & \\
\hline Blue & & & \\
\hline Green & & & \\
\hline Purple & & & \\
\hline Orange & & & \\
\hline Yellow & & & \\
\hline White & & & \\
\hline
\end{tabular}

\section{Response Coding guide for CHILDREN'S CAMP Question 1}

Full Credit

Code 2: 6 conditions to be satisfied

- Total girls $=26$

- Total boys $=20$

- Total adults $=$ four female and four male 
- Total (children and adults) per dormitory is within the limit for each dormitory

- People in each dormitory are of the same gender

- At least one adult must sleep in each dormitory to which children have been allocated

Partial Credit

Code 1: One or two conditions (mentioned in Code 2) violated. Violating the same condition more than once will be counted as ONE violation only.

- Forgetting to count the adults in the tally of the number of people in each dormitory

- The number of girls and the number of boys are interchanged (number of girls $=20$, number of boys $=26$ ), but everything else is correct. (Note that this counts as two conditions violated.)

- The correct number of adults in each dormitory is given, but not their names or gender. (Note that this violates both condition 3 and condition 5.)

No Credit

Code 0: Other responses.

Code 9: Missing.

\section{Trouble shooting - the IRRIGATION problem}

\section{Context: Society}

Levels: Level 1 (Irrigation, Question 1), Level 2 (Irrigation, Question 2 and Irrigation, Question 3)

PISA scale score: 497 (Irrigation, Question 1), 544 (Irrigation, Question 2) and 532 (Irrigation, Question 3)

Irrigation is an example of a trouble-shooting item. This problem presents students with a system of gates and canals, which provides means of distributing water across a network described by a pictorial diagram. Irrigation, Question 1 measures whether students understand the problem and how the gates in the irrigation network operate. Students proficient at Level 1 will typically answer correctly, as the task only requires the students to set the gates and then check if there is a path by which water can flow through the system. Students merely need to make a one-to-one transformation of the data from the table to the diagram and then trace it to see if there is a path from the inflow point to the outlet. 
Below is a diagram of a system of irrigation channels for watering sections of crops. The gates A to $\mathrm{H}$ can be opened and closed to let the water go where it is needed. When a gate is closed no water can pass through it.

This is a problem about finding a gate which is stuck closed, preventing water from flowing through the system of channels.

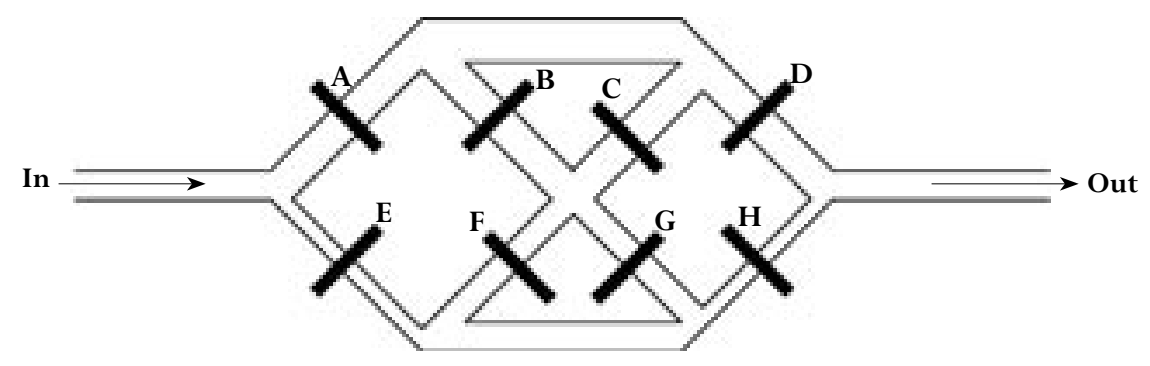

Michael notices that the water is not always going where it is supposed to.

He thinks that one of the gates is stuck closed, so that when it is switched to open, it does not open.

\section{IRRIGATION - Question 1}

Michael uses the settings given in Table 1 to test the gates.

Table 1. Gate Settings

\begin{tabular}{c|c|c|c|c|c|c|c}
\hline $\mathbf{A}$ & $\mathbf{B}$ & $\mathbf{C}$ & $\mathbf{D}$ & $\mathbf{E}$ & $\mathbf{F}$ & $\mathbf{G}$ & $\mathbf{H}$ \\
\hline Open & Closed & Open & Open & Closed & Open & Closed & Open \\
\hline
\end{tabular}

With the gate settings as given in Table 1, on the diagram below draw all the possible paths for the flow of water. Assume that all gates are working according to the settings.

\section{Response Coding guide for IRRIGATION Question 1}

Full Credit

Code 1: Flow paths as shown below: 
In

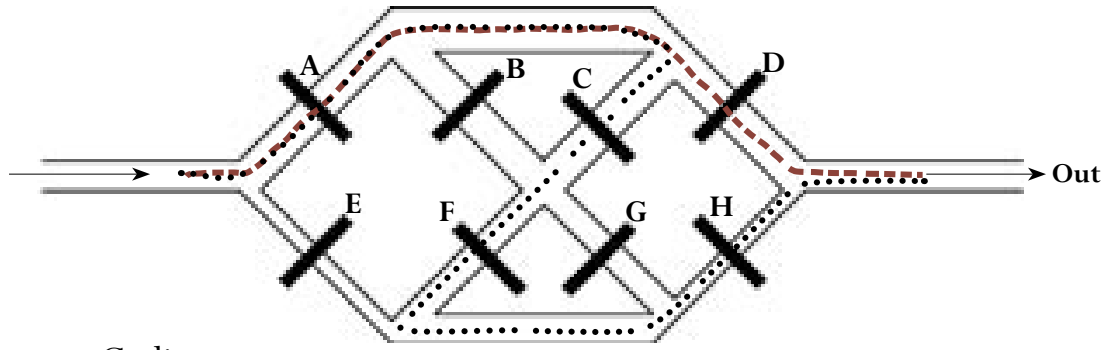

Response Coding notes:

Ignore any indications of the directions of flow.

Note that the response could be shown in the diagram provided, or in Figure A, or in words, or with arrows.

No Credit

Code 0: Other responses.

Code 9: Missing.

\section{IRRIGATION - Question 2}

Michael finds that, when the gates have the Table 1 settings, no water flows

through, indicating that at least one of the gates set to open is stuck closed.

Decide for each problem case below whether the water will flow through all the way. Circle "Yes" or "No" in each case.

\section{Problem Case \\ Gate $\mathbf{A}$ is stuck closed. All other gates are working properly as set in Table 1 .}

Gate $\mathbf{D}$ is stuck closed. All other gates are working properly as set in Table 1 .

Gate $\mathbf{F}$ is stuck closed. All other gates are working properly as set in Table 1 .
Will water flow through all the way?

Yes / No

Yes / No

Yes / No

\section{Response Coding guide for IRRIGATION Question 2}

Full Credit

Code 1: No, Yes, Yes, in that order.

No Credit

Code 0: Other responses.

Code 9: Missing.

\section{IRRIGATION - Question 3}

Michael wants to be able to test whether gate $\mathbf{D}$ is stuck closed.

In the following table, show settings for the gates to test whether gate $\mathbf{D}$ is stuck closed when it is set to open.

Settings for gates (each one open or closed)

\begin{tabular}{l|l|l|l|l|l|l|l}
$\mathbf{A}$ & $\mathbf{B}$ & $\mathbf{C}$ & $\mathbf{D}$ & $\mathbf{E}$ & $\mathbf{F}$ & $\mathbf{G}$ & $\mathbf{H}$ \\
\hline & & & & & & & \\
\hline
\end{tabular}




\section{Response Coding guide for IRRIGATION Question 3}

Full Credit

Code 1: A and E are not both closed. D must be open. H can only be open if water cannot get to it (e.g. other gates are closed preventing water from reaching $\mathrm{H}$ ). Otherwise $\mathrm{H}$ must be closed.

- H closed, all other gates open

No Credit

Code 0: Other responses.

Code 9: Missing.

The second problem, Irrigation, Question 2, requires student performances typically associated with Level 2 problem solvers. Such students have to understand and trouble shoot the mechanism, in this case the system of gates and canals when the gates are set as given in the first problem, to locate the potential problem when water does not flow through the system. This requires the students to keep in mind the representation and then apply deductive and combinatorial reasoning in order to find a solution.

Similarly, Irrigation, Question 3 is a Level 2 problem because it requires students to handle several interconnected relationships at once, moving between the gate settings and possible flow patterns to ascertain whether a particular gate setting will result in water flowing or not flowing through Gate D.

To summarise, these three items provide one example of each of the three problem types. In the decision-making problem students need to understand the given information, identify the relevant alternatives and the constraints involved, construct or apply external representations, select the best solution from a set of given alternatives and communicate the decision. In the system analysis and design problem students need to understand the complex relationships among a number of interdependent variables, identify their crucial features, create or apply a given representation, and design a system so that certain goals are achieved. Students also need to check and evaluate their work through the various steps along the way to an analysis or design. In the trouble-shooting problem students need to diagnose the problem, propose a solution and execute this solution. Students must understand how a device or procedure works, identify the relevant features for the task at hand and create a representation.

\section{The percentage of students at each proficiency level of problem solving}

Figure 2.2 also shows where each item from the three problem units presented above is located on the PISA problem-solving scale. A student who scores 468 on this scale is likely to be able to answer Cinema Outing, Question 2 correctly. To be precise, students have a 62 per cent chance of answering correctly a task ranked at their point score. This is the criterion used throughout PISA, and has

The three items above illustrate the three problem types at various levels of difficulty.

Students at each proficiency level have at least a 50 per cent chance of solving problems at that level. 
Country performance can be summarised in terms

of how many students are proficient at least at

Level 3, Level 2 and Level 1.

In some countries most students can solve relatively complex problems, while in others few can...

... with the proportion varying from above seven in ten students to below one in 20 .

In most countries, more than one student in ten are unable to solve basic problems at Level 1, and in five countries over half the students are unable to do so. been set in order to meet another condition: Each student is assigned to the highest level for which they would be expected to answer correctly the majority of assessment items. Thus, for example, in a test composed of items spread uniformly across Level 2 (with difficulty ratings of 499 to 592 score points), all students assigned to that level would expect to get at least 50 per cent of the items correct. Someone at the bottom of the level (scoring 499 points) would be expected to get close to 50 per cent of the items correct; someone in the middle or near the top of the level would get a higher percentage of items correct. For this to be true, a student scoring 499 points needs to have a 50 per cent chance of completing an item in the middle of level 3 and thus have a greater than 50 per cent chance of getting right an item rated at their score, 499 points. This latter probability needs to be 62 per cent to fulfil these conditions

Figure 2.3 and Table 2.1 classify students in participating countries by their highest level of problem-solving proficiency (note that a student proficient at Level 2, for example, is also proficient at Level 1). The percentage of students at or below Level 1 appears below the horizontal axis and the percentage at or above Level 2 appears above the same line. This shows at a glance how many students have higher level problem-solving skills compared to only basic problem-solving skills in each country. Note that this divide also corresponds approximately to how many students are above or below the OECD average in terms of problem-solving performance.

It is clear that in these terms country results vary greatly, from some countries where the great majority of students can solve problems at least at Level 2, to others where hardly any can. At the same time, the variation within countries in problem-solving ability is much larger. For example, in the majority of OECD countries, the top 10 per cent of students are proficient at Level 3, but the bottom 10 per cent of students are not proficient at Level 1 (Table 2.1).

On average, about half of the students in OECD countries score at Level 2 or above. The national percentages of students at Level 2 or above range from 70 per cent or more in Finland, Japan, Korea, and the partner country Hong Kong-China, to less than 5 per cent in the partner countries Indonesia and Tunisia. Figure 2.3 also shows that more than a third of the students in Japan and the partner country Hong Kong-China perform at Level 3. In 26 OECD countries and five partner countries between 30 and 43 per cent of students are proficient at Level 2, but in eight PISA countries below 20 per cent of students are proficient at this level.

The percentage of students with a low proficiency profile (unable to solve Level 1 problems) ranges from over half of all participating students in Mexico and Turkey, as well as in the partner countries Brazil, Indonesia and Tunisia, to below 10 per cent in Australia, Canada, Finland, Korea and the partner countries Hong Kong-China and Macao-China. There are comparatively high proportions of students with weak problem-solving skills in other OECD countries also: In Italy, Portugal and the United States, nearly a quarter fall 

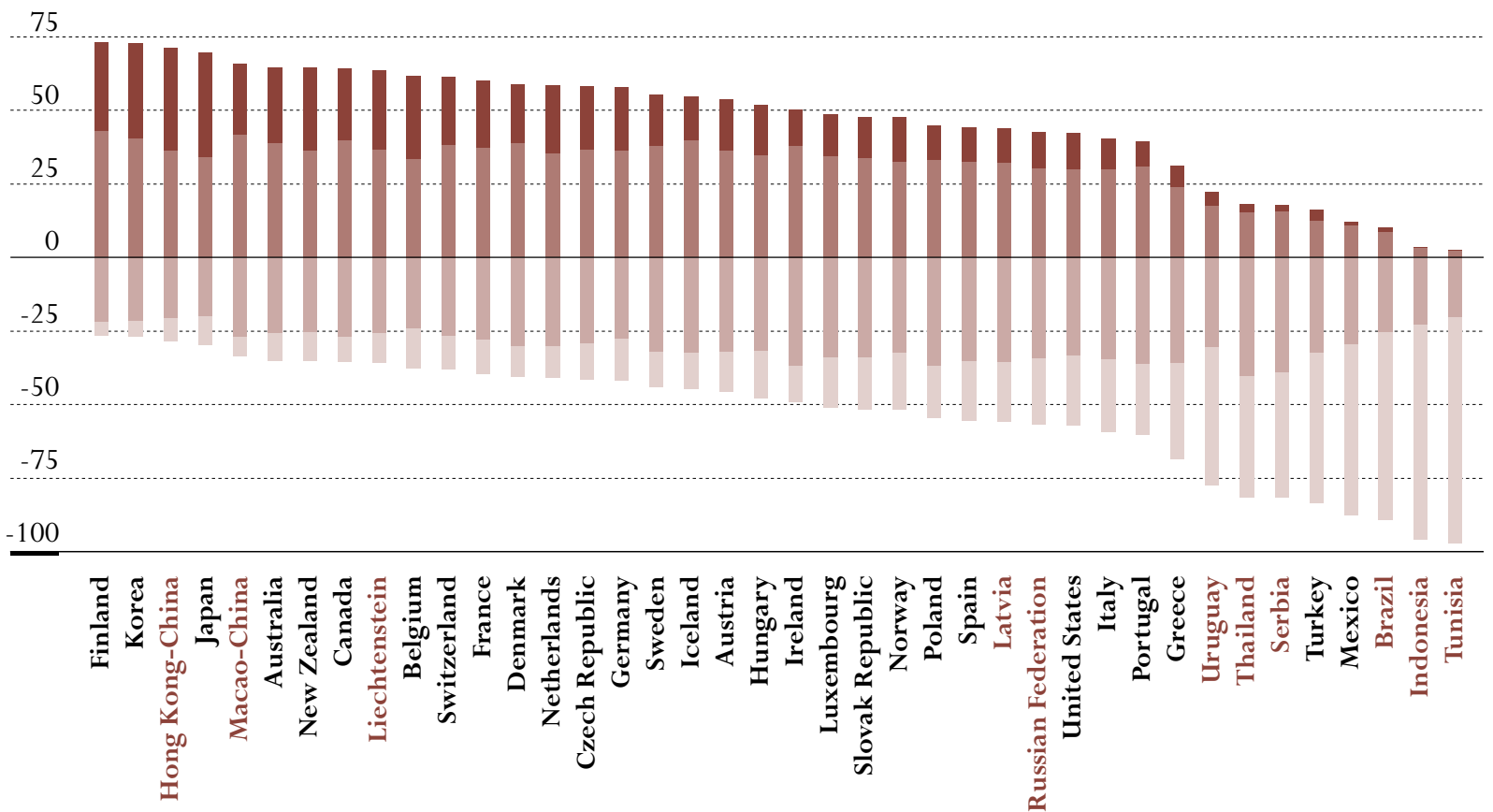

Countries are ranked in descending order of percentage of 15-year-olds in Levels 2 and 3.

Source: OECD PISA 2003 database, Table 2.1.

below Level 1, and in Greece nearly a third do. The percentage of students proficient at Level 1 varies from 21 per cent in Japan and the partner countries Hong Kong-China and Tunisia to 40 per cent in the partner country Thailand. Note, however, that in Japan the relatively small number of students at Level 1 is associated with the fact that nearly three-quarters of students are above Level 1, whereas in Tunisia over three-quarters are below Level 1.

\section{Mean performance of countries}

Along with the analysis of how students within countries are distributed across the various levels of proficiency in problem solving, there is interest in an overall measure of proficiency in problem solving. This can be achieved by estimating a mean problem-solving score for the country. This is shown in Figure 2.4.

As discussed in Box 2.1, when interpreting mean performance, only those differences between countries that are statistically significant should be taken into account. The figure shows those pairs of countries where the difference in their mean scores is sufficient to say with confidence that the higher performance by sampled students in one country holds for the entire population of enrolled

An overall mean score can be calculated for each country, though this hides variations.

Figure 2.4 shows where significant differences in these means can be detected. 
Figure 2.4 - Multiple comparisons of mean performance on the problem-solving scale

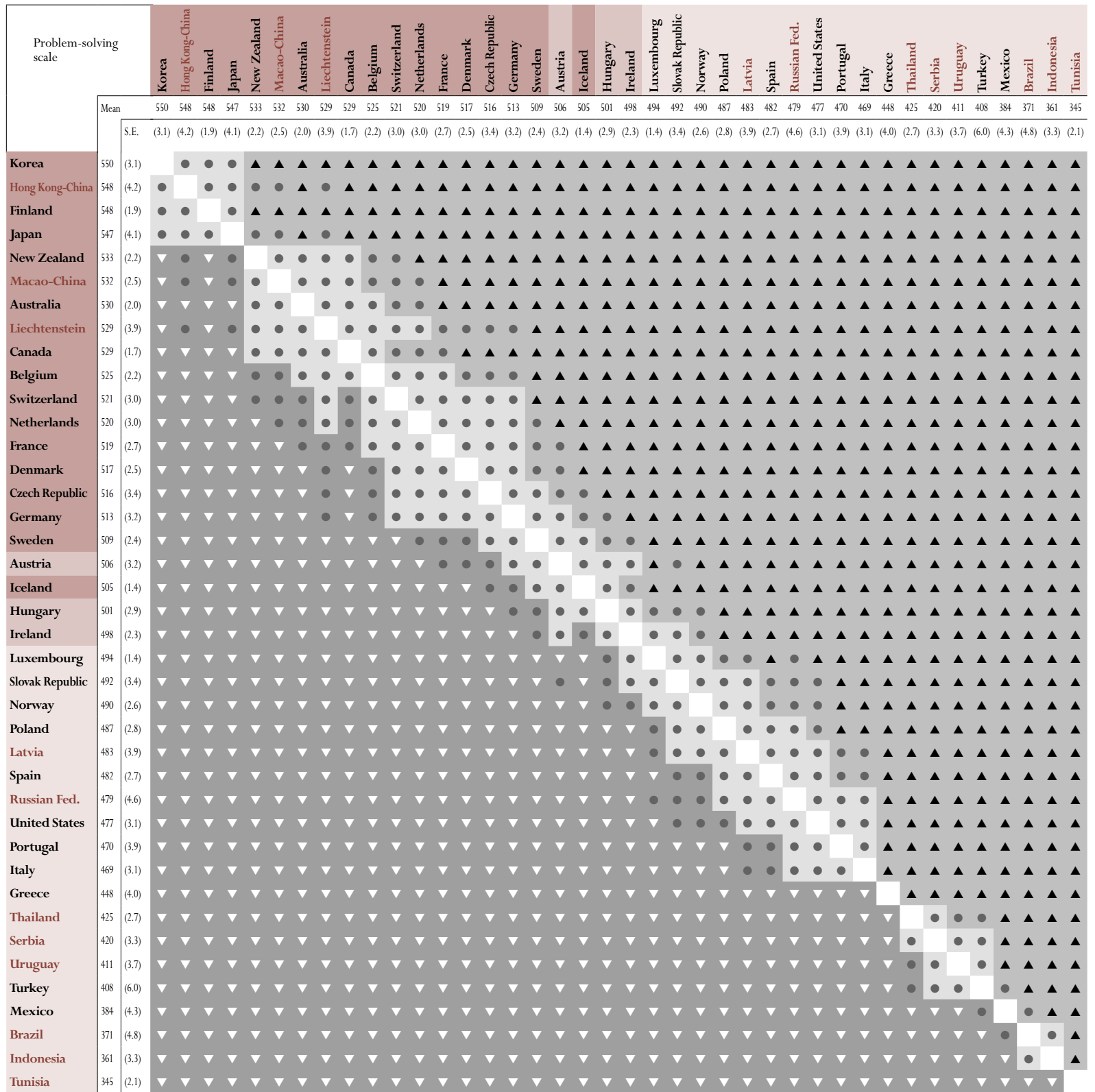

Range of rank*

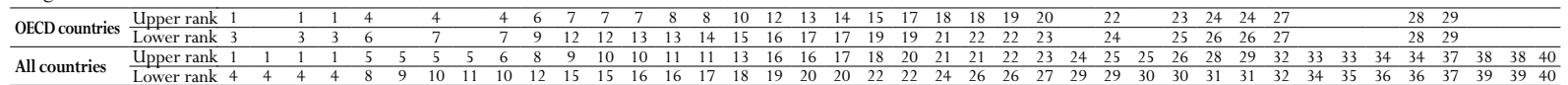

* Because data are based on samples, it is not possible to report exact rank order positions for countries. However, it is possible to report the range of rank order positions within which the country mean lies with 95 per cent likelihood.

Instructions:

Read across the row for a country to compare performance with the countries listed along the top of the chart. The symbols indicate whether the average performance of the country in the row is lower than that of the comparison country, higher than that of the comparison country, or if there is no statistically significant difference between the average achievement of the two countries.

Source: OECD, PISA 2003 database.
Without the Mean performance statistically significantly higher than in comparison country Bonferroni $\quad$ No statistically significant difference from comparison country

adjustment: Mean performance statistically significantly lower than in comparison country

\begin{tabular}{l|c|l} 
With the & M & Mean performance statistically significantly higher than in comparison country \\
\cline { 2 - 2 } Bonferroni & No statistically significant difference from comparison country
\end{tabular} adjustment: $\quad \nabla \quad$ Mean performance statistically significantly lower than in comparison country 


\section{Box 2.1 a Interpreting sample statistics}

Standard errors and confidence intervals. The statistics in this report represent estimates of national performance based on samples of students rather than the values that could be calculated if every student in every country had answered every question. Consequently, it is important to know the degree of uncertainty inherent in the estimates. In PISA 2003, each estimate has an associated degree of uncertainty, which is expressed through a standard error. The use of confidence intervals provides a means of making inferences about the population means and proportions in a manner that reflects the uncertainty associated with sample estimates. Under the usually reasonable assumption of a normal distribution, and unless otherwise noted in this report, there is a 95 per cent chance that the true value lies within the confidence interval.

Judging whether populations differ. This report tests the statistical significance of differences between the national samples in percentages and in average performance scores in order to judge whether there are differences between the populations that the samples represent. Each separate test follows the convention that, if in fact there is no real difference between two populations, there is no more than a 5 per cent probability that an observed difference between the two samples will erroneously suggest that the populations are different as the result of sampling and measurement error. In the figures and tables showing multiple comparisons of countries' mean scores, multiple comparison significance tests are also employed that limit to 5 per cent the probability that the mean of a given country will erroneously be declared to be different from that of any other country, in cases where there is in fact no difference.

15-year-olds. A country's performance relative to that of the countries listed along the top of the figure can be seen by reading across each row. The colours indicate whether the average performance of the country in the row is either lower than that of the comparison country, not statistically significantly different, or higher. When making multiple comparisons, e.g. when comparing the performance of one country with that of all other countries, a more cautious approach is required: Only those comparisons indicated by the upward and downward pointing symbols should be considered statistically significant for the purpose of multiple comparisons. ${ }^{1}$ Figure 2.4 also shows which countries perform above, at, or below the OECD average. Results from the United Kingdom were excluded from this and similar comparisons, because the data for England did not comply with the response rate standards which OECD countries had established to ensure that PISA yields reliable and internationally comparable data.

The top performing countries are Finland, Japan and Korea, as well as the partner country Hong Kong-China. These four countries perform indistinguishably well and are almost 50 score points, or around one-half of a proficiency level, ahead of the mean performance level for OECD countries, which is 500 score points. Other countries performing above this average are Australia, Belgium, Canada, the Czech Republic, Denmark, France, Germany, Iceland, the Netherlands,

The top performers in problem solving are Finland, Japan and Korea and the partner country Hong Kong-China. 
New Zealand, Sweden and Switzerland and the partner countries Liechtenstein and Macao-China. Another three countries, Austria, Hungary and Ireland, are clustered around the OECD mean, but their performances are not statistically significantly different from it. ${ }^{2}$ The remaining 19 countries all perform below the OECD average. These countries were Greece, Italy, Luxembourg, Mexico, Norway, Poland, Portugal, the Slovak Republic, Spain, Turkey and the United States, as well as the partner countries Brazil, Indonesia, Latvia, the Russian Federation, Serbia, ${ }^{3}$ Thailand, Tunisia and Uruguay.

Within-country variation around the mean can be used to describe patterns of results...

.... and a key indicator is the degree of performance variation within each country's distribution shown by the length of the bars in Figure 2.5.

\section{The distribution of problem-solving capabilities within countries}

While comparisons based on country means are useful in establishing the ordered list shown in Figure 2.4, they do little to describe the within-country variation in performance.

Figure 2.5 sheds further light on the performance distribution within countries. This analysis needs to be distinguished from the examination of the distribution of student performance across the PISA proficiency levels discussed above. Whereas the distribution of students across proficiency levels indicates the proportion of students in each country that can demonstrate a specified level of knowledge and skills, and thus compares countries on the basis of absolute benchmarks of student performance, the analysis below focuses on the relative distribution of scores, i.e. the gap that exists between students with the highest and the lowest levels of performance within each country. This is an important indicator of the equality of educational outcomes in mathematics.

The gradation bars in the figure show the range of performance in each country between the $5^{\text {th }}$ percentile (the point below which the lowest-performing 5 per cent of the students in a country score) and the $95^{\text {th }}$ percentile (the point below which 95 per cent of students perform or, alternatively, above which the 5 per cent highest-performing students in a country score). The density of the bar represents the proportion of students performing at the corresponding scale points. The solid, horizontal black line near the middle shows the mean score for each country (i.e. the subject of the discussion in the preceding section) and is located inside a shaded box that shows its confidence interval. The figure also indicates the $10^{\text {th }}, 25^{\text {th }}, 75^{\text {th }}$ and $90^{\text {th }}$ percentiles, i.e. the points above which 90 , 75, 25 and 10 per cent of students perform. The data related to Figure 2.5 are in Table 2.2 in Annex B.

The figure shows that there is wide variation in overall student performance on the mathematics scale within countries. The middle 90 per cent of the population shown by the length of the bars exceeds by far the range between the mean scores of the highest and lowest performing countries. The wide range covered by the performance distribution in each country suggests that educational programmes, schools or teachers need to cope with a wide range of student knowledge and skills. 
Gradation bars extend from the $5^{\text {th }}$ to the $95^{\text {th }}$ percentiles

- Mean score on the problem-solving scale

95\% confidence interval around the mean score $-90^{\text {th }}$ percentile

$-75^{\text {th }}$ percentile

$\triangleright 25^{\text {th }}$ percentile

$\triangleright 10^{\text {th }}$ percentile

OECD average

Performance on the problem-solving scale

750

700

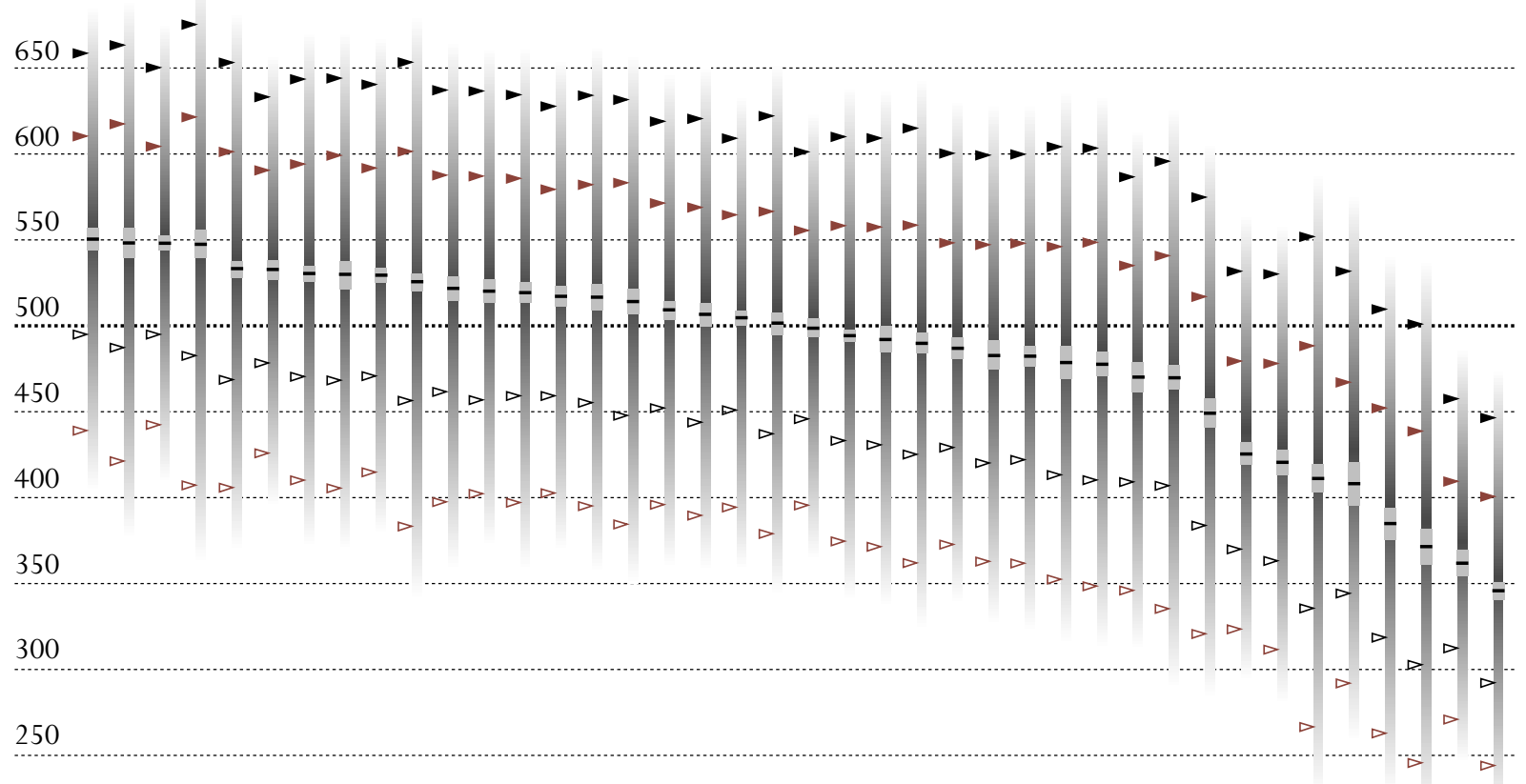

200

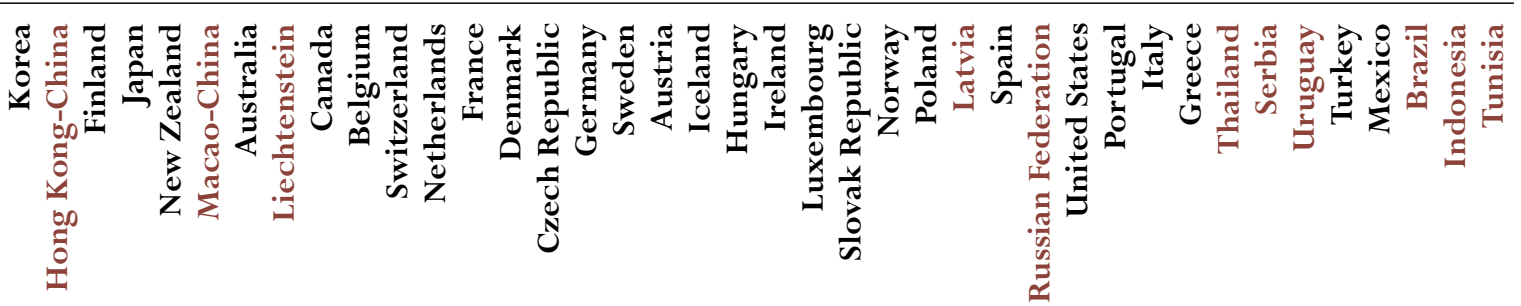

Source: OECD PISA 2003 database, Table 2.2.

Compare, for example, the vertical bars for Belgium, a country with an aboveaverage performance overall with those for Korea, the country with the highest mean score. The top of the bar and the first two identified lines (the $95^{\text {th }}$ and $90^{\text {th }}$ percentiles) are at similar points in these two countries, indicating that towards the top of the distribution students in Belgium perform at similar levels to their equivalents in Korea. However, when one looks further down the distribution, the performance of students in Belgium falls further below their peers than is the case for students in Korea. By the fifth percentile, students in Belgium are 64 score points, equivalent to two-thirds of a proficiency level,
For example, Belgium's highest performers do very well, as do those of Korea, but in the former there is much greater variation among weaker students. 
Other countries have distinctive patterns, with Finland and Korea, as well as the partner country Macao-China, doing best in having strong performance overall with low variation.

Patterns of withincountry variation differ considerably across countries. behind students in Korea. This greater range of performance in Belgium is shown by a much longer bar, and the relatively wide range of performance in the bottom part of the student distribution is shown by the fact that the lower segments are wider than those at the top.

Compared to the other three top performing countries, Japan has more students performing at both the highest and lowest levels. The students in Finland and Korea, as well as in the partner country Macao-China, in contrast, have lower variation between the $5^{\text {th }}$ to $95^{\text {th }}$ percentiles points than other high-performing countries.

Overall, there is a great deal of variability in patterns of problem-solving capabilities of 15 -year-olds in different countries. It is true that performance differences of students within each country are much greater than performance differences between countries: The difference between the means of the highest and lowest performing country (206 score points) is less than the range of performance between the $95^{\text {th }}$ and $5^{\text {th }}$ percentile points within each participating country. However, significant differences between countries in the average performance of students should not be overlooked and may raise questions about the future competitiveness of certain countries.

\section{Implications for policy}

The PISA cross-disciplinary assessment of problem solving was designed to assess the degree to which students in the OECD and the participating partner countries could solve problems situated in contexts that were not confined to one discipline and drew on students' knowledge from a variety of sources.

The design of the assessment placed particular emphasis on testing each student's ability to understand a problem situation, identify relevant information or constraints, represent possible alternatives or solution paths, select a solution strategy, solve the problem, check or reflect on the solution, and communicate the solution and reasoning behind it.

One in six OECD students, but much more in some countries, lack basic problem-solving skills.
The analysis of student performance on this assessment shows that about one in six students in the OECD area are only able to work in highly structured and straightforward settings, where they can deal with information available from direct observation or from very simple inferences. They are generally unable to analyse situations or solve problems that call for anything other than the direct collection of information, and are therefore characterised as weak or emergent problem solvers. In four countries - Mexico and the partner countries Brazil, Indonesia and Tunisia - mean student performance falls at this level (mean performance is less than 405 score points). The four highest performing countries - Finland, Japan, Korea and the partner country Hong Kong-China have between 5 and 10 per cent of their students performing below Level 1 . In the OECD countries on average, 17 per cent of students perform below Level 1. 
On average in the OECD countries 30 per cent of students are basic problem solvers. The mean performance of students in sixteen of the participating countries is at Level 1: Greece, Ireland, Italy, Luxembourg, Norway, Poland, Portugal, the Slovak Republic, Spain, Turkey and the United States and the partner countries Latvia, the Russian Federation, Serbia, Thailand and Uruguay. These students are consistently able to understand the nature of a problem and the relevant data associated with a problem's major features. In many situations, these 15-yearolds are able to make minor translations between ways in which the problem data might be represented. In addition, these students are generally capable of using the information to check a limited number of fairly direct statements related to the problem. However, the basic problem solvers are generally incapable of dealing with multi-faceted problems involving multiple data sources or requiring analytical reasoning with the information provided.

On average in the OECD countries, 34 per cent of students are reasoning, decisionmaking problem solvers. Mean student performance in 20 countries participating in PISA 2003 is at Level 2: Australia, Austria, Belgium, Canada, the Czech Republic, Denmark, Finland, France, Germany, Hungary, Iceland, Japan, Korea, the Netherlands, New Zealand, Sweden, Switzerland and the partner countries Hong Kong-China, Liechtenstein and Macao-China. The line between students performing at Level 1 and those performing at Level 2 is an important line of demarcation in terms of student competencies in problem solving. Students at Level 1 are limited, in general, to handling relatively straightforward problems that require the collection of information from readily available sources and making simple transformations of data from graphical forms or tabular forms to numerical forms for interpretation. Basic problem solvers are generally not capable of drawing data from multiple sources, comparing and contrasting these data and integrating the data into the development of a solution to a multifaceted problem. These are the very skills that are necessary in emergent workforce demands. New employee qualifications are focusing on the ability to deal with complexity, on communication skills, and on increased problemsolving capabilities (Green et al., 1997; Lerman and Skidmore, 1999; Johnson, 2000; Steedman, 1999; Workbase, 2000).

As 15-year-olds develop the problem-solving skills associated with Levels 2 and 3 of the PISA problem-solving scale, they have increased opportunities for employment and the ability to successfully participate in a rapidly changing world. They also exhibit the problem-solving knowledge and skills associated with enfranchised citizenship. These skills are marked by the problem-solving actions and outcomes described in the following two levels.

Students performing at Level 2 exhibit the capacity to apply analytical reasoning skills to solve problems involving decision making that requires comparisons of multiple alternatives. In doing so, these reasoning, decision-making problem solvers are able to handle a variety of representations of related information and use them to select the best of several alternatives in a variety of contexts. 15year-olds at Level 2 are also capable of drawing inferences in settings involving applications of deductive, inductive, and combinatorial reasoning.
Basic problem solvers at Level 1 can deal with simple problems only...

... and the ability to perform more complex tasks represents an important performance threshold between Level 1 and Level 2...

...with potential realworld consequences.

Level 2 is associated with crucial thinking skills. 
Fewer students can perform the most complex tasks at Level 3 than at the previous levels, but in some countries over a quarter can do so.

However, on average in the OECD countries, half of students lack the important ability to solve problems that are more complex than the basic problems at Level 1.
The highest identified level of problem solving, Level 3, includes student work that reflects not only the ability to confront and derive a solution to a problem, but also the capability to reflect on and use information about underlying relationships found in problem situations. Students at this level can construct their own representations of problems from pieces of information and then in systematic ways solve the problems and communicate their findings to others. Reflective, communicative problem solvers are capable of handling a greater number of variables, of handling time and sequential relationships, and a variety of other problem-specific constraints. None of the participating countries have their student mean performance in problem solving at Level 3. However, in Australia, Belgium, Canada, Finland, Japan, Korea and New Zealand and the partner countries Hong Kong-China and Liechtenstein 25 per cent or more of the students are capable of solving problems at this highest level. The four countries with the highest overall averages in problem solving - Finland, Japan, Korea, and the partner country Hong Kong-China - all have 30 per cent or more of their students at Level 3. On average in the OECD countries 18 per cent of students are reflective, communicative problem solvers.

If one considers the percentage of students performing at either Level 2 or Level 3 on the problem-solving scale to be one indicator of how well prepared 15 -year-olds are for productive participation in an emerging $21^{\text {st }}$ century society, the majority of students are prepared in only 22 of the 40 participating countries with comparable data. These data, combined with data from students' performances in other content areas, indicate that student literacy levels fail to meet expectations in many of the countries participating in PISA 2003. Such data also add to the emerging data on the spread of wealth and opportunity in countries worldwide.

Notes

1. Although the probability that a particular difference will falsely be declared to be statistically significant is low (5 per cent) in each single comparison, the probability of making such an error increases when several comparisons are made simultaneously. It is possible to make an adjustment for this which reduces to 5 per cent the maximum probability that differences will be falsely declared as statistically significant at least once among all the comparisons that are made. Such an adjustment, based on the Bonferroni method, has been incorporated into the multiple comparison charts in this volume, as indicated by the arrow symbols.

2. Note that while Iceland has a lower mean performance level than Austria, its standard error is also less than that of Austria. This leads to Iceland being statistically significantly above the OECD average, while Austria is found to be not statistically significantly different from the OECD average.

3. For the country Serbia and Montenegro, data for Montenegro are not available. The latter accounts for 7.9 per cent of the national population. The name "Serbia" is used as a shorthand for the Serbian part of Serbia and Montenegro. 


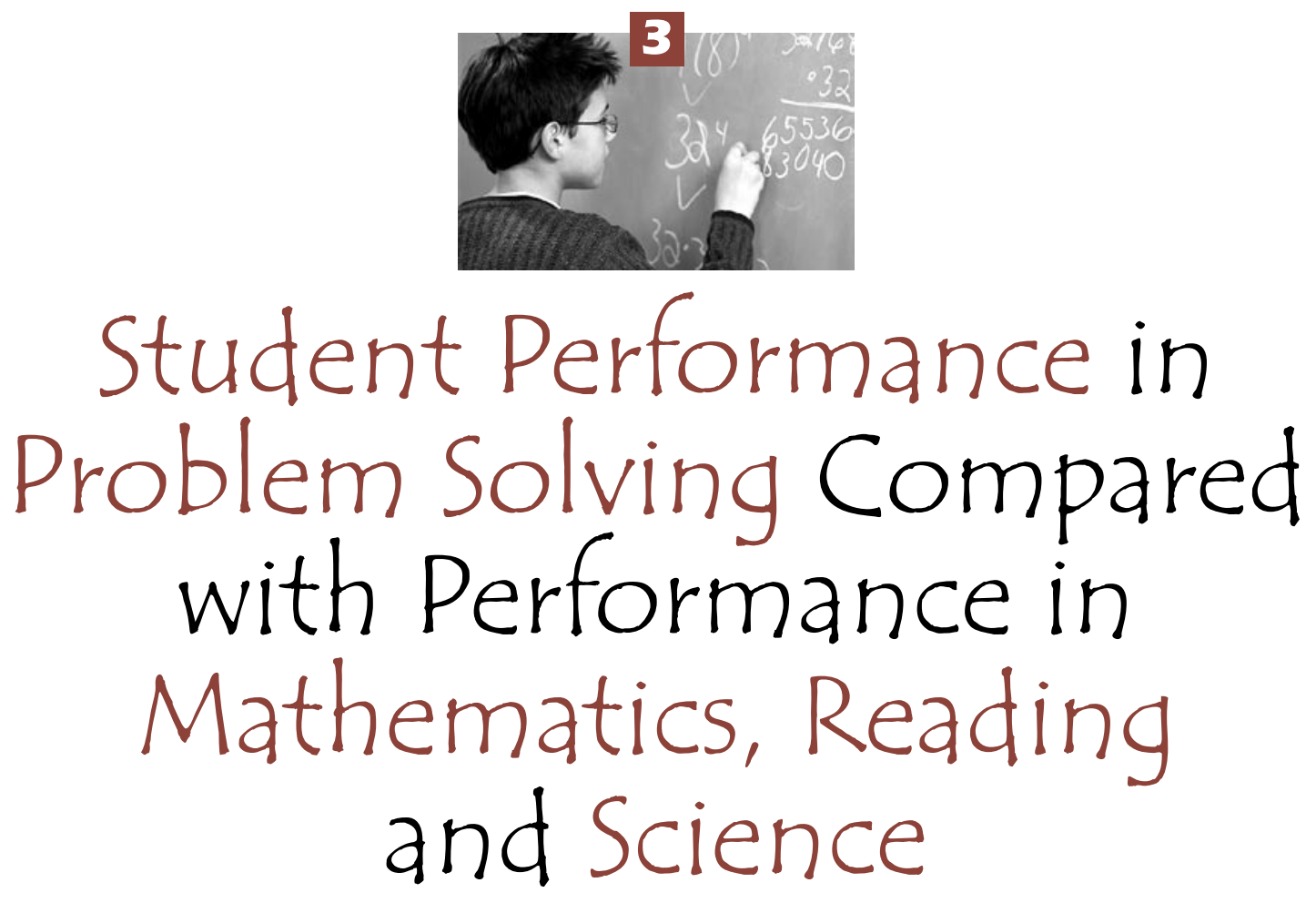

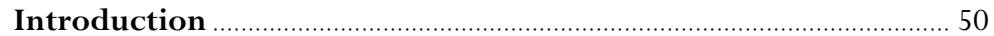

Problem-solving framework and test development …................... 50

- Emphasis on problem-solving processes ................................................. 50

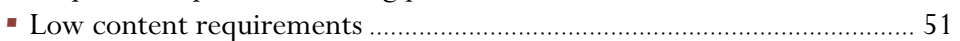

- The key skills tested in problem solving …………................................ 51

- Correlations between performance in reading, mathematics, science and problem solving ......................................................... 54

Comparison between performances in mathematics and problem solving at the country level …………………………........ 55

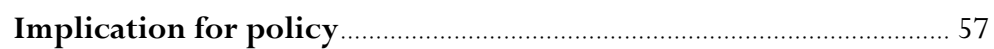


This chapter looks at how problem solving was assessed and what the results were, in relation to the other parts of PISA.

Each section of the assessment required students to show that they could solve as well as recognise a problem...

...thus assessing problem solving as a whole process, not just the component skills in isolation.

\section{Introduction}

This chapter looks further at the results of the PISA assessment of problem solving, and compares them with results from the mathematics, science and reading assessments.

\section{Problem-solving framework and test development}

Problem solving differs from mathematics, reading, and science in that it is not a traditional school subject. However, problem-solving skills are required in curricular subjects as well as in non-curricular areas. There are two main features that distinguish problem solving from the PISA assessments of mathematics, science and reading - the first relates to an emphasis on problem-solving processes, the second relates to the much lower levels of content knowledge required for the tasks.

\section{Emphasis on problem-solving processes}

Chapter 2 described the processes that underlie PISA problem-solving tasks. These relate to understanding the problem, characterising the problem, representing the problem, solving the problem, reflecting on the problem and communicating the problem solution. While not every problem-solving task in PISA involved all of the processes listed, it was established that each problemsolving unit should test students on most of these processes. A problem-solving unit refers to the description of a problem-solving situation followed by a number of individual questions about it, which are referred to as items. While some items within a unit may test only the understanding of the stated problem, it was deemed important that each problem-solving unit, at some point, require students to demonstrate their ability in actually solving a problem. For example, if a unit is of the decision-making problem type, then students are asked to make some decisions. If a unit is of the system analysis and design type, then students are asked to actually analyse the problem or design a solution. From this point of view, the problem-solving units differ from tasks in reading in that reading comprehension, while an important part of problem solving, is not the only process tested within a unit. Similarly, if a task requires some mathematical operations, these mathematical skills are not the only skills tested in a problemsolving unit.

Consequently, problem-solving units differ from those in the other assessment areas in that the units test for a majority of the problem-solving processes, not only for isolated processes such as reading comprehension, mathematical manipulations, or communication. The problem-solving units included in Chapter 4 show that each unit contains at least one item that leads to a decision or to an analysis or design of solutions. However, individual items that test the extent to which students understand a problem situation are also informative in showing whether the failure to arrive at a solution is due to a lack of understanding of the problem given. Thus, there is a hierarchy of problem-solving processes, in that understanding the problem is at the most basic level of the processes, 
without which no solutions can be reached. But to be proficient in problem solving, other skills relating to representation and analysis of problems are essential.

\section{Low content requirements}

Given that PISA 2003 was a paper-and-pencil test, it was inevitable that written text was required to state the problem situation. Consequently, as noted above, reading comprehension is a pre-requisite for problem solving. However, written texts were kept to a minimum in the problem-solving units. Of the ten problem-solving units in the test (presented in Chapter 4), only one unit is solely text-based in both the stimulus and in the items (Freezer). The other units use texts as well as diagrams and tables to convey the information, and to elicit answers. Two units (Design by Numbers $\odot$ and Transit System) have very little text involved, as both the stimulus and answer format involve diagrams or figures. The other units involve both texts and tables or diagrams, with minimal amount of reading load. Overall, the test designers were conscious of the amount of reading involved, and kept the level of text difficulty as low as possible, with nothing beyond everyday use of language.

Similarly, where mathematical manipulations were required, the tasks were limited to very simple mathematical operations (Energy Needs and Holiday). In contrast, in the PISA mathematics assessment, every item has mathematical content, most of which is beyond the level of simple, straightforward operations. In relation to science, no problem-solving item in the PISA 2003 assessment involved either scientific content or context.

Consequently, the items in the problem-solving assessment differ from those in the other three assessment areas in that there is little or no curriculum content required in order to correctly complete the problems as presented.

\section{The key skills tested in problem solving}

Given that the assessment of content knowledge is minimised, what are the main skills tested in the problem-solving assessment? The main cognitive skills tested relate to analytical reasoning. In most items, students are required to organise and analyse information, and derive solutions satisfying given constraints. Many problem situations in everyday life do not involve high levels of curriculum content knowledge. Instead, they involve the ability to reason, and the ability to approach problems in systematic ways such as elimination and enumeration. These are the key skills tested in the problem-solving assessment. From this point of view, problem solving fills a gap by testing the use of these skills in problem situations not already covered in the other three assessment areas.

Even though problem-solving items do not involve mathematical content knowledge, other than simple arithmetic in two items, it is still expected that there will be a high correlation between student performance in mathematics and problem solving. This is because mathematics also requires a high level of analytical reasoning skills, particularly for 15-year-olds, who are generally beyond the level of mastery of basic skills in mathematics (e.g. Carroll, 1996).

The key skill needed to solve problems is analytical reasoning...

...which is also an important requirement for mathematics tasks. 
Figure 3.1 - Analysis of two dominant factors in student performance on the problem-solving, reading and mathematics items

\section{A. Factor 1 has a higher loading than Factor 2 \\ Problem-solving item \\ Mathematics item}

\begin{tabular}{|c|c|c|c|}
\hline \multirow[b]{2}{*}{$\begin{array}{l}\text { Number of items loading higher } \\
\text { on Factor } 1 \text { than on Factor } 2\end{array}$} & \multirow[b]{2}{*}{ Item $^{1}$} & \multicolumn{2}{|c|}{ Factor loadings $^{2}$} \\
\hline & & Factor 1 & Factor 2 \\
\hline 0.350 to 0.400 & HOLIDAY - Question 2 & 0.393 & \\
\hline 11 mathematics items & SKATEBOARD - Question 13 & 0.391 & \\
\hline 1 problem-solving item & NUMBER CUBES - Question 3 & 0.368 & \\
\hline 0.300 to 0.349 & IRRIGATION - Question 3 & 0.346 & \\
\hline 19 mathematics items & ROBBERIES - Question 15 & 0.345 & \\
\hline \multirow[t]{9}{*}{7 problem-solving items } & SKATEBOARD - Question 12 & 0.335 & \\
\hline & WALKING - Question 5 & 0.334 & \\
\hline & COURSE DESIGN - Question 1 & 0.328 & \\
\hline & IRRIGATION - Question 2 & 0.321 & \\
\hline & LIBRARY SYSTEM - Question 2 & 0.318 & \\
\hline & IRRIGATION - Question 1 & 0.313 & \\
\hline & HOLIDAY - Question 1 & 0.310 & \\
\hline & ENERGY NEEDS - Question 2 & 0.303 & \\
\hline & WALKING - Question 4 & 0.301 & \\
\hline 0.250 to 0.299 & TEST SCORES - Question 16 & 0.298 & \\
\hline 20 mathematics items & SKATEBOARD - Question 14 & 0.298 & \\
\hline \multirow[t]{5}{*}{3 problem-solving items } & TRANSIT SYSTEM - Question 1 & 0.292 & \\
\hline & DESIGN BY NUMBERSC - Question 3 & 0.285 & \\
\hline & EXPORTS - Question 18 & 0.281 & \\
\hline & CARPENTER - Question 1 & 0.275 & \\
\hline & CHILDREN'S CAMP - Question 1 & 0.271 & \\
\hline 0.200 to 0.249 & CINEMA OUTING - Question 1 & 0.234 & \\
\hline 16 mathematics items & DESIGN BY NUMBERS@ - Question 1 & 0.234 & \\
\hline \multirow[t]{4}{*}{4 problem-solving items } & LIBRARY SYSTEM - Question 1 & 0.232 & \\
\hline & STAIRCASE - Question 2 & 0.213 & \\
\hline & DESIGN BY NUMBERSC - Question 2 & 0.207 & \\
\hline & GROWING UP - Question 8 & 0.201 & 0.198 \\
\hline 0.150 to 0.199 & CINEMA OUTING - Question 2 & 0.189 & \\
\hline 9 mathematics items & FREEZER - Question 1 & 0.188 & \\
\hline \multirow[t]{3}{*}{4 problem-solving items } & EXPORTS - Question 17 & 0.176 & \\
\hline & FREEZER - Question 2 & 0.170 & \\
\hline & ENERGY NEEDS - Question 1 & 0.157 & \\
\hline
\end{tabular}




\begin{tabular}{|c|c|c|c|}
\hline \multirow{2}{*}{\multicolumn{2}{|c|}{$\begin{array}{l}\text { Problem-solving item } \\
\text { Mathematics item }\end{array}$}} & & \\
\hline & & \multicolumn{2}{|c|}{ Factor loadings $^{2}$} \\
\hline $\begin{array}{l}\text { Number of items loading higher } \\
\text { on Factor } 2 \text { than on Factor } 1\end{array}$ & Item $^{1}$ & Factor 1 & Factor 2 \\
\hline \multicolumn{4}{|l|}{0.500 to 0.650} \\
\hline \multicolumn{4}{|l|}{9 reading items } \\
\hline \multicolumn{4}{|l|}{0.300 to 0.499} \\
\hline \multicolumn{4}{|l|}{4 reading items } \\
\hline 0.200 to 0.299 & EXCHANGE RATE - Question 10 & 0.201 & 0.227 \\
\hline 11 reading items & GROWING UP - Question 7 & 0.181 & 0.223 \\
\hline 3 mathematics items & EXCHANGE RATE - Question 9 & 0.165 & 0.217 \\
\hline 0.100 to 0.199 & GROWING UP - Question 6 & 0.182 & 0.196 \\
\hline 1 reading item & EXCHANGE RATE - Question 11 & 0.193 & 0.193 \\
\hline 6 mathematics items & & & \\
\hline
\end{tabular}

1. Chapter 4 presents all problem-solving items. Mathematics items listed in this figure are presented in Learning for Tomorrow's World - First Results from PISA 2003 (OECD, 2004a).

2. Factor loadings of less than 0.1 are not listed.

Source: OECD PISA database 2003, Table 3.1.

In order to better understand the cognitive demands of the problem-solving items, an exploratory analysis was carried out to identify patterns in student responses across PISA that suggest which groups of tasks are being influenced by certain common factors. This factor analysis was carried out using a random selection of 500 students from each OECD country participating in the PISA survey. Details of how it was conducted are given in Annex A2.

The results of the exploratory factor analysis suggest that different factors were influencing students' performance in reading and in mathematics, with problem-solving responses more closely associated with the mathematics factor. The full results of the factor analysis are provided in Table 3.1, Annex B. The main results for all problem-solving items as well as those mathematics items published in Learning for Tomorrow's World - First Results from PISA 2003 are presented in Figure 3.1. The analysis identified two presumed factors. The factor loadings shown in these figures indicate the strength of association with the two presumed factors. Figure 3.1, part A, shows all items that loaded higher on the first presumed factor than on the second presumed factor. (Loadings less than 0.1 in absolute values were omitted from the table and figures.) No reading items loaded higher on the first presumed factor than on the second presumed factor, however in total 75 mathematics items and 19 problem-solving items did. Bearing in mind that problem-solving items do not contain mathematical content other than simple arithmetic, this suggests that analytical reasoning is the skill identified in the first factor
The overlap in such cognitive requirements can be analysed through patterns of student responses.

Mathematics and problem solving seem to be closely linked... 
...by the common

analytical requirements

of most items.

Problem-solving items requiring less analysis

load lower...

...as do mathematics items requiring only basic computation.

However, other factors not explored here could also be important.

Individual students tend to obtain similar results across the three assessment areas, especially in mathematics and problem solving.
Figure 3.1, part B, shows items that loaded higher on the second presumed factor than on the first presumed factor. This was the case for 25 reading items and nine mathematics items. However, no problem-solving items loaded higher on the second factor than on the first factor and that holds even for those items that only tested the understanding of the problem. The second factor is therefore more clearly linked to reading items. The items with high loadings on the first factor (identified as the analytical reasoning factor) include Questions 1 and 2 of the Holiday unit, Questions 1, 2 and 3 of the Irrigation unit, Question 1 of the Course Design unit, Question 2 of the Library System unit, and Question 2 of the Energy Needs unit. These items all require high levels of analysing, reasoning, organising, checking and evaluating skills.

Problem-solving items that load relatively low on the first factor have characteristics that do not require a high level of analytical reasoning. For example, Questions 1 and 2 of the Freezer unit require an analysis of an everyday trouble-shooting situation, but unlike many other problem-solving questions do not involve the manipulation of parameters to satisfy constraints and specifications. Another example is Question 1 of the Energy Needs unit, which involves only looking up information in a table. Question 2 of the Cinema Outing unit also loaded relatively low on the first factor, presumably because it involved looking up information with a limited number of constraints.

Figure 3.1 not only reveals the nature of the problem-solving items, but also the nature of the mathematics items. The mathematics items loading high on the first factor require skills in enumeration, combinatorial reasoning and analytical reasoning. In contrast, Question 17 of the Exports unit had a relatively low loading on the first factor and required students to simply look up information in a graph. What the public would normally regard as mathematics - such as doing arithmetic and basic operations - was, in fact, not what the PISA mathematics assessment focused on. Rather, it tested the ability to analyse and reason using mathematics.

It must be noted that the two-factor analysis presented in Table 3.1, Annex B, does not provide a full explanation of the cognitive demands of the tasks in the PISA assessment. The data shown in Annex A2 indicate that there are other factors that could provide important information about the items, for example, in relation to curriculum content.

\section{Correlations between performance in reading, mathematics, science and problem solving}

Having identified some of the differences between problem solving and the other three assessment areas, it is possible to analyse and interpret relationships between students' performances in the PISA assessment areas.

Figure 3.2 shows the latent correlations between the four PISA assessment areas. Latent correlations are direct estimates of the strength of the association between student abilities. The high figures for the latent correlations suggest that 
students doing well in one area are likely to do well in other areas as well. The observed magnitudes of the latent correlations confirm the descriptions of the cognitive skills tested in the four assessment areas. Not surprisingly, problem solving correlates most highly with mathematics. The next highest correlation is with reading. The correlation between problem solving and science is somewhat lower which, once again, is not surprising given the lack of scientific content or context in the problem-solving items.

Figure 3.2 - Latent correlations between the four assessment areas

\begin{tabular}{l|c|c|c} 
& Mathematics & Reading & Science \\
\hline Mathematics & & & \\
\hline Reading & 0.77 & & \\
\hline Science & 0.83 & 0.83 & \\
\hline Problem solving & $\mathbf{0 . 8 9}$ & $\mathbf{0 . 8 2}$ & $\mathbf{0 . 8 0}$ \\
\hline
\end{tabular}

The correlation between problem solving and mathematics is also of about the same order of magnitude as the correlations among the four mathematics sub-scales.

\section{Comparison between performances in mathematics and problem solving at the country level}

For each country, the relative standing of the country's performance in mathematics and in problem solving can be compared. Given that the scores for mathematics and for problem solving were both scaled with a mean of 500 and a standard deviation of 100 among OECD countries, if a country has different mean scores for mathematics and for problem solving, this shows a difference in terms of how that country performs relative to the OECD average.

Taking a country's mean scores in mathematics and problem solving as the basis of comparison, if a country performs relatively better in mathematics than in problem solving, one can interpret this as showing that the students in the country have a better grasp of mathematics content as compared to other countries after accounting for the level of generic problem-solving skills of students. This may be an indication that mathematics instruction was particularly effective in the country. In contrast, if a country performs relatively better in problem solving, this may suggest that students have the potential to achieve better results in mathematics than that reflected in their current performance, since their level of generic problem-solving skills is relatively higher.

These differences are shown in Figure 3.3. In the Netherlands, Turkey and the partner country Serbia, ${ }^{1}$ students scored on average between 16 and 18 points higher in mathematics than in problem solving, and there was a difference of at least 10 score points in Iceland and in the partner countries Tunisia and Uruguay. As explained above, this may indicate that mathematics instruction is relatively effective in helping students reach their potential. On the other hand,
Country scores in these two assessment areas can be compared...

...giving an indication of whether student potential as shown by problem-solving skill is realised through the mathematics curriculum.

Although country scores are similar in the two assessment areas, some differences are noteworthy... 
Difference in PISA score is statistically significant

Difference in PISA score is not statistically significant

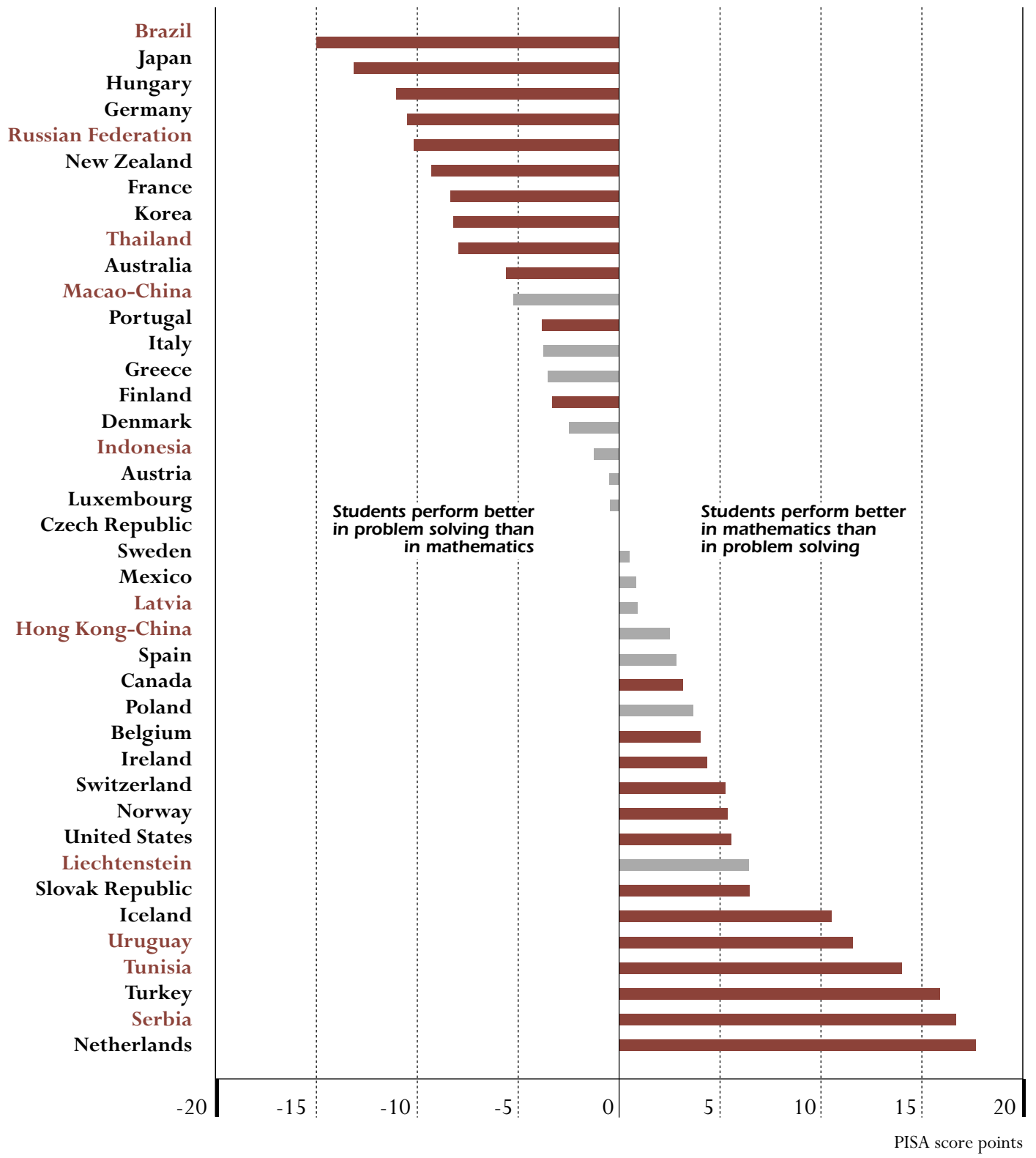

Source: OECD PISA 2003 database, Table 3.2.

... and in some cases,

these show up in country

rankings. students scored between 10 and 15 points more on average in problem solving than in mathematics in Germany, Hungary and Japan, as well as in the partner countries Brazil and the Russian Federation. This may indicate that students have generic skills that may not be fully exploited by the mathematics curriculum.

The magnitude of these differences is at the most just under a quarter of a proficiency level on the problem-solving scale and about a third on the six-level mathematics scale. In some cases, however, there are significant differences in 
country rankings on the two scales. For example, students in the Netherlands performed in the top five OECD countries in mathematics and are ranked between seventh and twelfth in problem solving. In mathematics, students in Hungary are ranked between nineteenth and twenty-third for OECD countries, but in problem solving they are ranked between fifteenth and nineteenth.

\section{Implications for policy}

The assessment of problem-solving skills in PISA 2003 takes the assessment further than in PISA 2000, in that problem solving is not a regular curriculum content area. Most work done with problem solving in the curriculum of schools is compartmentalised as problem solving in mathematics, in science, or in other subjects.

Even though the features of the tasks were quite different, there is still a strong relationship between students' performance levels in mathematics and reading and their performance in the problem-solving assessment. Analysis shows that two factors, a mathematics factor and a reading factor, account for a substantial amount of the variability in students' scores. However, the problem-solving items draw on aspects of reasoning that can be considered to be different to reasoning skills used in mathematics and reading. In fact, the reasoning skills identified as a factor in mathematics explain about 7.6 per cent of the variance in student performance in problem solving, while those identified as a factor in reading explain an additional 2.9 per cent of the variance. ${ }^{2}$

The results in problem solving are clearly not identical to those in other assessment areas. For example, in some countries students do significantly better in either mathematics or problem solving, relative to the OECD average. In these cases, it is important to look more closely at the features of the curriculum and instructional styles that might contribute to these discrepancies. Such variation has its core perhaps in analytical reasoning abilities, as the problemsolving items in the PISA assessment made little use of calculation beyond very straightforward whole number skills. If a country performs relatively better in mathematics than in problem solving, this suggests that students in this country have a better grasp of mathematical content as compared to other countries after accounting for the level of generic problem-solving skills of students. This may be an indication that mathematics instruction was particularly effective in the country. In contrast, if a country performs relatively better in problem solving, this may suggest that students have the potential to achieve better results in mathematics than that reflected in their current performance, as their level of generic problem-solving skills is relatively higher.

Problem solving represents a competency area that is distinct from those based in a particular discipline.

This distinction is clear despite an overlap in skills required, especially the reasoning skills needed for solving mathematical as well as general problems.

Stronger problem-solving competencies and weaker mathematics performance may indicate that the mathematics instruction provided does not fully exploit the potential of students. 
1. For the country Serbia and Montenegro, data for Montenegro are not available. The latter accounts for 7.9 per cent of the national population. The name "Serbia" is used as a shorthand for the Serbian part of Serbia and Montenegro.

2. See Annex A2 for results from the factor analysis regarding the total variance explained. 


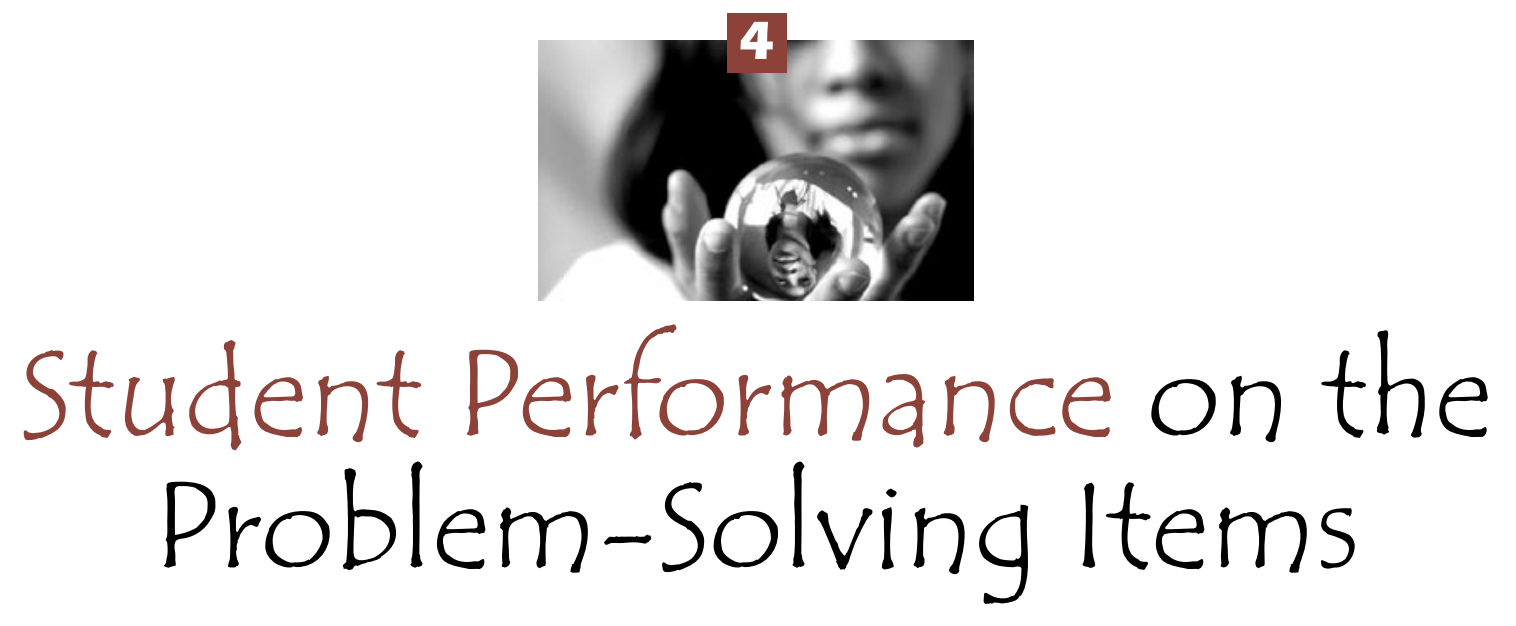

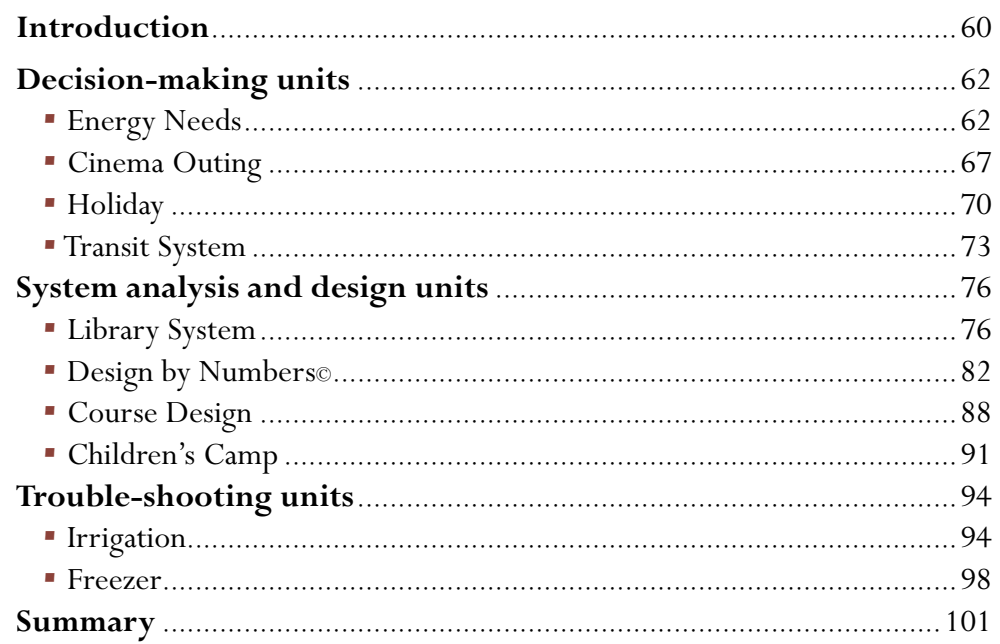




\section{Introduction}

This chapter describes all the questions used to assess students' problem solving capacity, showing how different skills were tested and how responses were marked.

It covers the

19 items summarised in Figure 4.1...

...which used several forms of questions...

... and sometimes allowed students partial credit for not fully correct answers.
The assessment of problem solving in PISA, like any assessment of student competencies, is centred on a framework and on the actual items used to assess what students can do. Chapter 1 discussed the framework; this chapter examines the problem-solving items. It looks at each of the 19 items used to assess problem solving, classified by their problem type: decision making, system analysis and design, and trouble shooting. The guide used by markers to code responses accompanies each item. Samples of student work are reproduced for many items with open-response formats. Where informative, these examples include work awarded both full credit and partial credit. This information is useful both to those interested in the international comparisons based on these items and to those involved in curriculum and teacher education activities in each of the countries participating in PISA 2003.

The 19 items used in the assessment were clustered into ten units, which ranged from one item to three items in length. Figure 4.1 shows for each unit exactly how many items were used and the type of problem posed, as well as what kind of answer was required for each item.

As in PISA 2000, the assessment instruments in PISA 2003 comprised "units of assessment" - a series of texts followed by a number of questions on various aspects of each text, aiming to make tasks as close as possible to those encountered in the real world. The questions varied in format. Some questions required students to construct their own responses, either by providing a brief answer from a wide range of possible answers (short-response items) or by constructing a longer response (open-constructed response items), allowing for the possibility of divergent, individual responses and opposing viewpoints. Other parts of the test were based on students constructing their own responses, but based on a very limited range of possible responses (closed-constructed response items), which are scored as either correct or incorrect. The remaining items were asked in multiple-choice format, in which students either made one choice from among four or five given alternatives (multiple-choice items) or a series of choices by circling a word or short phrase (for example "yes" or "no") for each point of credit (complex multiple-choice items).

The following description presents each unit of items along with the ways in which credit could be awarded for each item, and what PISA scale score and proficiency level those marks correspond to. On 11 items, only one level of credit was possible - for a correct answer; on seven items, students could get a partial or a full credit mark; and on one item, two partial credit scores or a full credit score were possible. Thus, a total of 28 different score point levels could be given for the 19 items. Partial credit was provided for partially correct or less sophisticated answers, and all of these items were marked by experts. To ensure consistency in the marking process, many of the more complex items were marked independently by up to four markers and a subsample of student responses from each country was marked independently in at least two of the 
participating countries. Finally, to verify that the marking process was carried out in equivalent ways across countries, an inter-country reliability study was carried out on a sub-set of items. The results show that very consistent marking was achieved across countries (for details on the marking process see Annex A7 and the PISA 2003 Technical Report [OECD, forthcoming]).

Figure 4.1 Problem-solving units and their characteristics

\begin{tabular}{l|l}
\multicolumn{1}{l}{ Unit name } & Item format \\
\hline Decision-making units & \multicolumn{1}{l}{} \\
\hline Energy Needs Q1 & Closed-constructed response \\
\hline Energy Needs Q2 & Open-constructed response \\
\hline Cinema Outing Q1 & Multiple choice \\
\hline Cinema Outing Q2 & Multiple choice \\
\hline Holiday Q1 & Closed-constructed response \\
\hline Holiday Q2 & Open-constructed response \\
\hline Transit System Q1 & Open-constructed response \\
\hline
\end{tabular}

\begin{tabular}{l|l}
\multicolumn{2}{l}{ System analysis and design units } \\
\hline Library System Q1 & Closed-constructed response \\
\hline Library System Q2 & Open-constructed response \\
\hline Design by Numbers Q1 & Multiple choice \\
\hline Design by Numbers Q2 & Multiple choice \\
\hline Design by Numbers Q3 & Open-constructed response \\
\hline Course Design Q1 & Open-constructed response \\
\hline Children's Camp Q1 & Open-constructed response \\
\hline
\end{tabular}

\begin{tabular}{l|l}
\multicolumn{2}{l}{ Trouble-shooting units } \\
\hline Irrigation Q1 & Open-constructed response \\
\hline Irrigation Q2 & Multiple choice \\
\hline Irrigation Q3 & Open-constructed response \\
\hline Freezer Q1 & Multiple choice \\
\hline Freezer Q2 & Multiple choice \\
\hline
\end{tabular}




\section{Decision-making units}

The first items to be examined are those associated with decision making. These items present students with a situation requiring a decision and ask them to choose among alternatives under a set of conditions constraining the situation. Students have to understand the situation provided, identify the constraints, possibly translate the way in which the information is presented, make a decision based on the alternatives under the constraints given, check and evaluate the decision, and then communicate the required answer. The factors creating difficulty in decision-making problems are the number of constraints the student has to deal with in working through the information provided and the amount of restructuring a student has to do in sorting through the information along the way to developing a solution.

There are four decision-making units in the item set. Three of the units have two questions each and one unit consists of a single question.

\section{ENERGY NEEDS}

This unit asks two questions of students. The first problem, shown below, is about selecting suitable food to meet the energy needs of a person in Zedland. Success indicated that a student was able to look up needed information for solving a problem. This item's demands were below those associated with Level 1.

Daily energy needs recommended for adults

\begin{tabular}{l|l|l|l}
\multicolumn{2}{l|}{} & Men & Women \\
\hline Age (years) & Activity level & Energy needed $(\mathrm{kJ})$ & Energy needed $(\mathrm{kJ})$ \\
\hline \multirow{3}{*}{ From 18 to 29} & Light & 10660 & 8360 \\
& Moderate & 11080 & 8780 \\
& Heavy & 14420 & 9820 \\
\hline \multirow{3}{*}{ From 30 to 59 } & Light & 10450 & 8570 \\
& Moderate & 12120 & 8990 \\
& Heavy & 14210 & 9790 \\
\hline \multirow{3}{*}{60 and above } & Light & 8780 & 7500 \\
& Moderate & 10240 & 7940 \\
& Heavy & 11910 & 8780 \\
\hline
\end{tabular}

\section{Activity level according to occupation}

Light:

Indoor sales person

Office worker

Housewife

\section{Moderate:}

Teacher

Outdoor salesperson

Nurse
Heavy:

Construction worker

Labourer

Sportsperson 


\section{ENERGY NEEDS - Question 1}

Mr David Edison is a 45-year-old teacher. What is his recommended daily energy need in $\mathrm{kJ}$ ?

Answer: kilojoules.

Jane Gibbs is a 19-year old high jumper. One evening, some of Jane's friends invite her out for dinner at a restaurant. Here is the menu:

\begin{tabular}{l|l|c} 
& MENU & $\begin{array}{c}\text { Jane's estimate of energy } \\
\text { per serving }(\mathrm{kJ})\end{array}$ \\
\hline Soups: & Tomato Soup & 355 \\
\hline Main courses: & Mexican Chicken & 585 \\
\hline & Caribbean Ginger Chicken & 960 \\
\hline & Pork and Sage Kebabs & 795 \\
\hline Salads: & Potato salad & 920 \\
\hline & Spinach, Apricot and Hazelnut Salad & 750 \\
\hline & Couscous Salad & 335 \\
\hline Desserts: & Apple and Raspberry Crumble & 480 \\
\hline & Ginger Cheesecake & 1380 \\
\hline Milkshakes: & Carrot Cake & 1005 \\
\hline & Chocolate & 565 \\
\hline & Vanilla & 1590 \\
\hline
\end{tabular}

The restaurant also has a special fixed price menu.
Fixed Price Menu
50 zeds
Tomato Soup
Caribbean Ginger Chicken
Carrot Cake

\section{ENERGY NEEDS - Question 2}

Jane keeps a record of what she eats each day. Before dinner on that day her total intake of energy had been $7520 \mathrm{k}$.

Jane does not want her total energy intake to go below or above her recommended daily amount by more than $500 \mathrm{~kJ}$.

Decide whether the special "Fixed Price Menu" will allow Jane to stay within $\pm 500 \mathrm{~kJ}$ of her recommended energy needs. Show your work.

\section{Response Coding guide for ENERGY NEEDS Question 1}

\section{Full Credit}

Code 1: 12120 kilojoules. If no answer is given, check whether the student circled " 12120 " in the table.

No Credit

Code 0: Other responses.

Code 9: Missing. 
Unit: Energy Needs

Question: Question 1

Problem type: Decision making

Item type: Closed-constructed response

Level: Below Level 1

PISA scale score: 361

Item code: $X 430 Q 01$
The scale score for the item indicates that correct performance on it is still significantly beneath the level of performance that would be judged to be indicative of performing at Level 1, that of a basic problem solver. A student who answers it correctly does need to understand the decision-making demands of this problem and be able to locate a table

entry by making appropriate links among at least three constraining factors (occupation, age and gender). However, correct performance here does not signify that students have developed a full set of skills that allow them to address problems consistently, showing understanding of the issues and factors at the heart of the problems, or consistently provide solutions to even the easiest of problems appropriate for students of their age level.

The second question in the Energy Needs unit was more demanding: full credit performance on the item is indicative of performance at Level 3. This item required a consideration of the case of Jane Gibbs, a 19-year-old high jumper. To answer it, students had to juggle the constraints of age, gender, and activity level. They also had to take account of the kilojoules already consumed in determining whether Jane can have the Fixed Price meal. It is these multiple connections that move the problem to a higher level.

\section{Response Coding guide for ENERGY NEEDS Question 2}

Full Credit

Code 2: Food from the fixed price menu does not contain enough energy for Jane to keep within $500 \mathrm{~kJ}$ of her energy needs. Work needs to show:

- Calculation of the total energy of the fixed price menu: $355+795+565=1715$.

- That the difference between $1715+7520$ and 9820 is more than 500 .

Partial Credit

Code 1: Correct method, but some minor errors in the computation leading to either correct or incorrect, but consistent, conclusion.

Or

Correctly adding up the total energy for the fixed price menu $(1715 \mathrm{~kJ})$, but incorrectly interpreting the question.

- 1715 is above $500 \mathrm{~kJ}$, so Jane should not have this.

$\bullet 1715+7520=9235$. This is within 500 of 8780 , so "Yes".

- Correct calculations, but concludes "Yes" or gives no conclusion. 
No Credit

Code 0: Other responses, including "No", without explanation.

- No, Jane should not order from the fixed price menu.

Or

Correct reasoning in words but no figures shown. That is, Code 1 needs to have some supporting figures.

- The fixed price menu does not have enough kJ, so Jane should not have it.

Code 9: Missing.

Unit: Energy Needs

Question: Question 2

Problem type: Decision making

Item type: Open-constructed response

Level: Level 2 (partial credit) and Level 3 (full credit)

PISA scale score: 587 (partial credit) and 624 (full credit)

Item code: $X 430 Q 02$
Student work on question 2, such as that shown in Figure 4.2 below, is indicative of Level 3 work. Such work reflects student understanding of the problem of comparing the items on the Fixed Price Menu with their appropriate

kilojoule $(\mathrm{kJ})$ ratings in the chart. A comparison of the $\mathrm{kJ}$ associated with the Fixed Price dinner, $1715 \mathrm{~kJ}$, and the $7520 \mathrm{~kJ}$ that Jane has already consumed gives a total of $9235 \mathrm{~kJ}$. An examination of this data with the $\mathrm{kJ}$ intake needs of a female with a heavy activity level and age 19 indicates a need of $9820 \mathrm{~kJ}$ per day. Thus, Jane's total only comes to 9235 , which is $585 \mathrm{~kJ}$ short of the recommended daily level. Hence, the Fixed Price Meal will not allow Jane to meet her recommended Energy Need level, even allowing for the $500 \mathrm{~kJ}$ variance mentioned.

Figure 4.2 Full credit student work on Energy Needs, Question 2

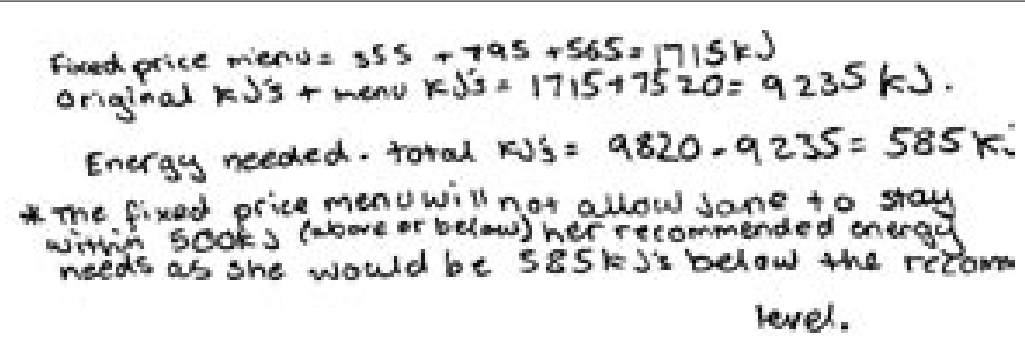

Students at Level 3 are considered reflective, communicative problem solvers because of their ability to manage all of the factors involved in a problem, in a clear, correct and coherent way. In addition to their systematic approach to a solution, these students are also capable of communicating the results to others.

Students failing to receive full credit on Question 2 have the opportunity of receiving partial credit. Figure 4.3 shows the work of a student who used a correct method, but lost track of the process after finding the kJ needed and the total in the fixed price menu. This work is indicative of students who lack the ability to reflect on and monitor their work. 


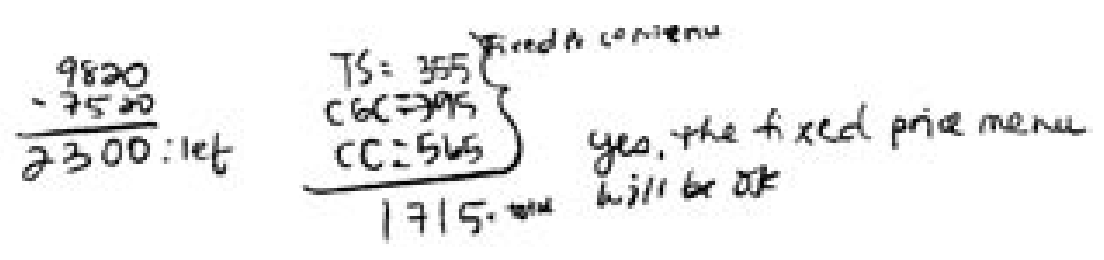

Figure 4.4 shows the work of a student who also received partial credit. This student correctly located the amount needed and correctly added the fixed price menu total to that of the amount already consumed that day. However, the student then drew the wrong conclusion.

Figure 4.4 Partial credit student work on Energy Needs, Question 2- example 2

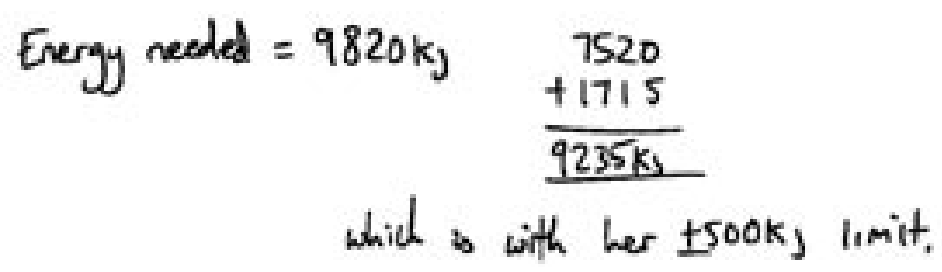

Partial credit performance associated with Question 2 is located at 587 on the PISA problem-solving scale. This point corresponds with a Level 2 performance. Such work signifies the ability to comprehend a problem, systematically approach it, combine different sources of information when needed and work toward a solution. In the example shown in Figure 4.4, the student found the energy amount needed and carried out the correct calculations, but then made a misstep in making a final judgment.

Finally, there are students who received no credit for their work on Question 2. Figure 4.5 contains a sample of such work. This work reflects a student who worked off-task, in solving another problem - the student apparently tried to figure out how Jane might have achieved a total of $7520 \mathrm{~kJ}$ of energy in her other meals that day. Often, however, students who achieved no credit were clearly on the right track but made a combination of arithmetic and logical errors.

Figure 4.5 - No credit student work on Energy Needs, Question 2

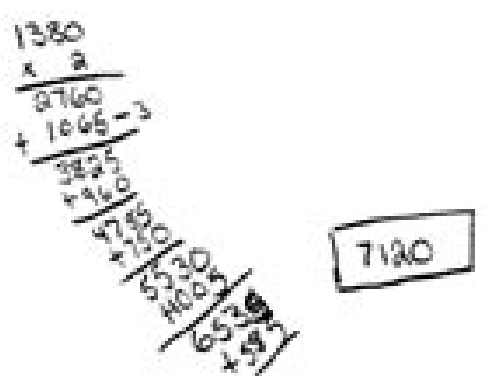


The second decision-making unit is Cinema Outing, presented as an example of a decision-making unit in Chapter 2. This unit centres on the situation of three friends making plans to attend a movie during a week of vacation from school. It is comprised of two questions. Students' responses are based on the general information and the question-specific information contained in the items shown below. Cinema Outing as a unit requires the student to read and analyse the information found in the lists of movies and times. The skills involved require careful consideration of relationships, noting the implications determined by the constraints in times, movies previously seen and conflicts in schedules, as well as parental concerns.

This problem is about finding a suitable time and date to go to the cinema.

Isaac, a 15-year-old, wants to organise a cinema outing with two of his friends, who are of the same age, during the one-week school vacation. The vacation begins on Saturday, $24^{\text {th }}$ March and ends on Sunday, $1^{\text {st }}$ April.

Isaac asks his friends for suitable dates and times for the outing. The following information is what he received.

Fred: "I have to stay home on Monday and Wednesday afternoons for music practice between 2:30 and 3:30.”

Stanley: "I have to visit my grandmother on Sundays, so it can't be Sundays. I have seen Pokamin and don't want to see it again."

Isaac's parents insist that he only goes to movies suitable for his age and does not walk home. They will fetch the boys home at any time up to 10 p.m.

Isaac checks the movie times for the vacation week. This is the information that he finds.

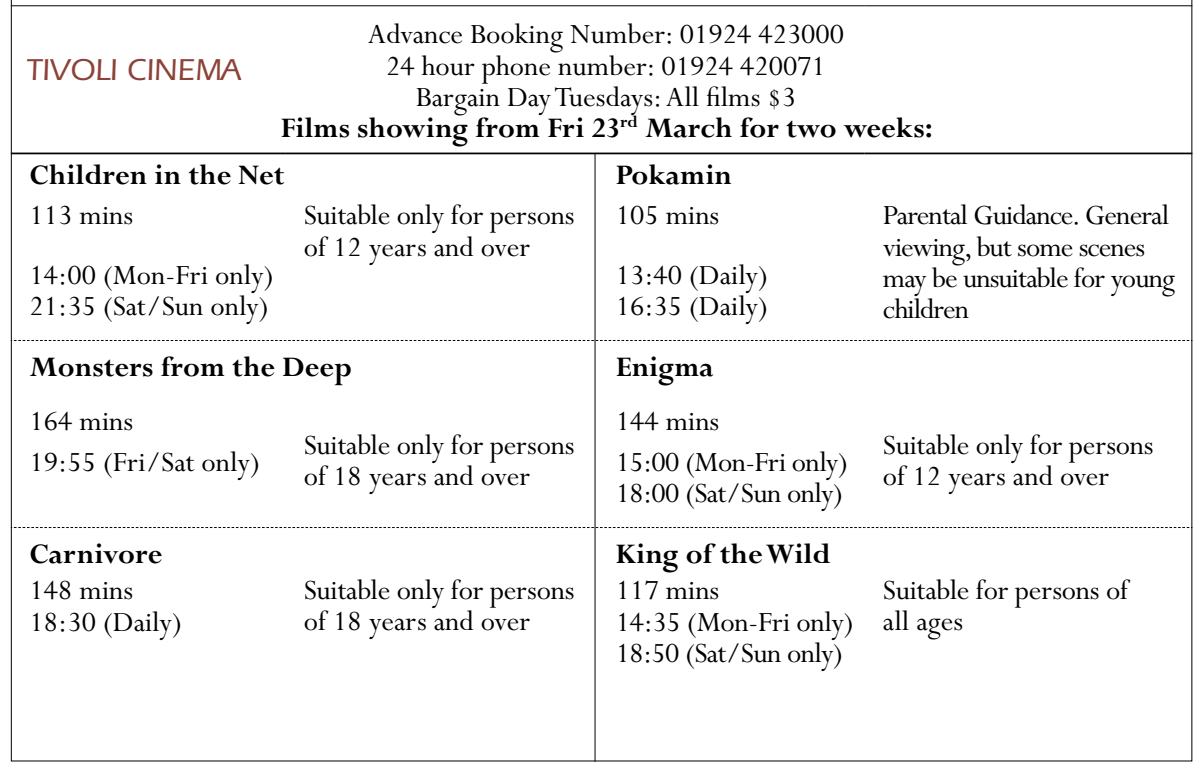




\section{CINEMA OUTING - Question 1}

Taking into account the information Isaac found on the movies, and the information he got from his friends, which of the six movies should Isaac and the boys consider watching?

Circle "Yes" or "No" for each movie.

\begin{tabular}{l|c}
\hline Movie & Should the three boys consider watching the movie? \\
\hline Children in the Net & Yes / No \\
\hline Monsters from the Deep & Yes / No \\
\hline Carnivore & Yes / No \\
\hline Pokamin & Yes / No \\
\hline Enigma & Yes / No \\
\hline King of the Wild & Yes / No \\
\hline
\end{tabular}

\section{CINEMA OUTING - Question 2}

If the three boys decided on going to "Children in the Net", which of the following dates is suitable for them?
A. Monday, $26^{\text {th }}$ March
B. Wednesday, $28^{\text {th }}$ March
C. Friday, $30^{\text {th }}$ March
D. Saturday, $31^{\text {st }}$ March
E. Sunday, $1^{\text {st }}$ April

Unit: Cinema Outing

Question: Question 2

Problem type: Decision making

Item type: Multiple choice

Level: Level 1

PISA scale score: 468

Item code: $X 601 Q 02$
The analysis of students' responses to Cinema Outing, Question 2 indicated that it was more accessible to students than Cinema Outing, Question 1. This may have resulted from the fact that students could answer Question 2 by eliminating films on the basis of a conflict with one constraint. A correct response to

Cinema Outing, Question 1 required attendance to multiple constraints at one time. This criterion of the number of constraints that must be attended to at one time is a major discriminator between performance at Level 1 and Level 2.

\section{Response Coding guide for CINEMA OUTING Question 2}

Full Credit

Code 1: C. Friday, $30^{\text {th }}$ March.

No Credit

Code 0: Other responses.

Code 9: Missing. 
Unit: Cinema Outing

Question: Question 1

Problem type: Decision making

Item type: Multiple choice

Level: Level 1 (partial credit) and Level 2 (full credit)

PISA scale score: 442 (partial credit) and 522 (full credit)

Item code: $X 601001$
Cinema Outing, Question 1 calls on students to show they understand the constraints imposed by the problem situation and to make a decision about whether there is even a possibility that the

three boys can see a given movie together. A correct answer is linked to a score of 522 on the problem-solving scale. Students who correctly respond to this item are able to make decisions about whether a given alternative is possible or not. This indicates understanding and the ability to interpret constraints in multiple combinations with regard to each of the possible alternatives. Such problem-solving performances are judged to be indicative of Level 2 problem-solving work.

\section{Response Coding guide for CINEMA OUTING Question 1}

Full Credit

Code 2: Yes, No, No, No, Yes, Yes, in that order.

Partial Credit

Code 1: One incorrect answer.

\section{No Credit}

Code 0: Other responses.

Code 9: Missing.

Students who answered all but one of the questions correctly received partial credit for the item. However, such responses were placed lower on the problemsolving scale at Level 1, with 442 points. 


\section{HOLIDAY}

The third decision-making unit, Holiday, asks two questions of students. It deals with the planning of a route and places to stay overnight on a holiday trip. Students were presented with a map and a chart showing the distances between the towns illustrated on the map.

This problem is about planning the best route for a holiday.

Figures 1 and 2 show a map of the area and the distances between towns.

Figure 1. Map of roads between towns

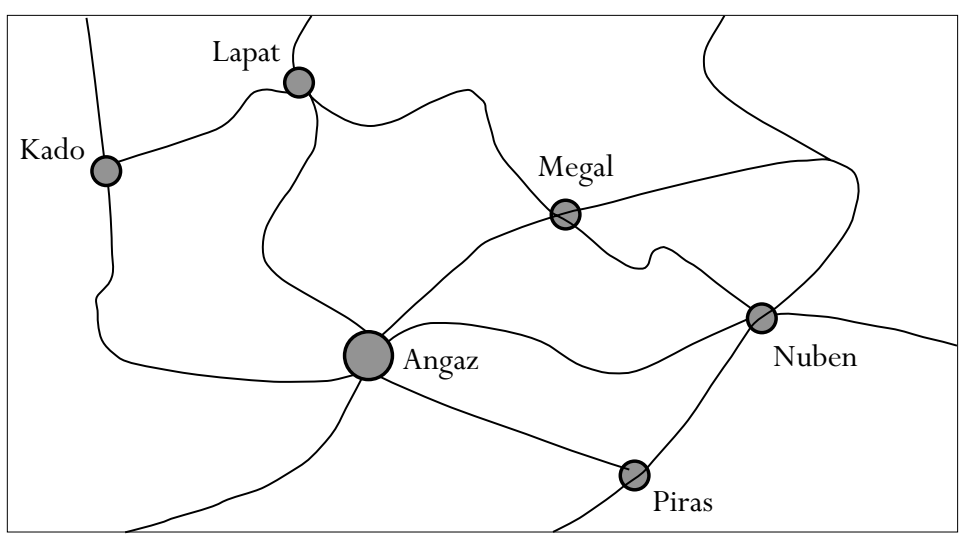

Figure 2. Shortest road distance of towns from each other in kilometres.

\begin{tabular}{|c|c|c|c|c|c|}
\hline Angaz & & & & & \\
\hline Kado & 550 & & & & \\
\hline Lapat & 500 & 300 & & & \\
\hline Megal & 300 & 850 & 550 & & \\
\hline Nuben & 500 & & 1000 & 450 & \\
\hline Piras & 300 & 850 & 800 & 600 & 250 \\
\hline & Angaz & Kado & Lapat & Megal & Nuben \\
\hline
\end{tabular}

\section{HOLIDAY - Question 1}

Calculate the shortest distance by road between Nuben and Kado.

Distance: kilometres.

\section{HOLIDAY - Question 2}

Zoe lives in Angaz. She wants to visit Kado and Lapat. She can only travel up to $\mathbf{3 0 0}$ kilometres in any one day, but can break her journey by camping overnight anywhere between towns. 
Zoe will stay for two nights in each town, so that she can spend one whole day sightseeing in each town.

Show Zoe's itinerary by completing the following table to indicate where she stays each night.

\begin{tabular}{c|l} 
Day & Overnight Stay \\
\hline 1 & Camp-site between Angaz and Kado. \\
\hline 2 & \\
\hline 3 & \\
\hline 4 & \\
\hline 5 & \\
\hline 6 & \\
\hline 7 & Angaz \\
\hline
\end{tabular}

Unit: Holiday
Question: Question 1
Problem type: Decision making
Item type: Closed-constructed response
Level: Level 2
PISA scale score: 570
Item code: $X 602 Q 01$

The stimulus materials for Holiday, Question 1 requirelittlein terms of reading text. However, students must read and interpret information from the map and from the distance chart. Some of the distances that they have to find in the chart require them to read distances starting from the bottom of the chart, rather than from the left down. For example, in determining the distance from Nuben to Piras, one needs to transform the search to that of finding the distance from Piras to Nuben. Examining students' work, one sees a variety of interpretations or errors that they made in responding to Question 1. For example, a student who responds 1100 kilometres may have determined the distance of the route that goes from Nuben to Piras to Angaz to Kado. Other students may have identified the shortest route, Nuben-Angaz-Kado, but calculated the distance incorrectly.

\section{Response Coding guide for HOLIDAY Question 1}

Full Credit

Code 1: 1050 kilometres.

No Credit

Code 0: Other responses.

- Nuben-Angaz-Kado, no distance given.

Code 9: Missing.

The second Holiday question was associated with performances scoring higher on the PISA scale. It asked students to make a decision about how to schedule their travel among the towns in terms of overnight stays. 
Unit: Holiday

Question: Question 2

Problem type: Decision making

Item type: Open-constructed response

Level: Level 2 (partial credit) and Level 3 (full credit)

PISA scale score: 593 (partial credit) and 603 (full credit)

Item code: $X 602 Q 02$
This question set a number of constraints that needed to be complied with simultaneously - a maximum of $300 \mathrm{~km}$ travelled in a given day, starting and finishing in Zoe's hometown of Angaz, visiting Kado and Lapat, and staying two nights in each of these cities so that she can achieve her vacation goals. Note that while full credit, associated with Level 3, could only be obtained for a fully correct answer, partial credit could be obtained with one entry incorrect, linked to a score right at the top of Level 2, only 11 score points below a fully correct answer at the bottom of Level 3. A student who made one mistake in calculating the answer to this problem was still able to go through the main steps of analytic reasoning required to solve it.

\section{Response Coding guide for HOLIDAY Question 2}

Full Credit

Code 2: Entries as shown below:

\begin{tabular}{c|l} 
Day & Overnight Stay \\
\hline 1 & Camp-site between Angaz and Kado. \\
\hline 2 & Kado \\
\hline 3 & Kado \\
\hline 4 & Lapat \\
\hline 5 & Lapat \\
\hline 6 & Camp-site between Lapat and Angaz (OR just "Camp-site”) \\
\hline 7 & Angaz \\
\hline
\end{tabular}

\section{Partial Credit}

Code 1: One error. An error means the entry is not correct for the corresponding day.

- "Sightseeing in Lapat" for day 3.

- A town name for day 6.

- No entry for day 6.

No Credit

Code 0: Other responses.

Code 9: Missing. 
This single-item unit requires students to look at a transit system map and information about fares and travel times and to calculate the best route, the cost and the time taken to travel between two stations.

The following diagram shows part of the transport system of a city in Zedland, with three railway lines. It shows where you are at present, and where you have to go.

Means a station on a railway line

- Means a station that is a junction where you can change from one railway line to another (Lines A, B or C).

The fare is based on the number of stations travelled (not counting the station where you start your journey). Each station travelled costs 1 zed. The time taken to travel between two adjacent stations is about 2 minutes. The time taken to change from one railway line to another at a junction is about 5 minutes.

\section{TRANSIT SYSTEM - Question 1}

The diagram indicates a station where you are currently at ("From here"), and the station where you want to go ("To here"). Mark on the diagram the best route in terms of cost and time, and indicate below the fare you have to pay, and the approximate time for the journey.

Fare: zeds. 
Unit: Transit System

Question: Question 1

Problem type: Decision making

Item type: Open-constructed response

Level: Level 3 (partial and full credit)

PISA scale score: 608 (partial credit) and 725 (full credit)

Item code: $X 415001$
Somewhat surprisingly, this decision-making item turned out to be the most difficult problem-solving item on the assessment. This may be due to the amount of external information that it required

students to bring to the solution of the problem posed. While there was no indication through different country results that students in some countries might have been more familiar with the use of a transit system, it appears that many students were unable to deal with the task of transferring from one train to another. In addition, there appeared to be confusion with regard to counting the number of segments on the route between the origin and destination.

The coding guide for the problem awards full credit if students show the correct route, the lowest fare and quickest time for the trip. However, if a student did not mark the map, but correctly gave the fare and time, they also are awarded full credit, as no route other than the correct one has that combination of fare and time.

\section{Response Coding guide for TRANSIT SYSTEM Question 1}

\section{Full Credit}

Code 21: Route as shown: fare 8 zeds; approximate time for journey:

21 minutes.

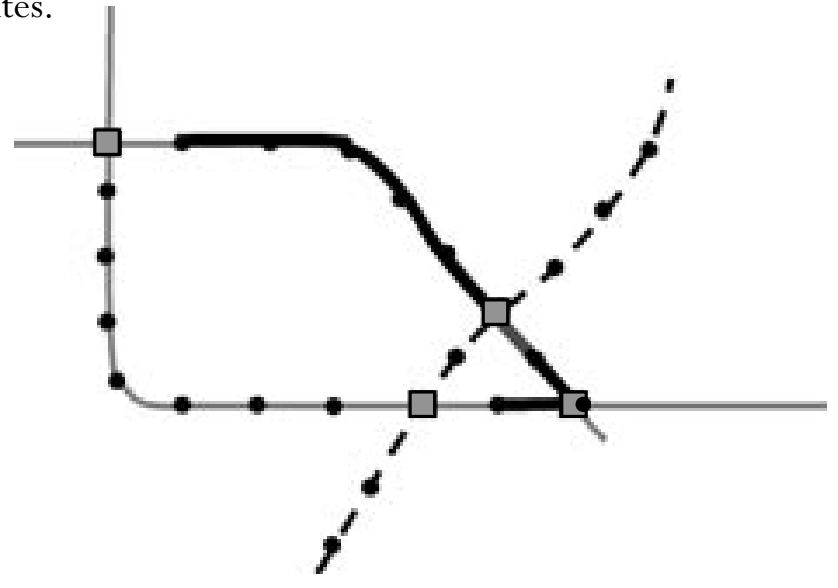

Code 22: No route shown; fare 8 zeds; time 21 minutes.

Partial Credit

Code 11: Best route shown, with correct fare or time, but not both.

- Best route shown; fare 8 zeds; time 26 minutes.

- Best route shown; fare missing; time 21 minutes.

Code 12: One of the two other possible routes shown, with correct fare and time for that route.

- Route shown is the one that first goes left; fare 10 zeds; time 25 minutes.

- Route shown is the one via Lines B, C \& A; fare 8 zeds; time 26 minutes. 
Code 13: No route shown, but correct fare AND time for one of the two other routes are given.

- No route shown; fare 10 zeds; time 25 minutes.

- No route shown; fare 8 zeds; time 26 minutes.

No Credit

Code 01: Best route shown, but both fare and time incorrect or missing.

- Best route shown; fare missing; time 26 minutes.

Code 02: Other responses.

- Lines B, C \& A route shown; fare and time missing.

Code 99: Missing. (Note that Code 99 should only be given when there is no route shown AND no fare given AND no time given.)

Note that the coding guide makes use of double-digit coding, which allows for the differentiation of students' responses in the data interpretation. Double-digit coding uses the first digit of the response code to indicate the score associated with a student's work. The second digit of the response code either indicates the method the student used in gaining that coding, or the type of error the student made. For example, a piece of student work that was assigned partial credit code 11 is shown in Figure 4.6. Here the student indicated the correct path and fare, but an incorrect journey time.

Figure 4.6 - Partial credit solution for Transit System (Response Coding Code 11)

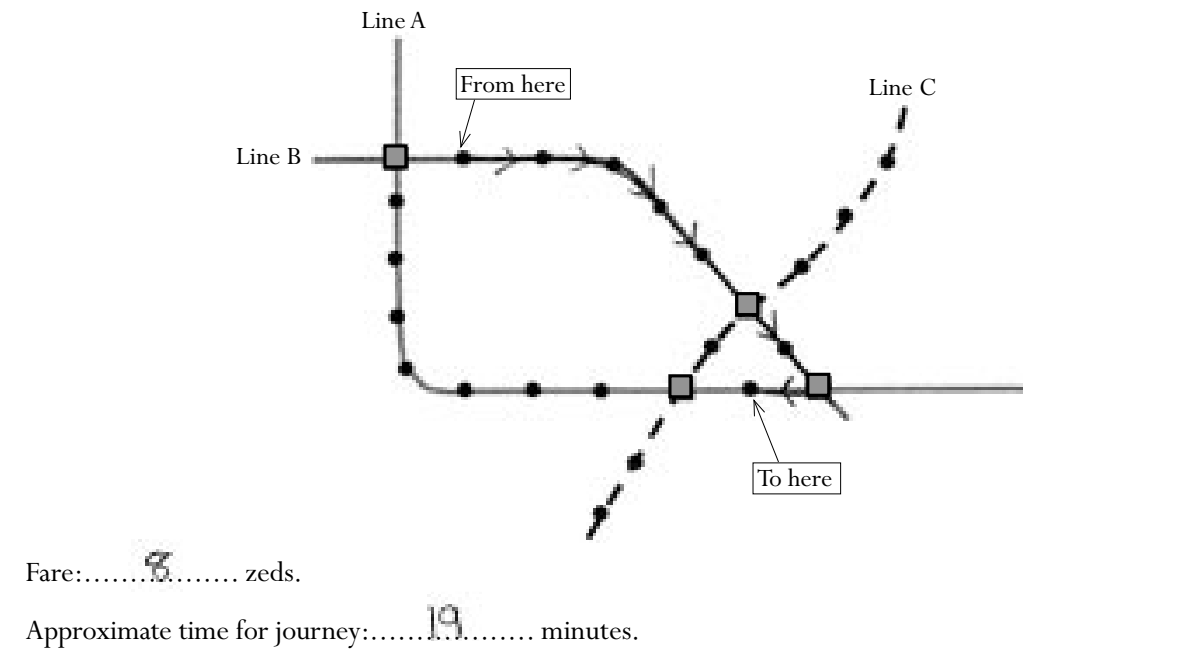

This coding makes it possible to analyse what it was that made students find this problem so difficult. Many found it hard to factor in the transfer time when changing from one line to another and apparently had difficulty dealing with the fact that the transfer time is in addition to the travel time. Another error source commonly observed in students' work was that they incorrectly counted stations or the links between stations in calculating costs and time, respectively. 


\section{System analysis and design units}

PISA included four units assessing students' capabilities to solve problems involving system analysis and design. One of these units had three items, two had two items each and the fourth unit had one item. System analysis and design problems differ from the decision-making items in that not all of the possible options are given nor are the constraints as obvious. In the system analysis and design problems, students have to develop an understanding of the problem, beginning with the identification of the relationships existing between the parts of the system, or to design a system with certain relationships among its main features. Next, students have to develop a representation that brings the inherent relationships into a manipulative form. From here the students can test the system or design by working with individual or sets of related features in the system. Finally, students are generally involved in justifying their analysis or defending their design.

\section{LIBRARY SYSTEM}

The system analysis and design unit with the most accessible question was the Library System unit. This unit contained two items. The first question required students to interpret rules for a system, identify which of the rules applied, and apply them. A correct response indicated that they understood the general nature of such a system. The second question involved the students in developing a flow chart that would implement a given set of rules.

The John Hobson High School library has a simple system for lending books: for staff members the loan period is 28 days and for students the loan period is 7 days. The following is a decision tree diagram showing this simple system:

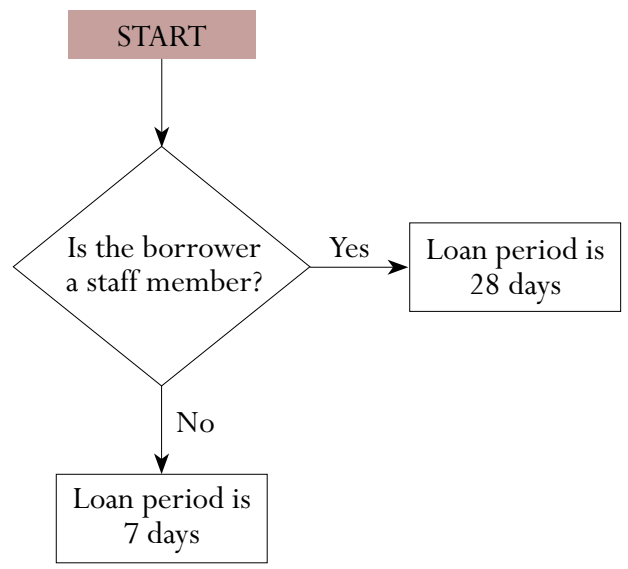


The Greenwood High School library has a similar, but more complicated, lending system:

- All publications classified as "Reserved" have a loan period of 2 days.

- For books (not including magazines) that are not on the reserved list, the loan period is 28 days for staff, and 14 days for students.

- For magazines that are not on the reserved list, the loan period is 7 days for everyone.

- Persons with any overdue items are not allowed to borrow anything.

\section{LIBRARY SYSTEM - Question 1}

You are a student at Greenwood High School, and you do not have any overdue items from the library. You want to borrow a book that is not on the reserved list. How long can you borrow the book for?

Answer: days.

\section{LIBRARY SYSTEM - Question 2}

Develop a decision tree diagram for the Greenwood High

School Library system so that an automated checking system can be designed to deal with book and magazine loans at the library. Your checking system should be as efficient as possible (i.e. it should have the least number of checking steps). Note that each checking step should have only two outcomes and the outcomes should be labelled appropriately (e.g. "Yes" and "No").

\section{START}

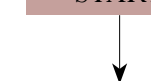

\footnotetext{
Unit: Library System

Question: Question 1

Problem type: System analysis and design

Item type: Closed-constructed response

Level: Level 1

PISA scale score: 437

Item code: $X 402 Q 01$
}

Using the rules of the system, the first question required students to determine for how long a student could borrow a book that was not on the reserve list. To respond correctly, the student had to understand the rules, recognize which ones applied to non-reserve book loans

to students, and then determine the loan period.

\section{Response Coding guide for LIBRARY SYSTEM Question 1}

Full Credit

Code 1: 14 days.

No Credit

Code 0: Other responses.

Code 9: Missing. 
This question is located at Level 1 because it only requires that students understand the nature of a problem and locate and retrieve information related to a major feature of the problem. In this case the check-out policies involved were welldefined and fairly easy to implement by checking the conditions given.

Unit: Library System

Question: Question 2

Problem type: System analysis and design

Item type: Open-constructed response

Level: Level 3 (partial and full credit)

PISA scale score: 658 (partial credit 1),

677 (partial credit 2) and 693 (full credit)

Item code: $X 402 Q 02$
The second library question was more difficult. It asked students to develop a flow chart illustrating the set of rules applied from a written list. The chart was to provide a design for developing an automated system that would provide the loan period for a given library item. Student responses could receive full credit, one of two partial credit scores according to the criteria listed overleaf, or no credit. The analysis of student work indicated that both full and partial credit responses are indicative of Level 3 performance. To construct the flow chart, even with minor errors, students must not only develop an understanding of the multiple regulations and the relationships between them for this library system, but organise and monitor their approach to constructing and communicating the solution. Handling such a problem in its totality requires students to keep track of the interrelationships involved even for the partial credit responses.

\section{Response Coding guide for LIBRARY SYSTEM Question 2}

Full Credit

Code 31: The most efficient system is a four-step check system as follows:

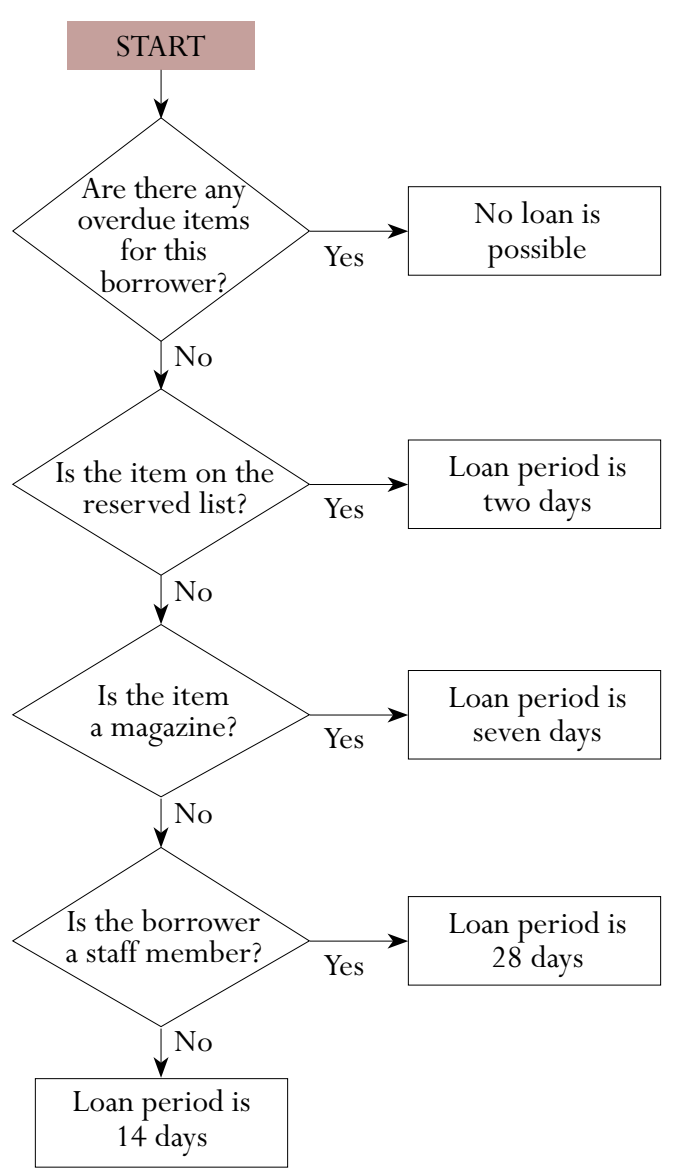


Partial Credit

Code 21: The four check steps are in the right sequence, but there is a minor error. For example:

- One loan period is incorrect.

- One loan period is missing.

- One or more Yes/No missing.

- OneYes/No incorrectly labelled. For example:

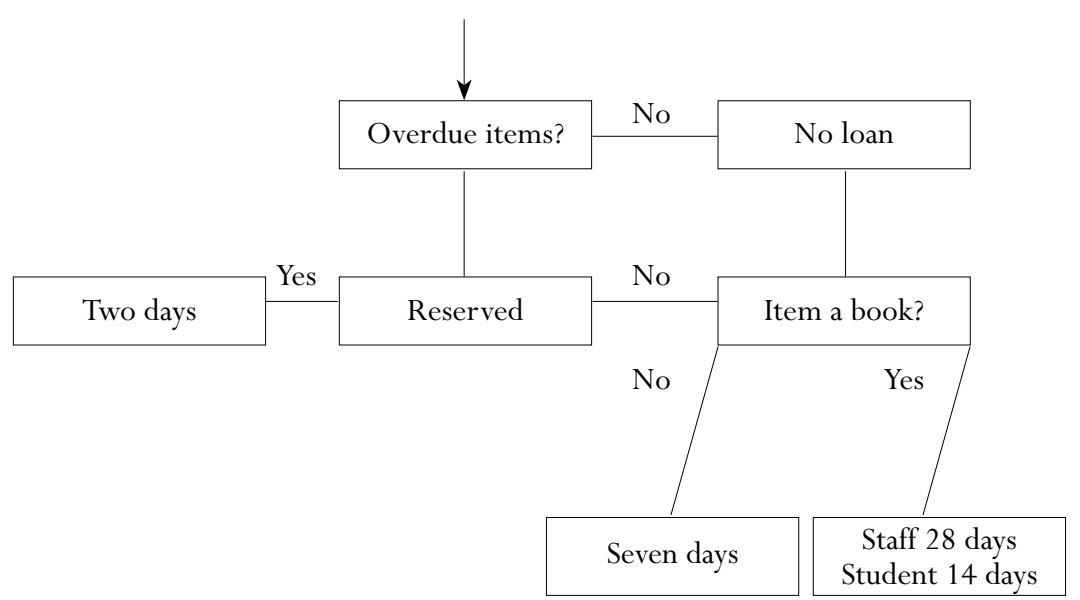

Code 22: The check for "overdue items" is written as a statement outside the decision tree diagram, but the other three check steps are completely correct and in the right sequence.

Code 23: Two check steps are out of order, resulting in five steps, as one extra check step is required. The system is still complete, but less efficient. Complete means that the checking system will produce the correct loan periods in all cases.

Code 11: The diagram is correct except that the first three check steps are out of order in one (but not both) of the following two ways:

- The checks for "reserved list" and "magazine" are interchanged.

- The checks for "overdue items" and "reserved list" are interchanged.

Code 12: The check for "overdue items" is written as a statement outside the decision tree diagram. The other three check steps are in the right sequence, but with a minor error.

\section{OR}

The check for "overdue items" is missing, but the other three check steps are completely correct and in the right sequence.

No Credit

Code 01: The system is complete, but has more than five check steps. 
Code 02: Other responses.

- System incomplete and is not covered by any of the partial credit codes.

- Five or more check steps, and the system is incomplete.

- Five check steps, with "overdue items" missing.

- A checking step has more than two outcomes.

Code 99: Missing.

Figure 4.7 provides an example of student work receiving full credit. This student has presented the work in a clear and concise fashion and followed the instructions that each decision point should have exactly two outcomes.

Figure 4.7 - Example of full credit response to Library System, Question 2

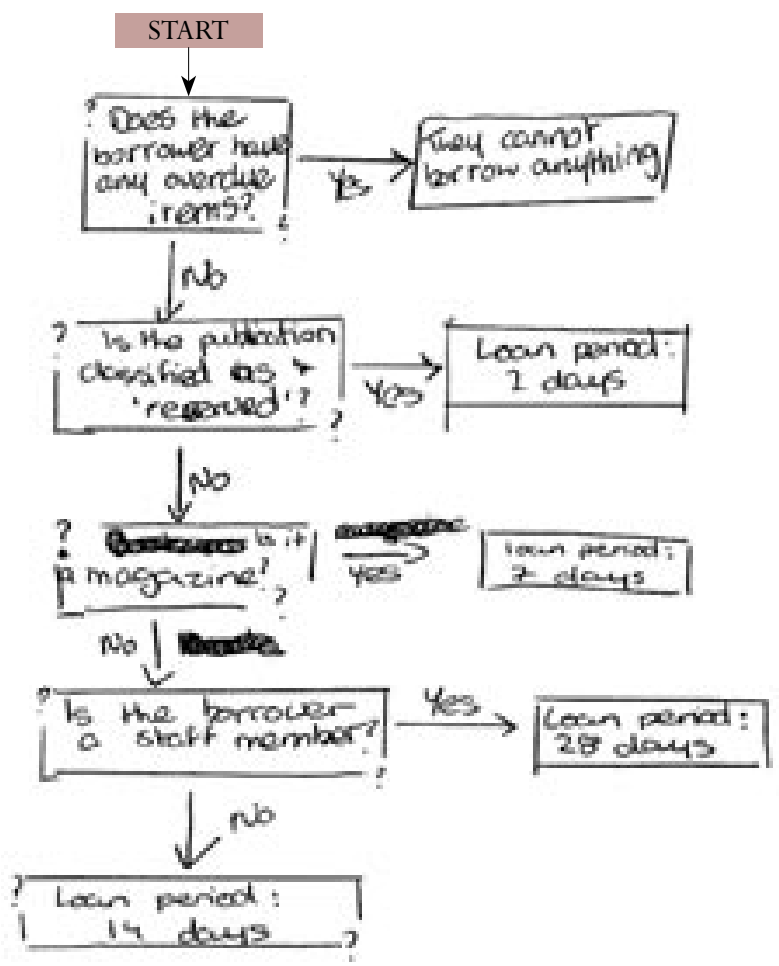

Figure 4.8 shows an example of student work receiving a partial credit code of 11. This double-digit partial credit score indicates that the student's work is correct except that the first three check steps are out of order in one (but not both) of the following two ways:

- The checks for "reserved list" and "magazine" are interchanged.

- The checks for "overdue items" and "reserved list" are interchanged. 


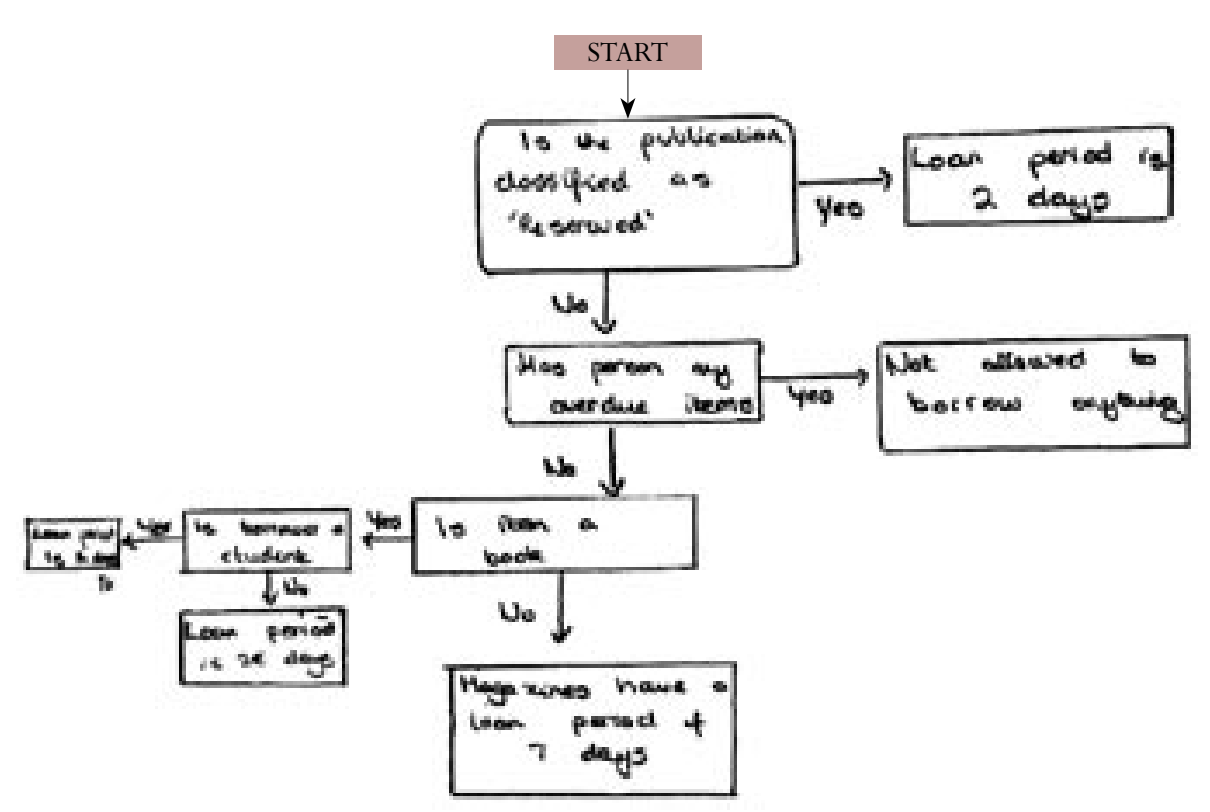

In fact, an examination of the rules and the student's work shows that this student has reversed the order of the checks for overdue books and items listed on the reserved list, but is otherwise correct. The overdue books criterion should have been listed first before any consideration is given to the length of any checkout period. Most students had difficulty in correctly handling the overdue books criterion.

The Library System unit was interesting in that it contained two questions of contrasting difficulty. The first question was the second easiest problem-solving item in PISA, while the second question was the second hardest overall. Thus in the framework of a single situation, problem-solving abilities at very different levels of difficulty could be assessed. 


\section{DESIGN BY NUMBERS@}

The system analysis and design unit containing the next easiest question was the Design by Numbers $\odot$ unit. This unit had three questions, the most of any unit in the assessment. The Design by Numbers $\odot$ unit was based on a context involving a language for graphical design developed by the Aesthetics and Computation Group at the MIT Media Laboratory. The system at the heart of this problem is a programming language that relates written instructions to actions taking place on a monitor-like screen on the page.

Design by Numbers is a design tool for generating graphics on computers. Pictures can be generated by giving a set of commands to the program.

Study carefully the following example commands and pictures before answering the questions.
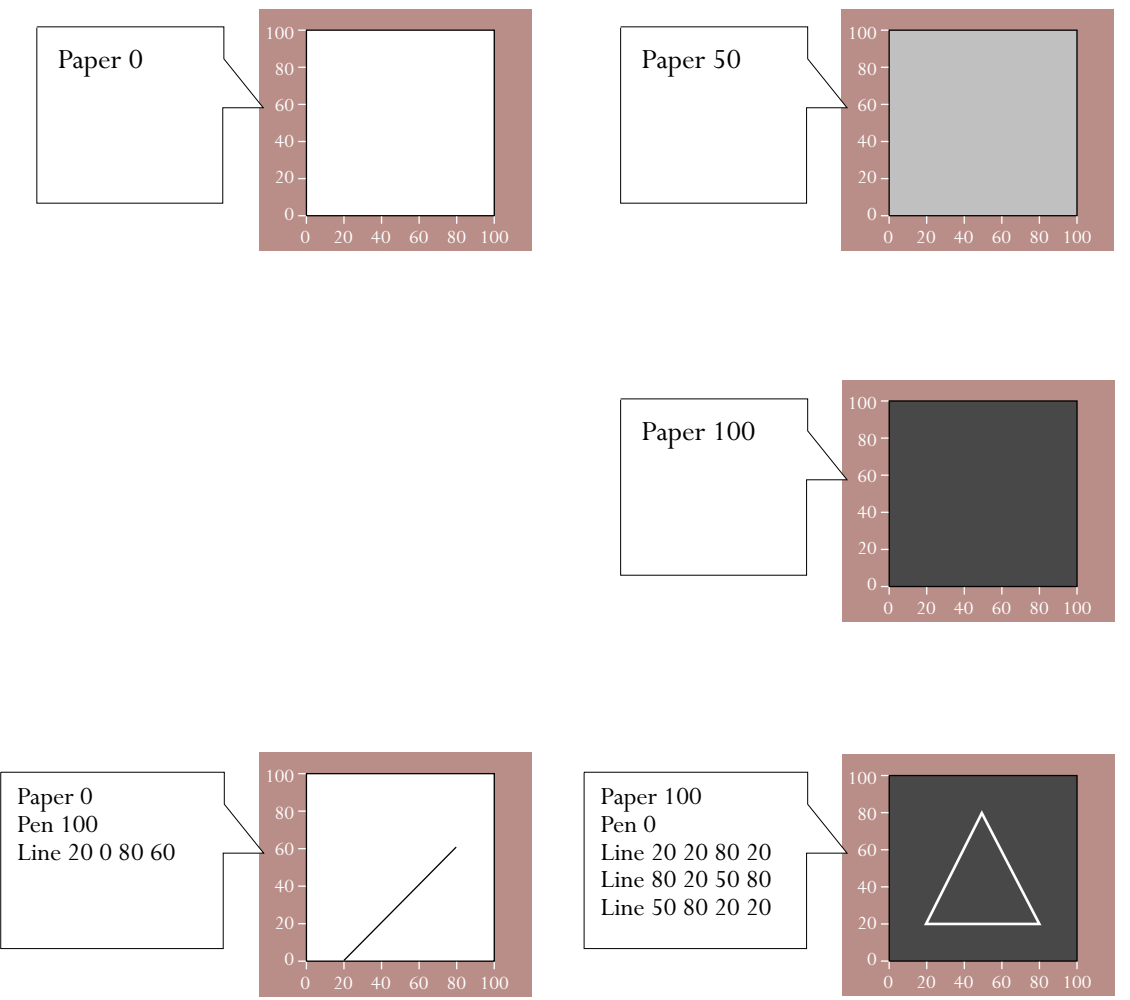

1. Design by Numbers was developed by the Aesthetics and Computation Group at the MIT Media Laboratory. Copyright 1999, Massachusetts Institute of Technology. The program can be downloaded from http: / / dbn.media.mit.edu. 
Which of the following commands generated the graphic shown below?
A. Paper O
B. Paper 20
C. Paper 50
D. Paper 75

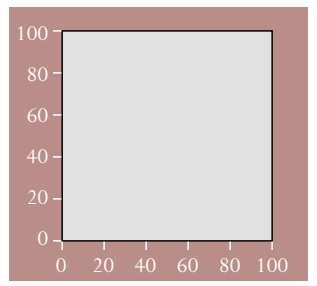

\section{DESIGN BY NUMBERSO - Question 2}

Which of the following set of commands generated the graphic shown below?
A. Paper 100 Pen O Line 80208060
B. Paper $O$ Pen 100 Line 80206080
C. Paper 100 Pen O Line 20808060
D. Paper O Pen 100 Line 20808060

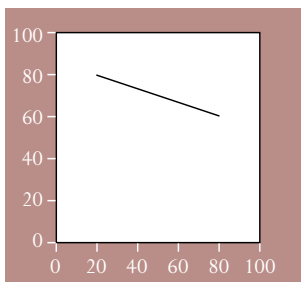

\section{DESIGN BY NUMBERS@ - Question 3}

The following shows an example of the "Repeat" command.

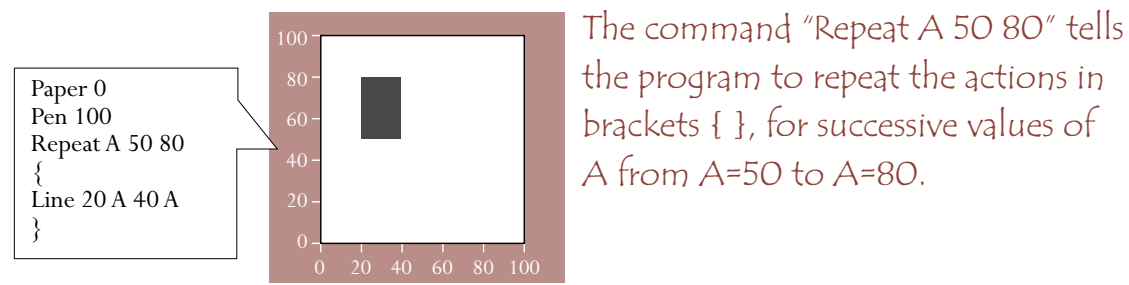

Write commands to generate the following graphic:

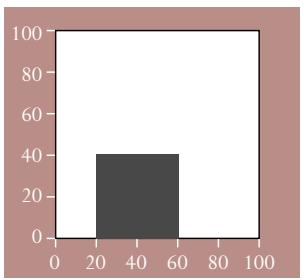

Unit: Design by Numbers $\odot$

Question: Question 1

Problem type: System analysis and design

Item type: Multiple choice

Level: Level 2

PISA scale score: 544

Item code: $X 412 Q 01$
The first question assessed students' ability to analyse a series of examples and abstract out the relationship between the shade level of the screen and the programming command line associated with that outcome. In this case, the sample screens show the commands of Paper, Pen, and Line. Comparing and contrasting the examples present, an analysis indicates that the command Paper is the appropriate command to give a blank shaded screen. In order to select Paper 20 as the appropriate answer, the student must compare the "paper" shadings shown. 


\section{Response Coding guide for DESIGN BY NUMBERS@ Question 1}

Full Credit

Code 1: B. Paper 20.

No Credit

Code 0: Other responses.

Code 9: Missing.

Unit: Design by Numbers(C)

Question: Question 2

Problem type: System analysis and design

Item type: Multiple choice

Level: Level 2

PISA scale score: 553

Item code: $X 412 Q 02$
The second question in the Design by Numbers $\odot$ unit involves a similar task to the first. However, the analysis required here involves the abstraction of a sequenced set of commands rather than a single command. The solution can still be found by selecting one of the alternatives in a multiple choice setting, but students have to distinguish between the effects of the values associated with Paper and Pen commands and then understand the coordinate structure for the Line command.

\section{Response Coding guide for DESIGN BY NUMBERS $\odot$ Question 2}

Full Credit

Code 1: D. Paper 0 Pen 100 Line 20808060.

No Credit

Code 0: Other responses.

Code 9: Missing.

Unit: Design by Numbers(C)

Question: Question 3

Problem type: System analysis and design

Item type: Open-constructed response

Level: Level 2 (partial credit) and Level 3 (full credit)

PISA scale score: 571 (partial credit) or 600 (full credit)

Item code: $X 412003$
The final item in the unit involves the design of a set of commands that will result in the design tool replicating a given figure on the screen. Here the student has to bring together the effects associated with the previous commands and add to that the Repeat command. This involves realising that the figure can be formed by drawing lines repeatedly, creating an appropriate command that needs to be repeated and then establishing the values that the program has to cycle through in the repetition pattern to allow embedded command lines to draw the figure. This involves more analysis than the previous items in the unit and has the added design feature of students having to write the command lines, rather than select them. 
Full Credit

Code 2: Correct commands.

- Note that in the Repeat command, 0 and 40 can be switched (i.e. Repeat 40 0). In the command Line 20 A 60 A, 20 and 60 can be switched (i.e. Line 60 A 20 A).

Paper 0

Pen 100

Repeat A 040

\{

Line 20 A 60 A

\}

- Note that in the Repeat command, 20 and 60 can be switched (i.e. Repeat 60 20). In the command Line A 0 A 40, 0 and 40 can be switched (i.e. Line A 40 A 0).

Paper 0

Pen 100

Repeat A 2060

\{

Line A 0 A 40

\}

(In short, 0 and 40 should be in theY position and 20 and 60 should be in the $\mathrm{X}$ position.)

Partial Credit

Code 1: Correct commands but incorrect placement of numbers in the Line command.

- Paper 0

Pen 100

Repeat A 2060

\{

Line 0 A 40 A

\}

Correct commands, but one incorrect number in either the Repeat or the Line command. Note that if there is any number other than 0 or 20 or 40 or 60 (e.g. 50 or 80 are used), or if the same number is repeated in the one command, then Code 0 should be given.

- Pen 100

Paper 0

Repeat A 040

\{

Line 0 A 60 A

\} 
Correct Repeat section, but missing or incorrect Paper or Pen command.

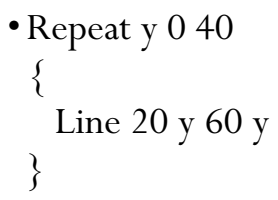

Correct numbers, but a small mistake in the Line command.

- Paper 0

Pen 100

Repeat A 2060

\{

A 0 A 40

\}

No Credit

Code 0: Other responses.

- Paper 0

Pen 100

Line 2006040

- Paper 0

Pen 100

Repeat A 2060

\{

Line A 20 A 60

\}

Code 9: Missing.

The work in Figure 4.9 shows the performance of a student who responds to the requirements of question three. The demands of this item place it in Level 3. (Note that the student's omission of the final $\}$ is not considered a significant error in this context. As the response coding guide of Question 3 indicates, minor syntax errors were disregarded in coding students' solution.)

Figure 4.9 - Example of full credit response for Design by Numbers@, Question 3

Write commands to generate the following graphic:
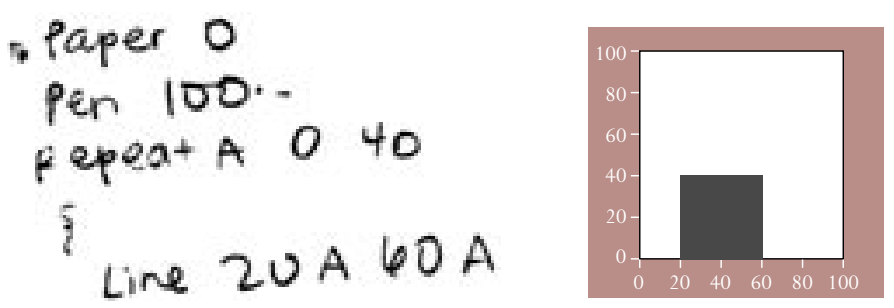
In designing such a program, a student considers and sequences a number of conditions, and determines the commands and variable values that will produce the desired result. Then the student has to write the command line and think through the potential output in a sequential manner, keeping in mind the impact of command on the final output. The mental load and the complexity required in developing the required design as well as the written communication of the design program places this item at Level 3.

Students who made a significant error in one of the command lines in terms of an incorrect value or missed one of the Paper or Pen commands were awarded partial credit. Such performances were considered Level 2 work and were placed on the PISA problem-solving scale at 571. 


\section{COURSE DESIGN}

This third system analysis and design unit contained one open-constructed response item. The item involves sequencing 12 courses of study over a three-year period when some courses have to be taken prior to other courses. It is similar to the normal planning of an individual's academic schedule when there are a number of prerequisite relationships among the courses.

A technical college offers the following 12 subjects for a three-year course, where the length of each subject is one year:

\begin{tabular}{c|c|l} 
& Subject Code & Subject Name \\
\hline 1 & M1 & Mechanics Level 1 \\
\hline 2 & M2 & Mechanics Level 2 \\
\hline 3 & E1 & Electronics Level 1 \\
\hline 4 & E2 & Electronics Level 2 \\
\hline 5 & B1 & Business Studies Level 1 \\
\hline 6 & B2 & Business Studies Level 2 \\
\hline 7 & B3 & Business Studies Level 3 \\
\hline 8 & C1 & Computer Systems Level 1 \\
\hline 9 & C2 & Computer Systems Level 2 \\
\hline 10 & C3 & Computer Systems Level 3 \\
\hline 11 & T1 & Technology and Information Management Level 1 \\
\hline 12 & T2 & Technology and Information Management Level 2 \\
\hline
\end{tabular}

\section{COURSE DESIGN - Question 1}

Each student will take four subjects per year, thus completing 12 subjects in three years.

A student can only take a subject at a higher level if the student has completed the lower level(s) of the same subject in a previous year. For example, you can only take Business Studies Level 3 after completing Business Studies Levels 1 and 2.

In addition, Electronics Level 1 can only be taken after completing Mechanics Level 1 , and Electronics Level 2 can only be taken after completing Mechanics Level 2. 
Decide which subjects should be offered for which year, by completing the

following table. Write the subject codes in the table.

\begin{tabular}{l|l|l|l|l} 
& Subject 1 & Subject 2 & Subject 3 & Subject 4 \\
\hline Year 1 & & & & \\
\hline Year 2 & & & & \\
\hline Year 3 & & & & \\
\hline
\end{tabular}

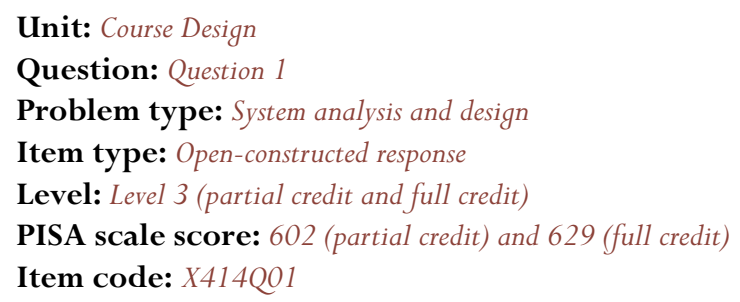
played a central role in the previous problems. In Course Design, students have to examine carefully the given relationships among the courses. Strong students note the central role played by course sequences of three years, slotting them into the school programme first. Then they place the courses lasting two years and finally one year. In doing so, students must also keep in mind a cross-course sequence requirement that Mechanics 1 (2) must be taken before Electronics 1 (2).

Student performance on the Course Design task identified two levels of response. Full credit responses linked to the PISA problem-solving scale at 629 , while the partial credit responses were placed at 602. Both of these values indicate student performances at Level 3. This level is appropriate given the number of interacting, interrelated courses in the problem. Further, these courses must be manipulated and placed in the schedule at the same time, as one placement creates or closes possibilities for other placements with each shift of a course.

\section{Response Coding guide for COURSE DESIGN Question 1}

Full Credit

Code 2: The order of subjects within a year is unimportant, but the list of subjects for each year should be as given below:

\begin{tabular}{c|c|c|c|c} 
& Subject 1 & Subject 2 & Subject 3 & Subject 4 \\
\hline Year 1 & B1 & M1 & T1 & C1 \\
\hline Year 2 & B2 & M2 & E1 & C2 \\
\hline Year 3 & B3 & T2 & E2 & C3 \\
\hline
\end{tabular}

\section{Partial Credit}

Code 1: Mechanics does not precede Electronics. All other constraints are satisfied. 
No Credit

Code 0: Other responses.

- Table completely correct except that E2 is missing and E1 is repeated where E2 should be or this cell is empty.

Code 9: Missing.

The coding guide shown in the response coding guide of Question 1 gives an example of what a correct response to the item would be. A response receiving partial credit is shown in Figure 4.10. Partial credit responses are characterised by having the courses with sequence numbers correctly placed in the schedule, but without satisfying the requirement that Mechanics must precede Electronics.

Figure 4.10 - Example of partial credit response for Course Design, Question 1

\begin{tabular}{c|c|c|c|c} 
& Module 1 & Module 2 & Module 3 & Module 4 \\
\hline Year 1 & B I & CI & HI & E2 \\
\hline Year 2 & B 2 & C2 & EI & TI \\
\hline Year 3 & B 3 & C 3 & M2 & T2 \\
\hline
\end{tabular}


The final system analysis and design problem also involves combinatorial reasoning. This item contains a common system problem of assignment of classes of people to positions consistent with specified relationships between the classes and between the people within the classes. These relationships concern adult-child, malefemale and the dormitory size. The manipulation of these is made somewhat more difficult by the different dormitory sizes and the fact that there are eight adults and seven dormitories - hence one dormitory will have two adults.

The Zedish Community Service is organising a five-day Children's Camp. 46 children ( 26 girls and 20 boys) have signed up for the camp, and 8 adults ( 4 men and 4 women) have volunteered to attend and organise the camp.

Table 1. Adults

\begin{tabular}{l}
\hline Mrs Madison \\
\hline Mrs Carroll \\
\hline Ms Grace \\
\hline Ms Kelly \\
\hline Mr Stevens \\
\hline Mr Neill \\
\hline Mr Williams \\
\hline Mr Peters \\
\hline
\end{tabular}

Table 2. Dormitories

\begin{tabular}{l|c}
\hline Name & Number of beds \\
\hline Red & 12 \\
\hline Blue & 8 \\
\hline Green & 8 \\
\hline Purple & 8 \\
\hline Orange & 8 \\
\hline Yellow & 6 \\
\hline White & 6 \\
\hline
\end{tabular}

\section{Dormitory rules:}

1. Boys and girls must sleep in separate dormitories.

2. At least one adult must sleep in each dormitory.

3. The adult(s) in a dormitory must be of the same gender as the children.

\section{CHILDREN'S CAMP - Question 1}

\section{Dormitory Allocation}

Fill the table to allocate the 46 children and 8 adults to dormitories, keeping to all the rules.

\begin{tabular}{l|l|l|l} 
Name & Number of boys & Number of girls & Name(s) of adult(s) \\
\hline Red & & & \\
\hline Blue & & & \\
\hline Green & & & \\
\hline Purple & & & \\
\hline Orange & & & \\
\hline Yellow & & & \\
\hline White & & & \\
\hline
\end{tabular}


Unit: Children's Camp

Question: Question 1

Problem type: System analysis and design

Item type: Open-constructed response

Level: Level 2 (partial credit) and Level 3 (full credit)

PISA scale score: 529 (partial credit) and 650 (full credit)

Item code: $X 417 Q 01$
Student performances on Children's Camp indicated that two levels of performance could be distinguished. A full credit response was placed on the PISA problemsolving scale at 650 and a

partial response at 529. The full credit response was within the scale interval associated with Level 3 problem-solving performance. This was quite appropriate given the number of interrelated variables and relationships. A partial score response was associated with Level 2 of problem solving. The response coding guidelines for partial credit allows students to violate one or two of the conditions required for a full credit response to the item. As such, it is considerably less stringent in its demands on the problem solver, although it still requires the student to attend to the variables and carry out considerable combinatorial reasoning. However, the load in information processing and relational checking is smaller.

\section{Response Coding guide for CHILDREN'S CAMP Question 1}

Full Credit

Code 2: 6 conditions to be satisfied

- Total girls $=26$

- Total boys $=20$

- Total adults $=$ four female and four male

- Total (children and adults) per dormitory is within the limit for each dormitory

- People in each dormitory are of the same gender

- At least one adult must sleep in each dormitory to which children have been allocated

Partial Credit

Code 1: One or two conditions (mentioned in Code 2) violated. Violating the same condition more than once will be counted as one violation only.

- Forgetting to count the adults in the tally of the number of people in each dormitory.

- The number of girls and the number of boys are interchanged (number of girls $=20$, number of boys $=26$ ), but everything else is correct. (Note that this counts as two conditions violated.)

- The correct number of adults in each dormitory is given, but not their names or gender. (Note that this violates both condition 3 and condition 5.)

No Credit

Code 0: Other responses.

Code 9: Missing. 
Figures 4.11 and 4.12 contain a full and partial credit response, respectively. Note that in the partial credit response, the student has answered everything correctly with the exception of placing two girls in the White dormitory. The most common mistake leading to a code 1 response was to omit the adults from the count of people in each dormitory.

Figure 4.11 - Example of full credit response for Children's Camp, Question 1

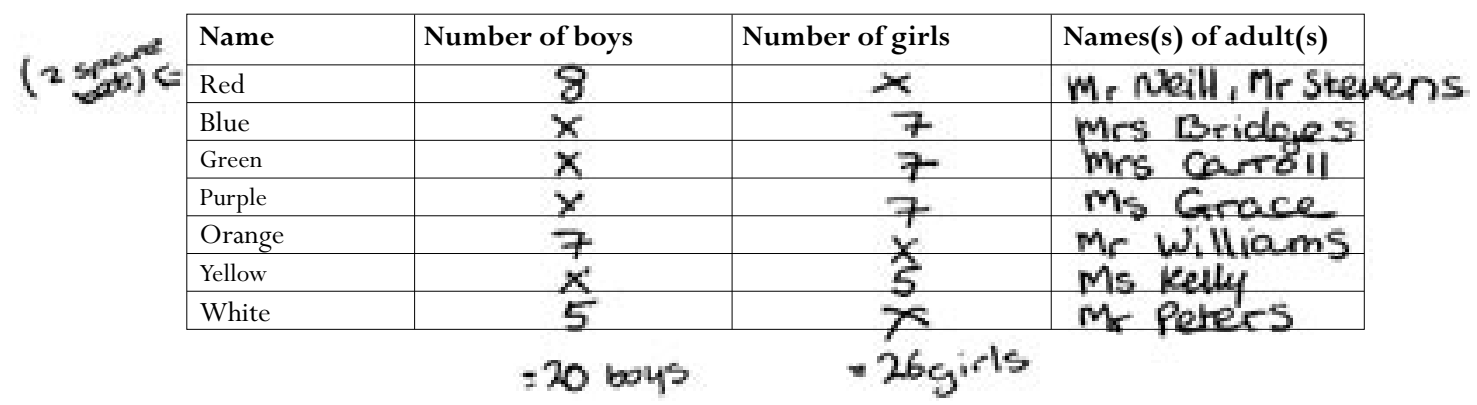

Figure 4.12 - Example of partial credit response for Children's Camp, Question 1

\begin{tabular}{|c|c|c|c|}
\hline Name & Number of boys & Number of girls & Names(s) of adult(s) \\
\hline Red & $\boldsymbol{\theta}$ & 10 & mpenclges apo \\
\hline Blue & 0 & 7 & \\
\hline Green & 0 & 7 & Kepe \\
\hline Purple & 7 & 0 & $m i n$ devens \\
\hline Orange & 7 & 0 & nir neik \\
\hline Yellow & 5 & 0 & mi williams. \\
\hline White & 1 & 2 & me Aokers. \\
\hline
\end{tabular}

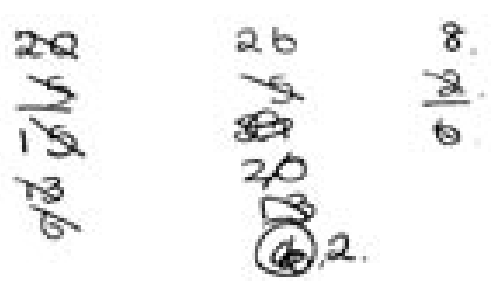

The partial credit response to Children's Camp shows the important role that re-evaluation and checking play in correctly responding to either a system analysis or a system design problem. All of the interrelated aspects of the system must be satisfied. 


\section{Trouble-shooting units}

The final two units comprising the PISA problem-solving assessment were drawn from the area of trouble shooting. These units have a total of five questions between them. The first problem has three questions and the second has two questions. Trouble-shooting units assess students' actions when confronted with a system or mechanism that is underperforming in some way. It may be a nonfunctioning appliance, such as a videotape recorder, or an appliance such as a sewing machine that just needs an adjustment to correct its performance.

To solve such problems, the student must be able to understand the main features of the system and the actions or responses that are expected of each of these features. Based on this understanding, the student must then be able to identify the causal-response relationships between interrelated parts and the role that such links play in the overall function of the mechanism or system of interest. The student can then diagnose the potential source of the present problem and propose and implement a potential remedy for the problem. Either action should then be evaluated or checked based on the available information for reasonableness or effective repair. Finally, students may need to communicate their solution in writing or through a diagram to explain their thinking and their recommended course of action. Such problems are complicated by the number of interrelated variables involved and the varied number of representations and translations that one might have to make in understanding the system or mechanism from directions or instruction booklets.

\section{IRRIGATION}

Irrigation was presented in Chapter 2 as an example of a trouble-shooting unit. It contains three questions and involves students in diagnosing the malfunctioning of an irrigation system designed to distribute water to crops on a farm. The system consists of a set of eight gates regulating flow along a system of canals. Each of the gates can either be open or closed. When a gate is closed, no water can flow through it.

Below is a diagram of a system of irrigation channels for watering sections of crops. The gates A to $\mathrm{H}$ can be opened and closed to let the water go where it is needed. When a gate is closed no water can pass through it.

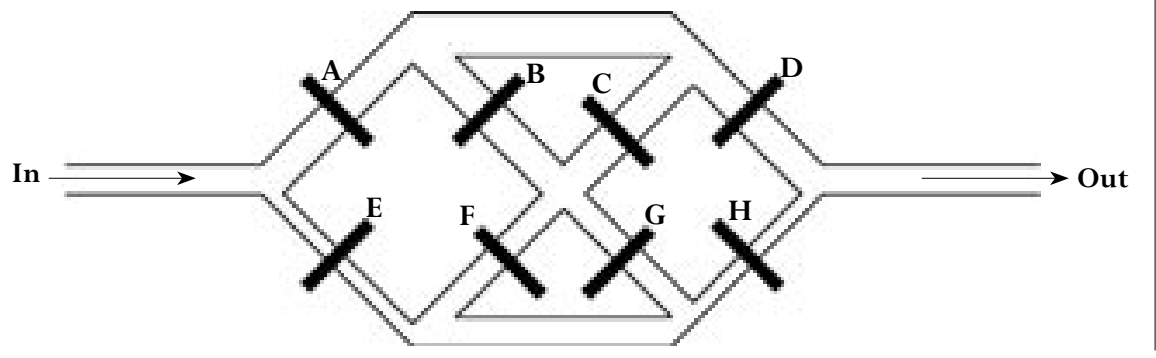


This is a problem about finding a gate which is stuck closed, preventing water from flowing through the system of channels.

Michael notices that the water is not always going where it is supposed to.

He thinks that one of the gates is stuck closed, so that when it is switched to open, it does not open.

\section{IRRIGATION - Question 1}

Michael uses the settings given in Table 1 to test the gates.

Table 1. Gate Settings

\begin{tabular}{c|c|c|c|c|c|c|c}
$\mathbf{A}$ & $\mathbf{B}$ & $\mathbf{C}$ & $\mathbf{D}$ & $\mathbf{E}$ & $\mathbf{F}$ & $\mathbf{G}$ & $\mathbf{H}$ \\
\hline Open & Closed & Open & Open & Closed & Open & Closed & Open \\
\hline
\end{tabular}

With the gate settings as given in Table 1, on the diagram below draw all the possible paths for the flow of water. Assume that all gates are working according to the settings.

\section{IRRIGATION - Question 2}

Michael finds that, when the gates have the Table 1 settings, no water flows through, indicating that at least one of the gates set to open is stuck closed.

Decide for each problem case below whether the water will flow through all the way. Circle "Yes" or "No" in each case.

\begin{tabular}{l|c} 
Problem Case & Will water flow through all the way? \\
\hline $\begin{array}{l}\text { Gate } \mathbf{A} \text { is stuck closed. All other gates } \\
\text { are working properly as set in Table 1. }\end{array}$ & Yes / No \\
\hline $\begin{array}{l}\text { Gate } \mathbf{D} \text { is stuck closed. All other gates } \\
\text { are working properly as set in Table 1. }\end{array}$ & Yes / No \\
\hline $\begin{array}{l}\text { Gate } \mathbf{F} \text { is stuck closed. All other gates } \\
\text { are working properly as set in Table 1. }\end{array}$ & Yes / No \\
\hline
\end{tabular}

\section{IRRIGATION - Question 3}

Michael wants to be able to test whether gate $\mathbf{D}$ is stuck closed.

In the following table, show settings for the gates to test whether gate $\mathbf{D}$ is stuck closed when it is set to open.

Settings for gates (each one open or closed)

\begin{tabular}{l|l|l|l|l|l|l|l}
$\mathbf{A}$ & $\mathbf{B}$ & $\mathbf{C}$ & $\mathbf{D}$ & $\mathbf{E}$ & $\mathbf{F}$ & $\mathbf{G}$ & $\mathbf{H}$ \\
\hline & & & & & & & \\
\hline
\end{tabular}


Unit: Irrigation

Question: Question 1

Problem type: Trouble shooting

Item type: Open-constructed response

Level: Level 1

PISA scale score: 497

Item code: $X 603001$
The first question poses an investigation for the students. The results show their understanding of the system of gates and the way(s) in which water flows through the system. The response mode for this question is different from that for other problems in the set. Students

have to draw (on the figure provided) the possible paths for water to flow through the system. A correct response is an indication that students are able to note the main features of the system, the gates and the canals, and their states, open/flowing or closed/not flowing. This is the information needed to begin to trouble shoot the system in the following problems.

\section{Response Coding guide for IRRIGATION Question 1}

Full Credit

Code 1: Flow paths as shown below:

Response Coding notes:

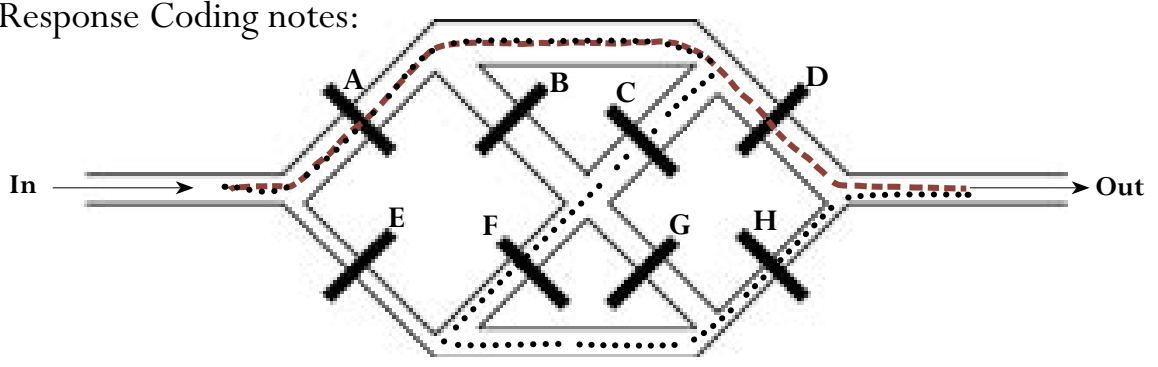

Ignore any indications of the directions of flow.

Note that the response could be shown IN THE DIAGRAM PROVIDED, OR IN FIGURE 1, OR IN WORDS, OR WITH ARROWS.

No Credit

Code 0: Other responses.

Code 9: Missing.

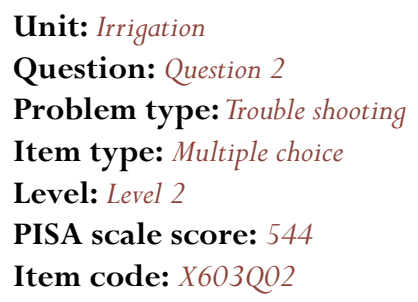

the gate settings are as in Question 1, except that (in each case) one of the gates that is supposed to be open is closed. This raises the problem-solving demands of the problem and shifts to Level 2, as students have to apply reasoning to analyse each of the gate settings and make a decision about whether water will flow all of the way through the system. A correct response requires students to examine the system anew and separate each analysis from the prior and subsequent analyses. 


\section{Response Coding guide for IRRIGATION Question 2}

Full Credit

Code 1: No, Yes, Yes, in that order.

No Credit

Code 0: Other responses.

Code 9: Missing.

Unit: Irrigation

Question: Question 3

Problem type: Trouble shooting

Item type: Open-constructed response

Level: Level 2

PISA scale score: 532

Item code: $X 603003$
The third irrigation question requires students to develop a test to determine whether gate $\mathrm{D}$ is stuck closed. To answer the question correctly, the student must decide on appropriate settings for the gates, knowing the inflow and outflow states of the irrigation system. This is a

Level 2 question, as it is slightly easier than Question 2. While the overall item demands are greater in Question 3, Question 2 involves multiple parts which must all be answered correctly to get the item correct.

\section{Response Coding guide for IRRIGATION Question 3}

Full Credit

Code 1: A and E are not both closed. D must be open. $\mathrm{H}$ can only be open if water cannot get to it (e.g. other gates are closed preventing water from reaching $\mathrm{H}$ ). Otherwise $\mathrm{H}$ must be closed.

- H closed, all other gates open

No Credit

Code 0: Other responses.

Code 9: Missing. 


\section{FREEZER}

The second trouble-shooting unit has two questions. This unit deals with diagnosing a probable cause for a malfunctioning home freezer unit. Students confronting this situation have to operate as the freezer user would in the situations described. Information is given in a manual and feedback from the mechanism, in this case the freezer, comes from observing a warning light, the state of the temperature control, and external indications that power is reaching the freezer motor. This problem is clearly one of diagnosing probable causes of a malfunctioning mechanism and hence is a classic trouble-shooting problem.

Jane bought a new cabinet-type freezer. The manual gave the following instructions:

- Connect the appliance to the power and switch the appliance on.

- You will hear the motor running now.

- A red warning light (LED) on the display will light up.

- Turn the temperature control to the desired position. Position 2 is normal.

\begin{tabular}{c|c} 
Position & Temperature \\
\hline 1 & $-15^{\circ} \mathrm{C}$ \\
\hline 2 & $-18^{\circ} \mathrm{C}$ \\
\hline 3 & $-21^{\circ} \mathrm{C}$ \\
\hline 4 & $-25^{\circ} \mathrm{C}$ \\
\hline 5 & $-32^{\circ} \mathrm{C}$ \\
\hline
\end{tabular}

- The red warning light will stay on until the freezer temperature is low enough. This will take 1 - 3 hours, depending on the temperature you set.

- Load the freezer with food after four hours.

Jane followed these instructions, but she set the temperature control to position 4. After four hours, she loaded the freezer with food.

After eight hours, the red warning light was still on, although the motor was running and it felt cold in the freezer.

\section{FREEZER - QUESTION 2}

Jane wondered whether the warning light was functioning properly. Which of the following actions and observations would suggest that the light was working properly?

Circle "Yes" or "No" for each of the three cases.

\begin{tabular}{l|c} 
Action and Observation & $\begin{array}{c}\text { Does the observation suggest that the } \\
\text { warning light was working properly? }\end{array}$ \\
\hline $\begin{array}{l}\text { She put the control to position } 5 \\
\text { and the red light went off. }\end{array}$ & Yes / No \\
\hline $\begin{array}{l}\text { She put the control to position } 1 \\
\text { and the red light went off. }\end{array}$ & Yes / No \\
\hline $\begin{array}{l}\text { She put the control to position } 1 \\
\text { and the red light stayed on. }\end{array}$ & Yes / No \\
\hline
\end{tabular}


FREEZER - Question 1

Jane read the manual again to see if she had done something wrong. She found the following six warnings:

1. Do not connect the appliance to an unearthed power point.

2. Do not set the freezer temperatures lower than necessary $\left(-18^{\circ} \mathrm{C}\right.$ is normal).

3. The ventilation grills should not be obstructed. This could decrease the freezing capability of the appliance.

4. Do not freeze lettuce, radishes, grapes, whole apples and pears, or fatty meat.

5. Do not salt or season fresh food before freezing.

6. Do not open the freezer door too often.

Ignoring which of these six warnings could have caused the delay in the warning light going out?

Circle "Yes" or "No" for each of the six warnings.

\begin{tabular}{c|c} 
Warning & $\begin{array}{c}\text { Could ignoring the warning have caused a delay in } \\
\text { the warning light going out? }\end{array}$ \\
\hline Warning 1 & Yes / No \\
\hline Warning 2 & Yes / No \\
\hline Warning 3 & Yes / No \\
\hline Warning 4 & Yes / No \\
\hline Warning 5 & Yes / No \\
\hline Warning 6 & Yes / No \\
\hline
\end{tabular}

Unit: Freezer

Question: Question $2^{1}$

Problem type: Trouble shooting

Item type: Multiple choice

Level: Level 2

PISA scale score: 573

Item code: $X 423 Q 02$

1. The numbering of the question here with Q2 preceding Q1 is only a reference to the order in which the questions were placed in the PISA assessment relative to how they were developed for the Field Trial. After the Field Trial, the order of the questions in the unit was reversed, but their original numbering was maintained for administrative purposes.
This question about the freezer problem called for students to diagnose the working of the warning light. Working through the three tests proposed, a student should indicate that moving the control to a warmer setting than the present one and getting the light to go off would potentially indicate that the freezer was still cooling down and had not yet reached the desired temperature at the present setting. Actions 1 and 3 would not provide information suggesting that the warning light was working properly. Getting these three answers correct is a Level 2 problemsolving task. 


\section{Response Coding guide for FREEZER Question 2}

Full Credit

Code 1: No, Yes, No, in that order.

No Credit

Code 0: Other responses.

Code 9: Missing.

Unit: Freezer

Question: Question 1

Problem type: Trouble shooting

Item type: Multiple choice

Level: Level 2

PISA scale score: 551

Item code: $X 423 Q 01$
Another freezer question further extended the trouble shooting process, posing a series of six options with yes-no responses. Here the student is confronted with a series of warnings from the manual associated with freezer malfunctioning. The student is then asked to determine which of these

warnings might be associated with a delay in the warning light turning off. This item was also judged to be at Level 2 as each of the decisions is based essentially on a single piece of information and its relationship to the mechanism. The question draws on a student's outside experience with freezers or similar appliances at a common sense level of knowledge that leads one to dismiss possible causes as irrelevant to a given situation.

\section{Response coding guide for FREEZER question 1}

Full Credit

Code 2: No, Yes, Yes, No, No, Yes, in that order.

Partial Credit

Code 1: One error.

No Credit

Code 0: Other responses.

Code 9: Missing. 


\section{Summary}

The 19 problems and 28 possible performance coding levels contained in the PISA cross-disciplinary problem-solving assessment provide a foundation for viewing students' problem solving in the three situations investigated: decision making, system analysis and design, and trouble shooting. Comparing the results with the model presented in Figure 2.1 of Chapter 2, shows how the characteristics of the problem types were carried through into the design of the stimulus materials and the items in each unit. Further, the potential sources of difficulty for items noted in the framework were indeed witnessed in the PISA problems in practice.

Figure 4.13 shows the range of scores associated with full credit in the questions belonging to each of the three problem types. This shows a decreasing range of score values as one moves from decision-making to system analysis and design to trouble-shooting problems. There is also a convergence of item difficulty around the middle of the scale, rather than at its extremes, as one moves across the problem types.

\section{Figure 4.13 - Graph of PISA problem-solving item scale values by problem type}

Although some problem types have a wider difficulty range than others...

These items and the way students responded show how problems differ in difficulty and type.

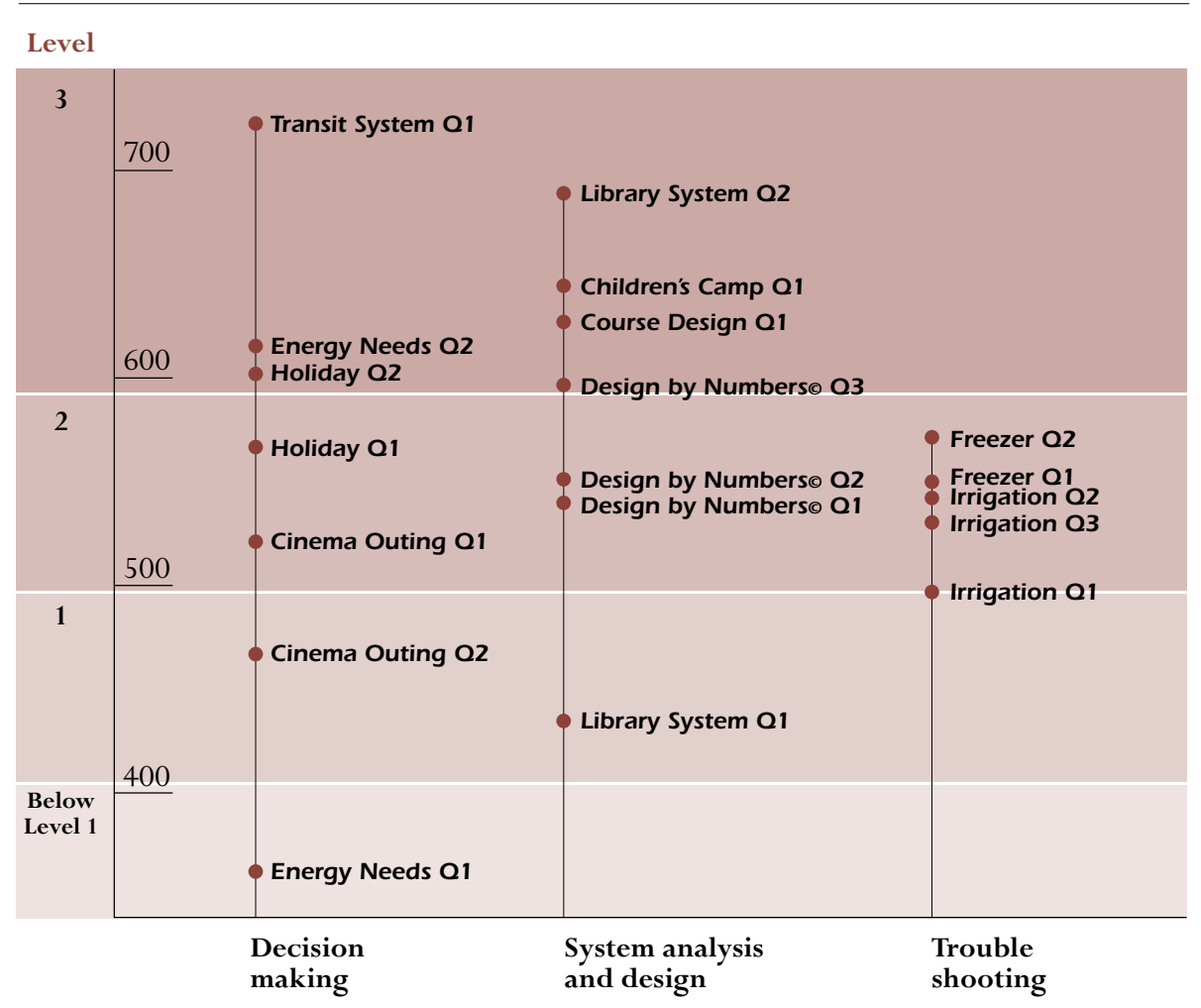

The analysis of the item performance indicates that the items between them cover the domain of problem solving as described in Chapter 2 and provide examples ...overall they cover the of student performance across the full range of the scale, from understanding domain as required. problems to the solution of problems and the communication of results. 


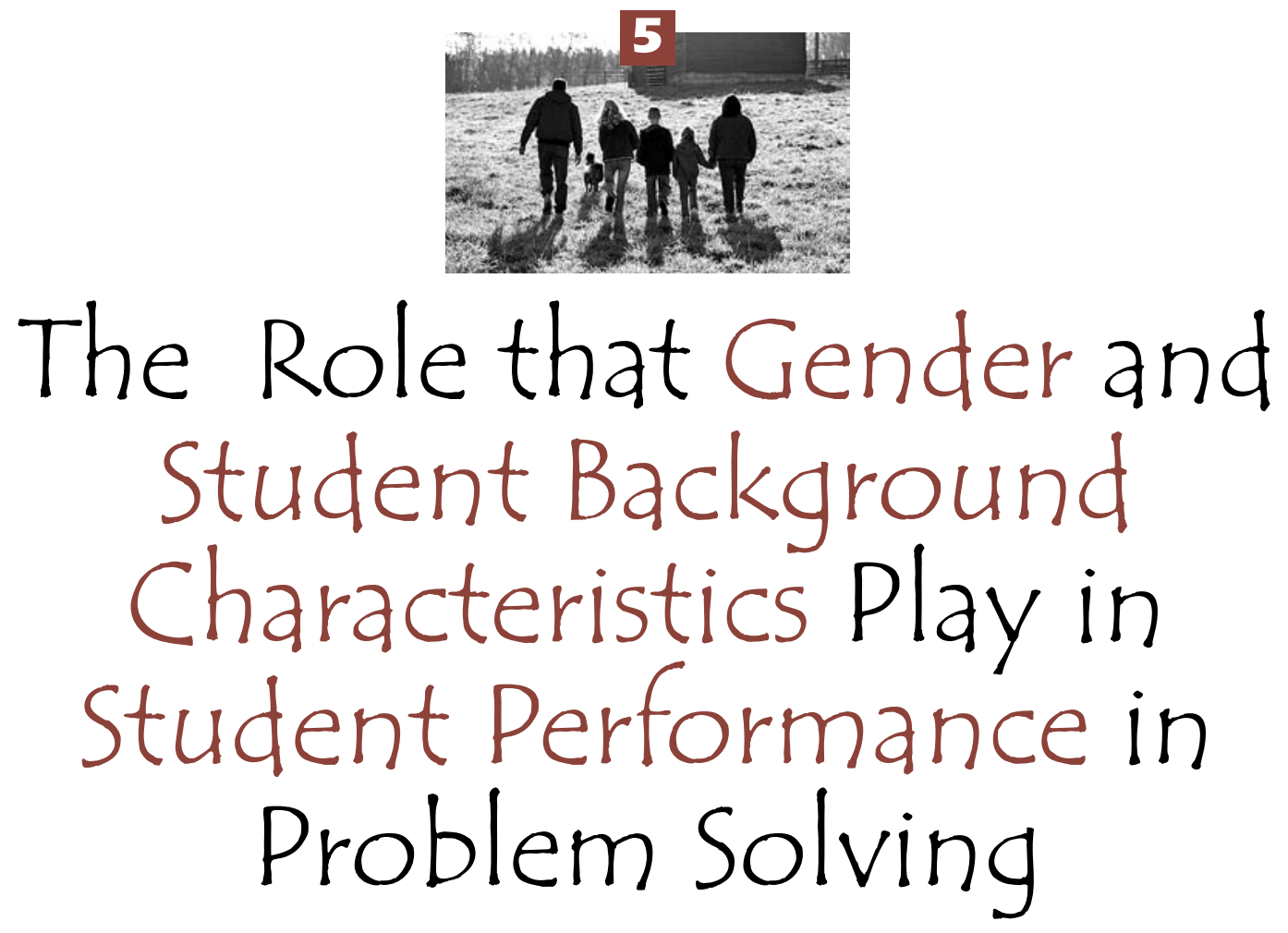

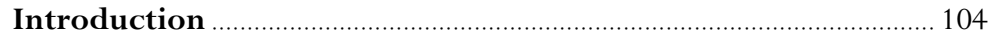

Gender differences in problem solving ........................................... 104

Comparison with gender differences in other assessment areas ..... 107

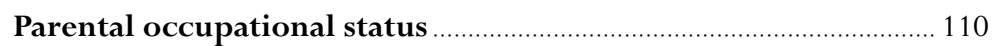

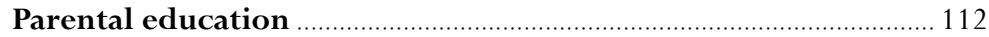

Possessions related to "classical" culture …………............................ 113

Family structure ……………………………………………................ 115

Place of birth and language spoken at home

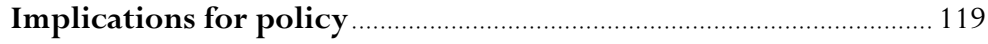


This chapter looks at how both gender and student background relate to performance.

Some recent studies have shown that females' historical disadvantage in mathematics performance is changing...

...although males are still ahead in mathematics, but behind in reading.

Are male strengths in mathematics reflected in a better general ability to solve problems?

\section{Introduction}

This chapter discusses how gender and student background characteristics relate to student performance in problem solving.

The PISA problem-solving tasks are intended to parallel situations in life and do not draw on specific curriculum knowledge. Therefore the effects of family, socio-economic and cultural background are particularly worth noting. Ideally, the future opportunities of any student should not depend on their socioeconomic background. If students with less-advantaged backgrounds are less proficient at solving problems, they may risk difficulties in the transition to work or further education. These difficulties can then perpetuate social disparities from one generation to the next.

This chapter explores the relationships between problem-solving performance and a variety of student, family, and social factors. It compares gender differences in problem-solving performance and in other PISA assessment areas and then considers the impact of students' background characteristics on their problemsolving performance. These analyses include the occupational status of parents, the education of parents, "cultural" features and the immigration status of students and their parents. Most of these background variables have been shown to affect student performance in various assessment areas.

\section{Gender differences in problem solving}

Given the importance education has on future opportunities in the life of an individual, all countries try to minimise gender-specific disadvantages for females or males in their education systems. Historically, this concern focused on gender-specific disadvantages affecting females. In recent studies, however, females have closed some gaps and even outperformed their male peers in some assessment areas.

Consequently, the underachievement of males has now also become a focus of educational research and policy development. Performance differences between female and male students found in recent international comparisons of student performance vary according to the assessment area. For instance, females generally outperformed males in reading while males tended to outperform females in mathematics (see also Learning for Tomorrow's World - First Results from PISA 2003, [OECD, 2004a]).

It is not clear whether one should expect there to be a gender difference in problem solving. On the one hand, the questions posed in the PISA problemsolving assessment were not grounded in content knowledge, so males' or females' advantage in having mastered a particular subject area should not have shown through. On the other hand, as demonstrated in Chapter 3, there is a strong link between the analytical reasoning skills needed in mathematics and those needed in problem solving, and there is also a strong correlation between the results of these two PISA assessment areas. The extent to which the advantage 
of male students in mathematics performance is replicated in problem solving may therefore give clues as to whether males do better in mathematics because they have mastered the subject better or because they have particular generic skills that help them solve mathematical problems.

Figure 5.1 shows the observed differences between the mean performance of female students and that of male students on the PISA problem-solving assessment. The length of the bars indicates the difference between genders on the problem-solving scale (to the right they show male students performing better, while to the left, they show female students performing better).

Figure 5.1 shows the differences between the mean performances of female and male students...

Figure 5.1 Gender differences in student performance in problem solving

Gender differences statistically significant $\quad$ Gender differences not statistically significant

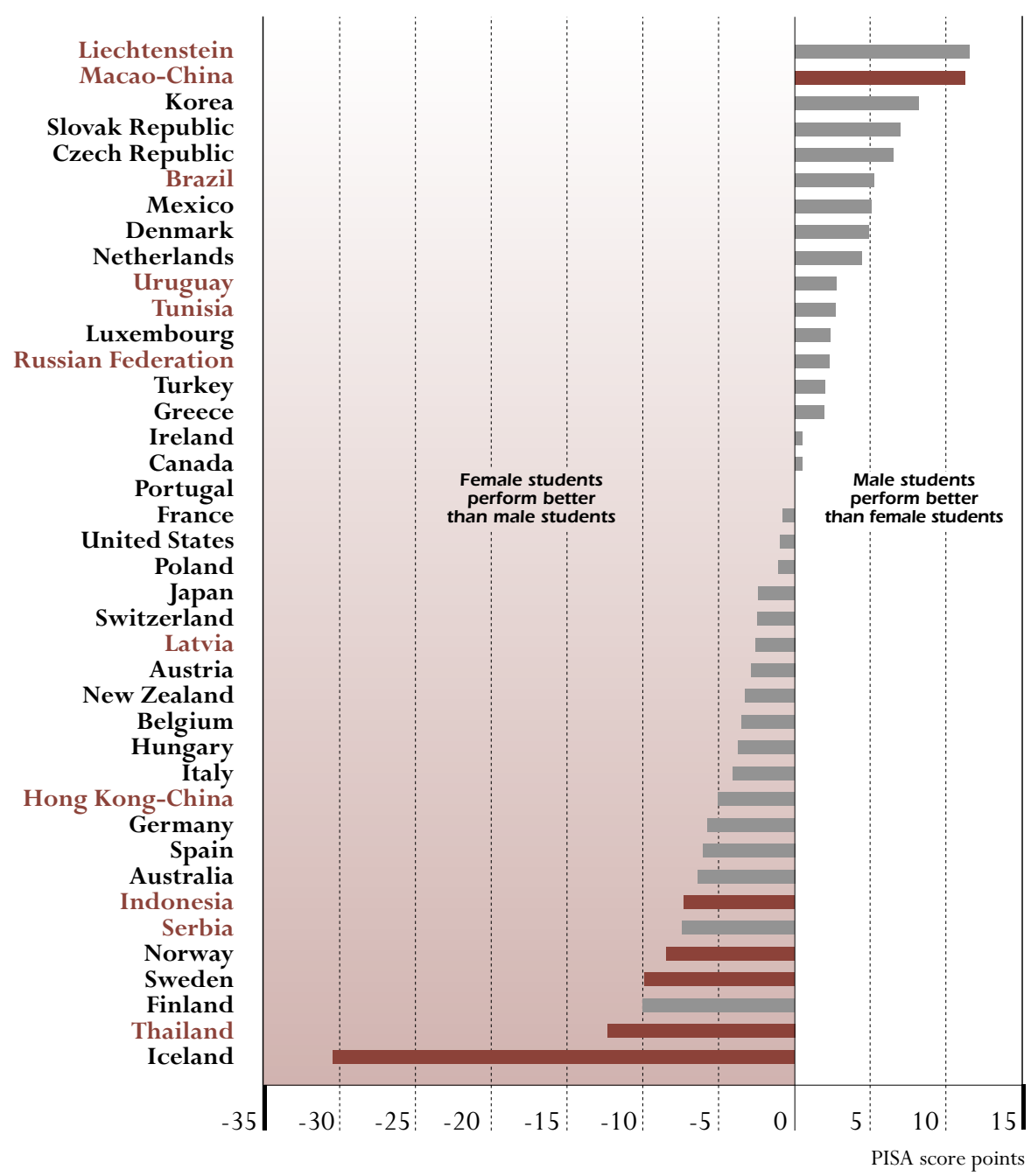

Countries are ranked in descending order of performance advantage for male students.

Source: OECD PISA 2003 database, Table 5.1. 
... and indicates only minor gender differences in problem solving, with these slightly in favour of females overall.

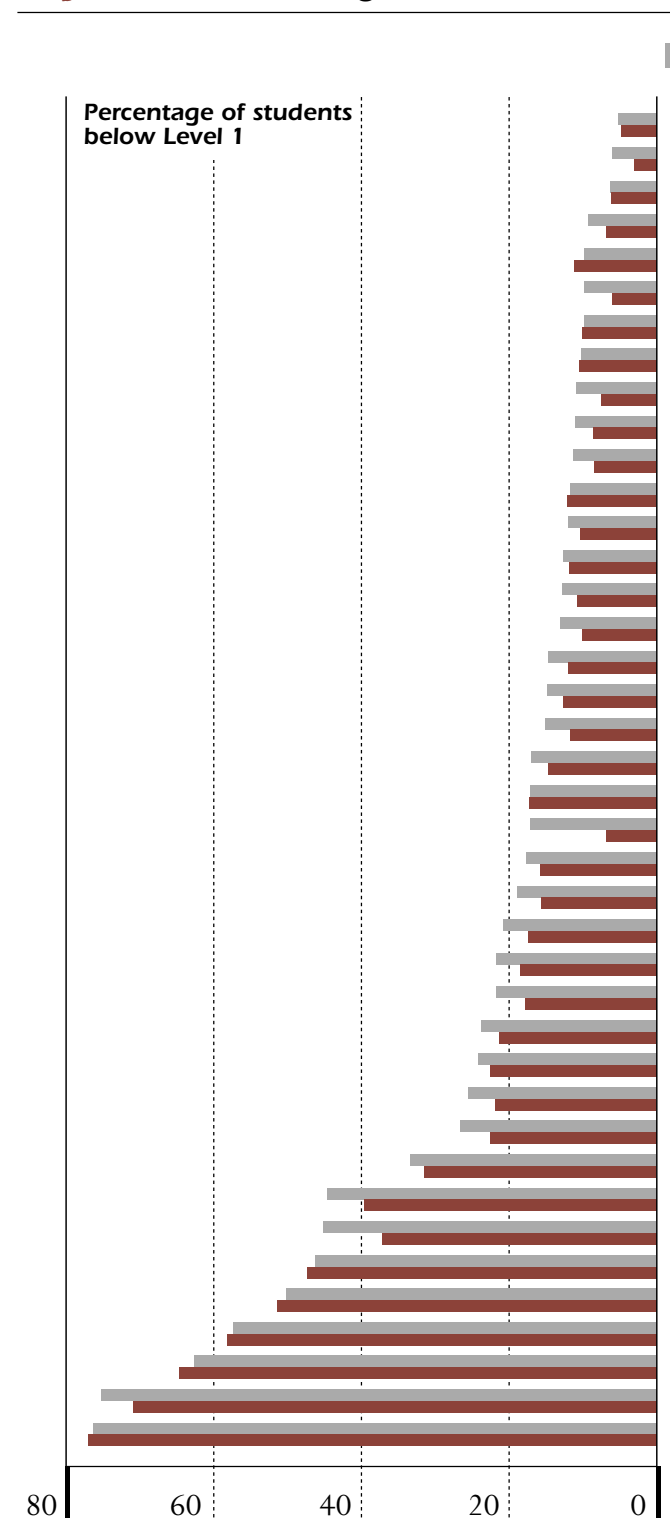

Strikingly, few countries show statistically significant gender differences in problem solving. In Iceland, Norway and Sweden, as well as in the partner countries Indonesia and Thailand, female students outperform male students in problem solving. The partner country Macao-China is the only country where male students outperform female students in problem solving. As in mathematics and reading (see Table 5.1), in Iceland the advantage that female students have in problem solving is by far the largest compared to the other participating countries: female students score 30 points more than male students, representing a third of a proficiency level. However, in the remaining countries the largest gap in either direction is 12 score points or less.

\section{Figure 5.2 Percentage of males and females performing below Level 1 and at Level 3 in problem solving}

Males Females

Korea
Finland
Macao-China
Canada
Netherlands

Hong Kong-China

Liechtenstein

Denmark

Australia

New Zealand

Japan

Czech Republic

Switzerland

Ireland

Sweden

France

Belgium

Germany

Austria

Hungary

Slovak Republic

Iceland

Luxembourg

Poland

Norway

Latvia

Spain

Russian Federation

United States

Portugal

Italy

Greece

Serbia

Thailand

Uruguay

Turkey

Mexico

Brazil

Indonesia

Tunisia

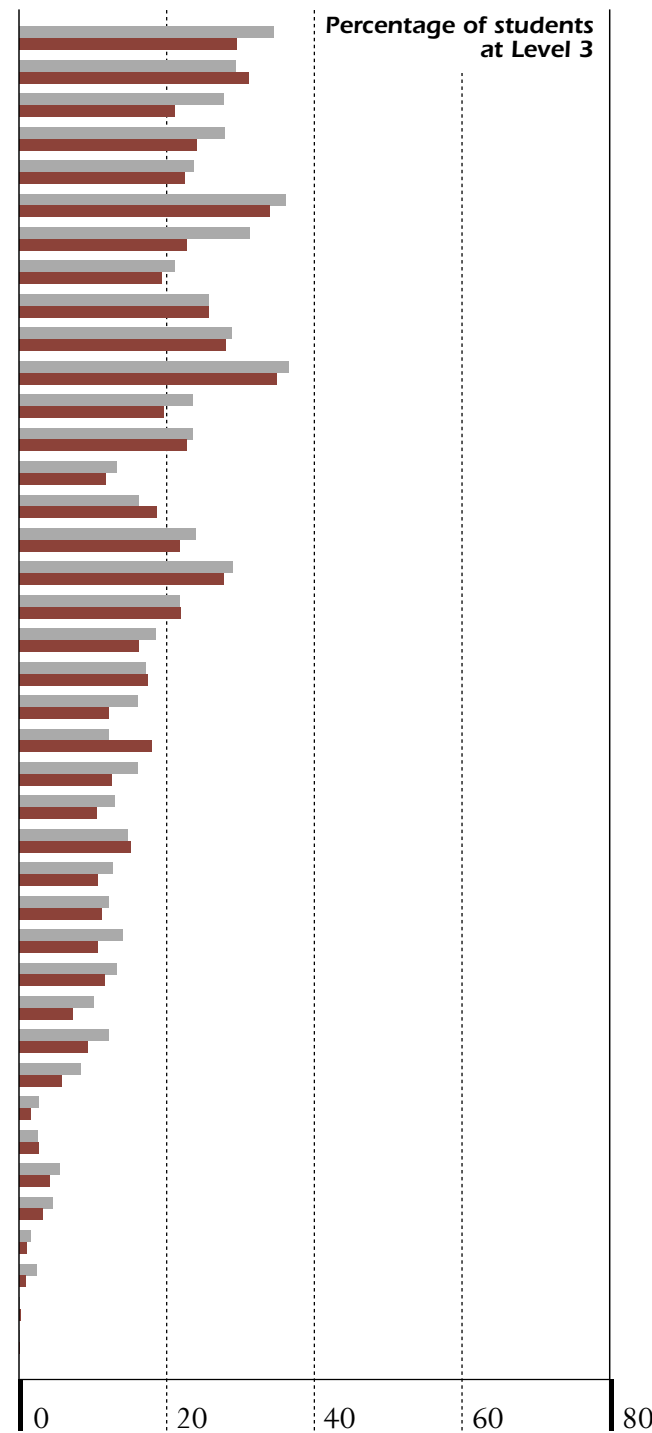

Countries are ranked in ascending order of the percentage of males performing below Level 1 on the problem-solving scale. Source: OECD PISA 2003 database, Table 5.1. 
Figure 5.2 shows the percentage of male and female students who are below Level 1 (basic problem solvers) and who are proficient at Level 3 (reflective, communicative problem solvers).

This comparison shows that typically in participating countries, there are slightly more male students at the lowest and at the highest proficiency level. On average in OECD countries, 18 per cent of male students and 16 per cent of female students are below Level 1, while 19 per cent of male students and 18 per cent of female students reach Level 3. Thus, while male and female students do not differ markedly in their average problem-solving performance, the performance of male students overall is more spread out towards the extremes. This is more obviously so in some countries than in others - for example in Italy, a third more male than female students (12 per cent rather than 9 per cent) have the highest problemsolving skills, while a sixth more males (27 per cent rather than 23 per cent) lack basic problem-solving skills. Male students are not over-represented at both extremes in every country, but in all countries there are more male students in at least one of these categories. Moreover, a systematic measure of the variability in performance, the standard deviation, shows that male performance is more dispersed in every country except in the partner country Indonesia. On average in the OECD countries, the standard deviation for male students is 6 score points higher than for female students. This difference is most pronounced in Italy (the standard deviation for female students is 94 score points and the standard deviation for male students is 110 score points), as well as in the partner country Hong Kong-China (the standard deviation for female students is 90 score points and the standard deviation for male students is 104 score points). The standard deviation for male students is at least 12 score points higher than for female students in Poland, Portugal, Turkey and the partner country Liechtenstein.

\section{Comparison with gender differences in other assessment areas}

As reported in Chapter 3, performance in problem solving is closely related to performance in mathematics. The comparison of gender differences in these two assessment areas becomes particularly interesting since male students outperform female students in mathematics in most participating countries (see Table 5.1), whereas there are no pronounced gender differences in problem-solving performance. Figure 5.3 shows the relationship between gender differences in mathematics (horizontal axis) and gender differences in problem solving (vertical axis) among countries.

In half the countries gender differences are consistent in mathematics and in problem solving (see Figure 5.3). In countries with the largest advantage of male students in mathematics, such as Korea and the partner country Liechtenstein, male students also perform better than female students in problem solving (though not statistically significantly so). In Iceland and the partner country Thailand, where female students outperform male students in mathematics, as well as in countries with low gender differences in mathematics (e.g. the partner countries Indonesia, Latvia and Serbia ${ }^{1}$ ), female students outperform male students in problem solving (statistically significantly so in Iceland, Indonesia and Thailand).
A review of gender differences at the highest and lowest proficiency levels...

...shows that there are slightly more males among both the strongest and the weakest problem solvers.

Male students' advantage in mathematics does not translate into stronger problem-solving skills...

...although in many countries males do relatively better in the two assessment areas. 
Figure 5.3 Gender differences in problem solving and in mathematics

Statistically significant gender differences in problem solving and mathematics
Statistically significant gender differences only in problem solving
Statistically significant gender differences only in mathematics
Gender differences in problem solving and mathematics are not statistically significant

Gender differences in problem solving

(Score point differences)

15

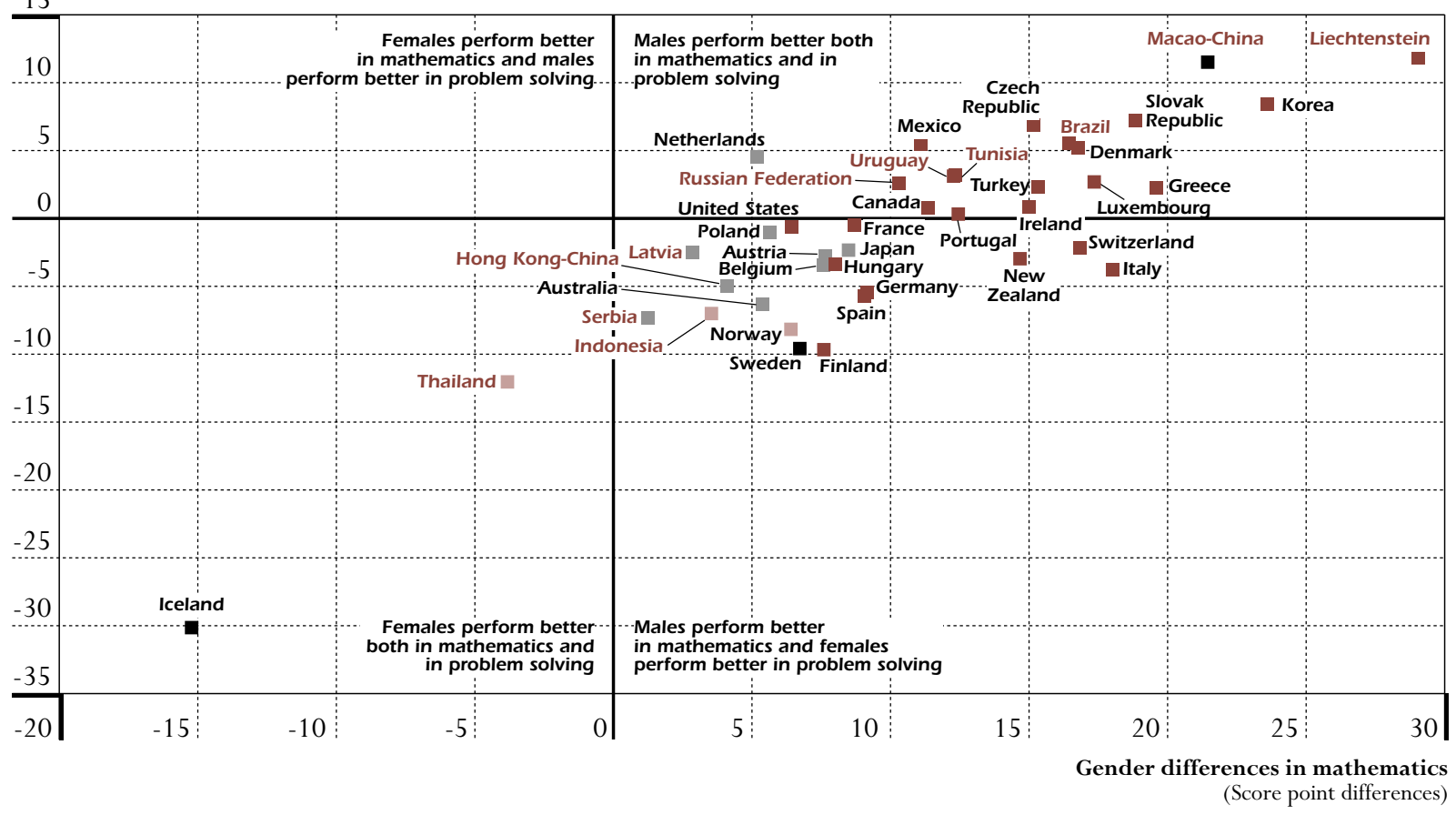

Positive values indicate that males perform better than females.

Source: OECD PISA 2003 database, Table 5.1.

Where female advantages in reading are strongest, female students also do relatively better in problem solving.
Figure 5.4 shows the relationship between gender differences in problem solving and gender differences in reading across countries. As when comparing problem solving to mathematics, the countries in which female students or male students do relatively better are similar across the two assessment areas. Even though the female reading advantage is not replicated in most countries for problem solving, where the female advantage in reading is relatively large such as Finland, Iceland and Norway, female students are also better problem solvers (statistically significantly so in Iceland and Norway). In Korea, the Netherlands and Mexico, as well as in the partner countries Liechtenstein and Macao-China, the advantage for female students in reading was relatively lower than in other countries and the advantage for female students disappears in problem solving (although the male advantage is only statistically significant in Macao-China). However, in Austria and Germany female students have a large advantage in reading, but their advantage in problem solving is small and not statistically significant. 
Statistically significant gender differences in problem solving and reading
- Statistically significant gender differences only in reading
Gender differences in problem solving and reading are not statistically significant

Gender differences in problem solving

(Score point differences)
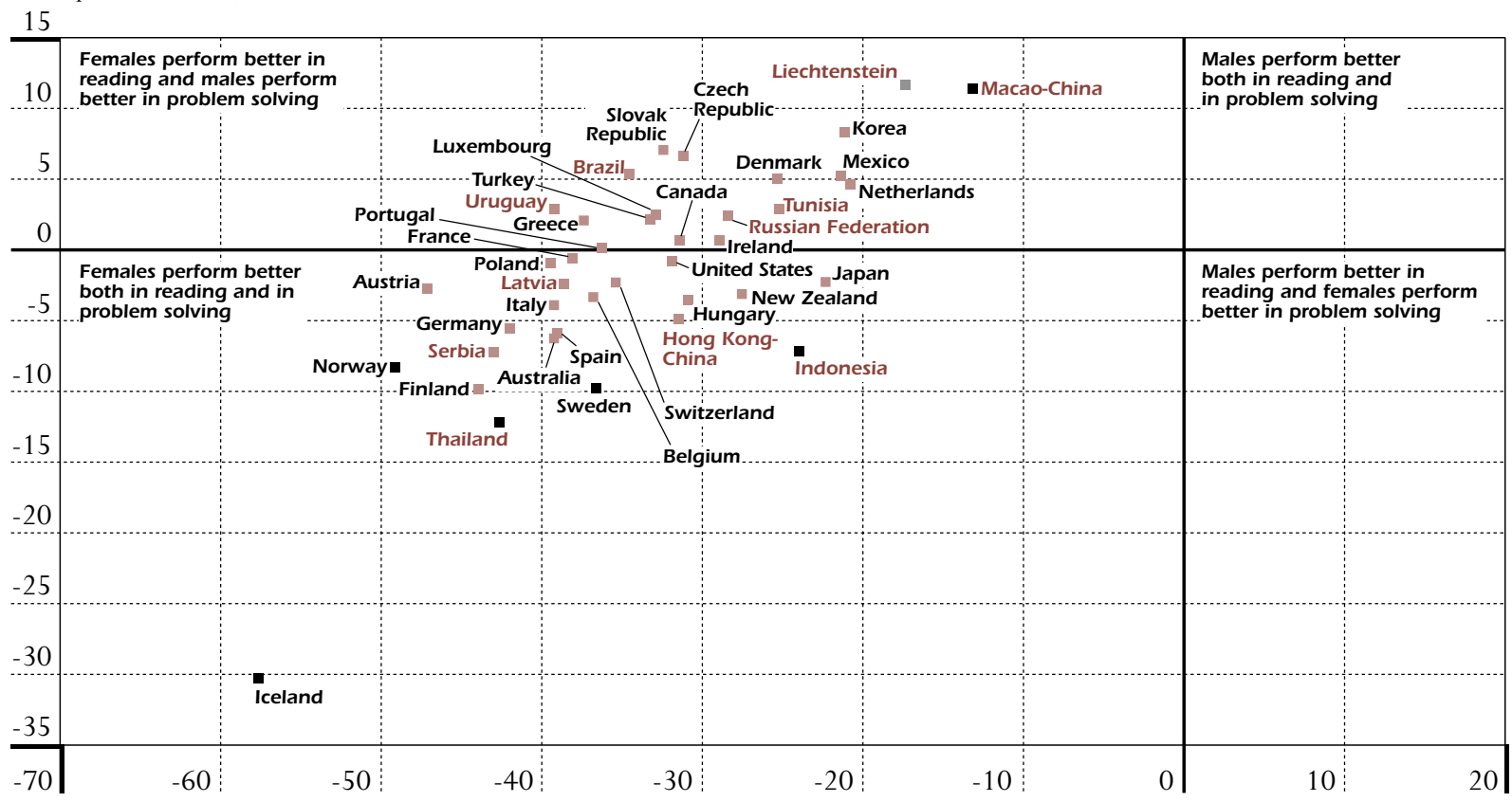

Gender differences in reading (Score point differences)

Positive values indicate that males perform better than females.

Source: OECD PISA 2003 database, Table 5.1.

Overall, a comparison of the different assessment areas shows gender differences to vary by area: Female students outperform their male peers in reading performance and male students reach somewhat higher levels of performance in mathematics. In contrast, in the majority of participating countries male and female students do not differ significantly in problem-solving performance, which is conceptualised to make cross-disciplinary demands on students' competencies. This may indicate that female and male students can draw on their own specific strengths when it comes to cross-disciplinary tasks. Male students' strengths in mathematics do not appear to derive from a superiority in analytical reasoning skills that has a disproportionate effect on general problem-solving abilities. Rather, genderspecific strengths seem to balance out in a way that leads to relatively equal outcomes for both genders in problem-solving performance. Moreover, the result may be viewed as an indication that in many countries there are no strong overall disadvantages for male students or female students as learners, but merely genderspecific strengths or preferences for certain subjects.
Thus it appears that neither gender is disadvantaged overall in problem solving, but each draws on their strengths. 
Nevertheless, variations

in gender differences remain important...

...with some countries better at containing them than others.

Comparing students' problem-solving performance with parents' occupational status gives an important indicator of social disadvantage.

How much difference does parental occupational status make on average to student scores?
However, this does not mean that gender differences do not matter. First, it is important to note that, as in PISA 2000, the size of gender differences in reading in favour of female students is markedly larger than the gender differences in mathematics in favour of male students. In addition, the high consistency of the relative size of a country's gender differences across the PISA assessment areas indicates that in some countries there are still general advantages for one of the genders, e.g. for female students in Iceland.

Second, note that some countries have been much more successful than others in achieving equal performance for male and female students in each assessment area. In the Netherlands, for instance, the only significant performance difference is a comparatively small one of 21 score points in reading performance in favour of female students, while no significant differences are found in mathematics or problem solving. In Greece and Italy, on the other hand, large advantages for female students in reading (37 and 39 score points respectively) and large advantages for male students in mathematics (19 and 18 score points respectively) are found within the same countries. However, these subjectspecific differences disappear in problem-solving performance: there is no significant gender difference for problem solving in Greece or Italy. PISA cannot show what is behind these performance differences, but it may be of interest to some education systems to encourage male and female students in the areas where they are significantly outperformed by the other gender.

\section{Parental occupational status}

Parental occupational status, which is often closely interrelated with other attributes of socio-economic status, has a strong association with student performance. Generally, countries are interested in minimising such disparities. PISA problem-solving performance reflects the capability to deal with crossdisciplinary tasks that approximate real-life situations. Therefore it is a useful indicator of students' chances to successfully manage future challenges in life.

The average performance gap in problem solving between students in the top quarter of PISA's international socio-economic index of occupational status (whose parents have occupations in fields such as medicine, university teaching and law) and those in the bottom quarter (with occupations such as smallscale farming, truck-driving and serving in restaurants), amounts to an average of 76 score points, or four-fifths of a proficiency level in problem solving. ${ }^{2}$ Expressed differently, one standard deviation (i.e. 16.4 units) on the PISA index of occupational status is associated with an average performance difference of 33 score points. Figure 5.5 shows the mean problem-solving performance for students in each quarter of the PISA index of occupational status. The length of the different lines represents the gap between students in the highest and lowest quarters of parental occupational status within each country.

Within OECD countries, students in the top national quarters on the international socio-economic index of occupational status reach a mean score of 542 score 


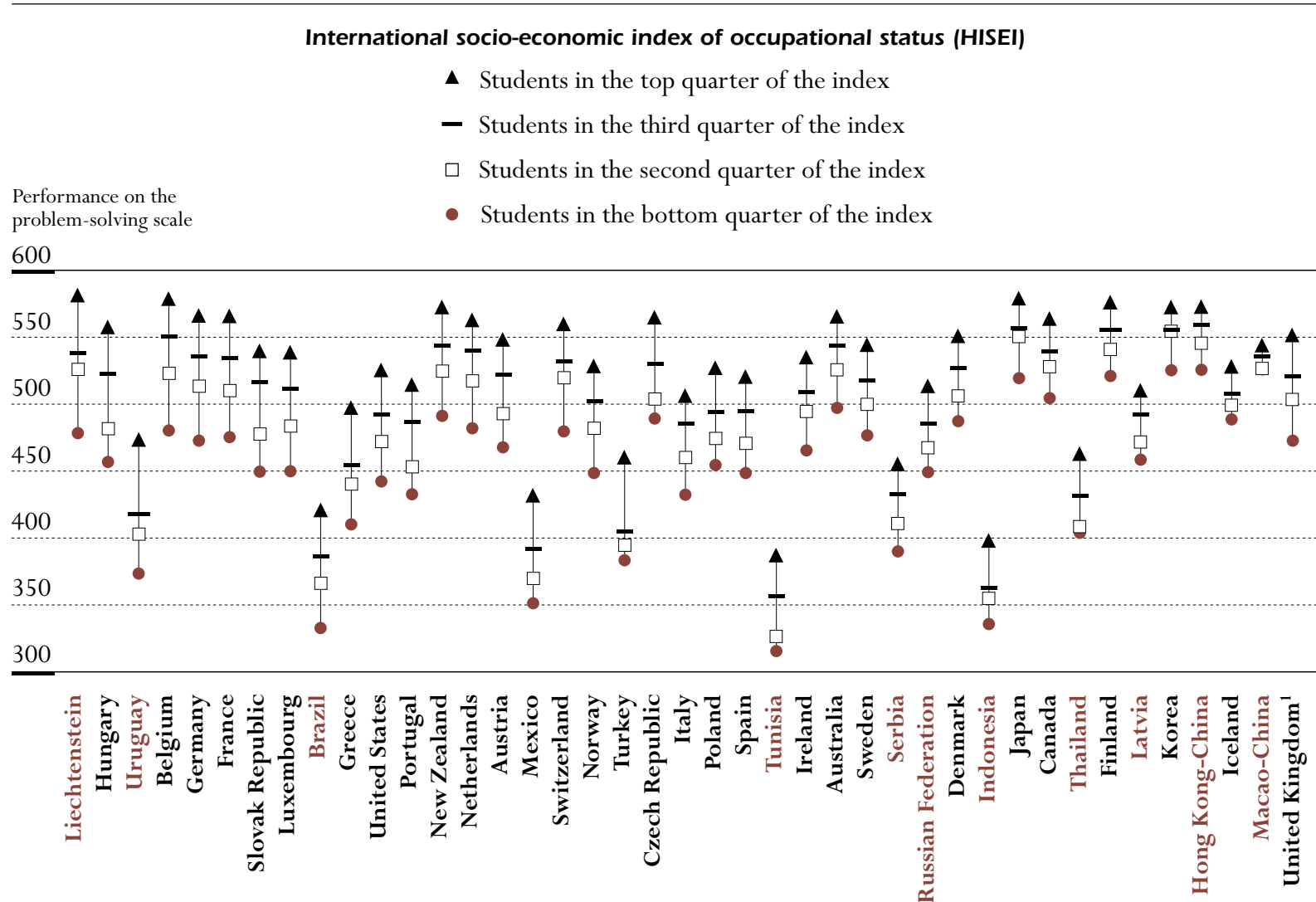

Countries are ranked in descending order of the difference in performance between students in the top and bottom quarters of the international socio-economic index of occupational status (HISEI).

1. Response rate too low to ensure comparability (see Annex A3).

Source: OECD PISA 2003 database, Table 5.2.

points on the problem-solving scale, or 42 score points above the OECD average. The average mean score in OECD countries for students in the bottom national quarters is only 465 score points. This means that students with parents in lower status occupations perform on average at the level of basic problem solvers (Level 1), while students with parents in higher status occupations perform on average at the level of reasoning, decision-making problem solvers (Level 2). As in previous OECD studies, this disadvantage associated with a low occupational status of students' parents is much more pronounced in some countries than in others. For instance, the difference between the problem-solving performance of the national top and bottom quarters on the index of parental occupation is equivalent to at least one proficiency level (94 score points) in Belgium (99 score points), Germany (94 score points) and Hungary (101 score points), as well as in the partner countries Liechtenstein (103 score points) and Uruguay (101 score points). In other countries this gap is limited to only half or less than half of a proficiency level (e.g. 40 score points in Iceland and 47 score points in Korea, as well as 47 score points in Hong Kong-China and 18 score points in Macao-China).
Figure 5.5 shows that it is equivalent to over one proficiency level in some countries, but less than half a proficiency level in others... 
... and that the strength

of the effect is much

higher in some countries

than in others.

The quarter of students

whose parents have the

highest and lowest levels

of education can be

compared...

... and parental

education can be seen to

be a significant predictor

across countries.
Furthermore, the analysis estimates the percentage of variability in student performance that can be predicted by the job that students' parents have. An amount of explained variance equal to zero means that there is no relationship between parental occupational status and problem-solving performance; an amount of 50 per cent of explained variance means that if one were to predict students' scores according to how well students with parents in similar occupations tend to perform, the result would show half of the variation in performance that is actually observed.

Within OECD countries on average, 11 per cent of the variation in student performance is explained by parental occupational status (Table 5.2). This effect is significant in all of the participating countries and strongest in Belgium, Germany, Hungary, Portugal and the Slovak Republic, as well as in the partner countries Brazil, Liechtenstein and Uruguay (effects of between 34 and 41 score points; between 13 and 17 per cent explained variance in all countries except Uruguay [12 per cent]). In Iceland, Japan and Korea, and in the partner countries Hong Kong-China, Latvia and Macao-China, parents' occupation explains only 1 to 5 per cent of the variation in problem-solving performance (effects of between 12 and 24 score points).

\section{Parental education}

A strong predictor of student performance consistently found in previous studies is parental level of education. Parental level of education is classified in accordance with the International Standard Classification of Education, (ISCED, OECD, 1999). The higher level of the two parents is used as a single index for each student's parental level of education. The index for parental education is standardised for the OECD countries to have a mean of 0 and a standard deviation of 1 to facilitate interpretation of the results. Figure 5.6 illustrates the effect of parental education on problem-solving performance by displaying the mean performance of students in four groups ranked by the national values of this index. The length of the lines indicates the gap between students in the group whose parents have the highest and lowest levels of education in each country.

The level of parental education is a significant predictor of student performance in problem solving across all participating countries except in the partner country Macao-China. The effect of one standard deviation difference in parental education ranges from 11 score points in Portugal (the lowest for an OECD country) to 33 score points in Hungary (the OECD average is 20 score points). Parental education explains between 1 and 19 per cent of variance in problem-solving performance in all participating countries (the OECD average is 10 per cent). The effect is strongest in the Czech Republic, Hungary, Poland and the Slovak Republic (between 26 and 33 score points), and least pronounced in Finland and Portugal and the partner countries Brazil, Indonesia, Hong Kong-China and Tunisia (between 7 and 11 score points). Although the effect of parental education on problem-solving performance is rather low in 
- Students in the top quarter of the index

- Students in the third quarter of the index

$\square$ Students in the second quarter of the index

Performance on the problem-solving scale

- Students in the bottom quarter of the index

600
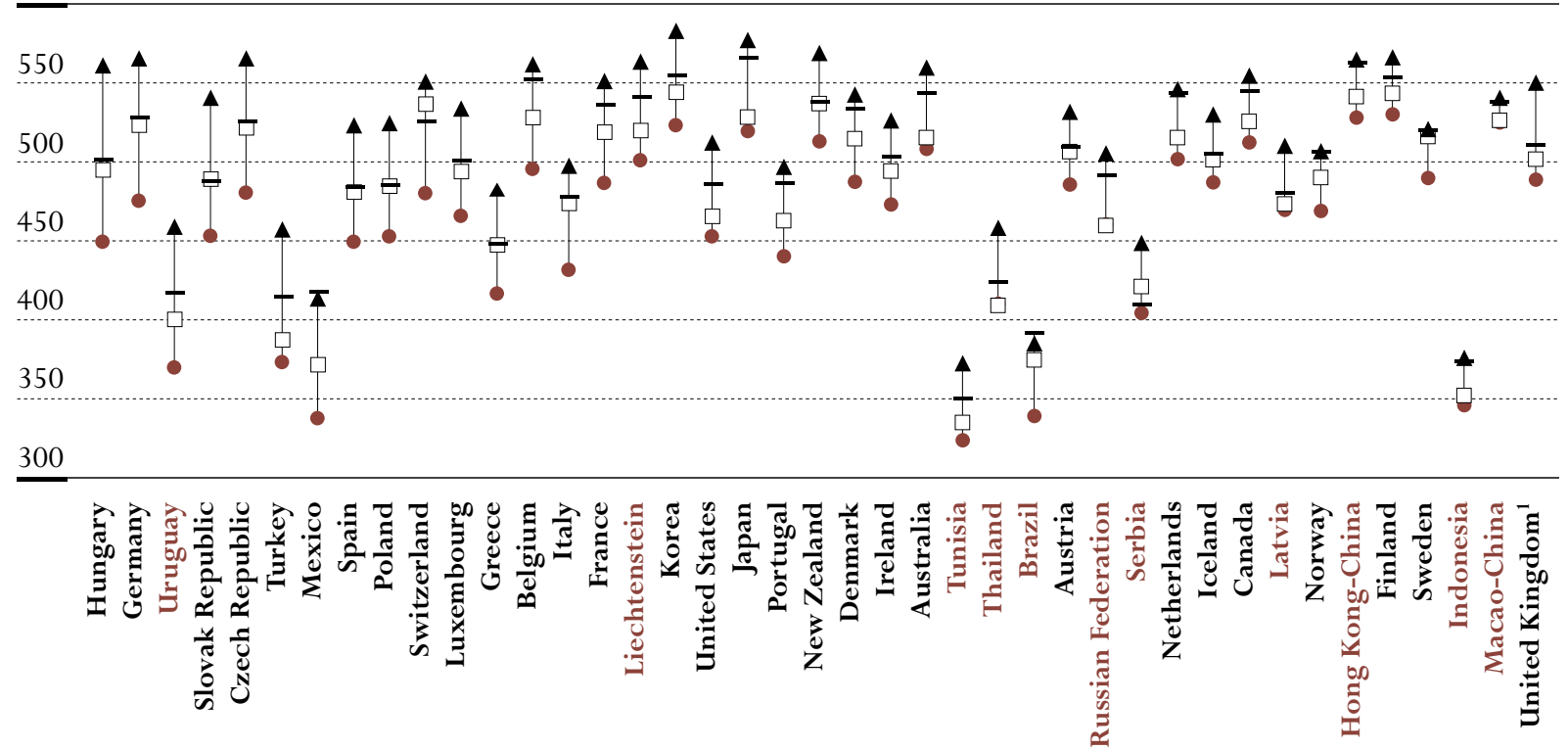

Countries are ranked in descending order of the difference in performance between students in the top and bottom quarters of the index of highest educational level of parents (HISCED).

1. Response rate too low to ensure comparability (see Annex A3).

Source: OECD PISA 2003 database, Table 5.3.

the countries with highest mean performances (e.g. Finland and Korea, and the partner country Hong Kong-China), there is no consistent relationship between mean performance within each country and the effect of parental education across all participating countries.

\section{Possessions related to "classical" culture}

Like the level of parental education, the available possessions related to "classical" culture in a student's family is another background variable that was shown to be positively related to student performance in previous studies. To obtain an index of possessions in the family home related to "classical" culture, students A similar analysis shows how many "classical" cultural possessions in PISA 2003 were asked whether they had classical literature, books of poetry, students have at home... and works of art in their homes. This index used is the same as in PISA 2000. As in PISA 2000, the highest levels of cultural possessions are found in Iceland, and the partner countries Latvia and the Russian Federation (see Chapter 4 in Learning for Tomorrow's World - First Results from PISA 2003, [OECD, 2004a]). 
.... and looks at the average scores of the quarters with the most and fewest of these possessions.

Figure 5.7 - Cultural possessions and student performance in problem solving
As for parental education, the index of cultural possessions was standardised for the OECD countries to have a mean of 0 and a standard deviation of 1 . To illustrate the effects of cultural possessions on problem-solving performance, the population within each country is again divided into quarters ranked by the national values of this index. Figure 5.7 shows the mean problem-solving performance for students in the top and bottom of these groups. Thus, the length of the different lines demonstrates the gap between students with the highest and lowest levels of cultural possessions in each country.

Cultural possessions are significantly positively related to problem-solving performance in all participating countries. On average in the OECD countries, the performance gap for students with one unit more on the index of cultural possessions is 25 score points for problem-solving performance and accounts for 6 per cent of variation in student performance. This effect is strongest in Belgium, Denmark, Hungary, Mexico and the United States (effects of between 31 and 42 score points; between 9 and 17 per cent of variance explained)

Index of possessions related to "classical" culture in the family home

- Students in the top quarter of the index

- Students in the third quarter of the index

$\square$ Students in the second quarter of the index

Performance on the problem-solving scale

- Students in the bottom quarter of the index

600

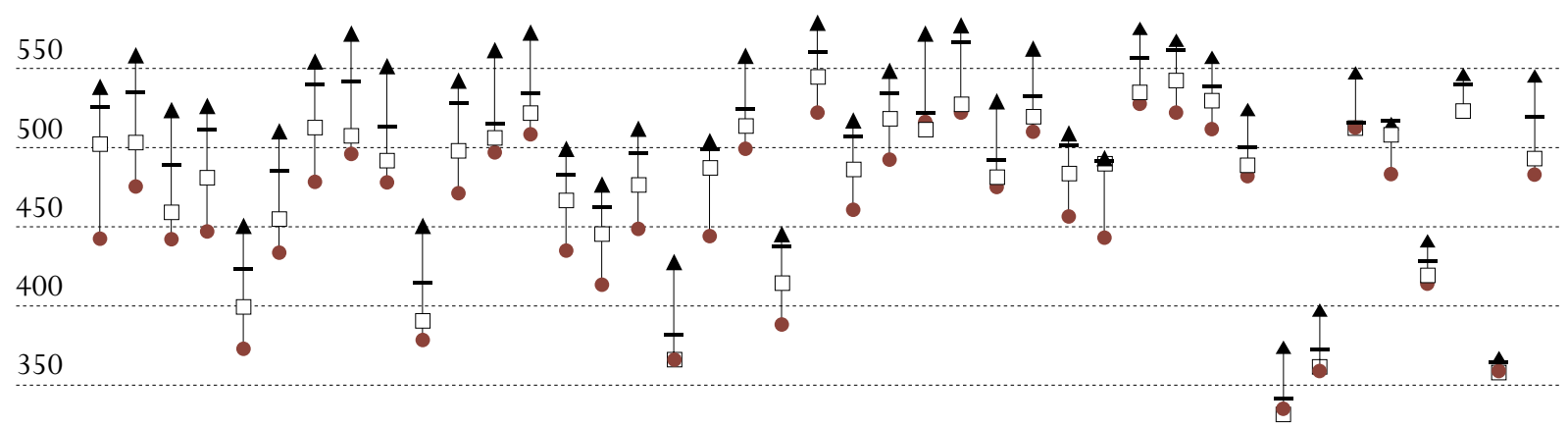

300

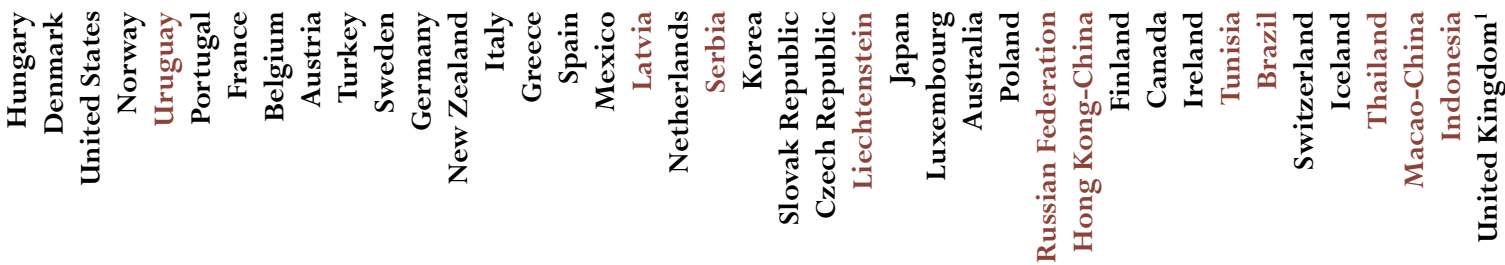

Countries are ranked in descending order of difference between the top and bottom quarters on the index of possessions related to "classical" culture in the family home and performance on the problem-solving scale.

1. Response rate too low to ensure comparability (see Annex A3).

Source: OECD PISA 2003 database, Table 5.4. 
and weakest in Canada and Switzerland, as well as in the partner countries Indonesia, Macao-China and Thailand (effects of between 5 and 18 score points; between 0.4 and 4 per cent of variance explained).

\section{Family structure}

The structure of a student's family is another background variable that can affect student performance. For example, students living with only one parent may receive less parental support with their learning compared to peers living with two parents. In PISA 2000, most distinct disadvantages in reading performance for students raised by a single parent were found in countries with high proportions of students in single-parent families. Figure 5.8 shows the percentage of students living in single-parent families and the mean problem-solving performance of students living in single-parent families and other family types.

Living with only one parent is often associated with lower performance...

Figure 5.8 - Type of family structure and student performance in problem solving

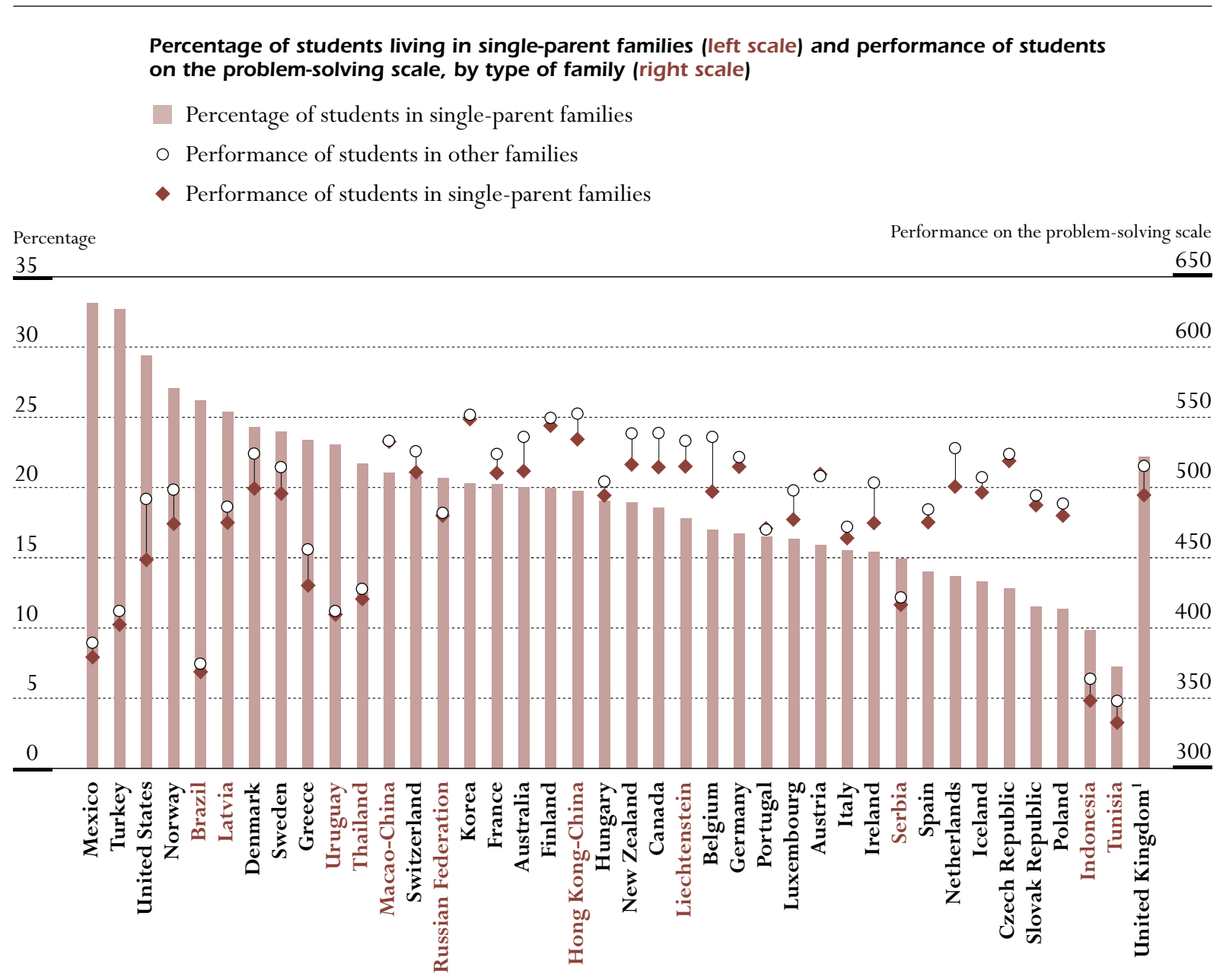

Note: Countries are ranked in descending order of percentage of students in single-parent families.

1. Response rate too low to ensure comparability (see Annex A3).

Source: OECD PISA 2003 database, Table 5.5. 
...although this

disadvantage varies

greatly and is not

significant in half the

PISA countries.

Problem-solving

performance can also

be compared according

to whether students and

their parents are native to

their country.

First-generation and non-native students show on average a clear disadvantage, though its extent varies widely between countries.
Within the OECD countries, between 11 and 33 per cent of students report to be living in a single-parent family (OECD average 19 per cent). ${ }^{3}$ On average in the OECD countries, students living in such families score 23 points less than peers living with both parents or in another form of family with two guardians. Still, results show that this effect is not unavoidable. In 16 countries there is no significant disadvantage for students from single-parent families (e.g. Austria, Korea and Portugal). Figure 5.8 reveals no pronounced relationship between the proportion of students living in single-parent families and the disadvantage in problem-solving performance found for this group. The largest disadvantages of students living in single-parent families are found in the United States (44 score points) with one of the highest proportion of these students (29 per cent) and in Belgium (39 score points) with a relatively low proportion (17 per cent). In Mexico and Turkey, with the highest proportions of students reporting living in single-parent families, the disadvantage of these students in problem-solving performance is relatively small, although statistically significant (10 score points). A need to provide educational support to students from single-parent families can be seen in many countries, especially those with a high proportion of students living in single-parent families and a pronounced disadvantage of these students in problem-solving performance.

\section{Place of birth and language spoken at home}

When families migrate from one country to another, their school-age children often find it hard to adjust to the new environment and often simultaneously are confronted with an unfamiliar language of instruction. In PISA, immigration status is assessed by asking students whether they and their parents were born in the country they are living in or in a different country. Based on these answers, students are classified into native students, who were born in and have parents who were born in the country of assessment, first-generation students, who were born in the country of assessment but whose parent(s) were born in a different country, and non-native students who were born in a different country. Figure 5.9 displays the percentages of first-generation and non-native students living within each country as well as the mean problem-solving performance of first-generation, non-native and native students.

Students classified as first-generation students and non-native students are on average at a clear disadvantage in terms of their problem-solving performance. On average in OECD countries, first-generation students score 26 points lower than native students and non-native students score 36 points lower. The differences in performance of students with an immigration background are not strongly related to the proportion of those among students within countries. In predominantly English-speaking countries with a relatively high proportion of students with an immigration background (Australia, Canada and the United States) and where 14 to 23 per cent of all 15 -year-olds are non-native or firstgeneration students, the disadvantage of these groups is relatively small. In several European countries (Belgium, France, Germany and Switzerland) with between 12 and 20 per cent non-native or first-generation students, these groups 


\section{Percentage of non-native and} first-generation students (left scale)

Percentage of non-native students

Percentage of first-generation students
Performance of non-native, first-generation and native students on the problem-solving scale (right scale)

- Mean performance of native students on the problem-solving scale

- Mean performance of first-generation students on the problem-solving scale

- Mean performance of non-native students on the problem-solving scale

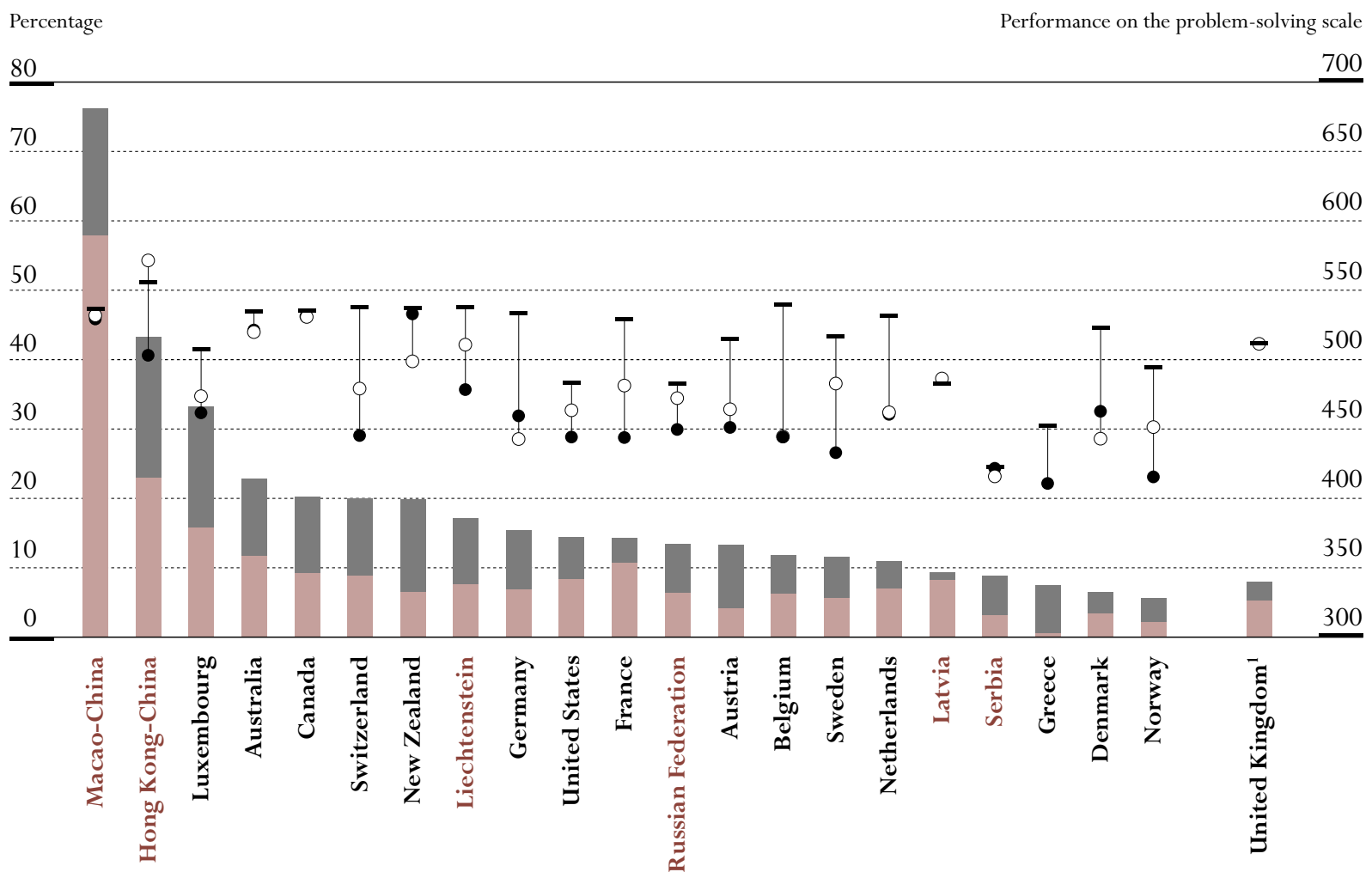

Note: Only countries with at least 3 per cent of students in at least one of these categories. Countries are ranked in descending order of the total percentage of non-native and first-generation students.

1. Response rate too low to ensure comparability (see Annex A3).

Source: OECD PISA 2003 database, Table 5.6.

perform distinctly less well than native students (a disadvantage of between 47 and 95 points). However, it should be noted that in some countries the mean performance of students with immigration backgrounds are based on very small numbers of students and should be interpreted carefully.

A consequence of immigration background may be that students speak a different language at home with their family than the language officially spoken in the country they live in and this is not limited to families with recent immigration history. Whatever the reason, students from families that speak a language at

A similar comparison can be made according to the language spoken at home... home that is different from the language of assessment or from other official languages or national dialects may experience difficulties in education due to a 
...with those not speaking the official language more than one proficiency level behind

in some countries. relatively unfamiliar language of instruction. Figure 5.10 displays the percentage of students speaking a language at home that is different from the language of assessment or from other official languages or national dialects within countries as well as the mean problem-solving performance of these students and their peers who speak the same language at home.

On average in the OECD countries, students speaking a different language at home score 39 points lower in problem solving than their peers speaking the language of assessment or another official language or national dialect at home. Again, this disadvantage is not related to the percentage of students not speaking an official language within each country. While the disadvantage of this group is

Figure 5.10 Home language and student performance in problem solving

\section{On the left scale:}

Percentage of students who speak a language at home most of the time that is different from the language of assessment, from other official languages or from other national dialects

\section{On the right scale:}

- Mean performance on the problem-solving scale of students who speak a language at home most of the time that is the same as the language of assessment, other official languages or other national dialects

- Mean performance on the problem-solving scale of students who speak a language at home most of the time that is different from the language of assessment, from other official languages or from other national dialects

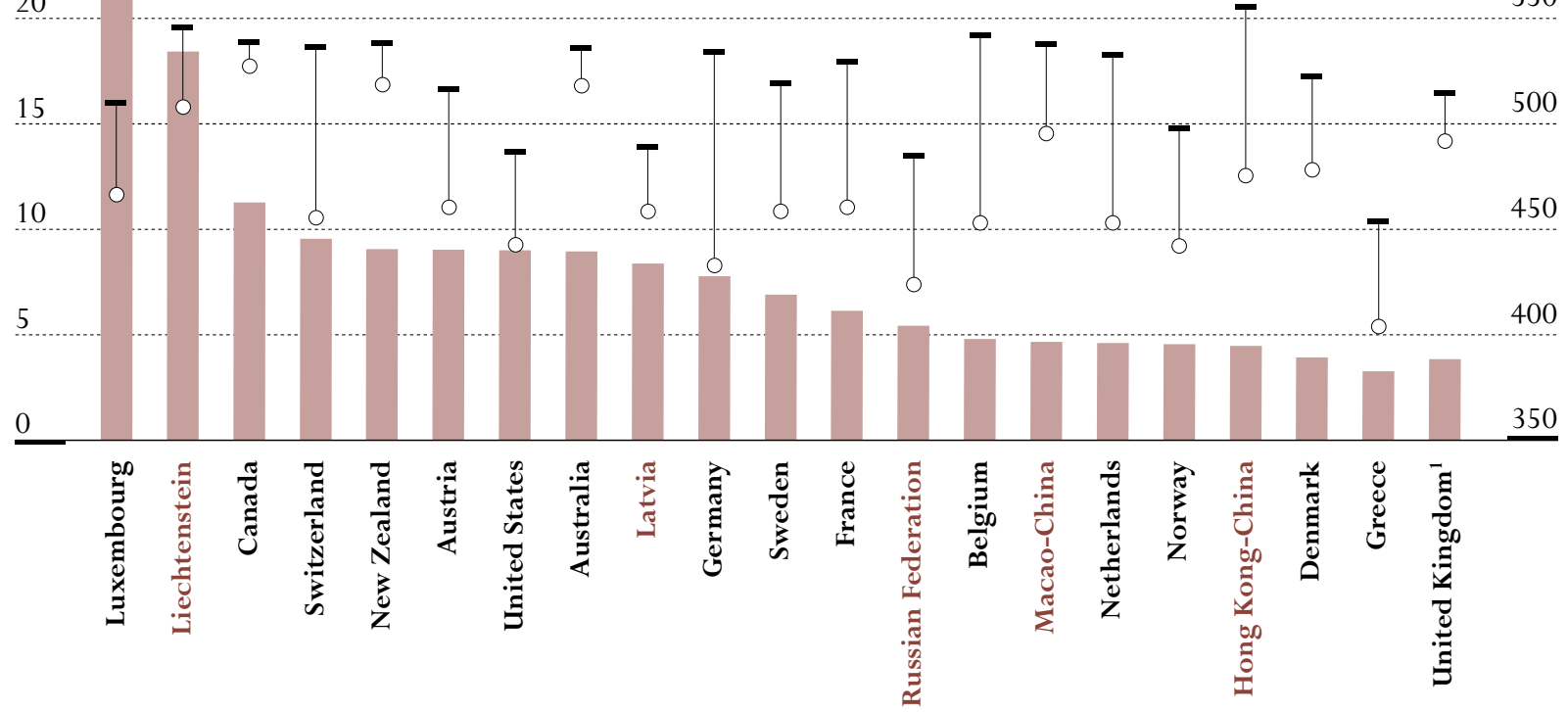

Note: Only countries with at least 3 per cent of students in at least one of these categories. Countries are ranked in descending order of students who speak a language at home most of the time that is different from the language of assessment, from other official languages or from national dialects.

1. Response rate too low to ensure comparability (see Annex A3).

Source: OECD PISA 2003 database, Table 5.7. 
relatively small in Australia and Canada (18 and 11 score points respectively), it is about one international standard deviation in Germany and Switzerland (101 and 81 score points respectively). In all of these countries between 8 and 11 per cent of 15 -year-old students do not speak an official language at home.

Effects of the place of birth and the language spoken at home on problem-solving performance certainly reflect difficulties students with migration background experience within education. These disadvantages can perpetuate existing socioeconomic gaps between the native population and immigrants across generations and should therefore be of concern for policy makers, especially in countries with a substantial number of immigrants. There are many different factors behind the relationship between students with a migration background and lower problemsolving performance, such as the previous educational experiences of these students, the unfamiliar language of instruction, the change from one education system to another, or other reasons. Learning for Tomorrow'sWorld - First Results from PISA 2003 (OECD, 2004a) examines some of these factors in more detail, and in particular, how they interact with other socio-economic characteristics.

\section{Implications for policy}

Prevailing issues in mathematics and science education over the past 50 years have been the eradication of gender differences in schooling and in re-examining cultural views about females' roles in these two subject areas. Vast improvements have been made in narrowing the gaps between male and female performance in school and in curriculum-related assessments in mathematics and science. However, little is directly known about gender differences in cross-curricular problem-solving performance when the emphasis is on real-world problems. The PISA 2003 assessment provides a window into the comparison of genderrelated performance for 15 -year-olds.

In contrast to performances in mathematics and reading, there are no consistent differences in the problem-solving performances of male and female students. This may indicate that gender specific strengths or preferences for certain subjects can be compensated for when solving cross-disciplinary tasks. In this sense, problem solving provides also a good overall indicator of educational outcomes for males compared with those of females in an individual country, and hence of the extent to which societies have removed gender-based disadvantages in cognitive performance. More generally, one could regard problem solving as an area not affected by particular characteristics of one part of the curriculum that may favour one group over another, and thus for example as a more neutral indicator of the extent of differences in opportunity based on student social background.

While male and female students do not differ markedly in their average performance, the variability of problem-solving performance is larger among males than females. More male students are found at the lower end of the performance distribution and consequently may face considerably restricted

Overall males are more likely to be found at the lower and upper ends of the performance distribution. 
As in mathematics performance, students' family backgrounds have an important effect on their general problemsolving capacities ...

...and educational strategies need to address this. opportunities in future life - a problem that warrants attention by policy makers. In addition, there may be disadvantages for females related to their under-representation at the highest performance level.

Most effects of background variables on problem-solving performance presented in this chapter are very similar to effects of the examined variables on performances in other assessment areas. This shows that students from less advantaged backgrounds are disadvantaged not only in relation to how well they pick up the school curriculum, but also in terms of their acquisition of general problem-solving skills. Countries should be concerned that social background has such a strong effect not just on curricular outcomes but also on acquisition of general skills. Many studies are pointing to the importance of employees acquiring problem-solving skills in the modern workplace (e.g. US Department of Labour, 1991, McCurry, 2002, ILO, 1998, OECD 2001b). In particular, employees in modern firms need to be able to participate effectively in problem-solving groups in which a cross-section of employees work together to streamline and improve the workplace in terms of efficiency and productivity.

The finding that inequities related to socio-economic and cultural background variables are not restricted to performance differences in school-related tasks underlines the importance of policy makers looking for strategies to raise problem-solving competence among disadvantaged groups.

Notes

1. For the country Serbia and Montenegro, data for Montenegro are not available. The latter accounts for 7.9 per cent of the national population. The name "Serbia" is used as a shorthand for the Serbian part of Serbia and Montenegro.

2. Father's or mother's occupation was used for this comparison, whichever was higher on the PISA international socioeconomic index of occupational status (HISEI).

3. Japan is excluded from the following analyses because of a high proportion of missing data. 
Carroll, J. B. (1996), "Mathematical abilities: Some results from factor analysis", R. J. Sternberg, \& T. Ben Zeev (eds.), The Nature of Mathematical Thinking, Lawrence Erlbaum Associates, Mahwah, N.J., 3-25.

Ganzeboom, H.B.G., P.M. De Graaf and D.J. Treiman (1992), "A standard international socio-economic index of occupational status”, Social Science Research, Vol. 21, Issue 1, Elsevier Ltd., 1-56.

Green, F., D. Ashton, B. Burchell, B. Davies, and A. Felkstead (1997), "An Analysis of Changing Work Skills in Britain”, paper presented at the Analysis of Low Wage Employment Conference, Centre for Economic Performance, London School of Economics, 12-13 December.

International Labour Office (1998), World Employment Report 1998-99 Employability in the Global Economy - How Training Matters, International Labour Office, Geneva.

Johnson, A. H. (2000), Changing Skills for a Changing World: Recommendations for Adult Literacy Policy In Aotearoa/New Zealand, Department of Labour Occasional Paper 2000, no. 2, Wellington, New Zealand.

Lerman, R. I., and F. Skidmore (1999), Helping Low-WageWorkers: Policies for the Future, Urban Institute, Washington, D.C.

McCurry, D. (2002), Notes towards an overarching model of cognitive abilities, unpublished report, Australian Council for Educational Research, Camberwell, Victoria.

OECD (1999), Classifying Educational Programmes: Manual for ISCED-97 Implementation in OECD Countries, OECD, Paris.

OECD (2001a), Knowledge and Skills for Life - First Results from PISA 2000, OECD, Paris.

OECD (2002a), Reading for Change - Performance and Engagement across Countries, OECD, Paris.

OECD (2002b), PISA 2000 Technical Report, OECD, Paris.

OECD (2003a), Literacy Skills for the World of Tomorrow - Further Results from PISA 2003, OECD, Paris.

OECD (2003b), The PISA 2003 Assessment Framework: Mathematics, Reading, Science and Problem Solving Knowledge and Skills, OECD, Paris.

OECD (2003c), Learners for Life - Student Approaches to Learning, OECD, Paris.

OECD (2003d), Student Engagement at School - A Sense of Belonging and Participation, OECD, Paris.

OECD (2003e), Education at a Glance, OECD, Paris.

OECD (2004a), Learning for Tomorrow's World - First Results from PISA 2003, OECD, Paris.

OECD (2004b), What Makes School Systems Perform, OECD, Paris.

OECD (forthcoming), School Factors Relating to Quality and Equity, OECD, Paris.

OECD (forthcoming), PISA 2003 Technical Report, OECD, Paris.

Steedman, H. (1999) “Low Skills: How the Supply is Changing across Europe”, in European Trends in Occupations and Qualifications, CEDEFOP, Luxembourg.

United States Department of Labour (1991), The Secretary's Commission on Achieving Necessary Skills (SCANS), What Work Requires of Schools: A SCANS Report for America 2000, United States Department of Labor, Washington, D.C.

Warm, T.A. (1985), "Weighted maximum likelihood estimation of ability in Item Response Theory with tests of finite length", Technical Report CGI-TR-85-08, U.S. Coast Guard Institute, Oklahoma City.

Workbase: The New Zealand Centre for Workforce Literacy Development (2000), Statement of Objectives, Workbase: The New Zealand Centre for Workforce Literacy Development, Auckland. 


\section{Annex A}

\section{TECHNICAL BACKGROUND}

Annex A1: Construction of indices and other derived measures from the student context questionnaire

Annex A2: Detailed results from the factor analysis in Chapter 3

Annex A3: The PISA target population and the PISA samples

Annex A4: Standard errors, significance tests and subgroup comparisons

Annex A5: Quality assurance

Annex A6: Development of the PISA assessment instruments

Annex A7: Reliability of the marking of open-ended items 


\section{Annex A1: Construction of indices and other derived measures from the student context questionnaire}

This section explains the indices derived from the student and school context questionnaires that are used in this report.

Several of PISA's measures reflect indices that summarise responses from students or school representatives (typically principals) to a series of related questions. The questions were selected from larger constructs on the basis of theoretical considerations and previous research. Structural equation modelling was used to confirm the theoretically expected behaviour of the indices and to validate their comparability across countries. For this purpose, a model was estimated separately for each country and collectively for all OECD countries.

For a detailed description of other PISA indices and details on the methods see the PISA 2000 Technical Report (OECD, 2002d) or the PISA 2003 Technical Report (OECD, forthcoming).

Unless otherwise indicated, where an index involves multiple questions and student responses, the index was scaled using a weighted maximum likelihood estimate (WLE) (see Warm, 1985), using a one-parameter item response model, which in the case of items with more than two categories was the Partial Credit Model. The scaling was done in three stages:

- The item parameters were estimated from equal-sized sub-samples of students from each OECD country.

- The estimates were computed for all students and all schools by anchoring the item parameters obtained in the preceding step.

- The indices were then standardised so that the mean of the index value for the OECD student population was zero and the standard deviation was one (countries being given equal weight in the standardisation process).

To illustrate the meaning of the international scores on the index, item maps were constructed that relate the index value to typical student responses to the questions asked. These item maps can be found on the website www.pisa.oecd.org. The vertical lines on the maps indicate for each of the index scores at the top of the figure which response a student is most likely to give, with zero representing the average student response across OECD countries.

It is important to note that negative values for an index do not necessarily imply that students responded negatively to the underlying questions. A negative value merely indicates that a group of students (or all students, collectively, in a single country) or principals responded less positively than all students or principals did on average across OECD countries. Likewise, a positive value on an index indicates that a group of students or principals responded more favourably, or more positively, than students or principals did, on average, in OECD countries.

Terms enclosed in brackets $<>$ in the following descriptions were replaced in the national versions of the student and school questionnaires by the appropriate national equivalent. For example, the term <qualification at ISCED level $5 A>$ was translated in the United States into "Bachelor's degree, post-graduate certificate program, Master's degree program or first professional degree program". Similarly the term < classes in the language of assessment $>$ in Luxembourg was translated into "German classes" or "French classes" depending on whether students received the German or French version of the assessment instruments.

For additional information on how these indices were constructed, see the PISA 2000 Technical Report (OECD, 2002b) or the PISA 2003 Technical Report (OECD, forthcoming).

\section{Student level variables}

\section{Student background}

\section{Family structure}

Students were asked to report who usually lived at home with them. The response categories were then grouped into four categories: i) single-parent family (students who reported living with one of the following: mother, father, female guardian or male guardian); ii) nuclear family (students who reported living with a mother and a father); iii) mixed family (students who reported living with a mother and a guardian, a father and a guardian, or two guardians); and iv) other response combinations. Non-responses are maintained as missing. 


\section{Parental occupations}

Students were asked to report their mothers' and fathers' occupations, and to state whether each parent was in full-time paid work; part-time paid work; not working but looking for a paid job; or "other".

The open-ended responses for occupations were then coded in accordance with the International Standard Classification of Occupations (ISCO 1988).

The PISA international socio-economic index of occupational status (ISEI) was derived from students' responses on parental occupation. The index captured the attributes of occupations that convert parents' education into income. The index was derived by the optimal scaling of occupation groups to maximise the indirect effect of education on income through occupation and to minimise the direct effect of education on income, net of occupation (both effects being net of age). For more information on the methodology, see Ganzeboom et al. (1992). The highest international socio-economic index of occupational status (HISEI) corresponds to the highest ISEI of either the father or the mother.

The variables on students' fathers' and mothers' occupations were also transformed into four socio-economic categories: i) white-collar high-skilled: legislators, senior officials and managers, professionals, technicians and associate professionals; ii) white-collar low-skilled: service workers, shop and market sales workers and clerks; iii) blue-collar high-skilled: skilled agricultural and fishery workers and craft and related trades workers; and iv) blue-collar low-skilled: plant and machine operators and assemblers and elementary occupations.

\section{Educational level of parents}

Parental education is a family background variable that is often used in the analysis of educational outcomes. Indices were constructed using information on the educational level of the father, the educational level of the mother, and the highest level of education between the two parents, referred to as the highest educational level of parents. Students were asked to identify the highest level of education of their mother and father on the basis of national qualifications, which were then coded in accordance with the International Standard Classification of Education (ISCED 1997, see OECD, 1999b) in order to obtain internationally comparable categories of educational attainment. The resulting categories were: $(0)$ for no education; (1) for the completion of $<$ ISCED Level $1>$ (primary education); (2) for completion of $<$ ISCED Level 2> (lower secondary education); (3) for the completion of $<$ ISCED Level 3B or 3C $>$ (vocational/pre-vocational upper secondary education, aimed in most countries at providing direct entry into the labour market); (4) for completion of <ISCED Level 3A $>$ (upper secondary education, aimed in most countries at gaining entry into tertiary-type A [university level] education) and/or $<$ ISCED Level 4> (non-tertiary post-secondary); (5) for qualifications in $<$ ISCED 5B $>$ (vocational tertiary); and (6) for completion of $<$ ISCED Level 5A, 6> (tertiary-type A and advanced research programmes).

\section{Immigration background}

The index on immigrant background was derived from students' responses to questions about whether or not their mother and their father were born in the country of assessment or in another country. The response categories were then grouped into three categories: i) "native" students (those students born in the country of assessment or who had at least one parent born in that country); ii) "first-generation" students (those born in the country of assessment but whose parents were born in another country); and iii) "non-native" students (those born outside the country of assessment and whose parents were also born in another country). For some comparisons, first-generation and non-native students were grouped together.

\section{Language used at home}

Students were asked if the language spoken at home most of the time or always was the language of assessment, another official national language, other national dialect or language, or another language. The index on language spoken at home distinguishes between students who report using the language of assessment, another official national language, a national dialect or another national language always or most of the time at home and those who report using another language always or most of the time at home.

In most countries, the languages were individually identified and were coded internationally to allow for further research and analysis in this area.

\section{Possessions related to "classical" culture in the family home}

The PISA index of possessions related to "classical" culture in the family home was derived from students' reports on the availability of the following items in their home: classic literature (examples were given), books of poetry and works of art (examples were given). Scale construction was performed through IRT scaling and positive values indicate higher levels of cultural possessions. 


\begin{tabular}{|c|c|c|c|c|c|c|c|}
\hline \multicolumn{8}{|c|}{$\begin{array}{l}\text { Annex A2: Detailed results from the factor analysis in Chapter } 3 \\
\text { Method used for the factor analysis }\end{array}$} \\
\hline \multicolumn{8}{|c|}{ Eigenvalues for the first 12 factors } \\
\hline \multicolumn{8}{|c|}{$\begin{array}{c}\text { Table } A 2.1 \\
\text { Eigenvalues of the first } \mathbf{1 2} \text { factors and total variance explained }\end{array}$} \\
\hline \multirow[b]{2}{*}{ Component } & \multicolumn{3}{|c|}{ Initial Eigenvalues } & \multicolumn{3}{|c|}{ Extraction sums of squared loadings } & \multirow{2}{*}{$\begin{array}{c}\begin{array}{c}\text { Rotation sums of } \\
\text { squared loadings }^{1}\end{array} \\
\text { Total }\end{array}$} \\
\hline & Total & $\begin{array}{c}\% \text { of } \\
\text { Variance }\end{array}$ & $\begin{array}{c}\text { Cumulative } \\
\%\end{array}$ & Total & $\begin{array}{c}\% \text { of } \\
\text { Variance }\end{array}$ & $\begin{array}{c}\text { Cumulative } \\
\%\end{array}$ & \\
\hline 1 & 9.768 & 7.631 & 7.631 & 9.768 & 7.631 & 7.631 & 8.998 \\
\hline 2 & 3.689 & 2.882 & 10.513 & 3.689 & 2.882 & 10.513 & 6.420 \\
\hline 3 & 3.668 & 2.866 & 13.379 & & & & \\
\hline 4 & 3.390 & 2.648 & 16.027 & & & & \\
\hline 5 & 3.259 & 2.546 & 18.573 & & & & \\
\hline 6 & 3.049 & 2.382 & 20.955 & & & & \\
\hline 7 & 3.029 & 2.367 & 23.322 & & & & \\
\hline 8 & 2.862 & 2.236 & 25.558 & & & & \\
\hline 9 & 2.714 & 2.120 & 27.678 & & & & \\
\hline 10 & 2.667 & 2.083 & 29.762 & & & & \\
\hline 11 & 2.607 & 2.037 & 31.798 & & & & \\
\hline 12 & 1.497 & 1.169 & 32.968 & & & & \\
\hline
\end{tabular}

Extraction Method: Principal Component Analysis.

1. When components are correlated, sums of squared loadings cannot be added to obtain a total variance.

It is clear that there is one dominant factor with an eigenvalue of 9.8 , followed by a group of 10 factors with eigenvalues between 2.6 and 3.7. To simplify the interpretations of the factor structure, two factors were chosen for the rotated solution. The rationale for the selection of two factors was not based on statistical criteria. Rather, it was based on a hypothesis that mathematics items and reading items should load separately on the first two factors, and it was of interest to see how the problem-solving items loaded on these two dimensions.

\section{Component correlation matrix}

Table A2.2 shows the component correlation matrix between the two factors.

Table A2.2

Component correlation matrix

\begin{tabular}{c|c|c} 
Component & $\mathbf{1}$ & $\mathbf{2}$ \\
\hline 1 & 1.000 & .362 \\
\hline 2 & .362 & 1.000 \\
\hline
\end{tabular}

Extraction Method: Principal Component Analysis.

Rotation Method: Oblimin with Kaiser Normalization. 


\section{A cautionary note about the exploratory factor analysis}

The results of the factor analysis are based on the analysis of correlations between variables at the student level. Due to the clustered structure of the PISA sample, these correlations reflect not only relations on the individual level but also heterogeneity between different schools. This means that correlations in terms of relations at individual level may be inflated due to general performance differences between students in different schools, countries etc. These inflated correlations will in turn lead to a more homogeneous factor structure - i.e. fewer dimensions - than one that would probably emerge from correlations where the clustered sampling is taken into account.

Overall, this analysis was not aimed at finding distinct cognitive factors in the PISA test. Rather, it was undertaken to provide some indication of the relative relationships between problem-solving items and mathematics and reading items. To this end, the results of the analysis showed clear indications that problem-solving items were more closely related to the general factor, and to mathematics items, than to reading items. 

Table A3.1

PISA target populations and samples

\begin{tabular}{|c|c|c|c|c|c|}
\hline & \multicolumn{5}{|c|}{ Population and sample information } \\
\hline & $\begin{array}{l}\text { Total population } \\
\text { of } 15 \text {-year-olds }\end{array}$ & $\begin{array}{c}\text { Total } \\
\text { Tolation } \\
\text { enrolled population } \\
\text { of } 15 \text {-year-olds } \\
\text { at grade } 7 \text { or above } \\
\end{array}$ & $\begin{array}{c}\text { (3) } \\
\text { Total in } \\
\text { national desired } \\
\text { target population }\end{array}$ & $\begin{array}{c}(4) \\
\text { Total } \\
\text { school-level } \\
\text { exclusions }\end{array}$ & $\begin{array}{l}\text { (5) } \\
\text { Total in national desired } \\
\text { target population after all } \\
\text { school exclusions and before } \\
\text { within-school exclusions }\end{array}$ \\
\hline Australia & 268164 & 250635 & 248035 & 1621 & 246414 \\
\hline Austria & 94515 & 89049 & 89049 & 321 & 88728 \\
\hline Belgium & 120802 & 118185 & 118185 & 561 & 117624 \\
\hline Canada & 398865 & 399265 & 397520 & 6600 & 390920 \\
\hline Czech Republic & 130679 & 126348 & 126348 & 1294 & 125054 \\
\hline Denmark & 59156 & 58188 & 58188 & 628 & 57560 \\
\hline Finland & 61107 & 61107 & 61107 & 1324 & 59783 \\
\hline France & 809053 & 808276 & 774711 & 18056 & 756655 \\
\hline Germany & 951800 & 916869 & 916869 & 5600 & 911269 \\
\hline Greece & 111286 & 108314 & 108314 & 808 & 107506 \\
\hline Hungary & 129138 & 123762 & 123762 & 3688 & 120074 \\
\hline Iceland & 4168 & 4112 & 4112 & 26 & 4086 \\
\hline Ireland & 61535 & 58997 & 58906 & 864 & 58042 \\
\hline Italy & 561304 & 574611 & 574611 & 2868 & 571743 \\
\hline Japan & 1365471 & 1328498 & 1328498 & 13592 & 1314906 \\
\hline Korea & 606722 & 606370 & 606370 & 2729 & 603641 \\
\hline Luxembourg & 4204 & 4204 & 4204 & 0 & 4204 \\
\hline Mexico & 2192452 & 1273163 & 1273163 & 46483 & 1226680 \\
\hline Netherlands & 194216 & 194216 & 194216 & 2559 & 191657 \\
\hline New Zealand & 55440 & 53293 & 53160 & 194 & 52966 \\
\hline Norway & 56060 & 55648 & 55531 & 294 & 55237 \\
\hline Poland & 589506 & 569294 & 569294 & 14600 & 554694 \\
\hline Portugal & 109149 & 99216 & 99216 & 826 & 98390 \\
\hline Slovak Republic & 84242 & 81945 & 81890 & 1042 & 80848 \\
\hline Spain 1 & 454064 & 418005 & 418005 & 1639 & 416366 \\
\hline Sweden & 109482 & 112258 & 112258 & 1615 & 110643 \\
\hline Switzerland & 83247 & 81020 & 81020 & 2760 & 78260 \\
\hline Turkey & 1351492 & 725030 & 725030 & 5328 & 719702 \\
\hline United Kingdom & 768180 & 736785 & 736785 & 24773 & 712012 \\
\hline United States & 3979116 & 3979116 & 3979116 & 0 & 3979116 \\
\hline $\begin{array}{l}\text { Brazil } \\
\text { Hono Kong-China }\end{array}$ & $\begin{array}{r}3618332 \\
75000\end{array}$ & 2359854 & 2348405 & $\begin{array}{r}0 \\
601\end{array}$ & 2348405 \\
\hline Hong Kong-China & 75000 & 72631 & 72631 & 601 & 72030 \\
\hline Indonesia ${ }^{\circ}$ & 4281895 & 3113548 & 2968756 & 9292 & 2959464 \\
\hline Latvia & 37544 & 37138 & 37138 & 1419 & 35719 \\
\hline Liechtenstein & 402 & 348 & 348 & 0 & 348 \\
\hline Macao-China & 8318 & 6939 & 6939 & 0 & 6939 \\
\hline Russian Federation & 2496216 & 2366285 & 2366285 & 23445 & 2342840 \\
\hline Serbia & 98729 & 92617 & 92617 & 4931 & 87686 \\
\hline Thailand & 927070 & 778267 & 778267 & 7597 & 770670 \\
\hline Tunisia & 164758 & 164758 & 164758 & 553 & 164205 \\
\hline Uruguay & 53948 & 40023 & 40023 & 59 & 39964 \\
\hline
\end{tabular}

Population and sample information

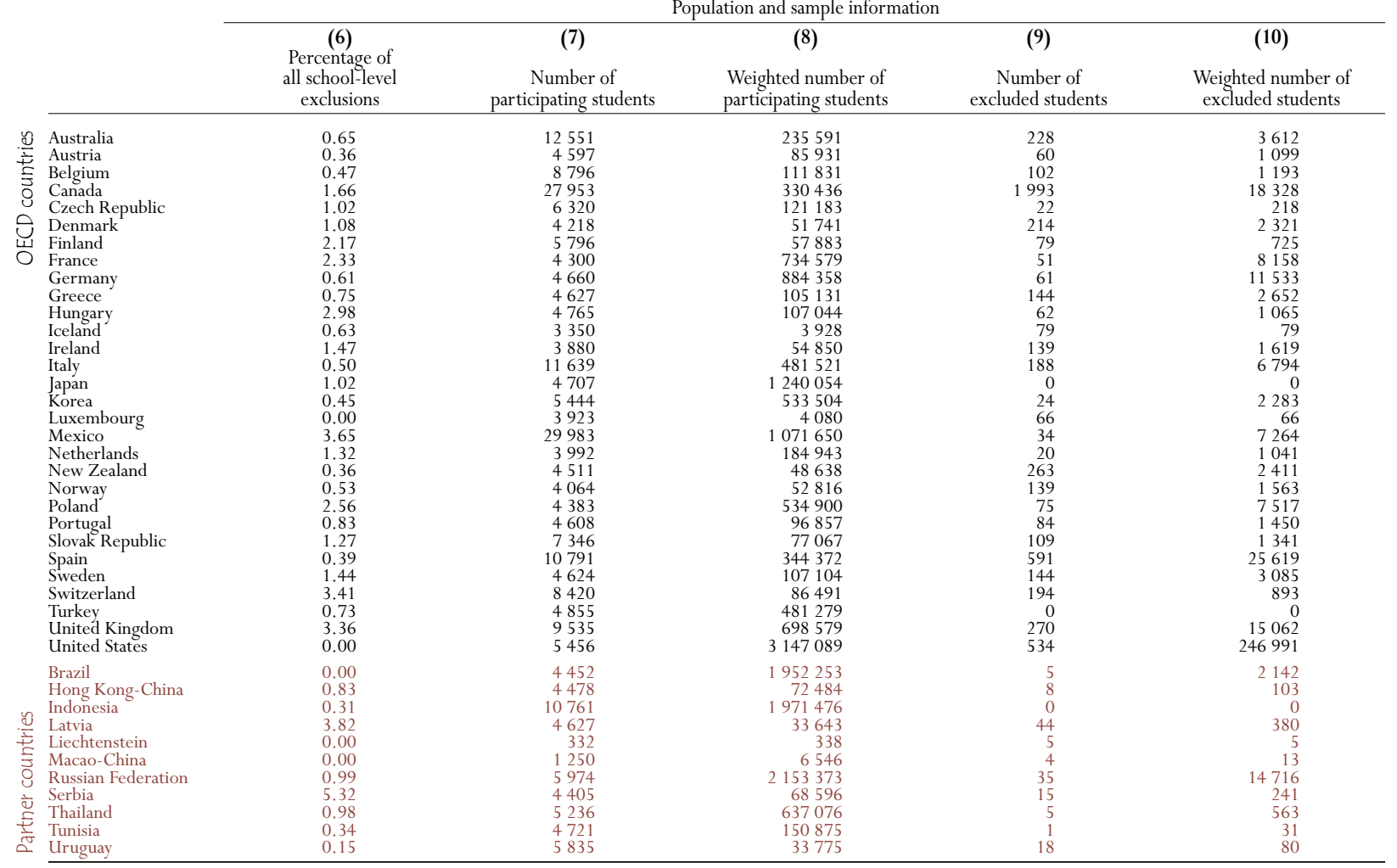


Table A3. 1 (continued)

PISA target populations and samples

\begin{tabular}{|c|c|c|c|c|c|}
\hline & \multicolumn{2}{|c|}{ Population and sample information } & \multicolumn{3}{|c|}{ Coverage indices } \\
\hline & $\begin{array}{c}\text { (11) } \\
\text { Within-school } \\
\text { exclusion rate } \\
(\%)\end{array}$ & $\begin{array}{c}(12) \\
\text { Overall } \\
\text { exclusion rate } \\
(\%)\end{array}$ & $\begin{array}{c}\text { (13) } \\
\text { Coverage index 1: } \\
\text { Coverage of national } \\
\text { desired population }\end{array}$ & $\begin{array}{l}\text { (14) } \\
\text { Coverage index 2: } \\
\text { Coverage of national } \\
\text { enrolled population }\end{array}$ & $\begin{array}{l}\text { (15) } \\
\text { Coverage index 3: } \\
\text { Percentage of } \\
\text { enrolled population }\end{array}$ \\
\hline $\begin{array}{l}\text { Australia } \\
\text { Austria } \\
\text { Belgium } \\
\text { Canada } \\
\text { Czech Republic } \\
\text { Denmark } \\
\text { Finland } \\
\text { France } \\
\text { Germany } \\
\text { Greece } \\
\text { Hungary } \\
\text { Iceland } \\
\text { Ireland } \\
\text { Italy } \\
\text { Japan } \\
\text { Korea } \\
\text { Luxembourg } \\
\text { Mexico } \\
\text { Netherlands } \\
\text { New Zealand } \\
\text { Norway } \\
\text { Poland } \\
\text { Portugal } \\
\text { Slovak Republic } \\
\text { Spain } \\
\text { Sweden } \\
\text { Switzerland } \\
\text { Turkey } \\
\text { United Kingdom } \\
\text { United States }\end{array}$ & $\begin{array}{l}1.51 \\
1.26 \\
1.06 \\
5.26 \\
0.18 \\
4.29 \\
1.24 \\
1.10 \\
1.29 \\
2.46 \\
0.99 \\
1.97 \\
2.87 \\
1.39 \\
0.00 \\
0.43 \\
1.59 \\
0.67 \\
0.56 \\
4.72 \\
2.87 \\
1.39 \\
1.47 \\
1.71 \\
6.92 \\
2.80 \\
1.02 \\
0.00 \\
2.11 \\
7.28\end{array}$ & $\begin{array}{l}2.15 \\
1.62 \\
1.53 \\
6.83 \\
1.20 \\
5.33 \\
3.38 \\
3.40 \\
1.89 \\
3.19 \\
3.94 \\
2.59 \\
4.29 \\
1.88 \\
1.02 \\
0.87 \\
1.59 \\
4.30 \\
1.87 \\
5.07 \\
3.39 \\
3.91 \\
2.30 \\
2.96 \\
7.29 \\
4.20 \\
4.39 \\
0.73 \\
5.40 \\
7.28\end{array}$ & $\begin{array}{l}0.98 \\
0.98 \\
0.98 \\
0.93 \\
0.99 \\
0.95 \\
0.97 \\
0.97 \\
0.98 \\
0.97 \\
0.96 \\
0.97 \\
0.96 \\
0.98 \\
0.99 \\
0.99 \\
0.98 \\
0.96 \\
0.98 \\
0.95 \\
0.97 \\
0.96 \\
0.98 \\
0.97 \\
0.93 \\
0.96 \\
0.96 \\
0.99 \\
0.95 \\
0.93\end{array}$ & $\begin{array}{l}0.97 \\
0.98 \\
0.98 \\
0.93 \\
0.99 \\
0.95 \\
0.97 \\
0.93 \\
0.98 \\
0.97 \\
0.96 \\
0.97 \\
0.96 \\
0.98 \\
0.99 \\
0.99 \\
0.98 \\
0.96 \\
0.98 \\
0.95 \\
0.96 \\
0.96 \\
0.98 \\
0.97 \\
0.93 \\
0.96 \\
0.96 \\
0.99 \\
0.95 \\
0.93\end{array}$ & $\begin{array}{l}0.93 \\
0.94 \\
0.98 \\
1.00 \\
0.97 \\
0.98 \\
1.00 \\
1.00 \\
0.96 \\
0.97 \\
0.96 \\
0.99 \\
0.96 \\
1.02 \\
0.97 \\
1.00 \\
1.00 \\
0.58 \\
1.00 \\
0.96 \\
0.99 \\
0.97 \\
0.91 \\
0.97 \\
0.92 \\
1.03 \\
0.97 \\
0.54 \\
0.96 \\
1.00\end{array}$ \\
\hline $\begin{array}{l}\text { Brazil } \\
\text { Hong Kong-China } \\
\text { Indonesia } \\
\text { Latvia } \\
\text { Liechtenstein } \\
\text { Macao-China } \\
\text { Russian Federation } \\
\text { Serbia } \\
\text { Thailand } \\
\text { Tunisia } \\
\text { Uruguay }\end{array}$ & $\begin{array}{l}0.11 \\
0.14 \\
0.00 \\
1.12 \\
1.46 \\
0.20 \\
0.68 \\
0.35 \\
0.09 \\
0.02 \\
0.24\end{array}$ & $\begin{array}{l}0.11 \\
0.97 \\
0.31 \\
4.89 \\
1.46 \\
0.20 \\
1.66 \\
5.66 \\
1.06 \\
0.36 \\
0.38\end{array}$ & $\begin{array}{l}1.00 \\
0.99 \\
1.00 \\
0.95 \\
0.99 \\
1.00 \\
0.98 \\
0.94 \\
0.99 \\
1.00 \\
1.00\end{array}$ & $\begin{array}{l}0.99 \\
0.99 \\
0.95 \\
0.95 \\
0.99 \\
1.00 \\
0.98 \\
0.94 \\
0.99 \\
1.00 \\
1.00\end{array}$ & $\begin{array}{l}0.65 \\
0.97 \\
0.73 \\
0.99 \\
0.87 \\
0.83 \\
0.95 \\
0.94 \\
0.84 \\
1.00 \\
0.74\end{array}$ \\
\hline
\end{tabular}

Note: For a full explanation of the details in this table please refer to the PISA 2003 Technical Report (OECD, forthcoming).

The sampling standards used in PISA permitted countries to exclude up to a total of 5 per cent of the relevant population either by excluding schools or by excluding students within schools. All but seven countries, New Zealand (5.1 per cent), Denmark (5.3 per cent), the United Kingdom (5.4 per cent), Serbia (5.7 per cent) ${ }^{1}$ Canada (6.8 per cent), the United States (7.3 per cent) and Spain (7.3 per cent) achieved this standard and in 20 countries the overall exclusion rate was less than 2 per cent. In some of the countries with exclusion rates exceeding 5 per cent, exclusions were inevitable. For example, in New Zealand 2.3 per cent of the students were excluded because they had less than one year of instruction in English, often because they were foreign fee-paying students and were therefore not able to follow the instructions of the assessment. When language exclusions are accounted for (i.e. removed from the overall exclusion rate), Denmark and New Zealand no longer had exclusion rates greater than 5 per cent. For details, see www.pisa.oecd.org.

Exclusions within the above limits include:

- At the school level: i) schools which were geographically inaccessible or where the administration of the PISA assessment was not considered feasible; and ii) schools that provided teaching only for students in the categories defined under "within-school exclusions", such as schools for the blind. The percentage of 15-year-olds enrolled in such schools had to be less than 2.5 per cent of the nationally desired target population ( $0.5 \%$ maximum for i) and $2 \%$ maximum for ii)). The magnitude, nature and justification of school-level exclusions are documented in the PISA 2003 Technical Report (OECD, forthcoming).

- At the student level: i) students with an intellectual disability; ii) students with a functional disability; and iii) students with a limited assessment language proficiency. Students could not be excluded solely because of low proficiency or normal discipline problems. The percentage of 15 -year-olds excluded within schools had to be less than 2.5 per cent of the nationally desired target population.

1. For the country Serbia and Montenegro, data for Montenegro are not available. The latter accounts for 7.9 per cent of the national population. The name "Serbia" is used as a shorthand for the Serbian part of Serbia and Montenegro. 
Table A3. 1 describes the target population of the countries participating in PISA 2003. Further information on the target population and the implementation of PISA sampling standards can be found in the PISA 2003 Technical Report (OECD, forthcoming).

- Column 1 shows the total number of 15-year-olds according to the most recent available information, which in most countries meant the year 2002 as the year before the assessment.

- Column 2 shows the number of 15-year-olds enrolled in schools in grades 7 or above (as defined above), which is referred to as the eligible population.

- Column 3 shows the national desired target population. Countries were allowed to exclude up to 0.5 per cent of students a priori from the eligible population, essentially for practical reasons. The following a priori exclusions exceed this limit but were agreed with the PISA Consortium: Australia excluded 1.04 per cent of its populations from TAFE colleges; France excluded 4.15 per cent of its students in Territoires d'Outre-Mer because they were students in outlying territories not subject to the national education system (students from outlying departments were included), as well as eligible students in hospitals or trade chambers; and Indonesia excluded 4.65 per cent of its students from four provinces because of security reasons.

- Column 4 shows the number of students enrolled in schools that were excluded from the national desired target population either from the sampling frame or later in the field during data collection.

- Column 5 shows the size of the national desired target population after subtracting the students enrolled in excluded schools. This is obtained by subtracting column 4 from column 3.

- Column 6 shows the percentage of students enrolled in excluded schools. This is obtained by dividing column 4 by column 3 and multiplying by 100 .

- Column 7 shows the number of students participating in PISA 2003. Note that this number does not account for 15 year-olds assessed as part of additional national options.

- Column 8 shows the weighted number of participating students, i.e. the number of students in the nationally defined target population that the PISA sample represents.

- Each country attempted to maximise the coverage of PISA's target population within the sampled schools. In the case of each sampled school, all eligible students, namely those 15 years of age, regardless of grade, were first listed. Sampled students who were to be excluded had still to be included in the sampling documentation, and a list drawn up stating the reason for their exclusion. Column 9 indicates the total number of excluded students, which is further described and classified into specific categories in Table A3.2. Column 10 indicates the weighted number of excluded students, i.e. the overall number of students in the nationally defined target population represented by the number of students excluded from the sample, which is also described and classified by exclusion categories in Table A3.2. Excluded students were excluded based on four categories: i) students with an intellectual disability - student has a mental or emotional disability and is cognitively delayed such that he/she cannot perform in the PISA testing situation; ii) students with a functional disability - student has a moderate to severe permanent physical disability such that he/she cannot perform in the PISA testing situation; and iii) students with a limited assessment language proficiency - student is unable to read or speak any of the languages of the assessment in the country and would be unable to overcome the language barrier in the testing situation. Typically a student who has received less than one year of instruction in the languages of the assessment may be excluded; and iv) other - which is a category defined by the national centres and approved by the international centre.

- Column 11 shows the percentage of students excluded within schools. This is calculated as the weighted number of excluded students (column 10) divided by the weighted number of excluded and participating students (column 8 plus column 10).

- Column 12 shows the overall exclusion rate which represents the weighted percentage of the national desired target population excluded from PISA either through school-level exclusions or through the exclusion of students within schools. It is calculated as the school-level exclusion rate (column 6 divided by 100) plus within-school exclusion rate (column 11 divided by 100) multiplied by 1 minus the school-level exclusion rate (column 6 divided by 100). This result is then multiplied by 100. Seven countries, namely Canada, Denmark, New Zealand, Spain, the United Kingdom, the United States and the partner country Serbia, had exclusion rates higher than 5 per cent (see also www.oecd.org for further information on these exclusions). When language exclusions were accounted for (i.e. removed from the overall exclusion rate), Denmark and New Zealand no longer had exclusion rates greater than 5 per cent.

- Column 13 presents an index of the extent to which the national desired target population is covered by the PISA sample. Canada, Spain, the United States and the partner country Serbia were the only countries where the coverage is below 95 per cent. 
Table A3.2

Exclusions

\begin{tabular}{|c|c|c|c|c|c|c|c|c|c|c|}
\hline & \multicolumn{5}{|c|}{ Student exclusions (unweighted) } & \multicolumn{5}{|c|}{ Student exclusions (weighted) } \\
\hline & $\begin{array}{c}\text { (1) } \\
\text { Number } \\
\text { of excluded } \\
\text { students with } \\
\text { disabilities } \\
\text { (code 1) }\end{array}$ & $\begin{array}{c}\text { (2) } \\
\text { Number } \\
\text { of excluded } \\
\text { students with } \\
\text { disabilities } \\
\text { (code 2) }\end{array}$ & $\begin{array}{c}\text { (3) } \\
\text { Number of ex- } \\
\text { cluded students } \\
\text { because of } \\
\text { language } \\
\text { (code 3) }\end{array}$ & $\begin{array}{c}\text { (4) } \\
\text { Number } \\
\text { s of excluded } \\
\text { students for } \\
\text { other reasons } \\
\text { (code 4) }\end{array}$ & \begin{tabular}{|c|}
$\mathbf{( 5 )}$ \\
$\begin{array}{c}\text { Total number } \\
\text { of excluded } \\
\text { students }\end{array}$ \\
\end{tabular} & \begin{tabular}{|c|} 
(6) \\
Weighted num- \\
ber of excluded \\
students with \\
disabilities \\
(code 1)
\end{tabular} & $\begin{array}{l}\text { (7) } \\
\text { Weighted num- } \\
\text { ber of excluded } \\
\text { students with } \\
\text { disabilities } \\
\text { (code 2) }\end{array}$ & $\begin{array}{l}\text { (8) } \\
\text { deighted num- } \\
\text { ber of excluded } \\
\text { students because } \\
\text { of language } \\
\text { (code 3) }\end{array}$ & 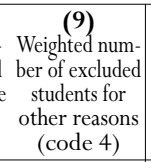 & $\begin{array}{c}\text { (10) } \\
\text { Total weighted } \\
\text { number of } \\
\text { excluded } \\
\text { students }\end{array}$ \\
\hline Australia & 33 & 133 & 62 & 0 & 228 & 457 & 2443 & 712 & 0 & 3612 \\
\hline Austria & 3 & 27 & 30 & 0 & 60 & 62 & 573 & 465 & 0 & 1099 \\
\hline Belgium & 4 & 49 & 49 & 0 & 102 & 64 & 507 & 622 & 0 & 1193 \\
\hline Canada & 100 & 1590 & 303 & 0 & 1993 & 874 & 13720 & 3734 & 0 & 18328 \\
\hline Czech Republic & 5 & 14 & 2 & 1 & 22 & 106 & 35 & 66 & 11 & 218 \\
\hline Denmark & 9 & 70 & 79 & 56 & 214 & 101 & 768 & 861 & 591 & 2321 \\
\hline Finland & 15 & 37 & 20 & 7 & 79 & 138 & 334 & 200 & 53 & 725 \\
\hline France & 9 & 31 & 11 & 0 & 51 & 1227 & 5110 & 1821 & 0 & 8158 \\
\hline Germany & 4 & 21 & 30 & 6 & 61 & 768 & 4526 & 5347 & 893 & 11533 \\
\hline Greece & 14 & 30 & 31 & 69 & 144 & 289 & 555 & 498 & 1310 & 2652 \\
\hline Hungary & 0 & 55 & 7 & 0 & 62 & 0 & 928 & 138 & 0 & 1065 \\
\hline Iceland & 12 & 45 & 22 & 0 & 79 & 12 & 45 & 22 & 0 & 79 \\
\hline Ireland & 14 & 78 & 16 & 31 & 139 & 152 & 906 & 183 & 377 & 1619 \\
\hline Italy & 20 & 99 & 69 & 0 & 188 & 619 & 3655 & 2521 & 0 & 6794 \\
\hline Japan & 0 & 0 & 0 & 0 & 0 & 0 & 0 & 0 & 0 & 0 \\
\hline Korea & 3 & 21 & 0 & 0 & 24 & 284 & 1999 & 0 & 0 & 2283 \\
\hline Luxembourg & 2 & 15 & 45 & 4 & 66 & 2 & 15 & 45 & 4 & 66 \\
\hline Mexico & 7 & 10 & 17 & 0 & 34 & 167 & 1618 & 5479 & 0 & 7264 \\
\hline Netherlands & 2 & 17 & 1 & 0 & 20 & 154 & 773 & 114 & 0 & 1041 \\
\hline New Zealand & 29 & 94 & 140 & 0 & 263 & 260 & 880 & 1271 & 0 & 2411 \\
\hline Norway & 7 & 90 & 42 & 0 & 139 & 77 & 1019 & 468 & 0 & 1563 \\
\hline Poland & 9 & 26 & 3 & 37 & 75 & 894 & 2623 & 310 & 3691 & 7517 \\
\hline Portugal & 14 & 55 & 15 & 0 & 84 & 255 & 929 & 265 & 0 & 1450 \\
\hline Slovak Republic & 16 & 74 & 19 & 0 & 109 & 108 & 913 & 320 & 0 & 1341 \\
\hline Spain & 34 & 421 & 136 & 0 & 591 & 1594 & 17246 & 6779 & 0 & 25619 \\
\hline Sweden & 1 & 110 & 33 & 0 & 144 & 18 & 2297 & 769 & 0 & 3085 \\
\hline Switzerland & 26 & 93 & 75 & 0 & 194 & 127 & 344 & 422 & 0 & 893 \\
\hline Turkey & 0 & 0 & 0 & 0 & 0 & 0 & 0 & 0 & 0 & 0 \\
\hline United Kingdom & 23 & 208 & 39 & 0 & 270 & 1146 & 12401 & 1515 & 0 & 15062 \\
\hline United States & 32 & 431 & 71 & 0 & 534 & 14239 & 201562 & 31190 & 0 & 246991 \\
\hline Brazil & 4 & 1 & 0 & 0 & 5 & 1642 & 500 & 0 & 0 & 2142 \\
\hline Hong Kong-China & 2 & 5 & 1 & 0 & 8 & 26 & 63 & 14 & 0 & 103 \\
\hline Indonesia & 0 & 0 & 0 & 0 & 0 & 0 & 0 & 0 & 0 & 0 \\
\hline Latvia & 21 & 23 & 0 & 0 & 44 & 148 & 231 & 0 & 0 & 380 \\
\hline Liechtenstein & 1 & 0 & 4 & 0 & 5 & 1 & 0 & 4 & 0 & 5 \\
\hline Macao-China & 4 & 0 & 0 & 0 & 4 & 13 & 0 & 0 & 0 & 13 \\
\hline Russian Federation & 13 & 19 & 3 & 0 & 35 & 4538 & 8969 & 1209 & 0 & 14716 \\
\hline Serbia & 5 & 8 & 2 & 0 & 15 & 78 & 129 & 34 & 0 & 241 \\
\hline Thailand & 4 & 1 & 0 & 0 & 5 & 463 & 100 & 0 & 0 & 563 \\
\hline Tunisia & 0 & 0 & 1 & 0 & 1 & 0 & 0 & 31 & 0 & 31 \\
\hline Uruguay & 5 & 9 & 4 & 0 & 18 & 30 & 38 & 12 & 0 & 80 \\
\hline
\end{tabular}

Exclusion codes:

Code 1: Functional disability - student has a moderate to severe permanent physical disability.

Code 2: Intellectual disability - student has a mental or emotional disability and has either been tested as cognitively delayed or is considered in the professional opinion of qualified staff to be cognitively delayed.

Code 3: Limited assessment language proficiency - student is not a native speaker of any of the languages of the assessment in the country and has limited proficiency in these languages.

Code 4: Other - defined by the national centres and approved by the international centre.

Note: For a full explanation of other details in this table please refer to the PISA 2003 Technical Report (OECD, forthcoming).

- Column 14 presents an index of the extent to which 15-year-olds enrolled in schools are covered by the PISA sample. The index measures the overall proportion of the national enrolled population that is covered by the non-excluded portion of the student sample. The index takes into account both school-level and student-level exclusions. Values close to 100 indicate that the PISA sample represents the entire education system as defined for PISA 2003. The index is the weighted number of participating students (column 8) divided by the weighted number of participating and excluded students (column 8 plus column 10), times the nationally defined target population (column 5) divided by the eligible population (column 2) (times 100). The same countries with index 1 below 0.95 also had index 2 below 0.95. In addition, France also had this index below 95 per cent due to the exclusion of Territoires d'Outre Mer. This was consistent with the results from PISA 2000.

- Column 15 presents an index of the percentage of enrolled population. This index is the total enrolled population of 15-year-olds (column 2) divided by the total population of 15-year-old students (column 1). 
This high level of coverage contributes to the comparability of the assessment results. For example, even assuming that the excluded students would have systematically scored worse than those who participated, and that this relationship is moderately strong, an exclusion rate in the order of 5 per cent would likely lead to an overestimation of national mean scores of less than 5 score points (on a scale with an international mean of 500 score points and a standard deviation of 100 score points). This assessment is based on the following calculations: If the correlation between the propensity of exclusions and student performance is 0.3 , resulting mean scores would likely be overestimated by 1 score point if the exclusion rate is 1 per cent, by 3 score points if the exclusion rate is 5 per cent, and by 6 score points if the exclusion rate is 10 per cent. If the correlation between the propensity of exclusions and student performance is 0.5 , resulting mean scores would be overestimated by 1 score point if the exclusion rate is 1 per cent, by 5 score points if the exclusion rate is 5 per cent, and by 10 score points if the exclusion rate is 10 per cent. For this calculation, a model was employed that assumes a bivariate normal distribution for the propensity to participate and performance. For details see the PISA 2003 Technical Report (OECD, forthcoming).

\section{Sampling procedures and response rates}

The accuracy of any survey results depends on the quality of the information on which national samples are based as well as on the sampling procedures. Quality standards, procedures, instruments and verification mechanisms were developed for PISA that ensured that national samples yielded comparable data and that the results could be compared with confidence.

Most PISA samples were designed as two-stage stratified samples (where countries applied different sampling designs, these are documented in the PISA 2003 Technical Report (OECD, forthcoming)). The first stage consisted of sampling individual schools in which 15-year-old students could be enrolled. Schools were sampled systematically with probabilities proportional to size, the measure of size being a function of the estimated number of eligible (15-year-old) students enrolled. A minimum of 150 schools were selected in each country (where this number existed), although the requirements for national analyses often required a somewhat larger sample. As the schools were sampled, replacement schools were simultaneously identified, in case a sampled school chose not to participate in PISA 2003.

In the case of Iceland, Liechtenstein and Luxembourg, all schools and all eligible students within schools were included in the sample. However, since not all students in the PISA samples were assessed in all domains, these national samples represent a complete census only in respect of the assessment of mathematical literacy as the major domain, and not for the assessment of problem solving.

Experts from the PISA Consortium performed the sample selection process for each participating country and monitored it closely in those countries where they selected their own samples.

The second stage of the selection process sampled students within sampled schools. Once schools were selected, a list of each sampled school's 15 -year-old students was prepared. From this list, 35 students were then selected with equal probability (all 15 -year-old students were selected if fewer than 35 were enrolled).

Data quality standards in PISA required minimum participation rates for schools as well as for students. These standards were established to minimise the potential for response biases. In the case of countries meeting these standards, it was likely that any bias resulting from non-response would be negligible, i.e. typically smaller than the sampling error.

A minimum response rate of 85 per cent was required for the schools initially selected. Where the initial response rate of schools was between 65 and 85 per cent, however, an acceptable school response rate could still be achieved through the use of replacement schools. This procedure brought with it a risk of increased response bias. Participating countries were, therefore, encouraged to persuade as many of the schools in the original sample as possible to participate. Schools with a student participation rate between 25 and 50 per cent were not regarded as participating schools, but data from these schools were included in the database and contributed to the various estimations. Data from schools with a student participation rate of less than 25 per cent were excluded from the database.

PISA 2003 also required a minimum participation rate of 80 per cent of students within participating schools. This minimum participation rate had to be met at the national level, not necessarily by each participating school. Follow-up sessions were required in schools in which too few students had participated in the original assessment sessions. Student participation rates were calculated over all original schools, and also over all schools whether original sample or replacement schools, and from the participation of students in both the original assessment and any follow-up sessions. A student who participated in the original or follow-up cognitive sessions was regarded as a participant. Those who attended only the questionnaire session were 
included in the international database and contributed to the statistics presented in this publication if he or she provided at least a description of his or her father's or mother's occupation.

Table A3. 3 shows the response rates for students and schools, before and after replacement.

- Column 1 shows the weighted participation rate of schools before replacement. This is obtained by dividing column 2 by column 3 .

- Column 2 shows the weighted number of responding schools before school replacement (weighted by student enrolment).

- Column 3 shows the weighted number of sampled schools before school replacement (including both responding and non responding schools) (weighted by student enrolment).

- Column 4 shows the unweighted number of responding schools before school replacement.

- Column 5 shows the unweighted number of responding and non responding schools before school replacement.

- Column 6 shows the weighted participation rate of schools after replacement. This is obtained by dividing column 7 by column 8. Canada, the United Kingdom and the United States did not meet PISA's requirements for response rates before replacement, which was 85 per cent. The participation rate of Canada before replacement was 79.9 per cent (column 1) reaching 84.4 per cent after replacement, thus short by 3.1 per cent of the required 87.5 per cent. In the United Kingdom, the response rate before replacement was 64.3 (column 1) falling short of the minimum requirement by 0.7 per cent. After replacement, the participation rate increased to 77.4 , still short of the final requirement. The United States achieved an initial participation rate of 64.9 before replacement reaching 68.1 after replacement

- Column 7 shows the weighted number of responding schools after school replacement (weighted by student enrolment).

- Column 8 shows the weighted number of schools sampled after school replacement (including both responding and nonresponding schools) (weighted by student enrolment).

- Column 9 shows the unweighted number of responding schools after school replacement.

- Column 10 shows the unweighted number of responding and non responding schools after school replacement.

- Column 11 shows the weighted student participation rate after replacement. This is obtained by dividing column 12 by column 13. The United Kingdom was the only country where the student participation rate of 77.9 per cent was below the required 80 per cent.

- Column 12 shows the weighted number of students assessed.

- Column 13 shows the weighted number of students sampled (including both students that were assessed and students who were absent on the day of the assessment).

- Column 14 shows the unweighted number of students assessed. Note that any students in schools with student response rates less than 50 per cent were not included in these rates (both weighted and unweighted).

- Column 15 shows the unweighted number of students sampled (including both students that were assessed and students who were absent on the day of the assessment). Note that any students in schools with student response rates less than 50 per cent were not included in these rates (both weighted and unweighted).

\section{Reporting of data for the United Kingdom in PISA 2003}

In order to ensure that PISA yields reliable and internationally comparable data, OECD Member countries agreed on a process for the validation of all national data submissions. As the basis for this process, PISA established technical standards for the quality of datasets which countries must meet in order to be reported in OECD publications. These standards are described in detail in the PISA 2003 Technical Report (OECD, forthcoming). One of the requirements is that initial response rates should be 85 per cent at the school level and 80 per cent at the student level. The response rates are reported in Table A3.3.

The United Kingdom fell significantly short of these standards, with a weighted school participation rate before replacement of 64.3 per cent at the school level. As mentioned above, the Technical Standards include an approved procedure through which countries with an initial school-level response rate of at least 65 per cent could improve response rates through the use of designated replacement schools. For the United Kingdom, a school-level response rate of 96 per cent was required, but only 77.4 per cent was achieved after replacement and it was 77.9 per cent at the student level. 
Table A3.3

\begin{tabular}{|c|c|c|c|c|c|c|c|c|c|c|}
\hline & \multicolumn{5}{|c|}{ Initial sample - before school replacement } & \multicolumn{5}{|c|}{ Final sample - after school replacement } \\
\hline & $\begin{array}{c}(1) \\
\text { Weighted school } \\
\text { participation } \\
\text { rate before } \\
\text { replacement } \\
(\%) \\
\end{array}$ & $\begin{array}{l}\text { (2) } \\
\text { Number } \\
\text { of responding } \\
\text { schools } \\
\text { (weighted by } \\
\text { enrolment) }\end{array}$ & $\begin{array}{l}\text { (3) } \\
\text { Weighted number of } \\
\text { schools sampled } \\
\text { (responding and non- } \\
\text { responding) (weighted } \\
\text { by enrolment) }\end{array}$ & $\begin{array}{l}\text { (4) } \\
\text { Number of } \\
\text { responding } \\
\text { schools } \\
\text { (unweighted) }\end{array}$ & \begin{tabular}{|c|}
$\mathbf{5})$ \\
Number of \\
responding and \\
non-responding \\
schools \\
(unweighted) \\
\end{tabular} & \begin{tabular}{|c}
$\mathbf{( 6 )}$ \\
Weighted school \\
participation \\
rate after \\
replacement \\
$(\%)$ \\
\end{tabular} & $\begin{array}{c}\text { (7) } \\
\text { Weighted } \\
\text { number of } \\
\text { responding } \\
\text { schools (weighted } \\
\text { by enrolment) } \\
\end{array}$ & $\begin{array}{c}\mathbf{( 8 )} \\
\text { Number of schools } \\
\text { sampled (responing } \\
\text { and non-responding) } \\
\text { (weighted by } \\
\text { enrolment) }\end{array}$ & $\begin{array}{c}\text { (9) } \\
\text { Number of } \\
\text { responding } \\
\text { schools } \\
\text { (unweighted) }\end{array}$ & $\begin{array}{c}\text { (10) } \\
\text { Number of } \\
\text { responding and } \\
\text { non-responding } \\
\text { schools } \\
\text { (unweighted) } \\
\end{array}$ \\
\hline Australia & 86.31 & 237525 & 275208 & 301 & 355 & 90.43 & 248876 & 275208 & 314 & 355 \\
\hline & & & $87^{\circ}$ & 192 & 194 & 99 & 87169 & 87795 & 192 & 194 \\
\hline Belgium & $\begin{array}{l}83.40 \\
79.95\end{array}$ & 98423 & 118010 & 248 & $\begin{array}{r}296 \\
1162\end{array}$ & $\begin{array}{r}95.63 \\
84.38\end{array}$ & 112775 & 117924 & 282 & 296 \\
\hline $\begin{array}{l}\text { Canada } \\
\text { Czech Republic }\end{array}$ & $\begin{array}{l}79.95 \\
91.38\end{array}$ & $\begin{array}{l}300328 \\
113178\end{array}$ & $\begin{array}{l}375622 \\
123855\end{array}$ & $\begin{array}{r}1040 \\
239\end{array}$ & $\begin{array}{r}1162 \\
262\end{array}$ & $\begin{array}{l}84.38 \\
9905\end{array}$ & $\begin{array}{l}316977 \\
122629\end{array}$ & $\begin{array}{r}375638 \\
123811\end{array}$ & $\begin{array}{l}1066 \\
259\end{array}$ & 1162 \\
\hline $\begin{array}{l}\text { Denmark } \\
\text { Dentic }\end{array}$ & $\begin{array}{l}81.38 \\
84.60\end{array}$ & $\begin{array}{r}113178 \\
47573\end{array}$ & $\begin{array}{r}123855 \\
56234\end{array}$ & $\begin{array}{l}239 \\
175\end{array}$ & $\begin{array}{l}262 \\
210\end{array}$ & $\begin{array}{l}99.05 \\
98.32\end{array}$ & $\begin{array}{r}122629 \\
55271\end{array}$ & $\begin{array}{r}123811 \\
56213\end{array}$ & $\begin{array}{l}259 \\
205\end{array}$ & $\begin{array}{l}262 \\
210\end{array}$ \\
\hline Finland & 97.39 & 58209 & 59766 & 193 & 197 & 100.00 & 59766 & 59766 & 197 & 97 \\
\hline France & 88.65 & 671417 & 757355 & 162 & 183 & 89.24 & 675840 & 757355 & 163 & 183 \\
\hline Germany & 98.06 & 886841 & 904387 & 211 & 216 & 98.82 & 893879 & 904559 & 213 & 216 \\
\hline Greece & & 82526 & 102384 & 145 & 179 & 95.77 & 104859 & 109490 & 171 & 179 \\
\hline $\begin{array}{l}\text { Hungary } \\
\text { Iceland }\end{array}$ & $\begin{array}{l}97.32 \\
9990\end{array}$ & $\begin{array}{l}115041 \\
4082\end{array}$ & $\begin{array}{l}118207 \\
4086\end{array}$ & $\begin{array}{l}248 \\
129\end{array}$ & & 99.37 & 117269 & 118012 & 252 & 262 \\
\hline $\begin{array}{l}\text { Iceland } \\
\text { Ireland }\end{array}$ & $\begin{array}{l}99.90 \\
90.24\end{array}$ & $\begin{array}{r}4082 \\
52791\end{array}$ & $\begin{array}{r}4086 \\
58499\end{array}$ & $\begin{array}{l}129 \\
139\end{array}$ & $\begin{array}{l}131 \\
154\end{array}$ & $\begin{array}{l}99.90 \\
92.84\end{array}$ & $\begin{array}{r}4082 \\
54310\end{array}$ & $\begin{array}{r}4086 \\
58499\end{array}$ & $\begin{array}{l}129 \\
143\end{array}$ & $\begin{array}{l}131 \\
154\end{array}$ \\
\hline $\begin{array}{l}\text { Iteland } \\
\text { Italy }\end{array}$ & $\begin{array}{l}90.24 \\
97.54\end{array}$ & 549168 & 563039 & 398 & $\begin{array}{l}154 \\
406\end{array}$ & $\begin{array}{r}92.84 \\
100.00\end{array}$ & $\begin{array}{r}54310 \\
563039\end{array}$ & $\begin{array}{r}58499 \\
563039\end{array}$ & $\begin{array}{l}143 \\
406\end{array}$ & $\begin{array}{l}154 \\
406\end{array}$ \\
\hline Japan & 87.12 & 1144942 & 1314227 & 131 & 150 & 95.91 & 1260428 & 1314227 & 144 & 50 \\
\hline & 95.89 & 589540 & 614825 & 143 & 149 & 100.00 & 614825 & 614825 & 149 & 149 \\
\hline Luxembourg & & 4087 & 4090 & 29 & 32 & 99.93 & 4087 & 4090 & 29 & 32 \\
\hline Mexi & 93.98 & 1132315 & 1204851 & 1090 & 1154 & 95.45 & 1150023 & 1204851 & 1102 & 1154 \\
\hline $\begin{array}{l}\text { Netherlands } \\
\text { New Zealand }\end{array}$ & 82.61 & 161682 & $\begin{array}{r}195725 \\
53135\end{array}$ & 144 & 175 & $\begin{array}{l}87.86 \\
9755\end{array}$ & $\begin{array}{l}171955 \\
51\end{array}$ & 195725 & 153 & 175 \\
\hline $\begin{array}{l}\text { New Zealand } \\
\text { Norwav }\end{array}$ & $\begin{array}{l}91.09 \\
87.87\end{array}$ & $\begin{array}{l}48401 \\
48219\end{array}$ & $\begin{array}{l}53135 \\
54874\end{array}$ & $\begin{array}{l}158 \\
175\end{array}$ & $\begin{array}{l}175 \\
200\end{array}$ & $\begin{array}{l}97.55 \\
9040\end{array}$ & $\begin{array}{l}51842 \\
49608\end{array}$ & $\begin{array}{l}53145 \\
54874\end{array}$ & $\begin{array}{l}171 \\
180\end{array}$ & 175 \\
\hline $\begin{array}{l}\text { Norway } \\
\text { Poland }\end{array}$ & $\begin{array}{l}8.81 \\
95.12\end{array}$ & $\begin{array}{r}48219 \\
531479\end{array}$ & $\begin{array}{r}54874 \\
558752\end{array}$ & $\begin{array}{l}175 \\
157\end{array}$ & $\begin{array}{l}200 \\
166\end{array}$ & $\begin{array}{l}90.40 \\
98.09\end{array}$ & $\begin{array}{r}49608 \\
548168\end{array}$ & $\begin{array}{r}54874 \\
558853\end{array}$ & 180 & 200 \\
\hline Portugal & 98 & 106174 & 106 & 152 & 15 & $\begin{array}{l}9.09 \\
99.31\end{array}$ & $\begin{array}{l}48168 \\
106174\end{array}$ & 106916 & $\begin{array}{l}163 \\
152\end{array}$ & 166 \\
\hline Slovak Republic & 98 & 406170 & 4128 & 377 & 38 & 100. & 412777 & $\begin{array}{l}106916 \\
412777\end{array}$ & $\begin{array}{l}152 \\
383\end{array}$ & $\begin{array}{l}153 \\
383 \\
383\end{array}$ \\
\hline $\mathrm{Sp}$ & 78 & 636 & 80626 & 223 & 284 & 99.08 & 80394 & 81141 & & \\
\hline & 9 & 112467 & 113511 & 185 & 188 & 99.08 & 112467 & 113511 & & \\
\hline Switzerland & 97.32 & 77867 & 80011 & 437 & 456 & 98.53 & 78838 & 80014 & & \\
\hline Turkey & 93.29 & 671385 & 719702 & 145 & 15 & 100.00 & 719405 & 719405 & & \\
\hline $\begin{array}{l}\text { United Kingdom } \\
\text { United States }\end{array}$ & 64.32 & 456818 & $\begin{array}{r}710203 \\
3774330\end{array}$ & 311 & 45 & 77.3 & 549059 & 709641 & & \\
\hline United Statés & 64.94 & 2451083 & 3774330 & 249 & 382 & 68.12 & 2571003 & 3774322 & 262 & 382 \\
\hline Brazil & 93.20 & 2181287 & 2340538 & 213 & 229 & 99.51 & 2328972 & 2340538 & 228 & 229 \\
\hline China & & $\begin{array}{r}59216 \\
2173824\end{array}$ & $\begin{array}{r}72312 \\
2173824\end{array}$ & 124 & $\begin{array}{l}151 \\
344\end{array}$ & $\begin{array}{r}95.90 \\
100.00\end{array}$ & $\begin{array}{r}69345 \\
2173824\end{array}$ & $\begin{array}{r}72312 \\
2173824\end{array}$ & 145 & $\begin{array}{l}151 \\
344\end{array}$ \\
\hline $\begin{array}{l}\text { Ind } \\
\text { Lat! }\end{array}$ & $\begin{array}{r}100.00 \\
95.31\end{array}$ & $\begin{array}{r}2113824 \\
33845\end{array}$ & $\begin{array}{r}2173824 \\
35509\end{array}$ & $\begin{array}{l}344 \\
157\end{array}$ & & $\begin{array}{r}100.00 \\
95.31\end{array}$ & $\begin{array}{r}2173845 \\
33845\end{array}$ & $\begin{array}{r}217502 \\
35509\end{array}$ & $\begin{array}{l}344 \\
157\end{array}$ & $\begin{array}{l}344 \\
164\end{array}$ \\
\hline Liechtenstein & 100.00 & 348 & 348 & 12 & 12 & 100.00 & 348 & 348 & 12 & 12 \\
\hline Macao-Chin & 100.00 & 6992 & 6992 & 39 & 39 & 100.00 & 6992 & 6992 & 39 & 39 \\
\hline Russian Federation & 99.51 & 1798096 & 1806954 & 210 & 211 & 100 & 1806954 & 1806954 & 211 & 211 \\
\hline Serb & 100.00 & 90178 & 901 & 14 & 14 & 100 & 90178 & 9 & 149 & 149 \\
\hline & 9 & 704344 & 77 & & 1 & & 769392 & 769392 & & 179 \\
\hline $\begin{array}{l}\text { Tunisia } \\
\text { Uruguay }\end{array}$ & $\begin{array}{r}100.00 \\
93.20\end{array}$ & $\begin{array}{r}163555 \\
39773\end{array}$ & $\begin{array}{r}163555 \\
42677\end{array}$ & $\begin{array}{l}149 \\
233\end{array}$ & $\begin{array}{l}149 \\
245\end{array}$ & $\begin{array}{r}100.00 \\
97.11\end{array}$ & $\begin{array}{r}163555 \\
41474\end{array}$ & $\begin{array}{r}163555 \\
42709\end{array}$ & $\begin{array}{l}149 \\
239\end{array}$ & $\begin{array}{l}149 \\
245\end{array}$ \\
\hline & & & & & & 97.11 & $414 / 4$ & 42709 & 239 & \\
\hline
\end{tabular}

Final sample - Students within schools after school replacement

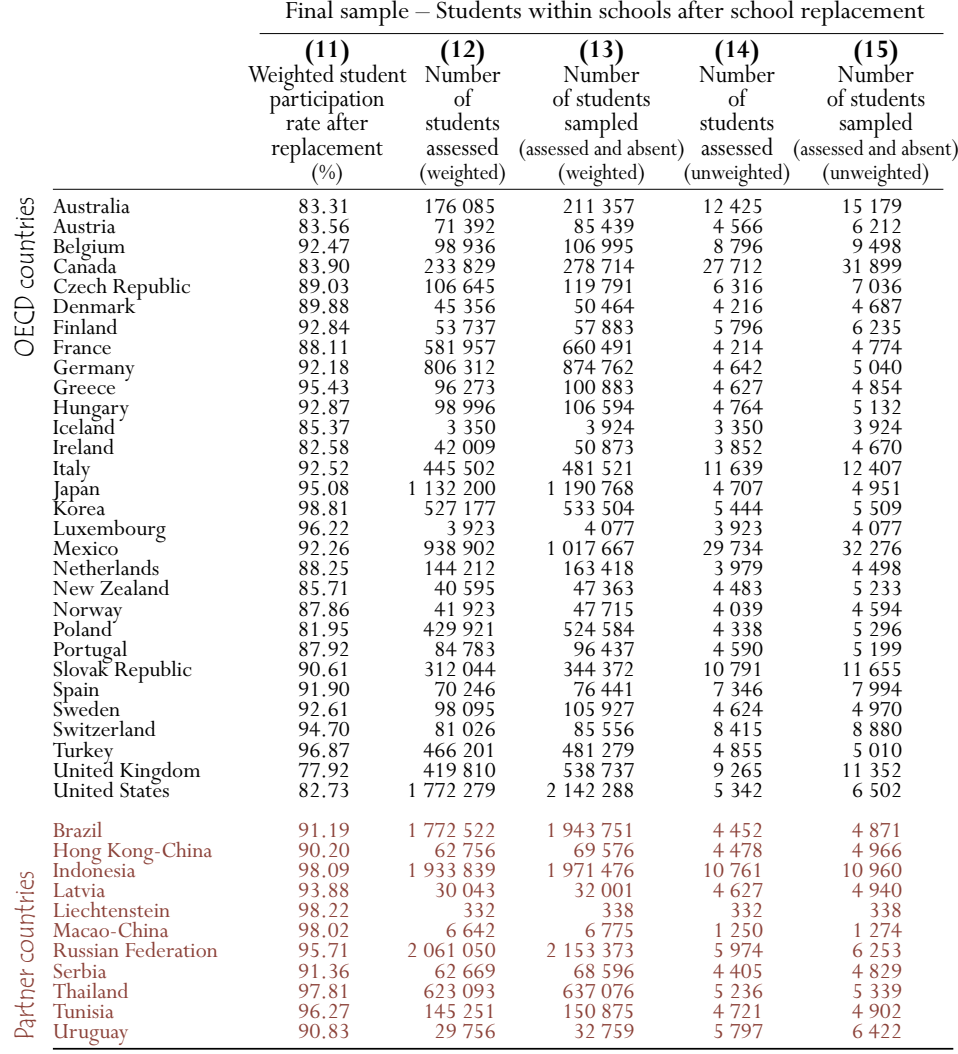


$\stackrel{m}{\varangle}$ The results of a subsequent bias analysis provided no evidence for any significant bias of school-level performance results but did suggest that there was potential non-response bias at student levels. The PISA Consortium concluded that it was not possible to reliably assess the magnitude, or even the direction, of this non-response bias and to correct for this. As a result, it is not possible to say with confidence that the United Kingdom's sample results reliably reflect those for the national population, with the level of accuracy required by PISA. The mean performance of the responding sample of United Kingdom pupils was 510 score points in problem solving. The uncertainties surrounding the sample and its bias are such that scores for the United Kingdom cannot reliably be compared with those of other countries.

The results are, however, accurate for many within-country comparisons between subgroups (e.g. males and females) and for relational analyses. The results for the United Kingdom have, therefore, been included in a separate category below the results for the other participating countries. Other data for the United Kingdom that are not reported in this volume are available at www.pisa.oecd.org to allow researchers to reproduce the results from the international comparisons.

All international averages and aggregate statistics include the data for the United Kingdom.

It should be noted that Scotland and Northern Ireland carried out an independent sample that met the PISA technical standards, and that these data are available at www.pisa.oecd.org. 
The statistics in this report represent estimates of national performance based on samples of students rather than values that could be calculated if every student in every country had answered every question. Consequently, it is important to have measures of the degree of uncertainty of the estimates. In PISA, each estimate has an associated degree of uncertainty, which is expressed through a standard error. The use of confidence intervals provides a way to make inferences about the population means and proportions in a manner that reflects the uncertainty associated with the sample estimates. From an observed sample statistic it can, under the assumption of a normal distribution, be inferred that the corresponding population result would lie within the confidence interval in 95 out of 100 replications of the measurement on different samples drawn from the same population.

In many cases, readers are primarily interested in whether a given value in a particular country is different from a second value in the same or another country, e.g. whether females in a country perform better than males in the same country. In the tables and charts used in this report, differences are labelled as statistically significant when a difference of that size, smaller or larger, would be observed less than 5 per cent of the time, if there was actually no difference in corresponding population values. Similarly, the risk of reporting as significant if there is, in fact, no correlation between two measures is contained at 5 per cent.

Although the probability that a particular difference will falsely be declared to be statistically significant is low ( 5 per cent) in each single comparison, the probability of making such an error increases when several comparisons are made simultaneously.

It is possible to make an adjustment for this which reduces to 5 per cent the maximum probability that differences will be falsely declared as statistically significant at least once among all the comparisons that are made. Such an adjustment, based on the Bonferroni method, has been incorporated into the multiple comparison charts in Chapters 2. The adjusted significance test should be used when the interest of readers is to compare a country's performance with that of all other countries. For comparing a single country with another single country, no adjustment is needed.

For all other tables and charts readers should note that, if there were no real differences on a given measure, then the multiple comparison in conjunction with a 5 per cent significance level, would erroneously identify differences on 0.05 times the number of comparisons made, occasions. For example, even though the significance tests applied in PISA for identifying gender differences ensure that, for each country, the likelihood of identifying a gender difference erroneously is less than 5 per cent, a comparison showing differences for 30 countries would, on average, identify 1.35 cases (0.05 times 30) with significant gender differences, even if there were no real gender difference in any of the countries. The same applies for other statistics for which significance tests have been undertaken in this publication, such as correlations and regression coefficients.

Throughout the report, significance tests were undertaken to assess the statistical significance of the comparisons made.

\section{Gender differences}

Gender differences in student performance or other indices were tested for statistical significance. Positive differences indicate higher scores for males while negative differences indicate higher scores for females. Differences marked in bold in the tables in Annex B1 are statistically significant at the 95 per cent confidence level. For examples, see Table 5.1, Annex B1.

\section{Performance differences between top and bottom quartiles}

Differences in average performance between the top quarter and the bottom quarter on the PISA indices were tested for statistical significance. Figures marked in bold indicate that performance between the top and bottom quarter of students on the respective index is statistically significantly different at the 95 per cent confidence level.

\section{Change in the performance per unit of the index}

For many tables in Annex B1, the difference in student performance per unit of the index shown was calculated. Figures in bold indicate that the differences are statistically significantly different from zero at the 95 per cent confidence level. 

The development of the PISA 2003 assessment instruments was an interactive process between the PISA Consortium, the various expert committees, the PISA Governing Board and national experts. A panel of international experts led, in close consultation with participating countries, the identification of the range of skills and competencies that were, in the respective assessment domains, considered to be crucial for an individual's capacity to fully participate in and contribute to a successful modern society. A description of the assessment domains - the assessment framework - was then used by participating countries, and other test development professionals, as they contributed assessment materials. The development of this assessment framework involved the following steps:

- development of a working definition for the domain and description of the assumptions that underlay that definition;

- evaluation of how to organise the set of tasks constructed in order to report to policy-makers and researchers on performance in each assessment domain among 15-year-old students in participating countries;

- identification of a set of key characteristics to be taken into account when assessment tasks were constructed for international use;

- operationalisation of the set of key characteristics to be used in test construction, with definitions based on existing literature and the experience of other large-scale assessments;

- validation of the variables, and assessment of the contribution which each made to the understanding of task difficulty in participating countries; and

- preparation of an interpretative scheme for the results.

The frameworks were agreed at both scientific and policy levels and subsequently provided the basis for the development of the assessment instruments. The frameworks are described in The PISA 2003 Assessment Framework - Mathematics, Reading, Science and Problem Solving Knowledge and Skills (OECD, 2003b). They provided a common language and a vehicle for participating countries to develop a consensus as to the measurement goals of PISA.

Assessment items were then developed to reflect the intentions of the frameworks and were piloted in a Field Trial in all participating countries before a final set of items was selected for the PISA 2003 Main Study.

Due attention was paid to reflecting the national, cultural and linguistic variety among OECD countries. As part of this effort the PISA Consortium used professional test item development teams in several different countries, including Australia, the United Kingdom, the Netherlands and Japan. In addition to the items that were developed by the PISA Consortium teams, assessment material was contributed by participating countries. The Consortium's multi-national team of test developers deemed a substantial amount of this submitted material as appropriate given the requirements laid out by the PISA assessment frameworks. As a result, the item pool included assessment items from Argentina, Australia, Austria, Canada, Czech Republic, Denmark, Finland, France, Germany, Greece, Ireland, Italy, Japan, Korea, the Netherlands, New Zealand, Norway, Portugal, Sweden, Switzerland, and the United States. About one-third of items selected for inclusion in the Field Trial were submitted by participating countries, and about 37 per cent of items selected for the Main Study were from participating countries.

Approximately 232 units comprising about 530 items were included in item bundles for national review, in the mathematics, problem solving and science areas. After the first consultation process, the Field Trial included 115 mathematics units with 217 mathematics items. Of these mathematics units, the stimulus material for 53 came from national contributions, 80 originated with the PISA Consortium, and one unit came from the Third International Mathematics and Science Study (TIMSS).

Each item included in the assessment pool was then rated by each country: for potential cultural, gender or other bias; for relevance to 15-year-olds in school and non-school contexts; and for familiarity and level of interest. A first consultation of countries on the item pool was undertaken as part of the process of developing the Field Trial assessment instruments. A second consultation was undertaken after the Field Trial to assist in the final selection of items for the Main Study.

Following the Field Trial, in which all items were tested in all participating countries, test developers and expert groups considered a variety of aspects in selecting the items for the Main Study: i) the results from the Field Trial, ii) the outcome of the item review from countries, and iii) queries received during the Field Trial marking process. The test developers and expert groups selected a final set of items in October 2002 which, following a period of negotiation, was adopted by participating countries at both scientific and policy levels. 

The process of marking open-ended items was an important step in ensuring the quality and comparability of results from PISA.

Detailed guidelines contributed to a marking process that was accurate and consistent across countries. The marking guidelines consisted of marking manuals, training materials for recruiting markers, and workshop materials used for the training of national markers. Before national training, the PISA Consortium organised training sessions to present the material and train the marking co-ordinators from the participating countries. The latter were then responsible for training their national markers.

For each assessment item, the relevant marking manual described the aim of the question and how to code students' responses to each item. This description included the credit labels - full credit, partial credit or no credit - attached to the possible categories of responses. PISA 2003 also included a system of double-digit coding for the mathematics and science items in which the first digit represented the score and the second digit represented different strategies or approaches that students used to solve the problem. The second digit generated national profiles of student strategies and misconceptions. By way of illustration, the marking manuals also included real examples of students' responses (drawn from the Field Trial) accompanied by a rationale for their classification.

In each country, a sub-sample of assessment booklets was marked independently by four markers and examined by the PISA Consortium. In order to examine the consistency of this marking process in more detail within each country and to estimate the magnitude of the variance components associated with the use of markers, the PISA Consortium conducted an inter-marker reliability study on the sub-sample of assessment booklets. Homogeneity analysis was applied to the national sets of multiple marking and compared with the results of the Field Trial. For details see the PISA 2003 Technical Report (OECD, forthcoming).

At the between-country level, an inter-country reliability study was carried out on a sub-set of items. The aim was to check whether the marking given by national markers was of equal severity in each country, both overall and for particular items. In this process, independent marking of the original booklets was undertaken by trained multilingual staff and compared to the ratings by the national markers in the various countries. The results showed that very consistent marks were achieved across countries. The average index of agreement in the inter-country reliability study was 92 per cent (out of 71941 student responses that were independently scored by the international verifiers). Agreement meant both cases where the international verifier agreed with at least three of the national markers and cases where the verifier disagreed with the national markers, but the adjudication undertaken by the PISA Consortium's test developers concluded, after reviewing the translated student's answer, that the national markers had given the correct mark. Only 6 countries had rates of agreement lower than 90 per cent (with a minimum of 86 per cent in Spain [Catalonian region]). On average, marking was too harsh in 1.8 per cent of cases and too lenient in 3.1 per cent of cases. The highest per cent of too harsh codes (7 per cent) was observed for the science items in Portugal, and the highest per cent of too lenient marks (10 per cent) was observed for the science items in Indonesia. A full description of this process and the results can be found in the PISA 2003 Technical Report (OECD, forthcoming). 


\section{Annex B}

\section{DATA TABLES}


Table 2.1

Percentage of students at each level of proficiency on the problem-solving scale

\begin{tabular}{|c|c|c|c|c|c|c|c|c|}
\hline & \multicolumn{8}{|c|}{ Proficiency levels } \\
\hline & \multicolumn{2}{|c|}{$\begin{array}{c}\text { Below Level } 1 \\
\text { (below } 405 \text { score points) }\end{array}$} & \multicolumn{2}{|c|}{$\begin{array}{c}\text { Level } 1 \\
\text { (from } 405 \text { to } 499 \text { score points) }\end{array}$} & \multicolumn{2}{|c|}{$\begin{array}{c}\text { Level } 2 \\
\text { (from } 499 \text { to } 592 \text { score points) }\end{array}$} & \multicolumn{2}{|c|}{$\begin{array}{c}\text { Level } 3 \\
\text { (above } 592 \text { score points) }\end{array}$} \\
\hline & $\%$ & S.E. & $\%$ & S.E. & $\%$ & S.E. & $\%$ & S.E. \\
\hline Australia & 9 & $(0.6)$ & 26 & $(0.7)$ & 39 & $(0.8)$ & 26 & $(0.8)$ \\
\hline Austria & 14 & $(1.0)$ & 32 & $(1.1)$ & 37 & $(1.1)$ & 17 & $(1.2)$ \\
\hline Belgium & 14 & $(0.7)$ & 24 & $(0.7)$ & 34 & $(0.8)$ & 28 & $(0.9)$ \\
\hline Canada & 8 & $(0.5)$ & 27 & $(0.7)$ & 40 & $(0.7)$ & 25 & $(0.7)$ \\
\hline Czech Republic & 12 & $(1.1)$ & 29 & $(1.2)$ & 37 & $(1.1)$ & 22 & $(1.2)$ \\
\hline Finland & 5 & $(0.5)$ & 22 & $(0.8)$ & 43 & $(0.8)$ & 30 & $(0.9)$ \\
\hline France & 12 & $(1.0)$ & 28 & $(1.0)$ & 37 & $(1.1)$ & 23 & $(1.0)$ \\
\hline Germany & 14 & $(1.0)$ & 28 & $(1.1)$ & 36 & $(1.5)$ & 22 & $(1.4)$ \\
\hline Greece & 33 & $(1.5)$ & 36 & $(1.0)$ & 24 & $(1.2)$ & 7 & $(0.8)$ \\
\hline Hungary & 16 & $(1.0)$ & 32 & $(1.4)$ & 35 & $(1.2)$ & 17 & $(1.2)$ \\
\hline Iceland & 12 & $(0.7)$ & 32 & $(1.0)$ & 40 & $(1.0)$ & 15 & $(0.6)$ \\
\hline Ireland & 13 & $(0.9)$ & 37 & $(1.2)$ & 38 & $(1.0)$ & 12 & $(0.8)$ \\
\hline Italy & 25 & (1.3) & 35 & $(1.2)$ & 30 & $(1.0)$ & 11 & $(0.7)$ \\
\hline Japan & 10 & $(1.0)$ & 20 & $(1.0)$ & 34 & $(1.2)$ & 36 & (1.6) \\
\hline Korea & 5 & $(0.5)$ & 22 & $(1.0)$ & 41 & $(1.1)$ & 32 & $(1.3)$ \\
\hline Luxembourg & 17 & $(0.7)$ & 34 & $(1.0)$ & 35 & $(1.0)$ & 14 & $(0.6)$ \\
\hline New Zealand & 10 & $(0.8)$ & 25 & $(0.8)$ & 36 & $(1.0)$ & 28 & $(0.9)$ \\
\hline Norway & 19 & $(0.9)$ & 33 & $(1.2)$ & 33 & $(1.0)$ & 15 & $(0.8)$ \\
\hline Poland & 18 & (1.0) & 37 & $(1.0)$ & 34 & $(1.1)$ & 12 & $(0.7)$ \\
\hline Portugal & 24 & $(1.7)$ & 36 & $(1.1)$ & 31 & $(1.4)$ & 9 & $(0.6)$ \\
\hline Slovak Republic & 17 & (1.4) & 34 & $(1.2)$ & 34 & $(1.3)$ & 14 & $(1.0)$ \\
\hline Spain & 20 & $(0.9)$ & 35 & $(1.1)$ & 33 & $(1.2)$ & 12 & $(0.8)$ \\
\hline Sweden & 12 & $(0.9)$ & 32 & $(1.1)$ & 38 & $(1.0)$ & 17 & $(1.0)$ \\
\hline Switzerland & 11 & $(0.7)$ & 27 & $(1.0)$ & 39 & (1.1) & 23 & (1.4) \\
\hline Turkey & 51 & $(2.5)$ & 33 & $(1.6)$ & 12 & $(1.6)$ & 4 & $(1.2)$ \\
\hline United States & 24 & $(1.1)$ & 34 & $(0.8)$ & 30 & $(1.0)$ & 12 & $(0.8)$ \\
\hline OECD total & 22 & $(0.4)$ & 30 & $(0.3)$ & 31 & $(0.4)$ & 17 & $(0.3)$ \\
\hline OECD average & 17 & $(0.2)$ & 30 & $(0.2)$ & 34 & $(0.2)$ & 18 & $(0.2)$ \\
\hline Brazil & 64 & $(1.9)$ & 26 & $(1.5)$ & 9 & $(1.1)$ & 2 & $(0.5)$ \\
\hline Hong Kong-China & 8 & $(1.1)$ & 21 & $(1.0)$ & 36 & $(1.2)$ & 35 & (1.4) \\
\hline Indonesia & 73 & $(1.7)$ & 23 & $(1.4)$ & 4 & $(0.6)$ & 0 & $(0.1)$ \\
\hline Latvia & 20 & $(1.5)$ & 36 & $(1.3)$ & 32 & $(1.4)$ & 12 & $(1.0)$ \\
\hline Liechtenstein & 10 & $(1.5)$ & 26 & $(2.4)$ & 37 & (3.6) & 27 & (2.6) \\
\hline Macao-China & 6 & $(0.8)$ & 27 & $(1.4)$ & 42 & $(2.0)$ & 24 & $(1.6)$ \\
\hline Russian Federation & 23 & $(1.7)$ & 34 & $(1.0)$ & 31 & $(1.3)$ & 12 & $(1.0)$ \\
\hline Serbia & 43 & $(1.7)$ & 39 & $(1.2)$ & 16 & $(1.2)$ & 2 & $(0.3)$ \\
\hline Thailand & 41 & (1.6) & 40 & $(1.1)$ & 16 & $(1.1)$ & 3 & $(0.5)$ \\
\hline United Kingdom $^{1}$ & $\mathrm{~m}$ & $\mathrm{~m}$ & $\mathrm{~m}$ & $\mathrm{~m}$ & $\mathrm{~m}$ & $\mathrm{~m}$ & $\mathrm{~m}$ & $\mathrm{~m}$ \\
\hline
\end{tabular}

1. Response rate too low to ensure comparability (see Annex A3). 
Table 2.2

Mean score and variation in student performance on the problem-solving scale

\begin{tabular}{|c|c|c|c|c|c|c|c|c|c|c|c|c|c|c|c|c|}
\hline & \multicolumn{2}{|c|}{ Mean score } & \multicolumn{2}{|c|}{ Standard deviation } & \multicolumn{2}{|c|}{5 th percentile } & \multicolumn{2}{|c|}{ 10th percentile } & \multicolumn{2}{|c|}{25 th percentile } & \multicolumn{2}{|c|}{ 75th percentile } & \multicolumn{2}{|c|}{ 90th percentile } & \multicolumn{2}{|c|}{ 95th percentile } \\
\hline & Mean & S.E. & S.D. & S.E. & Score & S.E. & Score & S.E. & Score & S.E. & Score & S.E. & Score & S.E. & Score & S.E. \\
\hline Australia & 530 & $(2.0)$ & 91 & $(1.4)$ & 371 & $(4.1)$ & 409 & $(3.5)$ & 469 & $(2.8)$ & 594 & $(2.1)$ & 644 & $(2.7)$ & 672 & (3.4) \\
\hline Austria & 506 & (3.2) & 90 & (1.7) & 357 & (5.1) & 388 & (4.5) & 443 & $(4.1)$ & 569 & $(4.0)$ & 621 & $(4.2)$ & 651 & (4.6) \\
\hline Belgium & 525 & $(2.2)$ & 104 & $(1.5)$ & 340 & $(5.0)$ & 383 & $(4.5)$ & 456 & (3.3) & 602 & $(2.6)$ & 653 & $(2.0)$ & 681 & (2.0) \\
\hline Canada & 529 & (1.7) & 88 & $(0.9)$ & 379 & (2.4) & 414 & $(2.8)$ & 471 & $(2.5)$ & 591 & (1.9) & 640 & $(2.1)$ & 669 & (2.4) \\
\hline Czech Republic & 516 & (3.4) & 93 & (1.9) & 356 & $(8.6)$ & 394 & $(6.2)$ & 454 & $(4.4)$ & 582 & (3.6) & 634 & (3.9) & 663 & $(4.0)$ \\
\hline Denmark & 517 & $(2.5)$ & 87 & (1.5) & 369 & $(5.0)$ & 402 & (4.3) & 459 & (3.1) & 578 & $(2.8)$ & 627 & (3.4) & 655 & (3.7) \\
\hline Finland & 548 & (1.9) & 82 & (1.2) & 409 & $(4.7)$ & 442 & (2.8) & 495 & (2.5) & 604 & (2.3) & 650 & (2.3) & 677 & (3.6) \\
\hline France & 519 & (2.7) & 93 & $(2.1)$ & 358 & $(6.1)$ & 396 & $(4.8)$ & 459 & (3.9) & 586 & (3.0) & 635 & (3.7) & 662 & $(4.5)$ \\
\hline Germany & 513 & (3.2) & 95 & $(1.8)$ & 351 & (5.9) & 383 & $(5.3)$ & 447 & $(4.8)$ & 583 & (4.3) & 632 & (2.7) & 658 & (3.2) \\
\hline Greece & 448 & $(4.0)$ & 99 & $(1.7)$ & 283 & $(5.6)$ & 319 & (5.3) & 383 & $(4.5)$ & 517 & $(4.6)$ & 574 & (5.7) & 607 & $(5.6)$ \\
\hline Hungary & 501 & (2.9) & 94 & $(2.0)$ & 343 & $(5.8)$ & 378 & $(4.1)$ & 436 & (3.8) & 567 & (3.9) & 622 & $(4.3)$ & 653 & (5.4) \\
\hline Iceland & 505 & (1.4) & 85 & (1.1) & 358 & (5.5) & 393 & (3.3) & 450 & $(2.2)$ & 564 & $(2.0)$ & 609 & (2.3) & 634 & (3.6) \\
\hline Ireland & 498 & (2.3) & 80 & (1.4) & 364 & (4.5) & 395 & (3.8) & 445 & $(3.1)$ & 555 & (2.7) & 601 & (2.8) & 625 & (3.2) \\
\hline $\begin{array}{l}\text { Italy } \\
\text { I }\end{array}$ & 469 & (3.1) & 102 & $(2.1)$ & 289 & $(8.7)$ & 334 & $(6.5)$ & 406 & $(4.7)$ & 540 & $(3.0)$ & 595 & (3.4) & 627 & (3.6) \\
\hline Japan & 547 & (4.1) & 105 & (2.7) & 362 & $(8.3)$ & 406 & (6.8) & 481 & $(5.7)$ & 621 & $(4.2)$ & 675 & (4.6) & 705 & (6.0) \\
\hline Korea & 550 & (3.1) & 86 & $(2.0)$ & 404 & $(4.6)$ & 438 & $(5.2)$ & 494 & (3.9) & 610 & $(3.5)$ & 658 & $(4.2)$ & 686 & $(5.5)$ \\
\hline Luxembourg & 494 & (1.4) & 92 & $(1.0)$ & 339 & (3.7) & 373 & $(2.3)$ & 432 & (2.4) & 558 & $(2.2)$ & 610 & (2.6) & 640 & (3.4) \\
\hline Mexico & 384 & (4.3) & 96 & $(2.0)$ & 227 & (5.4) & 262 & (5.2) & 317 & $(5.2)$ & 451 & (5.1) & 509 & (5.7) & 542 & (6.5) \\
\hline Netherlands & 520 & (3.0) & 89 & $(2.0)$ & 372 & $(5.9)$ & 401 & $(5.1)$ & 456 & $(4.9)$ & 587 & (3.6) & 636 & (3.3) & 662 & (3.7) \\
\hline New Zealand & 533 & (2.2) & 96 & (1.2) & 370 & (3.8) & 406 & (4.2) & 468 & (3.7) & 601 & $(2.4)$ & 653 & (2.5) & 682 & (2.8) \\
\hline Norway & 490 & (2.6) & 99 & $(1.7)$ & 322 & $(5.5)$ & 361 & $(4.6)$ & 424 & (3.7) & 559 & (3.3) & 615 & $(4.2)$ & 645 & (4.4) \\
\hline Poland & 487 & (2.8) & 90 & (1.7) & 338 & (5.6) & 372 & $(4.1)$ & 428 & (3.1) & 548 & (3.0) & 600 & (3.5) & 632 & (4.5) \\
\hline Portugal & 470 & (3.9) & 92 & $(2.1)$ & 311 & (7.9) & 345 & $(6.8)$ & 409 & (5.7) & 534 & (3.6) & 586 & (3.5) & 614 & (3.5) \\
\hline Slovak Republic & 492 & (3.4) & 93 & $(2.4)$ & 337 & (7.1) & 370 & $(5.9)$ & 430 & $(4.7)$ & 558 & $(3.6)$ & 609 & $(3.8)$ & 638 & $(4.2)$ \\
\hline Spain & 482 & (2.7) & 94 & (1.3) & 322 & (4.8) & 361 & (4.1) & 421 & (3.5) & 547 & (3.2) & 599 & (3.9) & 629 & (3.3) \\
\hline Sweden & 509 & (2.4) & 88 & (1.6) & 360 & (6.4) & 395 & $(4.4)$ & 451 & $(3.0)$ & 571 & (3.1) & 619 & (3.8) & 647 & (3.6) \\
\hline Switzerland & 521 & (3.0) & 94 & (1.9) & 358 & $(5.7)$ & 397 & $(4.0)$ & 461 & (3.3) & 587 & (3.9) & 637 & $(4.6)$ & 666 & $(5.2)$ \\
\hline Turkey & 408 & $(6.0)$ & 97 & $(4.4)$ & 257 & (7.8) & 291 & (6.6) & 343 & $(5.2)$ & 466 & $(7.7)$ & 531 & $(11.9)$ & 577 & $(18.6)$ \\
\hline United States & 477 & (3.1) & 98 & $(1.3)$ & 312 & $(5.6)$ & 347 & $(4.6)$ & 410 & $(4.1)$ & 548 & $(3.3)$ & 604 & $(4.0)$ & 635 & $(4.2)$ \\
\hline OECD total & 490 & (1.2) & 106 & $(0.8)$ & 308 & (2.7) & 348 & (2.2) & 418 & (1.7) & 566 & $(1.3)$ & 624 & $(1.3)$ & 656 & (1.4) \\
\hline OECD average & 500 & (0.6) & 100 & $(0.4)$ & 328 & (1.7) & 368 & (1.3) & 434 & (1.1) & 571 & $(0.8)$ & 625 & $(0.8)$ & 656 & $(0.8)$ \\
\hline Brazil & 371 & $(4.8)$ & 100 & $(2.6)$ & 211 & $(7.5)$ & 244 & $(6.1)$ & 302 & $(4.7)$ & 438 & $(5.7)$ & 501 & $(7.3)$ & 538 & $(8.3)$ \\
\hline Hong Kong-China & 548 & $(4.2)$ & 97 & (2.9) & 376 & $(10.5)$ & 420 & (7.9) & 487 & $(6.1)$ & 617 & $(3.2)$ & 664 & (2.9) & 690 & (3.7) \\
\hline Indonesia & 361 & (3.3) & 73 & (1.7) & 245 & $(4.2)$ & 270 & (3.8) & 312 & (3.6) & 409 & $(4.1)$ & 457 & (5.5) & 487 & (5.9) \\
\hline Latvia & 483 & (3.9) & 92 & (1.7) & 326 & $(7.0)$ & 362 & $(6.0)$ & 420 & $(5.4)$ & 547 & $(4.6)$ & 599 & $(4.1)$ & 628 & (4.9) \\
\hline Liechtenstein & 529 & (3.9) & 93 & $(4.2)$ & 369 & $(14.9)$ & 404 & $(11.1)$ & 468 & $(6.0)$ & 599 & $(9.3)$ & 644 & $(10.5)$ & 672 & $(12.0)$ \\
\hline Macao-China & 532 & $(2.5)$ & 81 & (2.6) & 395 & $(6.4)$ & 425 & $(5.6)$ & 478 & $(3.7)$ & 590 & $(4.3)$ & 633 & $(5.4)$ & 659 & $(6.5)$ \\
\hline Russian Federation & 479 & $(4.6)$ & 99 & $(2.1)$ & 314 & $(7.7)$ & 351 & $(7.0)$ & 413 & $(5.7)$ & 546 & $(5.1)$ & 604 & $(5.0)$ & 637 & $(5.6)$ \\
\hline Serbia & 420 & (3.3) & 86 & (1.6) & 279 & $(4.2)$ & 311 & $(4.4)$ & 363 & (3.9) & 478 & $(4.2)$ & 530 & $(4.9)$ & 560 & $(5.1)$ \\
\hline Thailand & 425 & (2.7) & 82 & $(1.6)$ & 293 & $(3.9)$ & 322 & $(3.4)$ & 369 & $(2.6)$ & 478 & $(4.0)$ & 532 & $(4.0)$ & 565 & $(6.0)$ \\
\hline Tunisia & 345 & (2.1) & 80 & (1.4) & 213 & (4.3) & 243 & (3.1) & 291 & $(2.5)$ & 400 & $(2.8)$ & 446 & $(4.1)$ & 474 & $(5.0)$ \\
\hline Uruguay & 411 & (3.7) & 112 & (1.9) & 224 & $(5.7)$ & 265 & $(5.1)$ & 334 & $(4.7)$ & 488 & $(5.5)$ & 552 & $(5.0)$ & 589 & $(5.7)$ \\
\hline United Kingdom $^{1}$ & $\mathrm{~m}$ & $\mathrm{~m}$ & $\mathrm{~m}$ & $\mathrm{~m}$ & $\mathrm{~m}$ & $\mathrm{~m}$ & $\mathrm{~m}$ & $\mathrm{~m}$ & $\mathrm{~m}$ & $\mathrm{~m}$ & $\mathrm{~m}$ & $\mathrm{~m}$ & $\mathrm{~m}$ & $\mathrm{~m}$ & $\mathrm{~m}$ & $\mathrm{~m}$ \\
\hline
\end{tabular}

1. Response rate too low to ensure comparability (see Annex A3). 
Table 3.1

Factor loadings of mathematics, reading and problem-solving items

The strength of association of each PISA item with two different presumed factors, calculated from students' responses

Problem-solving item Mathematics item Reading item

Item loads higher on factor 1 than on factor 2

\begin{tabular}{|c|c|c|c|c|c|c|c|c|}
\hline Items & $\begin{array}{l}\text { Factor } 1 \\
\text { Loading }\end{array}$ & $\begin{array}{l}\text { Factor } 2 \\
\text { Loading }\end{array}$ & Items & $\begin{array}{l}\text { Factor } 1 \\
\text { Loading }\end{array}$ & $\begin{array}{l}\text { Factor } 2 \\
\text { Loading }\end{array}$ & Items & $\begin{array}{l}\text { Factor } 1 \\
\text { Loading }\end{array}$ & $\begin{array}{l}\text { Factor } 2 \\
\text { Loading }\end{array}$ \\
\hline BRAILLE - Question 2 & 0.400 & & THE BEST CAR - Question 2 & 0.279 & 0.106 & DRUGGED SPIDERS - Question 5 & -0.136 & 0.642 \\
\hline HOLIDAY - Question 2 & 0.393 & & CASH WITHDRAWAL - Question 2 & 0.278 & & OPTICIAN - Question 6 & -0.100 & 0.609 \\
\hline SKATEBOARD - Question 13 & 0.391 & & CARBON DIOXIDE - Question 2 & 0.276 & & OPTICIAN - Question 3 & & 0.576 \\
\hline POPULATION PYRAMIDS - Question 3 & 0.380 & & CARPENTER - Question 1 & 0.275 & & EXCHANGE - Question 6 & & 0.576 \\
\hline BICYCLES - Question 3 & 0.372 & & CARBON DIOXIDE - Question 3 & 0.271 & & EXCHANGE - Question 1 & -0.110 & 0.557 \\
\hline BOOKSHELVES - Question 1 & 0.368 & & CHILDREN'S CAMP - Question 1 & 0.271 & & TELEPHONE - Question 1 & -0.117 & 0.556 \\
\hline NUMBER CUBES - Question 3 & 0.368 & & SEEING THE TOWER - Question 1 & 0.265 & & DRUGGED SPIDERS - Question 3 & & 0.541 \\
\hline POPULATION PYRAMIDS - Question 2 & 0.359 & & HEIGHT - Question 1 & 0.261 & 0.188 & DRUGGED SPIDERS - Question 2 & & 0.521 \\
\hline CONTAINERS - Question 1 & 0.356 & & CHAIR LIFT - Question 2 & 0.258 & & DRUGGED SPIDERS - Question 1 & -0.119 & 0.521 \\
\hline CUBES - Question 1 & 0.355 & & CHAIR LIFT - Question 1 & 0.256 & & OPTICIAN - Question 2 & & 0.494 \\
\hline SUPPORT FOR PRESIDENT - Question 1 & 0.353 & & NUMBER CHECK - Question 1 & 0.255 & & TELEPHONE - Question 5 & & 0.487 \\
\hline CARBON DIOXIDE - Question 1 & 0.350 & & PIPELINES - Question 1 & 0.254 & & OPTICIAN - Question 1 & & 0.371 \\
\hline LABELS - Question 1 & 0.348 & & RUNNING TRACKS - Question 1 & 0.252 & 0.171 & TELEPHONE - Question 2 & & 0.324 \\
\hline THERMOMETER CRICKET - Question 1 & 0.347 & & A VIEW ROOM - Question 1 & 0.250 & & SOUTH POLE - Question 5 & 0.102 & 0.291 \\
\hline CASH WITHDRAWAL - Question 1 & 0.346 & & RUNNING TRACKS - Question 2 & 0.246 & 0.160 & SOUTH POLE - Question 2 & 0.125 & 0.279 \\
\hline IRRIGATION - Question 3 & 0.346 & & THERMOMETER CRICKET - Question 2 & 0.236 & & SOUTH POLE - Question 1 & 0.169 & 0.261 \\
\hline THE FENCE - Question 1 & 0.346 & & CINEMA OUTING - Question 1 & 0.234 & & SOUTH POLE - Question 4 & 0.106 & 0.257 \\
\hline ROBBERIES - Question 15 & 0.345 & & DESIGN BY NUMBERSC - Question 1 & 0.234 & & SOUTH POLE - Question 6 & & 0.254 \\
\hline TILE ARRANGEMENT - Question 1 & 0.342 & & STEP PATTERN - Question 1 & 0.233 & & EMPLOYMENT - Question 1 & 0.150 & 0.248 \\
\hline BRICKS - Question 1 & 0.338 & & THIRD SIDE - Question 1 & 0.232 & & EMPLOYMENT - Question 1 (E) & 0.174 & 0.235 \\
\hline SCIENCE TESTS - Question 1 & 0.337 & & LIBRARY SYSTEM - Question 1 & 0.232 & & SHIRTS - Question 7 & 0.106 & 0.234 \\
\hline COLOURED CANDIES - Question 1 & 0.336 & & CAR DRIVE - Question 2 & 0.223 & & EMPLOYMENT - Question 2 & 0.121 & 0.233 \\
\hline SKATEBOARD - Question 12 & 0.335 & & LITTER - Question 1 & 0.221 & & SHIRTS - Question 5 & 0.153 & 0.230 \\
\hline WALKING - Question 5 & 0.334 & & STOP THE CAR - Question 1 & 0.221 & 0.142 & EXCHANGE RATE - Question 10 & 0.201 & 0.227 \\
\hline CAR DRIVE - Question 3 & 0.333 & & DIVING - Question 1 & 0.216 & 0.193 & GROWING UP - Question 7 & 0.181 & 0.223 \\
\hline COURSE DESIGN - Question 1 & 0.328 & & CUBE PAINTING - Question 4 & 0.215 & 0.122 & EXCHANGE RATE - Question 9 & 0.165 & 0.217 \\
\hline IRRIGATION - Question 2 & 0.321 & & STAIRCASE - Question 2 & 0.213 & & SHIRTS - Question 4 & 0.145 & 0.200 \\
\hline LIBRARY SYSTEM - Question 2 & 0.318 & & RUNNING TRACKS - Question 3 & 0.213 & 0.145 & GROWING UP - Question 6 & 0.182 & 0.196 \\
\hline POPULATION PYRAMIDS - Question 1 & 0.315 & & DESIGN BY NUMBERSC - Question 2 & 0.207 & & EXCHANGE RATE - Question 11 & 0.193 & 0.193 \\
\hline IRRIGATION - Question 1 & 0.313 & & HEIGHT - Question 3 & 0.207 & & THE BEST CAR - Question 1 & 0.173 & 0.187 \\
\hline HOLIDAY - Question 1 & 0.310 & & TOSSING COINS - Question 1 & 0.205 & & AESOP - Question 1 & & 0.179 \\
\hline BICYCLES - Question 2 & 0.308 & & CHOICES - Question 1 & 0.204 & & DIVING - Question 2 & 0.153 & 0.172 \\
\hline TRANSPORT - Question 1 & 0.308 & & CUBE PAINTING - Question 1 & 0.202 & 0.126 & MAKING A BOOKLET - Question 1 & 0.141 & 0.147 \\
\hline EARTHQUAKE - Question 1 & 0.305 & & GROWING UP - Question 8 & 0.201 & 0.198 & COMPUTER GAME - Question 1 & & 0.128 \\
\hline LOTTERIES - Question 1 & 0.304 & & CUBE PAINTING - Question 3 & 0.197 & 0.169 & & & \\
\hline INTERNET RELAY CHAT - Question 2 & 0.303 & & MAP - Question 1 & 0.196 & & & & \\
\hline ENERGY NEEDS - Question 2 & 0.303 & & TELEPHONE RATES - Question 1 & 0.194 & 0.133 & & & \\
\hline WALKING - Question 4 & 0.301 & & CINEMA OUTING - Question 2 & 0.189 & & & & \\
\hline TEST SCORES - Question 16 & 0.298 & & FORECAST OF RAIN - Question 1 & 0.189 & 0.130 & & & \\
\hline SKATEBOARD - Question 14 & 0.298 & & FREEZER - Question 1 & 0.188 & & & & \\
\hline NUMBER CHECK - Question 2 & 0.297 & & CUBE PAINTING - Question 2 & 0.184 & & & & \\
\hline POPULATION PYRAMIDS - Question 4 & 0.295 & & EXPORTS - Question 17 & 0.176 & & & & \\
\hline TRANSIT SYSTEM - Question 1 & 0.292 & & FREEZER - Question 2 & 0.170 & & & & \\
\hline INTERNET RELAY CHAT - Question 1 & 0.287 & & HEIGHT - Question 2 & 0.160 & & & & \\
\hline BICYCLES - Question 1 & 0.286 & & RUNNING TIME - Question 1 & 0.160 & & & & \\
\hline DESIGN BY NUMBERSC - Question 3 & 0.285 & & ENERGY NEEDS - Question 1 & 0.157 & & & & \\
\hline EXPORTS - Question 18 & 0.281 & & CAR DRIVE - Question 1 & 0.150 & & & & \\
\hline
\end{tabular}

Note: The items are arranged in order of the magnitudes of the factor loadings. Columns 1 and 2 show items where the factor 1 loading is higher than the factor 2 loading for an item, and the items are arranged in descending order of the factor 1 loadings. Column 3 shows items where the factor 2 loading is higher than the factor 1 loading for an item, and the items are arranged in descending order of factor 2 loadings.

Source: OECD, PISA 2003 database. 
Table 3.2

Difference between mean scores in mathematics and problem solving

\begin{tabular}{|c|c|c|}
\hline & (Math. - P.S.) & S.E. \\
\hline Australia & -5.6 & $(0.70)$ \\
\hline Austria & -0.5 & $(0.78)$ \\
\hline Belgium & 4.0 & $(0.78)$ \\
\hline Canada & 3.2 & $(0.53)$ \\
\hline Czech Republic & 0.0 & $(0.85)$ \\
\hline Denmark & -2.5 & (1.18) \\
\hline Finland & -3.3 & $(0.68)$ \\
\hline France & -8.4 & $(1.01)$ \\
\hline Germany & -10.5 & $(0.91)$ \\
\hline Greece & -3.6 & $(1.33)$ \\
\hline Hungary & -11.1 & $(0.82)$ \\
\hline Iceland & 10.5 & $(0.98)$ \\
\hline Ireland & 4.4 & $(0.79)$ \\
\hline Italy & -3.8 & $(1.22)$ \\
\hline Japan & -13.1 & $(1.06)$ \\
\hline Korea & -8.2 & $(0.79)$ \\
\hline Luxembourg & -0.4 & $(1.13)$ \\
\hline Mexico & 0.8 & $(1.30)$ \\
\hline Netherlands & 17.6 & $(1.33)$ \\
\hline New Zealand & -9.3 & $(1.01)$ \\
\hline Norway & 5.4 & $(1.24)$ \\
\hline Poland & 3.7 & $(1.20)$ \\
\hline Portugal & -3.8 & $(0.88)$ \\
\hline Slovak Republic & 6.4 & $(0.99)$ \\
\hline Spain & 2.8 & $(0.97)$ \\
\hline Sweden & 0.5 & $(1.27)$ \\
\hline Switzerland & 5.3 & $(0.83)$ \\
\hline Turkey & 15.9 & (1.27) \\
\hline United States & 5.5 & $(0.62)$ \\
\hline Brazil & -15.0 & $(0.99)$ \\
\hline Hong Kong-China & 2.5 & $(1.20)$ \\
\hline Indonesia & -1.3 & $(1.22)$ \\
\hline Latvia & 0.9 & $(1.33)$ \\
\hline Liechtenstein & 6.4 & $(2.80)$ \\
\hline Macao-China & -5.2 & $(1.77)$ \\
\hline Russian Federation & -10.2 & (1.35) \\
\hline Serbia & 16.7 & $(1.30)$ \\
\hline Thailand & -7.9 & $(1.23)$ \\
\hline Tunisia & 14.0 & $(1.23)$ \\
\hline Uruguay & 11.6 & $(1.41)$ \\
\hline United Kingdom $^{1}$ & $\mathrm{~m}$ & $\mathrm{~m}$ \\
\hline
\end{tabular}

Note: Values that are statistically significant are indicated in bold (see Annex A4).

1. Response rate too low to ensure comparability (see Annex A3). 
Table 5.1

Gender differences in mean score in student performance on the problem-solving, mathematics and reading scales and percentage of males and females below Level 1 and at Level 3 of the problem-solving scale

\begin{tabular}{|c|c|c|c|c|c|c|c|c|c|c|c|c|}
\hline & \multicolumn{12}{|c|}{ Problem solving } \\
\hline & \multicolumn{4}{|c|}{ Males } & \multicolumn{4}{|c|}{ Females } & & & \multirow{2}{*}{\multicolumn{2}{|c|}{$\begin{array}{c}\text { Explained variance } \\
\text { in student performance } \\
(\mathrm{r} \text {-squared } \times 100)\end{array}$}} \\
\hline & \multicolumn{2}{|c|}{ Mean score } & \multicolumn{2}{|c|}{ Standard deviation } & \multicolumn{2}{|c|}{ Mean score } & \multicolumn{2}{|c|}{ Standard deviation } & \multicolumn{2}{|c|}{ Gender difference } & & \\
\hline & Mean & S.E. & S.D. & S.E. & Mean & S.E. & S.D. & S.E. & Score dif. & S.E. & $\%$ & S.E. \\
\hline $\begin{array}{l}\text { Australia } \\
\text { Austria } \\
\text { Belgium } \\
\text { Canada } \\
\text { Czech Republic } \\
\text { Denmark } \\
\text { Finland } \\
\text { France } \\
\text { Germany } \\
\text { Greece } \\
\text { Hungary } \\
\text { Iceland } \\
\text { Ireland } \\
\text { Italy } \\
\text { Japan } \\
\text { Korea } \\
\text { Luxembourg } \\
\text { Mexico } \\
\text { Netherlands } \\
\text { New Zealand } \\
\text { Norway } \\
\text { Poland } \\
\text { Portugal } \\
\text { Slovak Republic } \\
\text { Spain } \\
\text { Sweden } \\
\text { Switzerland } \\
\text { Turkey } \\
\text { United States }\end{array}$ & $\begin{array}{l}527 \\
505 \\
522 \\
533 \\
520 \\
519 \\
543 \\
519 \\
511 \\
450 \\
499 \\
490 \\
499 \\
467 \\
546 \\
554 \\
495 \\
387 \\
522 \\
531 \\
486 \\
486 \\
470 \\
495 \\
479 \\
504 \\
520 \\
408 \\
477\end{array}$ & 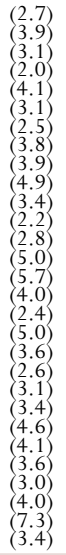 & $\begin{array}{r}95 \\
94 \\
108 \\
93 \\
95 \\
88 \\
87 \\
97 \\
96 \\
104 \\
96 \\
89 \\
81 \\
110 \\
111 \\
88 \\
95 \\
97 \\
89 \\
99 \\
103 \\
96 \\
99 \\
95 \\
98 \\
90 \\
96 \\
102 \\
101\end{array}$ & $\begin{array}{l}(1.5) \\
(2.1) \\
(1.9) \\
(2.1) \\
(1.8) \\
(2.9) \\
(2.3) \\
(2.3) \\
(1.5) \\
(1.9) \\
(3.6) \\
(2.3) \\
(2.6) \\
(2.2) \\
(1.6) \\
(2.0) \\
2.5 \\
(2.8) \\
1.8 \\
(2.0) \\
(5.6) \\
(1.6)\end{array}$ & $\begin{array}{l}533 \\
508 \\
527 \\
532 \\
513 \\
514 \\
553 \\
520 \\
517 \\
448 \\
503 \\
520 \\
498 \\
471 \\
548 \\
546 \\
493 \\
382 \\
518 \\
534 \\
494 \\
487 \\
470 \\
488 \\
485 \\
514 \\
523 \\
406 \\
478\end{array}$ & 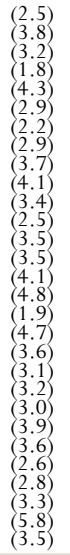 & $\begin{array}{r}87 \\
86 \\
101 \\
84 \\
91 \\
86 \\
77 \\
89 \\
92 \\
94 \\
92 \\
78 \\
78 \\
94 \\
99 \\
84 \\
88 \\
95 \\
89 \\
92 \\
94 \\
84 \\
86 \\
90 \\
89 \\
86 \\
92 \\
89 \\
95\end{array}$ & $\begin{array}{l}(1.8) \\
(2.3) \\
(2.2) \\
(2.6) \\
(2.2) \\
(2.4) \\
(2.2) \\
(1.9) \\
(1.6) \\
(1.7) \\
(3.0) \\
(2.6) \\
(2.6) \\
(2.6) \\
(2.7) \\
(1.8) \\
(2.1) \\
(1.6) \\
(2.1) \\
(4.1) \\
(1.9)\end{array}$ & $\begin{array}{r}-6.40 \\
-2.88 \\
-3.49 \\
0.49 \\
6.53 \\
4.90 \\
-9.99 \\
-0.78 \\
-5.71 \\
1.94 \\
-3.71 \\
-30.46 \\
0.52 \\
-4.06 \\
-2.41 \\
8.15 \\
2.37 \\
5.08 \\
4.45 \\
-3.27 \\
-8.46 \\
-1.07 \\
0.01 \\
6.93 \\
-6.04 \\
-9.90 \\
-2.46 \\
2.01 \\
-0.95\end{array}$ & 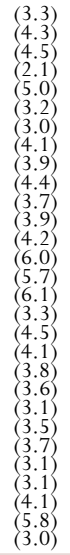 & $\begin{array}{l}0.1 \\
0.0 \\
0.0 \\
0.0 \\
0.1 \\
0.1 \\
0.4 \\
0.0 \\
0.1 \\
0.0 \\
0.0 \\
3.2 \\
0.0 \\
0.0 \\
0.0 \\
0.2 \\
0.0 \\
0.1 \\
0.1 \\
0.0 \\
0.2 \\
0.0 \\
0.0 \\
0.1 \\
0.1 \\
0.3 \\
0.0 \\
0.0 \\
0.0\end{array}$ & $\begin{array}{l}(0.1) \\
(0.1) \\
(0.1) \\
(0.2) \\
(0.1) \\
0.2) \\
(0.0) \\
(0.1) \\
(0.1) \\
(0.8) \\
(0.1) \\
(0.1) \\
(0.3) \\
(0.1) \\
(0.1) \\
0.1) \\
(0.2) \\
0.0) \\
0.0) \\
0.2 \\
0.1) \\
0.2 \\
0.1) \\
0.1) \\
(0.0)\end{array}$ \\
\hline $\begin{array}{l}\text { OECD total } \\
\text { OECD average }\end{array}$ & $\begin{array}{l}489 \\
499\end{array}$ & $\begin{array}{l}(1.4) \\
(0.8)\end{array}$ & $\begin{array}{l}109 \\
103\end{array}$ & $\begin{array}{l}(1.1) \\
(0.6)\end{array}$ & $\begin{array}{l}490 \\
501\end{array}$ & $\begin{array}{l}(1.3) \\
(0.8)\end{array}$ & $\begin{array}{r}103 \\
97\end{array}$ & $\begin{array}{l}(0.8) \\
(0.5)\end{array}$ & $\begin{array}{l}-0.67 \\
-1.71\end{array}$ & $\begin{array}{l}(1.5) \\
(0.8)\end{array}$ & $\begin{array}{l}0.0 \\
0.0\end{array}$ & $\begin{array}{l}(0.0) \\
(0.0)\end{array}$ \\
\hline $\begin{array}{l}\text { Brazil } \\
\text { Hong Kong-China } \\
\text { Indonesia } \\
\text { Latvia } \\
\text { Liechtenstein } \\
\text { Macao-China } \\
\text { Russian Federation } \\
\text { Serbia } \\
\text { Thailand } \\
\text { Tunisia } \\
\text { Uruguay }\end{array}$ & $\begin{array}{l}374 \\
545 \\
358 \\
481 \\
535 \\
538 \\
480 \\
416 \\
418 \\
346 \\
412 \\
\end{array}$ & $\begin{array}{l}(6.0) \\
(6.2) \\
(3.1) \\
(5.1) \\
(6.6) \\
(4.2) \\
(5.9) \\
(3.8) \\
(3.9) \\
(2.5) \\
(4.6)\end{array}$ & $\begin{array}{r}106 \\
104 \\
72 \\
97 \\
98 \\
85 \\
104 \\
91 \\
84 \\
80 \\
116 \\
\end{array}$ & $\begin{array}{l}(3.4) \\
3.8 \\
1.8 \\
(2.8) \\
5.8 \\
(4.2) \\
2.8 \\
(2.0) \\
2.3) \\
(1.9) \\
(2.4)\end{array}$ & $\begin{array}{l}368 \\
550 \\
365 \\
484 \\
524 \\
527 \\
477 \\
424 \\
431 \\
343 \\
409 \\
\end{array}$ & $\begin{array}{l}(4.3) \\
(4.0) \\
4.0 \\
4.0 \\
5.9 \\
(3.2) \\
(4.4) \\
(3.9) \\
(3.1) \\
(2.5) \\
(4.2) \\
\end{array}$ & $\begin{array}{r}95 \\
90 \\
74 \\
87 \\
87 \\
77 \\
93 \\
80 \\
80 \\
79 \\
108 \\
\end{array}$ & $\begin{array}{l}(2.4) \\
(2.6) \\
(2.1) \\
2.2 \\
5.2 \\
(2.9) \\
(2.0) \\
(2.2) \\
(2.0) \\
(1.6) \\
(2.4)\end{array}$ & $\begin{array}{r}5.21 \\
-5.06 \\
-7.30 \\
-2.57 \\
11.52 \\
11.22 \\
2.30 \\
-7.39 \\
-12.37 \\
2.71 \\
2.73 \\
\end{array}$ & $\begin{array}{l}(3.7) \\
(6.3) \\
(3.0) \\
(4.6) \\
(9.8) \\
(5.5) \\
(4.9) \\
(4.1 \\
4.3 \\
(2.6) \\
(4.8)\end{array}$ & $\begin{array}{l}0.1 \\
0.1 \\
0.3 \\
0.0 \\
0.4 \\
0.5 \\
0.0 \\
0.2 \\
0.6 \\
0.0 \\
0.0\end{array}$ & $\begin{array}{l}(0.1) \\
0.2) \\
0.2) \\
0.1) \\
0.7) \\
0.5) \\
0.1) \\
0.2) \\
(0.4) \\
0.1) \\
(0.1)\end{array}$ \\
\hline United Kingdom $^{1}$ & $\mathrm{~m}$ & $\mathrm{~m}$ & $\mathrm{~m}$ & $\mathrm{~m}$ & $\mathrm{~m}$ & $\mathrm{~m}$ & $\mathrm{~m}$ & $\mathrm{~m}$ & $\mathrm{~m}$ & $\mathrm{~m}$ & $\mathrm{~m}$ & $\mathrm{~m}$ \\
\hline
\end{tabular}

\begin{tabular}{|c|c|c|c|c|c|c|c|c|c|c|c|c|}
\hline & \multicolumn{8}{|c|}{ Problem solving } & \multicolumn{2}{|c|}{ Reading } & \multicolumn{2}{|c|}{ Mathematics } \\
\hline & \multicolumn{4}{|c|}{ Percentage of males } & \multicolumn{4}{|c|}{ Percentage of females } & \multirow{2}{*}{\multicolumn{2}{|c|}{$\begin{array}{c}\text { Gender difference } \\
\text { in reading }(\mathrm{M}-\mathrm{F})\end{array}$}} & \multirow{2}{*}{\multicolumn{2}{|c|}{$\begin{array}{c}\begin{array}{c}\text { Gender difference in } \\
\text { mathematics }(\mathrm{M}-\mathrm{F})\end{array} \\
\text { Gender difference }\end{array}$}} \\
\hline & \multicolumn{2}{|c|}{ Mean score } & \multicolumn{2}{|c|}{ Standard deviation } & \multicolumn{2}{|c|}{ Mean score } & \multicolumn{2}{|c|}{ Standard deviation } & & & & \\
\hline & $\begin{array}{l}\text { Below Level } 1 \text { (below } \\
405 \text { score points) }\end{array}$ & S.E. & $\begin{array}{l}\text { At Level } 3 \text { (above } \\
592 \text { score points) }\end{array}$ & S.E. & $\begin{array}{l}\text { Below Level } 1 \text { (below } \\
405 \text { score points) }\end{array}$ & S.E. & $\begin{array}{l}\text { At Level } 3 \text { (above } \\
592 \text { score points) }\end{array}$ & S.E. & $\begin{array}{c}\text { Score } \\
\text { difference }\end{array}$ & S.E. & $\begin{array}{c}\text { Score } \\
\text { difference }\end{array}$ & S.E. \\
\hline $\begin{array}{l}\text { Australia } \\
\text { Austria } \\
\text { Belgium } \\
\text { Canada } \\
\text { Czech Republic } \\
\text { Denmark } \\
\text { Finland } \\
\text { France } \\
\text { Germany } \\
\text { Greece } \\
\text { Hungary } \\
\text { Iceland } \\
\text { Ireland } \\
\text { Italy } \\
\text { Japan } \\
\text { Korea } \\
\text { Luxembourg } \\
\text { Mexico } \\
\text { Netherlands } \\
\text { New Zealand } \\
\text { Norway } \\
\text { Poland } \\
\text { Portugal } \\
\text { Slovak Republic } \\
\text { Spain } \\
\text { Sweden } \\
\text { Switzerland } \\
\text { Turkey } \\
\text { United States }\end{array}$ & $\begin{array}{l}10.8 \\
15.0 \\
14.6 \\
9.2 \\
11.7 \\
10.2 \\
5.9 \\
13.0 \\
14.9 \\
33.3 \\
16.9 \\
17.1 \\
12.6 \\
26.6 \\
11.3 \\
5.2 \\
17.7 \\
57.2 \\
9.8 \\
10.9 \\
20.8 \\
18.8 \\
25.6 \\
17.1 \\
21.7 \\
12.8 \\
50.9 \\
24.1\end{array}$ & $\begin{array}{l}(0.7) \\
(1.2) \\
(1.1) \\
(1.6) \\
(0.3) \\
(0.8) \\
(1.4) \\
(1.3) \\
(1.9) \\
(1.1) \\
(1.2) \\
(2.1) \\
(1.3) \\
(1.8) \\
(2.1) \\
(1.2) \\
(1.9) \\
(1.2) \\
(2.0) \\
(1.6) \\
(1.3) \\
(1.1) \\
(2.9) \\
(1.3)\end{array}$ & $\begin{array}{l}25.7 \\
18.5 \\
28.9 \\
27.9 \\
23.5 \\
21.0 \\
29.3 \\
24.0 \\
21.7 \\
8.4 \\
17.2 \\
12.2 \\
13.2 \\
12.1 \\
36.5 \\
34.6 \\
16.1 \\
1.6 \\
23.7 \\
28.8 \\
14.8 \\
13.0 \\
10.1 \\
16.0 \\
16.2 \\
23.4 \\
4.6 \\
13.2\end{array}$ & $\begin{array}{l}(1.2) \\
1.5 \\
(1.3) \\
(0.9) \\
(1.7) \\
1.3 \\
(1.2) \\
(1.3) \\
(1.6) \\
(1.4) \\
(1.4) \\
(0.9) \\
(1.0) \\
(2.3) \\
(1.7) \\
(0.9) \\
(1.4) \\
(1.1) \\
(0.9) \\
(1.0) \\
(1.2) \\
(1.2) \\
(2.0) \\
(1.5) \\
(1.1)\end{array}$ & $\begin{array}{r}7.5 \\
11.7 \\
12.0 \\
6.8 \\
12.0 \\
10.4 \\
3.0 \\
10.1 \\
12.7 \\
31.4 \\
14.7 \\
6.8 \\
11.9 \\
22.5 \\
8.4 \\
4.7 \\
15.8 \\
58.2 \\
11.2 \\
8.6 \\
17.4 \\
15.6 \\
21.8 \\
17.3 \\
17.8 \\
10.8 \\
10.4 \\
51.4 \\
22.6\end{array}$ & $\begin{array}{l}(0.8) \\
(1.3) \\
(0.5) \\
(1.5) \\
1.1 \\
(0.4) \\
(1.0) \\
(1.2) \\
(1.8) \\
(0.9) \\
(1.3) \\
(1.5) \\
(0.9) \\
(1.1) \\
(1.5) \\
(1.0) \\
(1.2) \\
(1.8) \\
(1.6) \\
(1.8) \\
(0.9) \\
(2.8) \\
(1.3)\end{array}$ & $\begin{array}{l}25.7 \\
16.1 \\
27.7 \\
24.1 \\
19.5 \\
19.4 \\
31.0 \\
21.7 \\
21.9 \\
5.8 \\
17.3 \\
17.9 \\
11.7 \\
9.2 \\
34.9 \\
29.5 \\
12.5 \\
1.0 \\
22.5 \\
27.9 \\
15.1 \\
10.5 \\
7.3 \\
12.1 \\
11.2 \\
18.7 \\
22.8 \\
3.2 \\
11.6\end{array}$ & $\begin{array}{l}(1.0) \\
(1.4) \\
1.1 \\
0.8 \\
1.5 \\
1.4 \\
(1.2) \\
(1.2) \\
1.8 \\
(0.9) \\
(1.4) \\
(1.2) \\
(0.7) \\
(1.5) \\
(2.2) \\
0.74) \\
(1.4) \\
(1.4) \\
(0.2) \\
(1.1) \\
(1.0) \\
(1.8) \\
1.34 \\
(1.1) \\
(0.9)\end{array}$ & $\begin{array}{l}-39 \\
-47 \\
-37 \\
-32 \\
-31 \\
-25 \\
-44 \\
-38 \\
-42 \\
-37 \\
-31 \\
-58 \\
-29 \\
-39 \\
-22 \\
-21 \\
-33 \\
-21 \\
-21 \\
-28 \\
-49 \\
-40 \\
-36 \\
-33 \\
-39 \\
-37 \\
-35 \\
-33 \\
-32\end{array}$ & 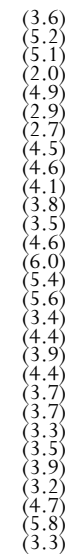 & $\begin{array}{r}5 \\
8 \\
8 \\
11 \\
15 \\
17 \\
7 \\
9 \\
9 \\
19 \\
8 \\
-15 \\
15 \\
18 \\
8 \\
23 \\
17 \\
11 \\
5 \\
14 \\
6 \\
6 \\
12 \\
19 \\
9 \\
7 \\
17 \\
15 \\
6\end{array}$ & 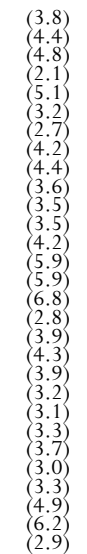 \\
\hline $\begin{array}{l}\text { OECD total } \\
\text { OECD average }\end{array}$ & 22.2 & $(0.5)$ & $\begin{array}{l}18.1 \\
190\end{array}$ & $(0.5)$ & $\begin{array}{l}20.5 \\
16.0\end{array}$ & $(0.5)$ & $\begin{array}{l}16.5 \\
17.6\end{array}$ & $(0.4)$ & $\begin{array}{l}-31 \\
-34\end{array}$ & $\begin{array}{l}(1.4) \\
(0.8)\end{array}$ & 10 & (1.4) \\
\hline $\begin{array}{l}\text { Brazil } \\
\text { Hong Kong-China } \\
\text { Indonesia } \\
\text { Latvia } \\
\text { Liechtenstein } \\
\text { Macao-China } \\
\text { Russian Federation } \\
\text { Serbia } \\
\text { Thailand } \\
\text { Tunisia } \\
\text { Uruguay }\end{array}$ & $\begin{array}{r}62.6 \\
9.8 \\
75.2 \\
21.7 \\
9.8 \\
6.3 \\
23.7 \\
44.6 \\
45.1 \\
76.3 \\
46.2\end{array}$ & $\begin{array}{l}(2.3) \\
(1.6 \\
(1.8) \\
(1.94 \\
2.4 \\
(1.3) \\
2.2 \\
2.0 \\
2.1 \\
(1.3) \\
(1.9)\end{array}$ & $\begin{array}{r}2.4 \\
36.1 \\
0.1 \\
12.7 \\
31.2 \\
27.7 \\
14.0 \\
2.7 \\
2.5 \\
0.1 \\
5.5\end{array}$ & $\begin{array}{l}(0.7) \\
(2.1) \\
(0.1) \\
(1.3) \\
(3.8) \\
(1.7) \\
(.5) \\
0.6 \\
0.5 \\
(0.1) \\
(0.8)\end{array}$ & $\begin{array}{r}64.7 \\
5.9 \\
70.9 \\
18.5 \\
10.0 \\
6.2 \\
21.3 \\
39.6 \\
37.2 \\
77.0 \\
47.4\end{array}$ & $\begin{array}{l}(1.9) \\
(0.8) \\
(2.2) \\
(1.7) \\
(1.5) \\
(1.6) \\
(2.0) \\
(1.7) \\
(2.0)\end{array}$ & $\begin{array}{r}0.9 \\
33.9 \\
0.2 \\
10.7 \\
22.7 \\
21.1 \\
10.6 \\
1.5 \\
2.7 \\
0.1 \\
4.0\end{array}$ & $\begin{array}{l}(0.3) \\
1.8 \\
0.1 \\
1.1 \\
3.5 \\
2.3 \\
1.1 \\
0.3 \\
0.7 \\
0.1 \\
(0.7)\end{array}$ & $\begin{array}{l}-35 \\
-32 \\
-24 \\
-39 \\
-17 \\
-13 \\
-29 \\
-43 \\
-43 \\
-25 \\
-39\end{array}$ & $\begin{array}{r}(3.9) \\
(5.5) \\
(2.8) \\
(4.2) \\
(11.9 \\
(4.8) \\
3.9 \\
3.9 \\
(4.1) \\
3.6 \\
(4.7)\end{array}$ & $\begin{array}{r}16 \\
4 \\
3 \\
3 \\
29 \\
21 \\
10 \\
1 \\
-4 \\
12 \\
12\end{array}$ & $\begin{array}{r}(4.1) \\
(6.6) \\
3.4 \\
(4.0) \\
(10.9 \\
(5.8) \\
4.4 \\
4.4 \\
(4.2) \\
(2.5) \\
(4.2)\end{array}$ \\
\hline United Kingdom $^{1}$ & $\mathrm{~m}$ & $\mathrm{~m}$ & $\mathrm{~m}$ & $\mathrm{~m}$ & $\mathrm{~m}$ & $\mathrm{~m}$ & $\mathrm{~m}$ & $\mathrm{~m}$ & $\mathrm{~m}$ & $\mathrm{~m}$ & $\mathrm{~m}$ & $\mathrm{~m}$ \\
\hline
\end{tabular}

Note: Values that are statistically significant are indicated in bold (see Annex A4).
1. Response rate too low to ensure comparability (see Annex A3). 
Table 5.2

International socio-economic index of occupational status (HISEI) and performance on the problem-solving scale, by national quarters of the index Results based on students' self-reports

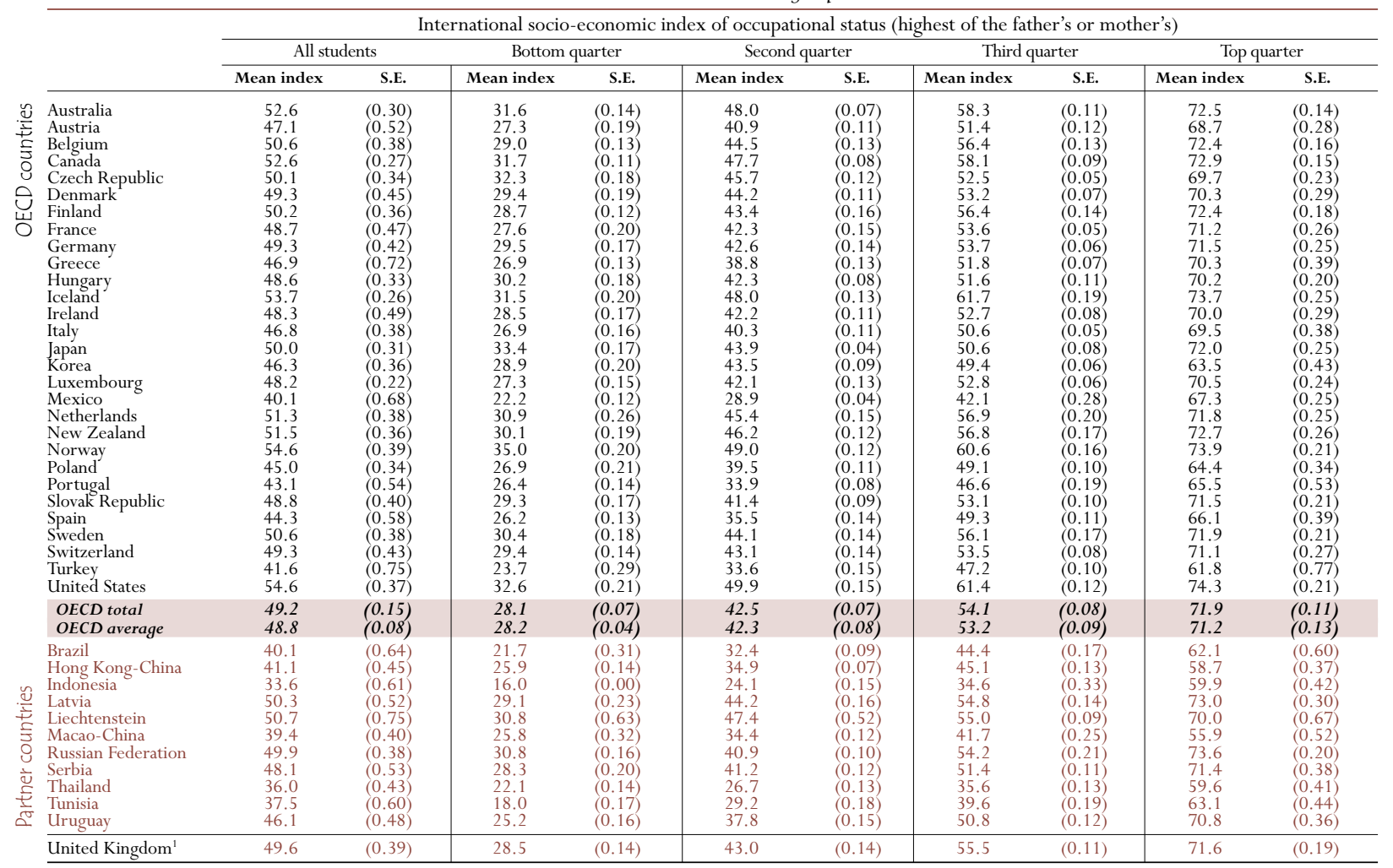

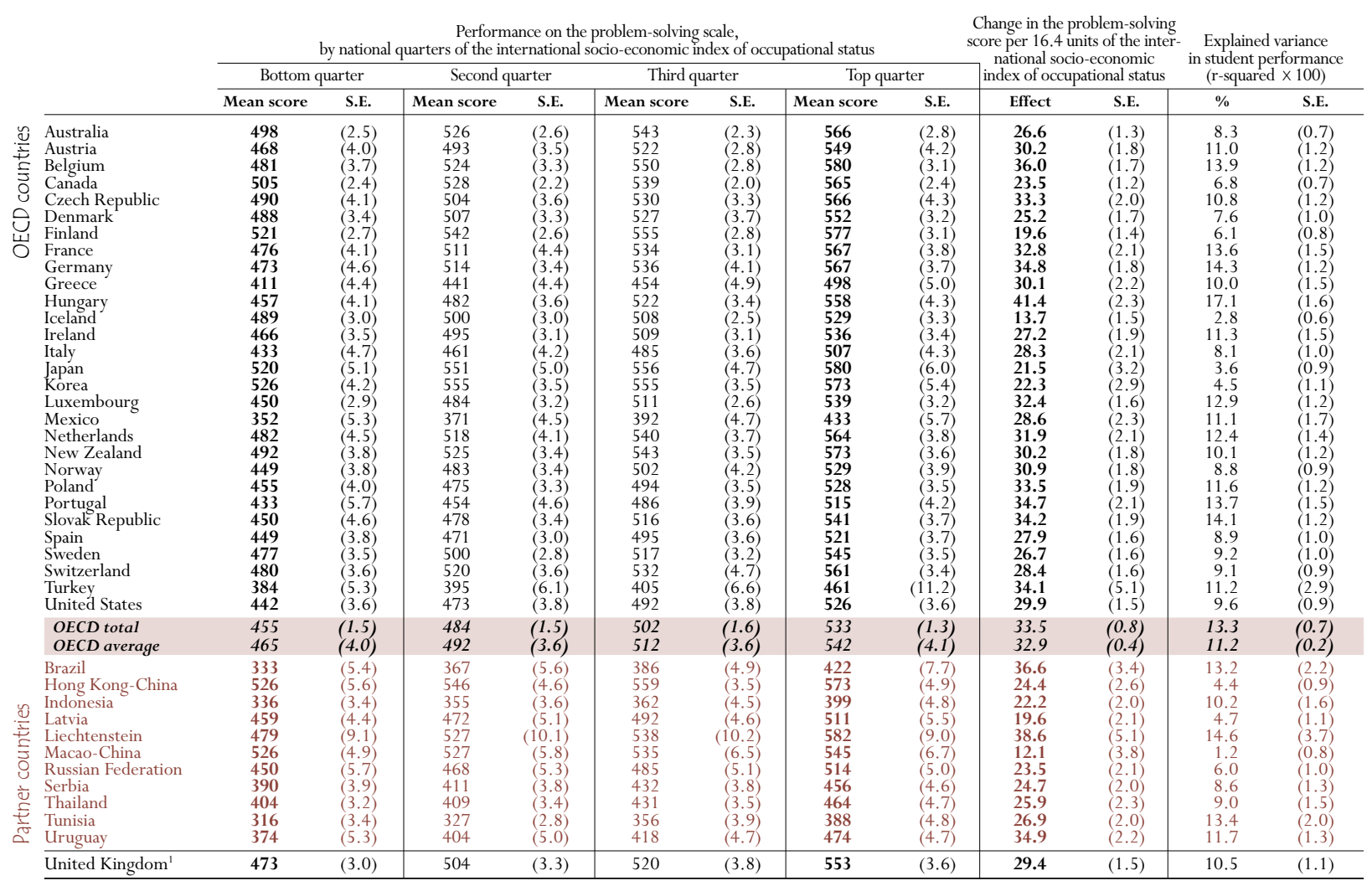

Note: Values that are statistically significant are indicated in bold (see Annex A4).
1. Response rate too low to ensure comparability (see Annex A3). 
Table 5.3

Index of highest educational level of parents (HISCED) ${ }^{1}$ and performance on the problem-solving scale, by national quarters of the index

Results based on students' self-reports

\begin{tabular}{|c|c|c|c|c|c|c|c|c|c|c|}
\hline & \multicolumn{10}{|c|}{ Index of highest educational level of parents (HISCED) } \\
\hline & \multicolumn{2}{|c|}{ All students } & \multicolumn{2}{|c|}{ Bottom quarter } & \multicolumn{2}{|c|}{ Second quarter } & \multicolumn{2}{|c|}{ Third quarter } & \multicolumn{2}{|c|}{ Top quarter } \\
\hline & Mean index & S.E. & Mean index & S.E. & Mean index & S.E. & Mean index & S.E. & Mean index & S.E. \\
\hline Australia & 4.62 & $(0.02)$ & 2.71 & $(0.03)$ & 4.17 & $(0.01)$ & 5.59 & $(0.01)$ & $\max$ & \\
\hline Austria & 4.07 & $(0.03)$ & 2.68 & $(0.03)$ & 3.33 & $(0.02)$ & 4.73 & $(0.01)$ & 5.55 & $(0.02)$ \\
\hline Belgium & 4.64 & $(0.03)$ & 2.88 & $(0.04)$ & 4.29 & $(0.01)$ & 5.41 & $(0.01)$ & $\max$ & \\
\hline Canada & 4.93 & $(0.02)$ & 3.62 & $(0.02)$ & 4.54 & $(0.01)$ & 5.56 & $(0.01)$ & $\max$ & \\
\hline Czech Republic & 4.23 & $(0.03)$ & 2.91 & $(0.01)$ & 3.93 & $(0.01)$ & 4.07 & $(0.01)$ & $\max$ & \\
\hline Denmark & 4.47 & $(0.04)$ & 2.69 & $(0.05)$ & 4.34 & $(0.02)$ & 5.00 & $(0.00)$ & 5.85 & $(0.01)$ \\
\hline Finland & 4.78 & $(0.02)$ & 3.06 & $(0.03)$ & 4.67 & $(0.01)$ & 5.40 & $(0.02)$ & $\max$ & \\
\hline France & 3.98 & $(0.04)$ & 2.00 & $(0.03)$ & 3.36 & $(0.02)$ & 4.54 & $(0.02)$ & $\max$ & \\
\hline Germany & 4.02 & $(0.04)$ & 1.90 & $(0.04)$ & 3.53 & $(0.02)$ & 4.65 & $(0.02)$ & 5.99 & $(0.00)$ \\
\hline Greece & 4.16 & $(0.06)$ & 1.84 & $(0.03)$ & 4.00 & $(0.00)$ & 4.80 & $(0.02)$ & $\max$ & \\
\hline Hungary & 4.24 & $(0.03)$ & 2.70 & $(0.02)$ & 3.94 & $(0.01)$ & 4.33 & $(0.01)$ & $\max$ & \\
\hline Iceland & 4.29 & $(0.02)$ & 2.49 & $(0.03)$ & 4.00 & $(0.00)$ & 4.67 & $(0.02)$ & $\max$ & \\
\hline Ireland & 4.22 & $(0.04)$ & 2.48 & $(0.06)$ & 4.00 & $(0.00)$ & 4.60 & $(0.02)$ & 5.79 & $(0.01)$ \\
\hline Italy & 3.86 & $(0.03)$ & 1.83 & $(0.01)$ & 3.43 & $(0.02)$ & 4.38 & $(0.01)$ & 5.81 & $(0.01)$ \\
\hline Japan & 4.78 & $(0.03)$ & 3.15 & $(0.06)$ & 4.32 & $(0.01)$ & 5.65 & $(0.02)$ & $\max$ & \\
\hline Korea & 4.07 & $(0.04)$ & 1.82 & $(0.03)$ & 3.74 & $(0.01)$ & 4.71 & $(0.03)$ & $\max$ & \\
\hline Luxembourg & 4.09 & $(0.03)$ & 1.42 & $(0.04)$ & 4.01 & $(0.01)$ & 5.00 & $(0.00)$ & 5.94 & $(0.01)$ \\
\hline Mexico & 2.91 & $(0.07)$ & 0.50 & $(0.02)$ & 1.71 & $(0.02)$ & 3.71 & $(0.05)$ & 5.70 & $(0.02)$ \\
\hline Netherlands & 4.55 & $(0.04)$ & 2.38 & $(0.06)$ & 4.00 & $(0.00)$ & 5.80 & $(0.02)$ & $\max$ & \\
\hline New Zealand & 4.24 & $(0.03)$ & 2.26 & $(0.04)$ & 4.00 & $(0.00)$ & 4.79 & $(0.01)$ & 5.91 & $(0.01)$ \\
\hline Norway & 4.75 & $(0.02)$ & 3.48 & $(0.03)$ & 4.51 & $(0.02)$ & 5.01 & $(0.00)$ & $\max$ & $(0.01)$ \\
\hline Poland & 4.10 & $(0.02)$ & 2.90 & $(0.02)$ & 3.99 & $(0.00)$ & 4.01 & $(0.00)$ & 5.50 & $(0.03)$ \\
\hline Portugal & 2.74 & $(0.06)$ & 0.27 & $(0.01)$ & 1.46 & $(0.02)$ & 3.48 & $(0.03)$ & 5.74 & $(0.02)$ \\
\hline Slovak Republic & 4.26 & $(0.03)$ & 3.05 & $(0.04)$ & 4.00 & $(0.00)$ & 4.06 & $(0.01)$ & 5.93 & $(0.01)$ \\
\hline Spain & 3.66 & $(0.07)$ & 0.87 & $(0.01)$ & 3.21 & $(0.03)$ & 4.57 & $(0.02)$ & $\max$ & \\
\hline Sweden & 4.66 & $(0.03)$ & 2.69 & $(0.04)$ & 4.43 & $(0.01)$ & 5.52 & $(0.02)$ & $\max$ & \\
\hline Switzerland & 3.88 & $(0.04)$ & 1.87 & $(0.02)$ & 3.14 & $(0.01)$ & 4.66 & $(0.01)$ & 5.86 & $(0.01)$ \\
\hline Turkey & 2.81 & $(0.09)$ & 0.83 & $(0.02)$ & 1.59 & $(0.02)$ & 3.49 & $(0.03)$ & 5.35 & $(0.04)$ \\
\hline United States & 4.69 & $(0.03)$ & 3.41 & $(0.06)$ & 4.01 & $(0.00)$ & 5.36 & $(0.02)$ & $\max$ & $(0.01)$ \\
\hline $\begin{array}{l}\text { OECD total } \\
\text { OECD average }\end{array}$ & $\begin{array}{l}4.18 \\
4.16\end{array}$ & $\begin{array}{l}(0.01) \\
(0.01)\end{array}$ & $\begin{array}{l}1.88 \\
1.92\end{array}$ & $\begin{array}{l}(0.01) \\
(0.01)\end{array}$ & $\begin{array}{l}3.99 \\
3.92\end{array}$ & $\begin{array}{l}(0.00) \\
(0.00)\end{array}$ & $\begin{array}{l}4.86 \\
4.78\end{array}$ & $\begin{array}{l}(0.01) \\
(0.02)\end{array}$ & $\begin{array}{l}\max \\
\max \end{array}$ & \\
\hline Brazil & 3.66 & $(0.07)$ & 0.87 & $(0.03)$ & 2.62 & $(0.04)$ & 5.16 & $(0.03)$ & $\max$ & \\
\hline Hong Kong-China & 2.59 & $(0.04)$ & 0.94 & $(0.01)$ & 2.00 & $(0.00)$ & 2.79 & $(0.01)$ & 4.62 & $(0.04)$ \\
\hline Indonesia & 2.83 & $(0.06)$ & 0.72 & $(0.02)$ & 1.58 & $(0.02)$ & 3.68 & $(0.02)$ & 5.33 & $(0.03)$ \\
\hline Latvia & 4.83 & $(0.03)$ & 3.73 & $(0.02)$ & 4.39 & $(0.02)$ & 5.18 & $(0.01)$ & $\max$ & \\
\hline Liechtenstein & 3.92 & $(0.07)$ & 2.02 & $(0.08)$ & 3.12 & $(0.03)$ & 4.75 & $(0.04)$ & 5.83 & $(0.04)$ \\
\hline Macao-China & 2.58 & $(0.05)$ & 0.65 & $(0.04)$ & 1.93 & $(0.02)$ & 3.27 & $(0.07)$ & 4.46 & $(0.05)$ \\
\hline $\begin{array}{l}\text { Russian Federation } \\
\text { Serbia }\end{array}$ & $\begin{array}{l}4.83 \\
4.19\end{array}$ & $(0.03)$ & $\begin{array}{l}3.90 \\
2.68\end{array}$ & $(0.01)$ & $\begin{array}{l}4.00 \\
3.27\end{array}$ & $(0.00)$ & & $(0.0$ & $\max$ & \\
\hline $\begin{array}{l}\text { Serbia } \\
\text { Thailand }\end{array}$ & $\begin{array}{l}4.19 \\
2.39\end{array}$ & $\begin{array}{l}(0.04) \\
(0.05)\end{array}$ & $\begin{array}{l}2.68 \\
0.93\end{array}$ & $\begin{array}{l}(0.02) \\
(0.02)\end{array}$ & 1.27 & $\begin{array}{l}(0.02) \\
(0.00)\end{array}$ & $\begin{array}{l}5.00 \\
2.58\end{array}$ & $\begin{array}{l}(0.00) \\
(0.03)\end{array}$ & $\begin{array}{l}5.83 \\
5.06\end{array}$ & $(0.02)$ \\
\hline $\begin{array}{l}\text { Ihauland } \\
\text { Tunisia }\end{array}$ & 2.46 & $(0.06)$ & 0.54 & $(0.02)$ & 1.43 & $(0.02)$ & $\begin{array}{l}2.58 \\
2.97\end{array}$ & $(0.03)$ & $\begin{array}{l}3.06 \\
4.90\end{array}$ & $(0.03)$ \\
\hline Uruguay & 3.88 & $(0.05)$ & 1.31 & $(0.02)$ & 3.12 & $(0.03)$ & 5.08 & $(0.01)$ & $\max$ & \\
\hline United Kingdom ${ }^{1}$ & 4.20 & $(0.03)$ & 2.53 & $(0.03)$ & 3.71 & $(0.01)$ & 4.68 & $(0.01)$ & 5.89 & $(0.01)$ \\
\hline
\end{tabular}

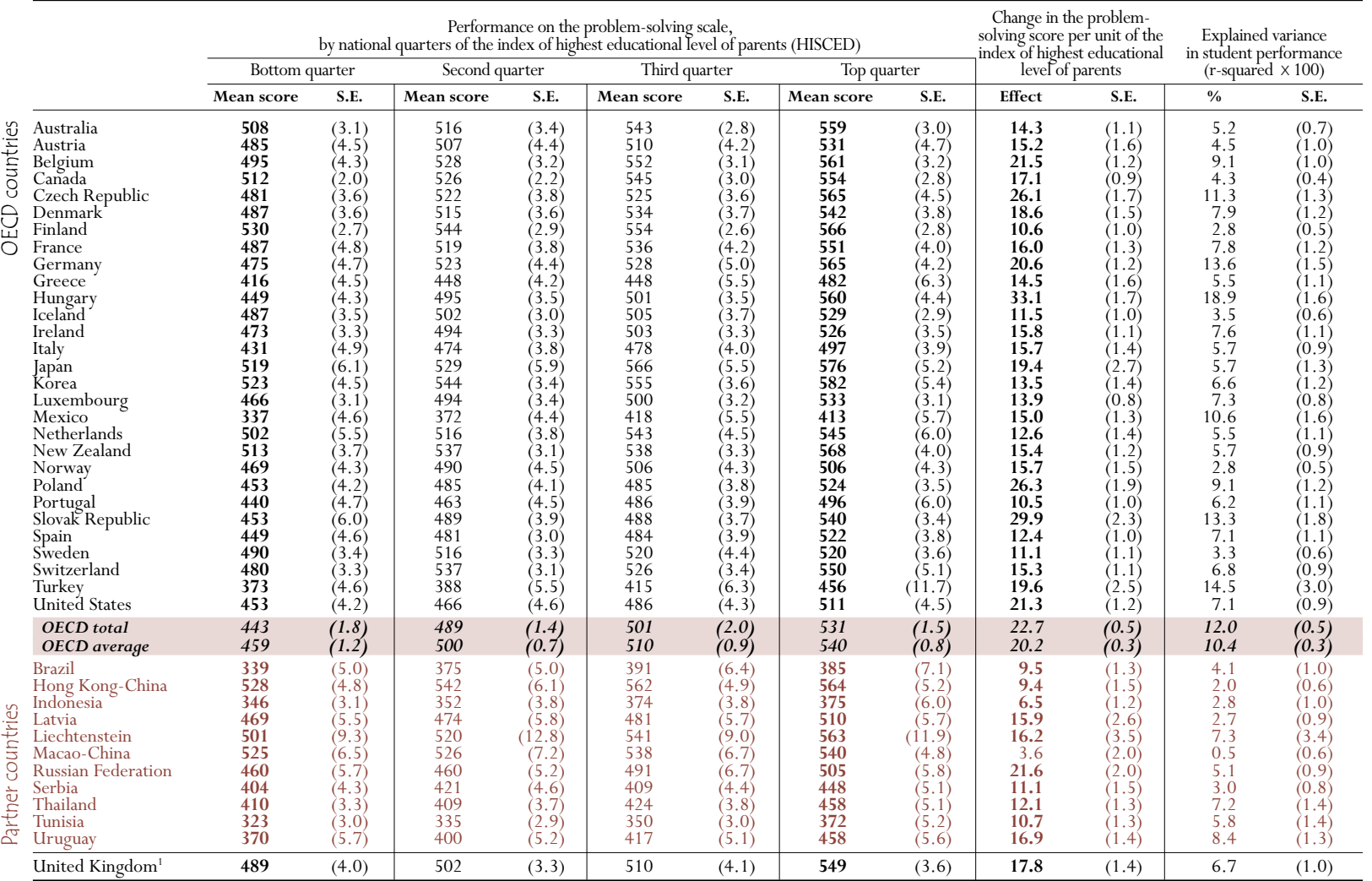

Note: Values that are statistically significant are indicated in bold (see Annex A4)

1. Highest Educational level of Parents (HISCED) corresponds to the higher level of education (ISCED) of either parent.

2. Response rate too low to ensure comparability (see Annex A3). 
Table 5.4

Index of possessions related to "classical" culture in the family home and performance on the problem-solving scale, by national quarters of the index Results based on students' self-reports

\begin{tabular}{|c|c|c|c|c|c|c|c|c|c|c|}
\hline & \multicolumn{10}{|c|}{ Index of possessions related to "classical" culture in the family home } \\
\hline & \multicolumn{2}{|c|}{ All students } & \multicolumn{2}{|c|}{ Bottom quarter } & \multicolumn{2}{|c|}{ Second quarter } & \multicolumn{2}{|c|}{ Third quarter } & \multicolumn{2}{|c|}{ Top quarter } \\
\hline & Mean index & S.E. & Mean index & S.E. & Mean index & S.E. & Mean index & S.E. & Mean index & S.E. \\
\hline Australia & -0.12 & $(0.01)$ & $\min$ & & -0.64 & $(0.01)$ & 0.13 & $(0.01)$ & 1.31 & $(0.00)$ \\
\hline Austria & -0.05 & $(0.03)$ & $\min$ & & -0.48 & $(0.01)$ & 0.28 & $(0.01)$ & 1.29 & $(0.01)$ \\
\hline Belgium & -0.30 & $(0.02)$ & $\min$ & & -0.94 & $(0.01)$ & -0.05 & $(0.01)$ & 1.08 & $(0.01)$ \\
\hline Canada & 0.00 & $(0.01)$ & $\min$ & & -0.40 & $(0.01)$ & 0.32 & $(0.01)$ & $\max$ & \\
\hline Czech Republic & 0.26 & $(0.02)$ & -1.00 & $(0.02)$ & -0.02 & $(0.01)$ & 0.71 & $(0.01)$ & $\max$ & \\
\hline Denmark & -0.01 & $(0.03)$ & $\min$ & & -0.45 & $(0.01)$ & 0.35 & $(0.00)$ & $\max$ & \\
\hline Finland & 0.11 & $(0.02)$ & $\min$ & & -0.28 & $(0.01)$ & 0.65 & $(0.01)$ & $\max$ & \\
\hline France & -0.05 & $(0.02)$ & $\min$ & & -0.44 & $(0.01)$ & 0.30 & $(0.01)$ & 1.22 & $(0.01)$ \\
\hline Germany & 0.00 & $(0.02)$ & $\min$ & & -0.44 & $(0.01)$ & 0.37 & $(0.01)$ & $\max$ & \\
\hline Greece & 0.23 & $(0.03)$ & -0.94 & $(0.01)$ & -0.07 & $(0.01)$ & 0.59 & $(0.01)$ & $\max$ & \\
\hline Hungary & 0.31 & $(0.02)$ & -0.97 & $(0.02)$ & 0.16 & $(0.01)$ & 0.69 & $(0.01)$ & $\max$ & \\
\hline Iceland & 0.79 & $(0.01)$ & -0.42 & $(0.02)$ & 0.90 & $(0.02)$ & 1.35 & $(0.00)$ & $\max$ & \\
\hline Ireland & -0.26 & $(0.02)$ & $\min$ & & -0.85 & $(0.02)$ & 0.01 & $(0.01)$ & 1.07 & $(0.01)$ \\
\hline Italy & 0.19 & $(0.02)$ & -1.18 & $(0.01)$ & -0.08 & $(0.01)$ & 0.67 & $(0.01)$ & $\max$ & \\
\hline Japan & -0.43 & $(0.02)$ & $\min$ & & -1.12 & $(0.01)$ & -0.18 & $(0.01)$ & 0.85 & $(0.01)$ \\
\hline Korea & 0.16 & $(0.02)$ & -1.14 & $(0.01)$ & -0.11 & $(0.01)$ & 0.55 & $(0.01)$ & $\max$ & \\
\hline Luxembourg & -0.03 & $(0.01)$ & $\min$ & & -0.51 & $(0.01)$ & 0.31 & $(0.01)$ & $\max$ & \\
\hline Mexico & -0.68 & $(0.03)$ & $\min$ & & -1.28 & $(0.00)$ & -0.65 & $(0.02)$ & 0.49 & $(0.02)$ \\
\hline Netherlands & -0.31 & $(0.02)$ & $\min$ & & -0.78 & $(0.02)$ & -0.16 & $(0.01)$ & 0.96 & $(0.02)$ \\
\hline New Zealand & -0.18 & $(0.02)$ & $\min$ & & -0.62 & $(0.01)$ & 0.06 & $(0.01)$ & 1.11 & $(0.01)$ \\
\hline Norway & 0.15 & $(0.02)$ & $\min$ & & -0.30 & $(0.01)$ & 0.84 & $(0.02)$ & $\max$ & \\
\hline Poland & 0.25 & $(0.02)$ & -0.84 & $(0.02)$ & -0.04 & $(0.01)$ & 0.53 & $(0.01)$ & $\max$ & \\
\hline Portugal & -0.08 & $(0.03)$ & $\min$ & & -0.55 & $(0.01)$ & 0.27 & $(0.01)$ & 1.24 & $(0.01)$ \\
\hline Slovak Republic & 0.35 & $(0.02)$ & -0.93 & $(0.02)$ & 0.10 & $(0.01)$ & 0.88 & $(0.01)$ & $\max$ & \\
\hline Spain & 0.15 & $(0.02)$ & -1.17 & $(0.01)$ & -0.11 & $(0.01)$ & 0.54 & $(0.01)$ & $\max$ & \\
\hline Sweden & 0.10 & $(0.02)$ & -1.26 & $(0.00)$ & -0.28 & $(0.00)$ & 0.59 & $(0.01)$ & $\max$ & \\
\hline Switzerland & -0.37 & $(0.03)$ & $\min$ & & -1.02 & $(0.01)$ & -0.13 & $(0.01)$ & 0.95 & $(0.02)$ \\
\hline Turkey & -0.11 & $(0.03)$ & $\min$ & & -0.51 & $(0.02)$ & 0.22 & $(0.01)$ & 1.12 & $(0.01)$ \\
\hline United States & -0.04 & $(0.02)$ & $\min$ & & -0.57 & $(0.01)$ & 0.34 & $(0.01)$ & $\max$ & \\
\hline $\begin{array}{l}\text { OECD total } \\
\text { OECD average }\end{array}$ & $\begin{array}{r}-0.10 \\
0.00\end{array}$ & $\begin{array}{l}(0.01) \\
(0.00)\end{array}$ & $\begin{array}{l}-1.28 \\
-1.28\end{array}$ & $\begin{array}{l}(0.00) \\
(0.00)\end{array}$ & $\begin{array}{l}-0.62 \\
-0.45\end{array}$ & $\begin{array}{l}(0.01) \\
(0.00)\end{array}$ & $\begin{array}{l}0.21 \\
0.38\end{array}$ & $\begin{array}{l}(0.01) \\
(0.02)\end{array}$ & $\begin{array}{l}1.29 \\
1.35\end{array}$ & $\begin{array}{l}(0.01) \\
(0.00)\end{array}$ \\
\hline Brazil & -0.33 & $(0.02)$ & -1.28 & $(0.00)$ & -0.83 & & -0.06 & & 0.86 & $(0.02)$ \\
\hline Hong Kong-China & -0.44 & $(0.03)$ & min & & -1.04 & $(0.01)$ & -0.22 & $(0.01)$ & 0.78 & $(0.02)$ \\
\hline Indonesia & -0.65 & $(0.02)$ & $\min$ & & $\min$ & & -0.51 & $(0.01)$ & 0.46 & $(0.02)$ \\
\hline Latvia & 0.40 & $(0.02)$ & -0.91 & $(0.02)$ & 0.25 & $(0.01)$ & 0.92 & $(0.02)$ & $\max$ & \\
\hline Liechtenstein & -0.27 & $(0.05)$ & $\min$ & & -0.85 & $(0.05)$ & -0.04 & $(0.03)$ & 1.09 & $(0.05)$ \\
\hline $\begin{array}{l}\text { Macao-China } \\
\text { Russian Federation }\end{array}$ & $\begin{array}{r}-0.50 \\
0.48\end{array}$ & $\begin{array}{l}(0.02) \\
(0.02)\end{array}$ & $\min _{-0.67}$ & $\left(\begin{array}{lll}0 & 02\end{array}\right)$ & $\begin{array}{r}-1.16 \\
0.38\end{array}$ & $(0.02)$ & $\begin{array}{r}-0.24 \\
0.85\end{array}$ & $(0.01)$ & 0.69 & $(0.03)$ \\
\hline $\begin{array}{l}\text { Russian Federation } \\
\text { Serbia }\end{array}$ & $\begin{array}{l}0.48 \\
0.14\end{array}$ & $(0.03)$ & min & $(0.02)$ & -0.22 & $(0.01)$ & $\begin{array}{l}0.85 \\
0.73\end{array}$ & $\begin{array}{l}(0.01) \\
(0.01)\end{array}$ & $\begin{array}{l}\max \\
\max \end{array}$ & \\
\hline Thailand & -0.21 & $(0.02)$ & $\min$ & & -0.62 & $(0.01)$ & 0.05 & $(0.01)$ & 1.02 & $(0.01)$ \\
\hline Tunisia & -0.63 & $(0.02)$ & $\min$ & & $\min$ & & -0.47 & $(0.01)$ & 0.50 & $(0.02)$ \\
\hline Uruguay & 0.07 & $(0.02)$ & -1.21 & $(0.01)$ & -0.22 & $(0.01)$ & 0.38 & $(0.00)$ & 1.32 & $(0.00)$ \\
\hline United Kingdom $^{1}$ & -0.03 & $(0.02)$ & $\min$ & & -0.61 & $(0.01)$ & 0.40 & $(0.01)$ & $\max$ & \\
\hline
\end{tabular}

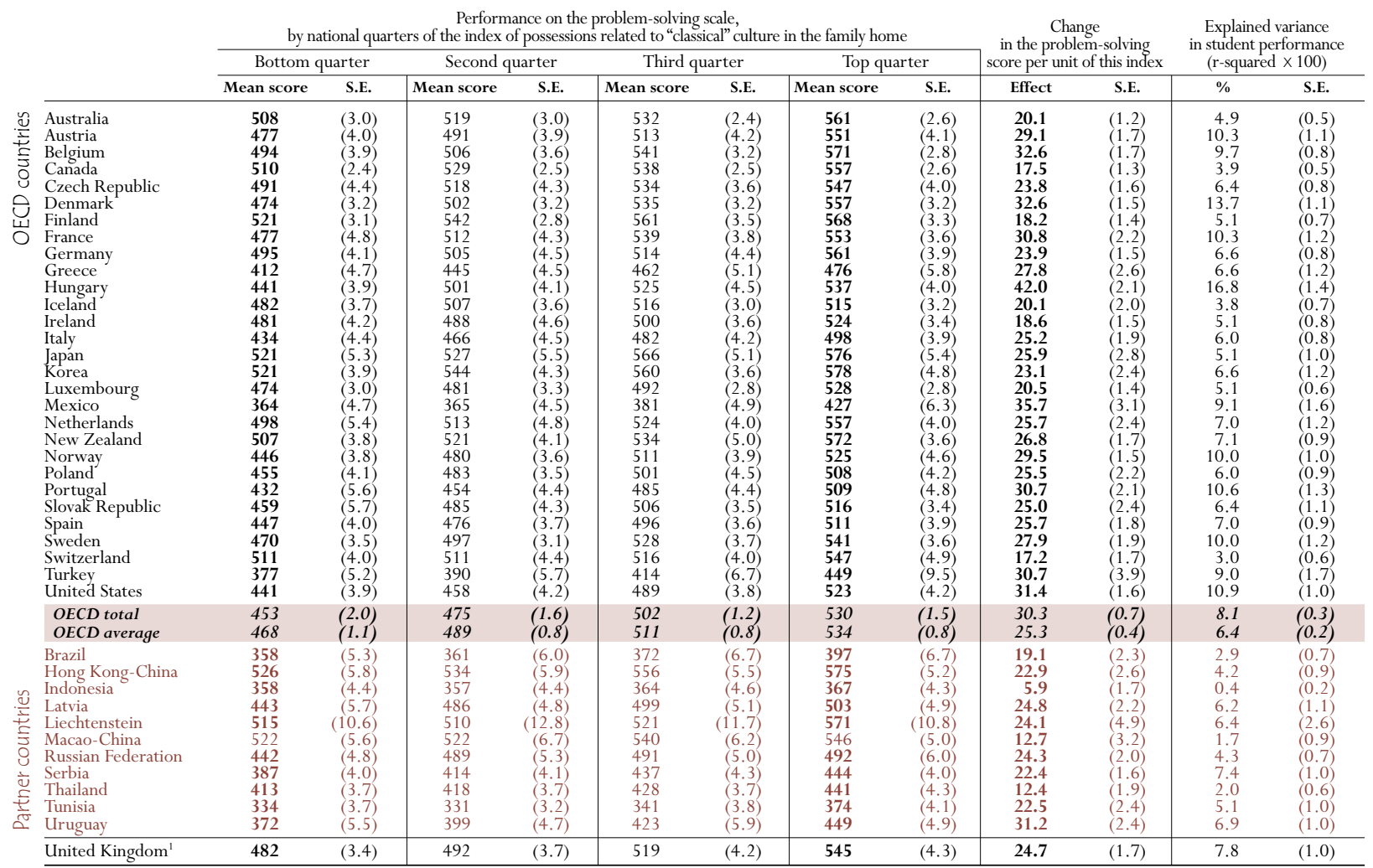

Note: Values that are statistically significant are indicated in bold (see Annex A4). "Min" is used for countries with more than 25 per cent of students at the lowest value on this index, which is -1.28 . "Max" is used for countries with more than 25 per cent of students at the highest value of this index, which is 1.35 .

1. Response rate too low to ensure comparability (see Annex A3). 
Table 5.5

Percentage of students and performance on the problem-solving scale, by type of family structure Results based on students' self-reports

\begin{tabular}{|c|c|c|c|c|c|c|c|c|c|c|}
\hline & \multicolumn{4}{|c|}{ Students from single-parent families } & \multicolumn{4}{|c|}{ Students from other types of families } & \multicolumn{2}{|c|}{$\begin{array}{c}\text { Difference in problem-solving } \\
\text { performance (single-parent } \\
\text { families - other types of families) }\end{array}$} \\
\hline & $\%$ of students & S.E. & Mean score & S.E. & $\%$ of students & S.E. & Mean score & S.E. & Difference & S.E. \\
\hline Australia & 20.0 & $(0.5)$ & 511 & (2.7) & 80.0 & $(0.5)$ & 535 & $(2.1)$ & -25 & $(2.5)$ \\
\hline Austria & 15.9 & $(0.6)$ & 509 & $(4.6)$ & 84.1 & $(0.6)$ & 508 & $(3.1)$ & 1 & $(4.1)$ \\
\hline Belgium & 17.0 & $(0.5)$ & 496 & $(4.3)$ & 83.0 & $(0.5)$ & 535 & $(2.3)$ & -39 & $(3.9)$ \\
\hline Canada & 18.6 & $(0.4)$ & 514 & $(3.0)$ & 81.4 & $(0.4)$ & 538 & $(1.6)$ & -24 & $(3.0)$ \\
\hline Czech Republic & 12.8 & $(0.5)$ & 518 & $(3.8)$ & 87.2 & $(0.5)$ & 523 & $(3.2)$ & -5 & (3.6) \\
\hline Denmark & 24.3 & $(1.1)$ & 499 & (3.9) & 75.7 & $(1.1)$ & 523 & $(2.8)$ & -25 & (3.8) \\
\hline Finland & 20.0 & $(0.7)$ & 543 & (3.3) & 80.1 & $(0.7)$ & 549 & $(1.8)$ & -6 & (3.0) \\
\hline France & 20.3 & $(0.7)$ & 510 & (3.9) & 79.8 & $(0.7)$ & 523 & $(2.8)$ & -14 & (3.9) \\
\hline Germany & 16.7 & $(0.6)$ & 514 & (5.7) & 83.3 & $(0.6)$ & 521 & $(3.4)$ & -7 & (5.1) \\
\hline Greece & 23.4 & $(1.0)$ & 430 & (5.3) & 76.6 & $(1.0)$ & 455 & $(4.3)$ & -26 & $(5.0)$ \\
\hline Hungary & 19.0 & $(0.7)$ & 494 & $(4.3)$ & 81.0 & $(0.7)$ & 504 & $(2.9)$ & -10 & $(4.0)$ \\
\hline Iceland & 13.3 & $(0.6)$ & 496 & (4.3) & 86.7 & $(0.6)$ & 507 & $(1.5)$ & -11 & (4.6) \\
\hline Ireland & 15.4 & $(0.7)$ & 474 & (4.1) & 84.6 & $(0.7)$ & 503 & $(2.4)$ & -29 & (3.9) \\
\hline Italy & 15.5 & $(0.6)$ & 463 & (4.6) & 84.5 & $(0.6)$ & 471 & $(3.1)$ & -8 & (4.1) \\
\hline Japan & $\mathrm{m}$ & $\mathrm{m}$ & $\mathrm{m}$ & $\mathrm{m}$ & $\mathrm{m}$ & $\mathrm{m}$ & $\mathrm{m}$ & $\mathrm{m}$ & $\mathrm{m}$ & $\mathrm{m}$ \\
\hline Korea & 20.3 & $(0.6)$ & 548 & (4.6) & 79.7 & $(0.6)$ & 551 & $(3.0)$ & -3 & (3.4) \\
\hline Luxembourg & 16.3 & $(0.5)$ & 476 & (3.9) & 83.7 & $(0.5)$ & 497 & $(1.5)$ & -21 & (4.4) \\
\hline Mexico & 33.1 & $(0.8)$ & 378 & (6.1) & 66.9 & $(0.8)$ & 389 & $(4.1)$ & -10 & $(4.3)$ \\
\hline Netherlands & 13.7 & $(0.9)$ & 500 & $(5.2)$ & 86.3 & $(0.9)$ & 527 & $(3.0)$ & -28 & (5.1) \\
\hline New Zealand & 18.9 & $(0.7)$ & 515 & (4.1) & 81.1 & $(0.7)$ & 538 & $(2.3)$ & -22 & (4.4) \\
\hline Norway & 27.1 & $(0.7)$ & 473 & $(4.0)$ & 72.9 & $(0.7)$ & 498 & $(2.9)$ & -25 & $(4.2)$ \\
\hline Poland & 11.4 & $(0.5)$ & 479 & (5.7) & 88.7 & $(0.5)$ & 488 & $(2.7)$ & -9 & $(5.2)$ \\
\hline Portugal & 16.5 & $(0.6)$ & 470 & (5.9) & 83.5 & $(0.6)$ & 470 & $(3.9)$ & 0 & $(4.7)$ \\
\hline Slovak Republic & 11.5 & $(0.5)$ & 487 & $(5.2)$ & 88.5 & $(0.5)$ & 494 & $(3.4)$ & -7 & (4.6) \\
\hline Spain & 14.0 & $(0.5)$ & 475 & $(4.8)$ & 86.0 & $(0.5)$ & 484 & $(2.9)$ & -9 & $(4.8)$ \\
\hline Sweden & 24.0 & $(0.7)$ & 495 & (3.6) & 76.0 & $(0.7)$ & 514 & $(2.5)$ & -19 & (3.4) \\
\hline Switzerland & 20.8 & $(0.7)$ & 510 & (3.9) & 79.2 & $(0.7)$ & 525 & $(3.3)$ & -15 & (3.6) \\
\hline Turkey & 32.7 & $(1.3)$ & 402 & $(6.5)$ & 67.3 & $(1.3)$ & 412 & $(6.3)$ & -10 & (4.4) \\
\hline United States & 29.4 & $(0.9)$ & 448 & $(4.2)$ & 70.6 & $(0.9)$ & 491 & $(3.0)$ & -44 & (3.5) \\
\hline OECD total & 23.4 & $(0.3)$ & 458 & $(2.0)$ & 76.6 & $(0.3)$ & 492 & $(1.2)$ & -34 & (1.6) \\
\hline OECD average & 19.4 & $(0.1)$ & 481 & (1.1) & 80.6 & $(0.1)$ & 504 & $(0.6)$ & -23 & $(0.9)$ \\
\hline Brazil & 26.2 & $(0.9)$ & 368 & (6.8) & 73.8 & $(0.9)$ & 374 & $(4.7)$ & -6 & (5.6) \\
\hline Hong Kong-China & 19.7 & $(0.7)$ & 534 & $(5.6)$ & 80.3 & $(0.7)$ & 552 & $(4.1)$ & -18 & $(4.0)$ \\
\hline Indonesia & 9.9 & $(0.5)$ & 347 & $(5.0)$ & 90.2 & $(0.5)$ & 363 & $(3.3)$ & -16 & $(4.5)$ \\
\hline Latvia & 25.4 & $(0.9)$ & 474 & (5.1) & 74.6 & $(0.9)$ & 486 & $(4.0)$ & -12 & $(4.1)$ \\
\hline Liechtenstein & 17.8 & $(2.1)$ & 514 & $(12.1)$ & 82.2 & $(2.1)$ & 533 & $(4.8)$ & -18 & $(14.0)$ \\
\hline Macao-China & 21.1 & $(1.3)$ & 532 & (6.7) & 78.9 & $(1.3)$ & 533 & $(2.9)$ & -1 & (7.7) \\
\hline Russian Federation & 20.7 & $(0.6)$ & 479 & $(4.8)$ & 79.3 & $(0.6)$ & 481 & $(4.2)$ & -2 & (3.4) \\
\hline Serbia & 14.9 & $(0.7)$ & 416 & $(4.6)$ & 85.1 & $(0.7)$ & 421 & $(3.4)$ & -6 & $(4.4)$ \\
\hline Thailand & 21.7 & $(0.8)$ & 420 & $(4.1)$ & 78.3 & $(0.8)$ & 427 & $(2.8)$ & -7 & (3.6) \\
\hline Tunisia & 7.3 & $(0.4)$ & 332 & (5.1) & 92.7 & $(0.4)$ & 348 & $(2.3)$ & -16 & $(5.2)$ \\
\hline Uruguay & 23.1 & $(0.6)$ & 409 & $(4.5)$ & 76.9 & $(0.6)$ & 412 & $(4.0)$ & -3 & $(4.3)$ \\
\hline United Kingdom ${ }^{1}$ & 22.2 & $(0.6)$ & 494 & $(3.5)$ & 77.8 & $(0.6)$ & 515 & $(2.6)$ & -21 & (3.3) \\
\hline
\end{tabular}

Note: Values that are statistically significant are indicated in bold (see Annex A4).

1. Response rate too low to ensure comparability (see Annex A3). 
Table 5.6

Percentage of students and performance on the problem-solving scale, by students' nationality and the nationality of their parents Results based on students' self-reports

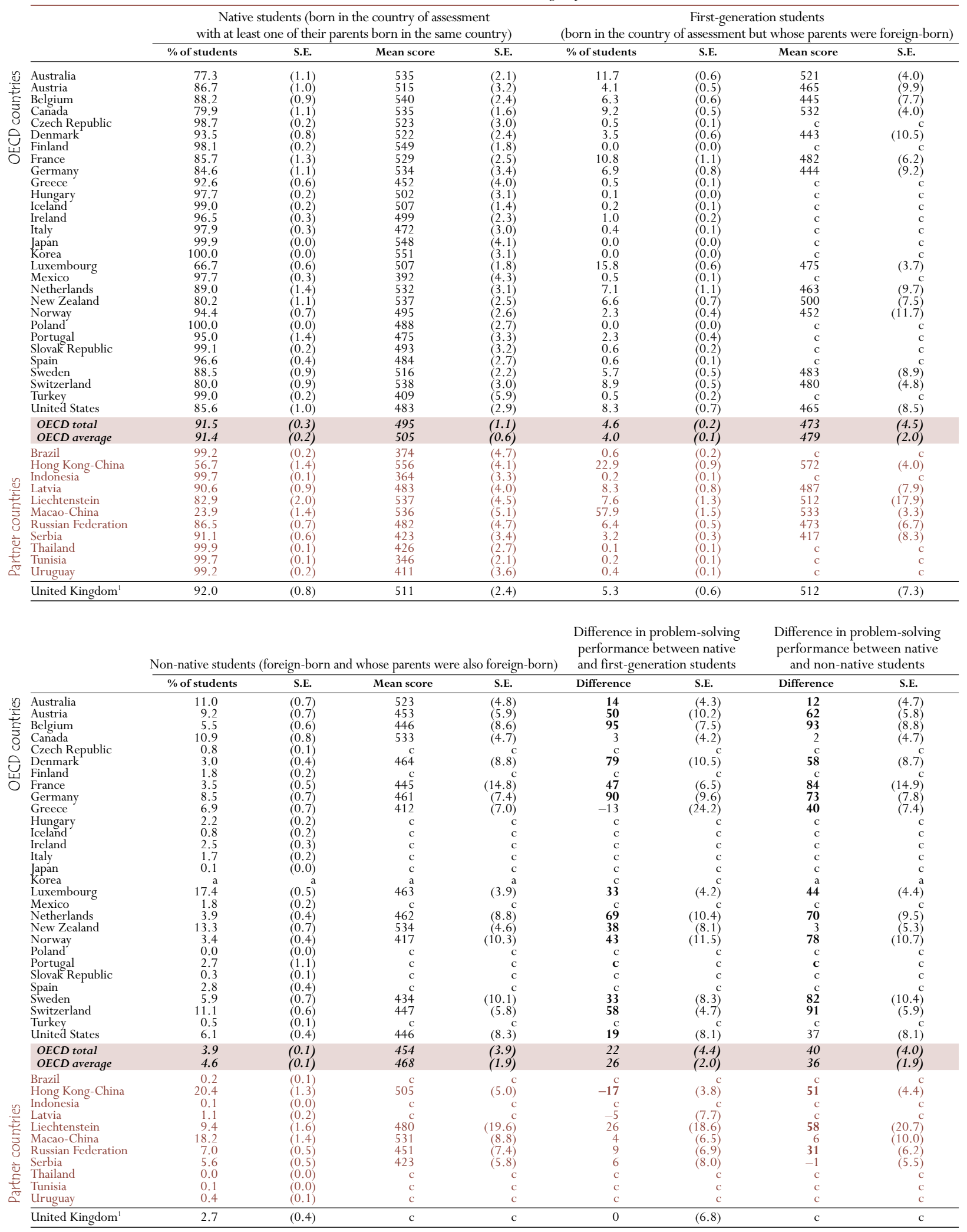

Note: Values that are statistically significant are indicated in bold (see Annex A4).
1. Response rate too low to ensure comparability (see Annex A3). 
Table 5.7

Percentage of students and performance on the problem-solving scale, by language spoken at home Results based on students' self-reports

\begin{tabular}{|c|c|c|c|c|c|c|c|c|c|c|}
\hline & \multicolumn{4}{|c|}{$\begin{array}{l}\text { Language spoken at home most of the time } \\
\text { IS DIFFERENT from the language of assessment, } \\
\text { from other official languages or from other national dialects }\end{array}$} & \multicolumn{4}{|c|}{$\begin{array}{l}\text { Language spoken at home most of the time } \\
\text { ISTHE SAME as the language of assessment, } \\
\text { other official languages or other national dialects }\end{array}$} & \multicolumn{2}{|c|}{$\begin{array}{l}\text { Difference in problem-solving } \\
\text { performance (students speaking } \\
\text { the same language - students } \\
\text { speaking a different language) }\end{array}$} \\
\hline & $\%$ of students & S.E. & Mean score & S.E. & $\%$ of students & S.E. & Mean score & S.E. & Difference & S.E. \\
\hline Australia & 8.9 & $(0.7)$ & 515 & (5.3) & 91.1 & $(0.7)$ & 533 & (1.9) & 18 & $(5.2)$ \\
\hline Austria & 9.0 & $(0.7)$ & 458 & (7.8) & 91.0 & $(0.7)$ & 514 & $(3.2)$ & 56 & (7.7) \\
\hline Belgium & 4.8 & $(0.4)$ & 450 & $(8.2)$ & 95.2 & $(0.4)$ & 539 & $(2.3)$ & 89 & (8.4) \\
\hline Canada & 11.2 & $(0.7)$ & 524 & $(4.4)$ & 88.8 & $(0.7)$ & 536 & $(1.6)$ & 11 & $(4.3)$ \\
\hline Czech Republic & 0.9 & $(0.2)$ & $\mathrm{c}$ & c & 99.1 & $(0.2)$ & 523 & $(3.1)$ & c & c \\
\hline Denmark & 3.9 & $(0.5)$ & 475 & $(10.2)$ & 96.1 & $(0.5)$ & 520 & $(2.5)$ & 44 & (10.4) \\
\hline Finland & 1.8 & $(0.2)$ & $\mathrm{c}$ & c & 98.2 & $(0.2)$ & 549 & $(1.9)$ & c & c \\
\hline France & 6.1 & $(0.7)$ & 458 & $(9.1)$ & 93.9 & $(0.7)$ & 526 & $(2.5)$ & 69 & $(9.3)$ \\
\hline Germany & 7.7 & $(0.6)$ & 430 & $(6.5)$ & 92.3 & $(0.6)$ & 531 & (3.3) & 101 & (6.3) \\
\hline Greece & 3.2 & $(0.4)$ & 401 & $(11.0)$ & 96.8 & $(0.4)$ & 451 & $(3.9)$ & 49 & $(11.0)$ \\
\hline Hungary & 0.6 & $(0.1)$ & c & c & 99.4 & $(0.1)$ & 502 & $(3.0)$ & c & c \\
\hline Iceland & 1.6 & $(0.2)$ & c & c & 98.4 & $(0.2)$ & 506 & $(1.4)$ & c & c \\
\hline Ireland & 0.8 & $(0.2)$ & c & c & 99.2 & $(0.2)$ & 498 & $(2.3)$ & c & c \\
\hline Italy & 1.6 & $(0.2)$ & c & c & 98.4 & $(0.2)$ & 474 & $(3.0)$ & c & c \\
\hline Japan & 0.2 & $(0.1)$ & c & c & 99.8 & $(0.1)$ & 551 & $(4.1)$ & c & c \\
\hline Korea & 0.1 & $(0.0)$ & c & c & 99.9 & $(0.0)$ & 551 & $(3.1)$ & c & c \\
\hline Luxembourg & 25.0 & $(0.6)$ & 464 & $(2.8)$ & 75.0 & $(0.6)$ & 507 & $(1.6)$ & 43 & (3.3) \\
\hline Mexico & 1.1 & $(0.3)$ & c & c & 98.9 & $(0.3)$ & 386 & $(4.2)$ & c & c \\
\hline Netherlands & 4.6 & $(0.6)$ & 450 & $(10.0)$ & 95.4 & $(0.6)$ & 530 & $(3.1)$ & 79 & (10.3) \\
\hline New Zealand & 9.0 & $(0.7)$ & 516 & (6.3) & 91.0 & $(0.7)$ & 535 & (2.4) & 20 & $(7.0)$ \\
\hline Norway & 4.5 & $(0.5)$ & 439 & (9.7) & 95.5 & $(0.5)$ & 495 & $(2.5)$ & 56 & $(9.8)$ \\
\hline Poland & 0.2 & $(0.1)$ & c & c & 99.8 & $(0.1)$ & 487 & $(2.7)$ & c & c \\
\hline Portugal & 1.4 & $(0.2)$ & c & c & 98.6 & $(0.2)$ & 472 & (3.9) & c & $\mathrm{c}$ \\
\hline Slovak Republic & 1.4 & $(0.3)$ & c & c & 98.6 & $(0.3)$ & 494 & $(3.2)$ & c & c \\
\hline Spain & 1.7 & $(0.3)$ & c & c & 98.3 & $(0.3)$ & 482 & $(2.7)$ & c & c \\
\hline Sweden & 6.9 & $(0.7)$ & 456 & (9.3) & 93.1 & $(0.7)$ & 516 & $(2.2)$ & 61 & $(9.3)$ \\
\hline Switzerland & 9.5 & $(0.7)$ & 453 & (6.7) & 90.5 & $(0.7)$ & 534 & (3.4) & 81 & $(6.3)$ \\
\hline Turkey & 1.2 & $(0.6)$ & c & c & 98.8 & $(0.6)$ & 408 & $(6.0)$ & c & c \\
\hline United States & 9.0 & $(0.7)$ & 440 & $(7.2)$ & 91.0 & $(0.7)$ & 484 & $(3.0)$ & 44 & $(7.1)$ \\
\hline OECD total & 4.5 & $(0.2)$ & 449 & (4.1) & 90.7 & $(0.3)$ & 494 & (1.1) & 46 & $(4.2)$ \\
\hline OECD average & 4.5 & $(0.1)$ & 465 & (1.9) & 91.2 & $(0.1)$ & 504 & $(0.7)$ & 39 & (2.0) \\
\hline Brazil & 0.5 & $(0.1)$ & c & c & 99.5 & $(0.1)$ & 372 & $(4.8)$ & c & c \\
\hline Hong Kong-China & 4.5 & $(0.4)$ & 473 & $(9.8)$ & 95.6 & $(0.4)$ & 553 & $(4.0)$ & 80 & $(9.1)$ \\
\hline Indonesia & 2.1 & $(0.3)$ & c & c & 97.9 & $(0.3)$ & 362 & (3.3) & $\mathrm{c}$ & $\mathrm{c}$ \\
\hline Latvia & 8.3 & $(1.1)$ & 456 & $(8.8)$ & 91.7 & $(1.1)$ & 486 & (3.9) & 30 & $(8.1)$ \\
\hline Liechtenstein & 18.4 & $(2.2)$ & 505 & $(11.6)$ & 81.6 & $(2.2)$ & 543 & $(4.9)$ & 38 & $(12.6)$ \\
\hline Macao-China & 4.6 & $(0.7)$ & 493 & $(13.6)$ & 95.4 & $(0.7)$ & 535 & $(2.8)$ & 42 & $(14.6)$ \\
\hline Russian Federation & 5.4 & $(1.3)$ & 421 & $(13.3)$ & 94.6 & $(1.3)$ & 482 & $(4.4)$ & 61 & $(12.4)$ \\
\hline Serbia & 1.5 & $(0.2)$ & c & c & 98.5 & $(0.2)$ & 421 & (3.4) & c & c \\
\hline Thailand & a & a & a & a & 100.0 & $(0.0)$ & 426 & $(2.7)$ & a & a \\
\hline Tunisia & 0.4 & $(0.1)$ & c & c & 99.6 & $(0.1)$ & 344 & $(2.2)$ & c & c \\
\hline Uruguay & 1.9 & $(0.4)$ & c & c & 98.1 & $(0.4)$ & 414 & $(3.7)$ & c & c \\
\hline United Kingdom ${ }^{1}$ & 3.8 & $(0.6)$ & 489 & $(11.7)$ & 96.2 & $(0.6)$ & 512 & $(2.5)$ & 23 & $(11.7)$ \\
\hline
\end{tabular}

Note: Values that are statistically significant are indicated in bold (see Annex A4).

1. Response rate too low to ensure comparability (see Annex A3). 


\section{Annex c}

THE DEVELOPMENT AND IMPLEMENTATION OF PISA A COLLABORATIVE EFFORT 
Annex C: The development and implementation of PISA - a collaborative effort

\section{Introduction}

PISA is a collaborative effort, bringing together scientific expertise from the participating countries, steered jointly by their governments on the basis of shared, policy-driven interests.

A PISA Governing Board on which each country is represented determines, in the context of OECD objectives, the policy priorities for PISA and oversees adherence to these priorities during the implementation of the programme. This includes the setting of priorities for the development of indicators, for the establishment of the assessment instruments and for the reporting of the results.

Experts from participating countries also serve on working groups that are charged with linking policy objectives with the best internationally available technical expertise. By participating in these expert groups, countries ensure that the instruments are internationally valid and take into account the cultural and educational contexts in OECD Member countries, the assessment materials have strong measurement properties, and the instruments place an emphasis on authenticity and educational validity.

Through National Project Managers, participating countries implement PISA at the national level subject to the agreed administration procedures. National Project Managers play a vital role in ensuring that the implementation of the survey is of high quality, and verify and evaluate the survey results, analyses, reports and publications.

The design and implementation of the surveys, within the framework established by the PISA Governing Board, is the responsibility of an international consortium, referred to as the PISA Consortium, led by the Australian Council for Educational Research (ACER). Other partners in this consortium include the Netherlands National Institute for Educational Measurement (Citogroep), The National Institute for Educational Research in Japan (NIER), the Educational Testing Service in the United States (ETS), and WESTAT in the United States.

The OECD Secretariat has overall managerial responsibility for the programme, monitors its implementation on a day-to-day basis, acts as the secretariat for the PISA Governing Board, builds consensus among countries and serves as the interlocutor between the PISA Governing Board and the international consortium charged with the implementation of the activities. The OECD Secretariat also produces the indicators and analyses and prepares the international reports and publications in cooperation with the PISA consortium and in close consultation with Member countries both at the policy level (PISA Governing Board) and at the level of implementation (National Project Managers).

The following lists the members of the various PISA bodies and the individual experts and consultants who have contributed to PISA.

\section{Members of the PISA Governing Board}

Chair: Ryo Watanabe

Australia: Wendy Whitham

Austria: Helmut Bachmann and Jürgen Horschinegg

Belgium: Dominique Barthélémy, Christiane Blondin and Liselotte van de Perre

Brazil: Eliezer Pacheco

Canada: Satya Brink and Dianne Pennock

Czech Republic: Jan Koucky

Denmark: Jørgen Balling Rasmussen

Finland: Jari Rajanen

France: Gérard Bonnet

Germany: Hans Konrad Koch, Elfriede Ohrnberger and Botho Priebe

Greece: Vassilis Koulaidis
Hong Kong-China: Esther Ho Sui Chu

Hungary: Péter Vári

Iceland: Júlíus K. Björnsson

Indonesia: Bahrul Hayat

Ireland: Gerry Shiel

Italy: Giacomo Elias and Angela Vegliante

Japan: Ryo Watanabe

Korea: Kye Young Lee

Latvia: Andris Kangro

Luxembourg: Michel Lanners

Macao-China: Lam Fat Lo

Mexico: Felipe Martínez Rizo

Netherlands: Jules L. Peschar

New Zealand: Lynne Whitney

Norway: Alette Schreiner

Poland: Stanislaw Drzazdzewski 
Portugal: Glória Ramalho

Russian Federation: Galina Kovalyova

Serbia: Dragica Pavlovic Babic

Slovak Republic: Vladimir Repas

Spain: Carme Amorós Basté, Guillermo Gil and Josu Sierra Orrantia

Sweden: Anita Wester

Switzerland: Katrin Holenstein and Heinz Rhyn

Thailand: Sunee Klainin

Tunisia: Néjib Ayed

Turkey: Sevki Karaca and Ruhi Kilç

United Kingdom: Lorna Bertrand and Liz Levy

United States: Mariann Lemke and Elois Scott

Uruguay: Pedro Ravela

Special Advisor: Eugene Owen

\section{PISA 2003 National Project Managers}

Australia: John Cresswell and Sue Thomson

Austria: Günter Haider and Claudia Reiter

Belgium: Luc van de Poele

Brazil: Mariana Migliari

Canada: Tamara Knighton and Dianne Pennock

Czech Republic: Jana Paleckova

Denmark: Jan Mejding

Finland: Jouni Välijärvi

France: Anne-Laure Monnier

Germany: Manfred Prenzel

Greece: Vassilia Hatzinikita

Hong Kong-China: Esther Ho Sui Chu

Hungary: Péter Vári

Iceland: Almar Midvik Halldorsson

Indonesia: Bahrul Hayat

Ireland: Judith Cosgrove

Italy: Maria Teresa Siniscalco

Japan: Ryo Watanabe

Korea: Mee-Kyeong Lee

Latvia: Andris Kangro

Luxembourg: Iris Blanke

Macao-China: Lam Fat Lo

Mexico: Rafael Vidal

Netherlands: Erna Gille

New Zealand: Fiona Sturrock

Norway: Marit Kjaernsli

Poland: Michal Federowicz

Portugal: Lídia Padinha

Russian Federation: Galina Kovalyova

Serbia: Dragica Pavlovic Babic

Slovak Republic: Paulina Korsnakova
Spain: Guillermo Gil

Sweden: Karin Taube

Switzerland: Huguette McCluskey

Thailand: Sunee Klainin

Tunisia: Néjib Ayed

Turkey: Sevki Karaca

United Kingdom: Rachael Harker, Graham Thorpe

United States: Mariann Lemke

Uruguay: Pedro Ravela

\section{OECD Secretariat}

Andreas Schleicher (overall co-ordination of PISA and Member country relations)

Miyako Ikeda (project management)

Claire Shewbridge (project management)

Claudia Tamassia (project management)

Sophie Vayssettes (statistical support)

Juliet Evans (administrative support)

Kate Lancaster (editorial support)

\section{PISA Expert Groups}

\section{Mathematics Expert Group}

Jan de Lange (Chair) (Utrecht University, The Netherlands)

Werner Blum (Chair) (University of Kassel, Germany)

Vladimir Burjan (National Institute for Education, Slovak Republic)

Sean Close (St Patrick's College, Ireland)

John Dossey (Consultant, United States of America)

Mary Lindquist (Columbus State University, United States of America)

Zbigniew Marciniak (Warsaw University, Poland)

Mogens Niss (Roskilde University, Denmark)

Kyung-Mee Park (Hongik University, Korea)

Luis Rico (University of Granada, Spain)

Yoshinori Shimizu (Tokyo Gakugei University, Japan)

\section{Reading Expert Group}

Irwin Kirsch (Chair) (Educational Testing Service, United States)

Marilyn Binkley (National Center for Educational Statistics, United States)

Alan Davies (University of Edinburgh, United Kingdom)

Stan Jones (Statistics Canada, Canada)

John de Jong (Language Testing Services, The Netherlands)

Dominique Lafontaine (Université de Liège Sart Tilman, Belgium)

Pirjo Linnakylä (University of Jyväskylä, Finland)

Martine Rémond (Institut National de Recherche

Pédagogique, France) 


\section{Science Expert Group}

Wynne Harlen (Chair) (University of Bristol, United Kingdom)

Peter Fensham (Monash University, Australia)

Raul Gagliardi (University of Geneva, Switzerland)

Svein Lie (University of Oslo, Norway)

Manfred Prenzel (Universität Kiel, Germany)

Senta A. Raizen (National Center for Improving Science

Education (NCISE), United States)

Donghee Shin (KICE, Korea)

Elizabeth Stage (University of California, United States)

\section{Problem Solving Expert Group}

John Dossey (Chair) (Consultant, United States of America)

Beno Csapo (University of Szeged, Hungary)

Jan De Lange (Utrecht University, The Netherlands)

Eckhard Klieme (German Institute for International

Educational Research, Germany)

Wynne Harlen (University of Bristol, United Kingdom)

Ton de Jong (University of Twente, The Netherlands)

Irwin Kirsch (Educational Training Service, United States)

Stella Vosniadou (University of Athens, Greece)

\section{PISA Technical Advisory Group}

Keith Rust (Chair) (Westat)

Ray Adams (ACER, Australia)

Pierre Foy (Statistics Canada, Canada)

Aletta Grisay (Belgium)

Larry Hedges (The University of Chicago, United States)

Eugene Johnson (American Institutes for Research, United States)

John de Jong (Language Testing Services, The Netherlands)

Irwin Kirsch (Educational Testing Service, United States)

Steve May (Ministry of Education, New Zealand)

Christian Monseur (HallStat SPRL, Belgium)

Norman Verhelst (Citogroep, The Netherlands)

J. Douglas Willms (University of New Brunswick, Canada)

\section{PISA Consortium}

\section{Australian Council for Educational Research}

Ray Adams (Project Director of the PISA Consortium)

Alla Berezner (data management, data analysis)

Eveline Gerbhardt (data processing, data analysis)

Marten Koomen (management)

Dulce Lay (data processing)

Le Tu Luc (data processing)

Greg Macaskill (data processing)

Barry McCrae (science instruments, test development

mathematics and problem solving)

Martin Murphy (field operations and sampling)
Van Nguyen (data processing)

Alla Routitsky (data processing)

Wolfram Schulz (Coordinator questionnaire development. data processing, data analysis)

Ross Turner (Coordinator test development)

Maurice Walker (sampling, data processing, questionnaire development)

Margaret Wu (test development mathematics and problem solving, data analysis)

John Cresswell (test development science)

Juliette Mendelovits (test development reading)

Joy McQueen (test development reading)

Beatrice Halleux (translation quality control)

\section{Westat}

Nancy Caldwell (Director of the PISA Consortium for field operations and quality monitoring)

Ming Chen (weighting)

Fran Cohen (weighting)

Susan Fuss (weighting)

Brice Hart (weighting)

Sharon Hirabayashi (weighting)

Sheila Krawchuk (sampling and weighting)

Christian Monseur (consultant) (weighting)

Phu Nguyen (weighting)

Mats Nyfjall (weighting)

Merl Robinson (field operations and quality monitoring)

Keith Rust (Director of the PISA Consortium for sampling and weighting)

Leslie Wallace (weighting)

Erin Wilson (weighting)

\section{Citogroep}

Steven Bakker (science test development)

Bart Bossers (reading test development)

Truus Decker (mathematics test development)

Erna van Hest (reading test development and quality monitoring)

Kees Lagerwaard (mathematics test development)

Gerben van Lent (mathematics test development)

Ico de Roo (science test development)

Maria van Toor (office support and quality monitoring)

Norman Verhelst (technical advice, data analysis)

\section{Educational Testing Service}

Irwin Kirsch (reading test development)

\section{Other experts}

Cordula Artelt (questionnaire development)

Aletta Grisay (technical advice, data analysis, translation, questionnaire development)

Donald Hirsch (editorial review) 
OECD PUBLICATIONS, 2 rue André-Pascal, PARIS CEDEX 16 PRINTED IN FRANCE

(962004131P1) ISBN 92-64-00642-7 - No. 538332004 